\title{
Global Diversity, Endemism, and Conservation of Mammals
}

\author{
Weston Whitfield Sechrest \\ Acton, Massachusetts
}

B.S., Wake Forest University, 1997

\author{
A Dissertation presented to the Graduate Faculty \\ of the University of Virginia in Candidacy for the Degree of \\ Doctor of Philosophy \\ Department of Biology \\ University of Virginia \\ May 2003
}




\section{Abstract}

Understanding the world's biodiversity is a central goal of ecological, evolutionary, and conservation sciences. The rapid spread of humanity's influence across the globe makes this a time-dependent priority. However, millions of species are not described, and most that have been described are not well studied. This information forms the basis of sound ecological and evolutionary research, and incomplete data for most areas and taxonomic groups creates a large gap in scientific knowledge.

The goal of my research has been to advance the biodiversity science for mammals. I have used current technology and data sources to compile the most complete database on species' distributions for any Class. I describe in detail where all species of mammals live, and how this relates to broad-scale patterns in diversity across this group.

In the introductory Chapter, I describe the general threats to the world's biodiversity, and the current state of knowledge about the extent of human impacts. The second Chapter explains the methods: how the data on mammal geographic ranges were gathered, including advantages and problems with the existing data. The third Chapter assesses patterns of diversity across all terrestrial mammals, which sets the stage for the rest of the analytical chapters.

Conservation science necessarily focuses attention on species that are narrow endemics and on those that are threatened. In the fourth Chapter, I describe the patterns of endemism in mammals, and how this translates across taxonomic groups and areas. The fifth Chapter assesses the extent of two measures of human impact, human population density and land-use intensity, in terms of threat to mammals. This study is 
the first to explicitly measure human impacts for all species in one group, and, as such, sets a standard for analyzing global threats to species. The last Chapter describes how one specific biodiversity pattern, measured using species' evolutionary history, can be applied to ongoing conservation strategies.

My research has allowed testing of global hypotheses of biodiversity across mammals, such as how patterns of endemism differ among Orders of mammals. The results have implications for the science of biodiversity, and the application to ecology, evolution, and conservation. 
Global Diversity, Endemism, and Conservation of Mammals

\section{Table of Contents}

\section{Chapter 1}

Biodiversity threats

Pages

$1-23$

Chapter 2

Mapping species ranges

$23-54$

Chapter 3

Biogeography of the world's mammal species

Chapter 4

Global mammalian endemism

$121-164$

Chapter 5

The geography of human threats to mammals

$165-201$

Chapter 6

Hotspots and the conservation of evolutionary history

$202-219$

Conclusions 
Chapter 1

Biodiversity threats

The introductory chapter was published as an article in the Encylopedia of Life Sciences. I contributed the majority of the writing and ideas. Thomas Brooks contributed to the final writing of the publication.

Sechrest, W. and T.M. Brooks. 2001. Biodiversity - Threats. In Encyclopedia of Life Sciences, http://www.els.net. Nature Publishing Group, London. 


\section{Chapter 1}

\section{Biodiversity threats}

\section{Introduction}

Biological diversity or biodiversity is defined as the variety of the planet's living organisms and their interactions. The term biodiversity encompasses all of life's variation, expressed in genes, individuals, populations, species, communities and ecosystems. Quantitative measures of biodiversity most often focus on a taxonomic unit, typically the species, although aspects of ecological diversity can also be measured. Biodiversity is a dynamic entity, and has changed throughout the history of life on Earth. Over $99 \%$ of all species that have existed on this planet are now extinct. Present biodiversity is nonetheless impressive, with over 1.75 million species described and at least an order of magnitude more species still unknown.

The mechanisms responsible for biodiversity change are the evolutionary processes of speciation and extinction, along with ecological processes over shorter time periods. Extinction and speciation are well catalogued in the paleontological record as key to fluctuations in biodiversity. Species interactions, environmental change, and even cosmic disturbances (meteors, tidal interactions, and solar processes) have played key roles in shaping past and present biodiversity. Over the course of life on this planet, average background extinction rates have been punctuated by extinction episodes, the five most devastating of which are termed mass extinctions.

A sixth new mass extinction is occurring now. This recent threat to biodiversity arose in the early Pliocene, marking the beginning of hominid activities affecting biodiversity on increasingly larger scales, aided by tool and fire use. Prehistoric 
extinctions triggered by humans include loss of megafauna in North America, Australia, Asia, and to a lesser extent South America and Africa. For example, in a short time period around 30,000 B.P., Australia lost $86 \%$ of its genera of large vertebrates, including mammals, birds, and a few large reptiles. This extinction trend continued into the late Holocene, with oceanic island extinctions in the Pacific and other regions, including Madagascar and New Zealand, decimating several thousand bird species along with losses of other taxa, transforming many island ecosystems.

The transition from gathering and hunting cultures to sedentary agricultural societies that began around 10,000 years ago spurred human population growth from several million to over 6 billion in the year 2000. This population growth, coupled with the proliferation of new technologies accompanying resource consumption, has created a biodiversity threat rivaling all past natural threats. Modern human actions threaten biological diversity on a worldwide scale, over an extremely short geologic time period. The source of danger to biodiversity includes taxonomically specific threats such as exploitation, introduced species, and genetic and behavioral degradation, all of which can interact and ultimately result in extinction. These threats interact with the community and ecosystem level threats of habitat degradation, fragmentation, and destruction, pollution and global climate change, causing disruption and alteration of community and ecosystem structure and function. These anthropogenic threats have potentially triggered a sixth mass extinction. 


\section{Extinction}

The most obvious loss of biodiversity is the extinction of unique taxa. Extinction occurs when no more individuals of a taxonomic group survive, either within a local area or globally. The taxonomic unit of extinction is usually measured as a species, though extinction can be assessed at subspecific or population levels. A species, by definition, is unique evolutionarily; each species has distinct genetic, evolutionary, behavioral, and ecological attributes that once lost cannot be replaced. The process of extinction and speciation has been continual, as new species have arisen others have dwindled and become extinct. The one constant of evolutionary change has provided varying amounts of diversity over geologic time.

Throughout the history of life on this planet, losses of biodiversity are common. There is paleontological evidence for five mass extinctions, during which many taxonomic groups lost a majority of species. The current extinction crisis has seen species lost at a rate perhaps 1,000 to 10,000 times the average background rate identified by the fossil record. Indeed, the present extinction episode may eventually rival in rate and magnitude all previous episodes on this planet. The cause of virtually all of the present extinctions lies ultimately in anthropogenic actions.

Current taxonomic extinction risk has been systematically assessed by several organizations, most notably the International Union for the Conservation of Nature and Natural Resources (IUCN). Detailed information is available for well-known groups of organisms, including most vertebrates and higher plants, and to a much lesser extent for invertebrates, other plants and fungi. Since 1600, 1.84\% of mammals and $1.20 \%$ of bird species have become extinct. Present calculations put 25 percent of mammals and 11 
percent of birds at risk of extinction with a probability of at least 10 percent over the next 100 years. Species at risk are mainly those that have small range or population sizes, especially species that have become rare due to human activity. Delayed extinction following habitat loss or other mechanisms of abundance and range reduction may take tens to thousands of years even if all present anthropogenic threats cease. Invertebrates and marine taxa have had comparatively little scientific attention paid to them, though by all calculations they contain a significant amount of species at risk of extinction in the foreseeable future. Certain terrestrial and marine geographic regions, typically in the tropics, contain high proportions of endemic species. These areas are often concurrently facing disproportionately greater threat from habitat loss and other perils.

Extinction, by reducing overall diversity, creates a more biologically and ecologically uniform biosphere. As well as the loss to ecological diversity, the phylogenetic history of each species or taxonomic group that has followed its own unique evolutionary path is lost forever. The ultimate tool for increasing diversity, evolutionary change, requires extremely long geologic time periods. Ecosystem recovery from drastic biodiversity losses in previous mass extinctions required millions of years.

\section{Genetic and behavioral degradation of taxa}

Biological diversity ensconces the diversity of populations within species, as well as genetic and behavioral diversity within populations. Species differences are the most easily recognizable form of diversity, although differences at the population and genetic levels are necessary components to species survival. As the line between species is

sometimes vague - for example, due to hybridization or asexual reproduction - the 
distinction between populations within species is likewise often difficult to establish. There are two main mechanisms of genetic and behavioral degradation, the outright loss of populations and alteration of populations as a result of human activity. Extreme examples of both can be seen in captive populations, of relevance to biodiversity when most or all surviving individuals of a species are in captivity, such as Spix's Macaw (Cyanopsitta spixi), but the main threat from such degradation is to wild populations. Many behavioral differences exist among species' populations, for example certain chimpanzee populations utilize different tools. Behaviors are not reserved to vertebrates; invertebrates can also alter or lose behaviors as a result of human influence. For example, the Monarch butterfly (Danaus plexippus), though not endangered as a species, has populations that undergo remarkable migrations along the west and east coasts of North America, involving several generations, from California and Mexico, respectively, northward and back to small over-wintering areas where they are threatened with habitat loss. The loss of unique behaviors such as this will take a toll on overall diversity, and indeed can have long-term cascading effects on other populations and species. Alteration of behaviors in response to human activity also lessens the natural diversity, as many species, such as sparrows (Passer domesticus) and pigeons (Columba livia), have become acclimated to humans and have lost many of their natural behaviors.

Populations within species often show many genetic differences that are translated into different biological and ecological roles in local ecosystems. Over the range of a species, populations may have different life histories, such as onset of breeding. Populations of a species in separate geographic areas may be part of different communities and associated food webs or competitive interactions. Loss of a population 
can have consequences for the biodiversity of local ecosystems, as well as the overall genetic diversity within the species. Genetic diversity is also critical for survival over evolutionary time, as loss of populations within species lowers genetic diversity, making them less equipped to adapt to environmental or ecological changes.

Conservation genetics is a field that focuses on the genetic consequences of population and species fragmentation and decline. A large effective population size, between 5,000 and 10,000 individuals, is theorized to be sufficient to assure long-term survival. Theoretical and empirical studies of small populations have demonstrated the potential negative effects of inbreeding depression and loss of genetic adaptability, Allee effects, demographic and environmental stochasticity, and susceptibility to disease and catastrophes such as hurricanes. Reduction in population size can precipitate problems such as appearance of deleterious alleles and loss of overall genetic diversity that can potentially lead to population or species extinctions. These problems are exacerbated by other threats to biodiversity, including habitat fragmentation and climatic change, such that small populations are often a short prelude to extinction.

\section{Habitat destruction}

One of the most devastating threats to biodiversity is the outright loss of habitat from human activity. Habitat loss typically involves conversion of land into other uses, including urban and agricultural areas. Once removed, a natural habitat is often permanently lost, although natural or artificial restoration of some habitats is possible over time. 
Terrestrial ecosystems suffer habitat destruction in a variety of ways, such as deforestation, desertification, urbanization and burning. Many terrestrial ecosystems have been converted to urban and agricultural areas. Temperate regions in Europe and North America have lost almost all primary vegetation over the last few centuries, often for the inefficient purpose of raising crops to feed animals for human consumption, although some areas have since regenerated secondary forests. The situation is different in many tropical regions, where most primary vegetation losses have occurred over the last century. In the tropics, where most necessary nutrients are contained in the living biomass, loss of vegetation over large areas can result in permanent land transformation, as soils are relatively poor in nutrients. For example, Madagascar historically contained forested areas, although over the course of the couple thousand years or so, human colonists have cleared forests typically using fire, which resulted in the island's interior being covered by grassland, agricultural fields and denuded land.

Habitat destruction is also a major threat to biodiversity in aquatic regions. This type of habitat loss occurs from dam construction, filling wetlands, diverting water flow, and pollution. The majority of freshwater ecosystems have been altered, and many vital wetland and aquatic habitats have been destroyed. Wetland loss has accounted for lowering diversity, as they are often important centers of regional and local diversity. In oceanic environments, habitat has been destroyed in many river deltas, which often empty large quantities of fertilizers, pesticides, and industrial pollutants into gulfs and bays, creating zones absent of viable habitats. The use of bottom sea trawling is equivalent to deforestation on land, with vast stretches of diverse sea bottom transformed to barren landscape. 
The impact of habitat loss on biodiversity can be described using a simple empirical model, the species-area relationship. This states that the number of species found in an area is a consistently related to the size of that area (specifically, by a power function with an exponent of a quarter). Thus, if an area is reduced in size by half, approximately a sixth of the species found within it will eventually become extinct. Clearly, all of these extinctions will not happen immediately (although some will), but will occur over a time-lag, the length of which is dependent on the absolute size of the area remaining. For example, the length of the time-lag for the loss of mammal species from the Indonesian Greater Sunda islands following the rise of sea levels at the end of the Pleistocene was on the order of millennia. In contrast, the extinction of bird species from forest fragments in Kenya has been shown to have occurred over less than a century. In summary, maintenance of viable habitats is crucial for the survival of biodiversity, without which many species will become extinct.

\section{Habitat degradation and fragmentation}

Less devastating but more insidious than outright destruction of habitats is their fragmentation and degradation. Degradation of habitats occurs when some aspect of the natural environment is removed or altered. Alteration can include addition of pollutants, which make habitats less suitable for some organisms. Other activity such as heavy human or livestock usage can also degrade habitat quality. Extraction of resources, such as removing certain plant species, can affect ecosystem structure and function. Another form of degradation includes activities or management techniques that disrupt natural cycles or disturbance regimes. These include crop irrigation, which disrupts water flow, 
and managed natural fire suppression in areas where fire-adapted species occur.

Freshwater ecosystems have been degraded; over sixty percent of the world's total water flow has been altered, mostly for power generation by dams, agriculture, flood control and drinking water. The impacts on biodiversity are clear; the Aral Sea has lost twothirds of its volume and over half of its surface area due mainly to irrigation, and salinity levels have tripled. Of the twenty-four native species, perhaps only four retain viable populations.

Unfortunately, habitat fragmentation has also increased in ecosystems as a result of human alteration and destruction of habitat. Natural habitats always have some degree of heterogeneity, but increased disturbance due to human causes has created a new problem. Isolation of habitats in fragments of their original size leads to 'edge effects'. Habitat edges experience a different microclimate than that experienced within the interior of a habitat. Changes in the local microclimate can result from wind throw, increased sunlight, and erosion. Many species, including mammalian carnivores such as wolves, require large home ranges in relatively continuous tracts of land. Fragmentation upsets the ecosystem by decreasing the ability of species with large home ranges or specialist habitats to survive, while at the same time providing opportunities for species that proliferate on the edges of habitat, such as the nest-parasitic Brown-headed Cowbird (Molothrus ater) in the forest/grassland ecotone.

New genetic research has begun to uncover the importance of continuous habitat in the maintenance of populations. Fragmentation of habitat can also result in decreased populations and range size for many species. Some species will not disperse across fragmented habitats and planned corridors are necessary for continued connection 
between populations and maintenance of genetic diversity. The genetic consequences of small population size are exacerbated by disruption of dispersal patterns in fragmented habitats.

\section{Pollution}

Pollution is defined as contamination of the natural environment. Pollution can be in the form of liquids, solids, gases, or even forms of electromagnetic radiation input into air, water, or land. Since the industrial revolution, the input of organic and inorganic substances into the environment by humans has become a growing threat to biodiversity.

Pollution can be acute, with a single incident, or chronic, with the addition of substances to the environment over a continuous time period. Examples of acute environmental disasters include oil spills, refinery and shipping accidents, and nuclear accidents. Although the initial effects of these disasters can result in massive biodiversity loss, there are often longer lasting repercussions as well. An example of an acute disaster with long lasting effects is the prolonged ecological impact of radioactive material downwind of the Chernobyl nuclear power plant in the Ukraine following an explosion in 1986. Sources of chronic pollution include emissions from industry and human biomass burning, agricultural runoff, erosion, automobile emissions, and other continuous activities. Although the immediate effects of chronic pollution may be small, sustained rates and accumulation of chronic pollution can be as devastating as acute environmental disasters.

There are many examples of pollution and its impact on biodiversity. Released toxic elements and compounds tend to bioaccumulate in organisms, with species at 
higher trophic levels often incorporating more toxins into their tissues due to biomagnification through food webs. Artificial lights can change predator-prey dynamics, whereas underwater sonic pollution has been shown to affect marine mammal behavior adversely. Adaptation by organisms in response to pollution can reduce diversity. For example, insect resistance to pesticides can create hardy taxa that can devastate natural ecosystems. While the attention called to these problems by Rachel Carson's "Silent Spring" has led to the introduction of strict regulation of pesticide use in many countries, harmful chemicals including DDT are still used as pesticides in much of the tropics.

The biodiversity effects of pollution often hit higher levels of organization, altering community and ecosystem structure and functions. Natural substances redistributed or manufactured by humans can also pollute the environment. Examples include freshwater eutrophication, acid deposition, and ozone depletion. Eutrophication of fresh water bodies results from the chronic additions of nutrient runoff from agriculture, such as nitrogen and phosphorus, as well as atmospheric nutrient deposition from industry. This affects hard to measure changes like reduction in microorganism diversity and can have cascading effects on local plant diversity and the animals dependent on them. Acid deposition (either dry or wet) is caused by the emission of sulfur dioxide and nitrous oxides, mainly by industrial and automobile emissions, into the atmosphere. Acid deposition is particularly devastating due to the vast geographical areas that can be affected. In the case of acid deposition, soil and water far from the site of pollution emission are often affected. The upper atmosphere's ozone layer has been reduced due to chlorofluorocarbons and other ozone depleting chemicals released into the atmosphere. This has allowed more penetration of ultraviolet light, which can be harmful 
to biological organisms. Research has indicated that open ocean plankton communities have changed as a result.

\section{Global climate change}

Biological organisms interact with their environment and vice versa, and so environmental change is a key determinant of which organisms speciate, which thrive and which become extinct. Perhaps the most crucial mechanism of environmental change is the global climate. Climate change is reflected in alterations in atmospheric, hydrological, and biogeochemical cycles. These changes are associated with volcanic activity, changes in atmospheric chemistry, tidal changes, glaciations and melting of ice caps. Fluctuations such as slight changes in average daily temperatures, the duration of rainy seasons, nightly temperature, the carbon cycle, and solar radiation, among others, can affect biological organisms. Plants respond to critical climatic variables such as daily high temperatures, extended droughts, and other changes. Invertebrates have physiologically established tolerance levels, and cannot survive outside of certain ranges. Vertebrates, such as mammals, are associated with certain habitat types. Species that migrate are susceptible to local changes in climate, and as such could be the first to be affected.

The average temperatures in the twentieth century were 0.5 degrees Celsius higher than over recent centuries. Recent research on ice cores and tree rings, along with other evidence, has established the scientific data necessary to demonstrate this trend of increasing temperature. The worldwide international authority on climate change, the Intergovernmental Panel on Climate Change (IPCC) has conclusively acknowledged that 
human activity has played a role in the current climatic warming. Models are being constantly revised to predict possible consequences and the magnitude of global climate change due to human activities, with the expected increase of 1.5 to 4.0 degrees Celsius. Human activities that affect global climate change include the production of air pollution from sources such as fossil fuel combustion and burning of forests. Agriculture also plays a large role by reducing available forests that serve as carbon sinks and releasing large amounts of methane from livestock.

The message is grim for the planet's biological diversity. Slight changes in climatic patterns could have major effects, while any large local, regional or global change could have cataclysmic effects. Already, delicate oceanic coral reef ecosystems have declined recently as ocean temperatures have increased. Other particularly vulnerable species are those that cannot track climatic changes: species with small range size; insular island or mountaintop species; and those with low reproductive capability; and those with little dispersal ability such as many plants and freshwater organisms confined to dispersal through waterways. Past climatic changes have resulted in ecosystems with different species compositions, due to species' different abilities to track or adapt to climatic changes. Coastal regions could be quickly inundated due to rapidly rising sea levels, which would prove catastrophic for some of the most delicate and diverse communities in this ecotone.

\section{Introduced species}

Introduced species are those that are found in areas outside of their native range. The anthropogenic mechanisms for introduction are direct transport, removal of 
competitors, habitat change and human-induced climate change. Only some species introduced into new areas become established, and only some of the established species cause large changes in native biodiversity. Certain species have become human commensals, colonizing areas where humans inhabit, including the house mouse (Mus musculus), Norway rat (Rattus norvegicus), black rat (Rattus rattus), domestic cat (Felis catus), dog (Canis familiaris), and pig (Sus scrofa).

Species that are successful invaders into new areas are generally ones that can tolerate novel environmental conditions, competition, predation, and other ecological interactions, and have intrinsic biological characteristics including high reproductive capability, broad diet, and high dispersal rates. Few species are successful invaders, because many cannot survive in new environments. For instance, though there are over two thousand rodent species, only a handful are commonly introduced. Plant species have wreaked havoc to many ecosystems, for example in North America, purple loosestrife (Lythrum salicaria) has taken over many wetland areas and kudzu vine (Pueraria lobata) is common along the edges of forests. In Africa, the water hyacinth (Eichhornia crassipes), introduced from the New World, is causing ecological and economical devastation to lake systems.

Many islands have been successfully colonized by animals that have filled vacant ecological niches. This is demonstrated across the Pacific, for example, by feral cats (Felis catus) when introduced into predator-free islands, and by goat (Capra hircus) and sheep (Ovis aries) grazing on islands lacking large herbivores. Such introductions have contributed to the extinction and endangerment of many bird and plant species, because 
naive insular populations are extremely vulnerable to predation or competition from nonnative species.

The increased fragmentation, degradation, and destruction of habitats, along with other threats, will certainly open more niches for non-native species introductions. Species diversity in ecosystems is apparently important in preventing introduced species from establishing, perhaps due to increased stability. The anthropogenic transport and relocation of species threaten biogeographic differences in fauna and flora. The result could potentially drastically lessen biodiversity, resulting in a taxonomically and ecologically homogenized planet.

\section{Disease}

A special case of the threats to biodiversity caused by species introductions is the expansion of pathogens or parasites resulting from human activity. Disease can result from genetic disorders, pathogens such as viruses or bacteria, or parasites. Coevolution of hosts and pathogens over evolutionary time results in coexistence of both host and pathogens. Imbalance resulting from human activity, such as reduction of populations to small size, opens conditions for pathogen spread. Diseases are often transmitted across different species, with the new host species often devastated by the new pathogen. For example, American chestnut (Castanea dentata) trees are all but wiped out due to the introduction of chestnut blight fungus (Cryphonectria parasitica) that had evolved in Asia with the closely related Chinese chestnut (Castanea mollissima).

Organisms that are affected by environmental contaminants, such as exposure to organochlorines, may play a role in lowering immune response and resistance to disease. 
Compromised immune function resulting from contaminants or stress can potentially push populations or species at risk over the edge. Canine distemper virus killed most of the remaining wild black-footed ferrets (Mustela nigripes), forcing capture of the rest (which have subsequently been used in a reintroduction program). Introduced diseases are often more deadly, as host-pathogen dynamics are usually the product of a long history of coevolution.

\section{Exploitation}

In general, any changes to an ecosystem can potentially result in biodiversity loss. One of the most direct anthropogenic mechanisms for the loss of diversity is extraction of biological organisms from their natural environment. Globally, most ecosystems have only relatively recently experienced large-scale extraction by humans.

Humans extract biological organisms from nature for food, energy, and other resources. Some of the most widespread exploitation is in the form of fishing, hunting, and logging. The majority of human food is obtained from domestic crops and animals, though hunting and gathering in natural habitats is still common. The killing of wildlife species by humans constitutes a serious threat to biodiversity. The bush meat trade in Africa comprises a culturally based demand for wild animals, mostly ungulate and primate species, and has decimated many populations and species. In both freshwater and marine areas, food extraction is primarily on wild species. The direct threat of harvesting on native biodiversity has been felt, as most marine fisheries have experienced drastic collapses in target species. 
Vertebrate species are especially targeted for food and other economic benefits. Despite the Convention on the International Trade in Endangered Species (CITES) and other treaties banning the trade of many endangered species, target species including tigers (Panthera tigris) and elephants (Loxodonta africana) are still decimated by poaching. Many cultures hold economic, spiritual or medicinal significance for whole or a part from certain species. The demand for products from wild species threatens to bring many to extinction, such as bear parts for traditional Asian medicines, crocodile skins, and rhinoceros horns, in addition to collections for the wild pet trade. Such superstitions can be equally devastating to plant populations. As an example, wild ginseng (Panax quinquefolium) and many other species are now extinct across much of the USA as a result of over-harvesting for the illegal trade in "herbal" medicines which end up lining the shelves of drug-stores across the country.

A special class of exploitation is the logging of forests, which presents probably the greatest single threat to biodiversity worldwide. The sustainability of most logging operations even in temperate regions is highly questionable, and it is probable that all logging in the tropical forests is unsustainable. Already, most of the world's temperate and tropical regions have lost significant proportions of forested areas. For example, $15 / 25$ of the world's biodiversity "hotspots" are in the tropical forests, each holding the entire global range of more than $1 \%$ of the world's plant species and now retaining less than a third of its historical forest cover. Only five major forested wildernesses remain: three in the tropics - the Amazon and Congo Basins and the island of New Guinea; plus the boreal forests of Canada and Russia. 
Recently, focus has been on sustainable usage of biological resources, most often setting quotas on number of organisms killed, or restrictions of certain areas. For marine areas, research has shown that fish stocks are often tied into source populations, which disperse larva or adults to other areas through ocean currents. Protection of source populations could mitigate some of the pressure on a species. The success of long-term sustainable exploitation has yet to be proved, though use of scientific research is increasingly necessary to prevent complete collapse of target species.

\section{Summary}

The current threats to biodiversity all have one element in common. They are directly or indirectly the result of one dominant species, Homo sapiens. This differs from other major episodes of biodiversity loss, when natural environmental and ecological change was the cause. Habitat loss, degradation and fragmentation, pollution and climate change, introduced species and disease, and direct exploitation have together precipitated a global disaster for biological diversity. As a result much of the genetic, species, and ecological diversity is at great risk. 


\section{References}

Baillie, J. \& Groombridge, B. (eds.) 1996. IUCN Red List of Threatened Animals. International Union for the Conservation of Nature and Natural Resources, Gland, Switzerland.

Carson, R. 1962. Silent Spring. Houghton Mifflin, Boston, USA.

Grenfell, B.T. \& Dobson, A.P. 1995. Infectious Diseases of Wildlife. Cambridge University Press, Cambridge, UK.

Laurance, W.F. \& Bierregaard, R.O., Jr. (eds.) 1998. Tropical Forest Remnants: Ecology, Management, and Conservation of Fragmented Communities. University of Chicago Press, Chicago, USA.

Soulé, M.E. (ed.) 1987. Viable Populations for Conservation. Cambridge University Press, Cambridge, UK.

Peters, R.L. \& Lovejoy, T.E. (eds.) 1992. Global Warming and Biological Diversity. Yale University Press, Newhaven, USA.

Pimm, S.L., Russell, G.J., Gittleman, J.L. \& Brooks, T.M. 1995. The future of biodiversity. Science 269: 347-350.

Walter, K.S. \& Gillett, H.J. 1998. 1997 IUCN Red List of Threatened Plants. International Union for the Conservation of Nature and Natural Resources, Gland, Switzerland.

Williamson, M. 1996. Biological Invasions. Chapman \& Hall, London, UK. Wilson, E.O. 1993. The Diversity of Life. Belknap Press, Cambridge, USA. 


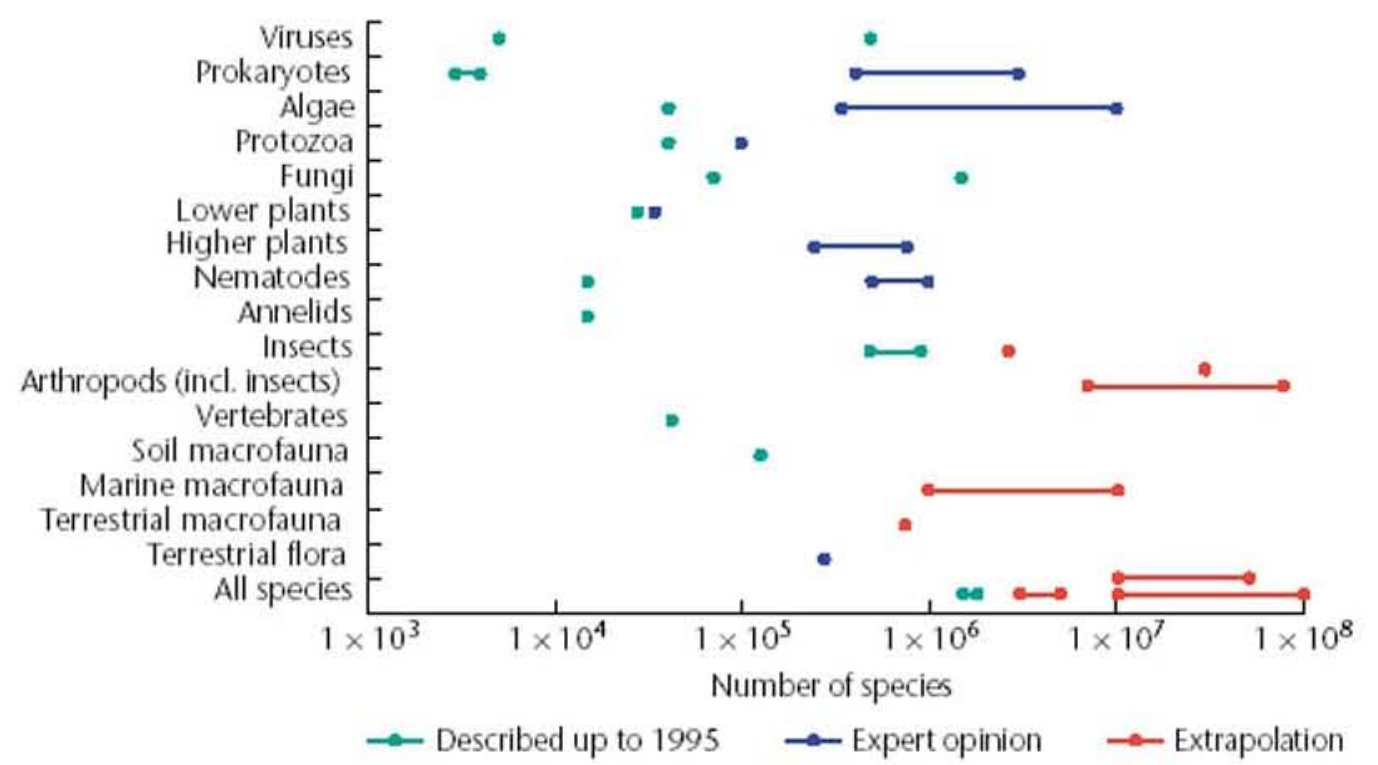

Figure 1 Number of described species and estimates of species numbers, including expert opinions of taxonomic specialists and various extrapolations (Pimm et al., 1995) 


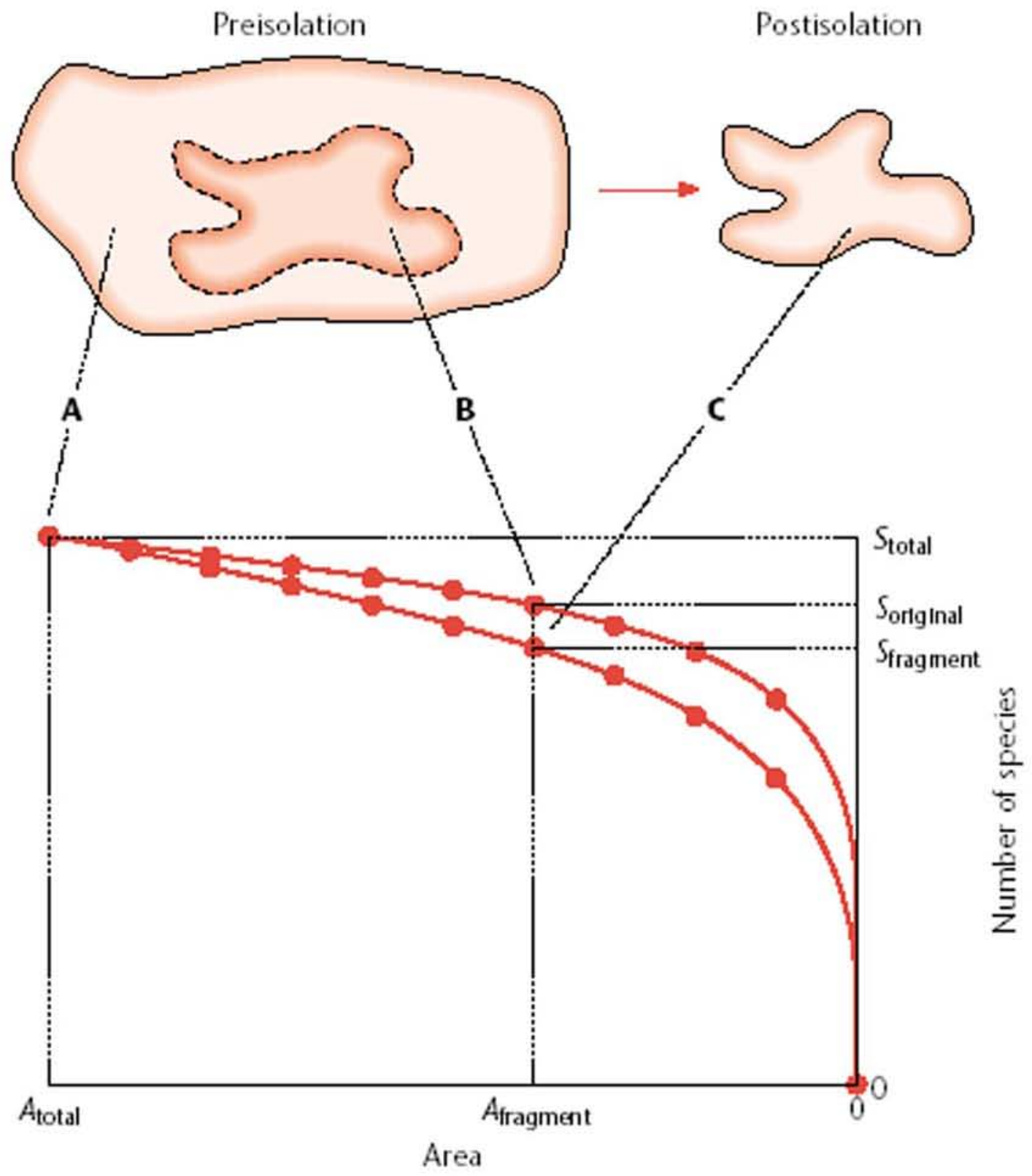

Figure 2 Typical species-area relationships. Larger areas (A) have more species than smaller ones (B, C), and areas that have long been isolated such as islands - have proportionally fewer species (C) than do equal sized a reas that are nested within continuous habitat (B) (Pimm and Brooks, 1999). 


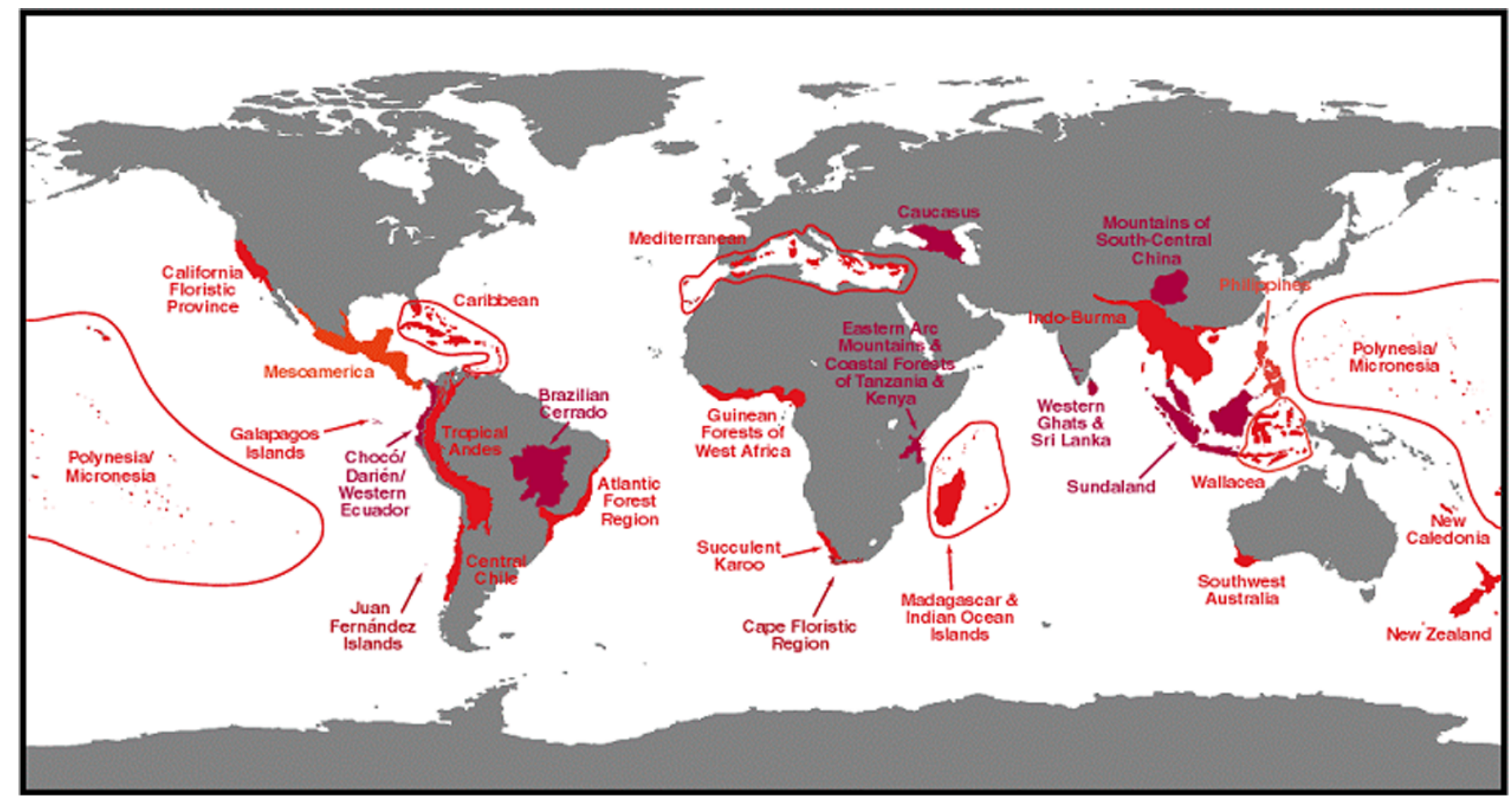

Figure 3 The 25 hotspots. The hotspot expanses comprise 30 to $33 \%$ of the red areas (Myers et al., 2000). 


\section{Chapter 2}

\section{Mapping Species Ranges in GIS}

\section{Introduction}

Understanding why species inhabit certain areas rather than others is critical to determining the ecological and evolutionary factors underlying biological diversity. Species differences in geographic ranges signify patterns of speciation, extinction, rarity, species richness, and general trends in biodiversity. The crucial element in testing for patterns and processes is a taxonomically complete and analytically rigorous database of geographic ranges. This study focuses on measuring - for the first time - the geographic ranges of all mammal species.

"If there is a basic unit of biogeography, it is the geographic range of a species" (Brown et al., 1996). The reasons for geographic range being profoundly important are easily seen when recognizing that a species' range is closely tied to so many biological features. Geographic ranges are influenced by behavior, anatomy, physiology, ecology

and evolutionary history. In essence, each species can tolerate a certain range of physical factors, such as temperature, precipitation, etc., which influence where individuals can survive. A species is thus constrained to live within its 'fundamental niche', the areas within its physiological tolerances. However, the area where a species actually occurs, its 'realized niche', is important because it also reflects ecology and history (Hutchinson, 1957; Brown, 1995). For example, a species may be excluded from certain areas due to 
competition with other organisms or physical barriers to dispersal. All of these factors contribute to determining where a species exists.

Macroecological studies, because they necessarily rely on synthetic databases, are only as good as the quality and quantity of available data. Compiling information in a rigorous manner is problematic and clear methodologies are required to minimize and quantify the error inherent in such meta-databases. Geographic range measurements have typically been summarized in comparative analyses as some measure of linear extent, area within limits, or number of areas occupied (Gaston, 1994). Measurement of a species' geographic range can be divided into two categories: extent of occurrence (EO) and area of occupancy (AO). The extent of occurrence is the distance or area between the outer limits where a species is found. The area of occupancy is the area where a species is actually found. Brown et al.'s (1996) review of weaknesses inherent in large-scale geographic range studies highlights the problems of missing data (unknown, unaccounted for, or extinct species), spatial scale (regional, continental, or worldwide), and inconsistent variable measurements. Common problems in measuring geographic range were reviewed by Gaston (1994) and include: (1) data quality of spatial occurrence varies across an individual species' range, as some parts are mapped more accurately than others; (2) error associated with species' range size measures is negatively correlated with size, as species distributed over smaller ranges will tend to have a proportionately higher area of underrepresented range; (3) distinguishing core range from vagrant species records; (4) historical versus present range size, which may have been altered by modern human activity; (5) occurrence information based on presence data, not absence data, as areas not recorded may be because of poor sampling (Gaston, 1994). These are important 
limitations to any macroecological study. One aim of this effort - to collect a complete database of mammalian ranges - was to assess to what extent these weaknesses are distributed across taxa and regions.

My research attempts to ameliorate many of these problems associated with previous macroecological research on geographic ranges. Data collection has followed a consistent methodology, which allows for accurate hypothesis testing. The use of a geographic information system (GIS) permits more advanced measurement of data as well as more detailed and sophisticated analyses. The spatial data are easily integrated into different GIS platforms, and so can also be readily manipulated for further analyses. Another strength in work is the total taxonomic coverage within the Class Mammalia, comprising over 5,000 species found throughout the world's terrestrial and marine areas. The current availability of data for classifying species according to threat status, range extent, and historical range extent allows for quantitative comparative analyses of largescale patterns and processes.

Distribution maps have been compiled for each mammal species. Sources for range data include primary literature, museum records, secondary sources, IUCN reports, and unpublished range maps. Spatial data gathered have been in the form of range-filling maps, absence/presence binary maps, and point records, and in some cases published textual range information. Using these data for range analyses are complicated by sampling bias and scaling problems (Gaston, 1996). Many species are known from only one or more point localities, though their range may be considerably greater. Species in developed countries are more extensively sampled, as are species within designated reserve areas. Sampling problems are further complicated by scale, as range maps can be 
very accurate, based on survey data, or fairly crude, based on habitat type or anecdotal observation. Time-scale differences in species record collection is also apparent, as some records reflect historical, pre-twentieth century ranges, whereas some are modern records. The spatial scale at which the data are collected is also important, as grid cells of different sizes change the range extent calculated (Lawes and Piper, 1998). One of the main arguments against utilizing binary maps, which record presence or absence within a grid with cells of predetermined size, is that they do not take into account density estimates or other important criteria. Range maps based on grids, interpolation, or rangefilled maps are all based on observation of a species within a given area. A species can be recorded as present within a grid cell if one specimen or thousands have been found. Well-established areas of a species' geographic range should ideally be given more weight than areas where few individuals have been observed. However, this information is unavailable for most species, so its use is prohibitive. Binary maps, though not ideal, can be appropriately used for broad scale analyses to determine diversity and biogeographic patterns (van Jaarsveld et al., 1998). Therefore, the methods employed here focus on determining the extent of occurrence (EO) of each species of mammal, based on published information.

Geographic ranges of all mammal species were measured, and this information is used to investigate the factors that may be correlated with diversity in this class (see Chapters 3-6). There are many reasons that mammals have been chosen for this research. Mammals have radiated into an impressive global diversity within the last sixty million years (McKenna and Bell, 1997). Although a few studies have examined geographic ranges of groups of mammals in specific regions (Pagel et al., 1991; Letcher and Harvey, 
1994), these offer only a fraction of the total knowledge available. To date, no systematic study has been conducted on mammal distributions worldwide, though two studies have examined country level data (Ceballos and Brown, 1995; Mace and Balmford, 2000). My analyses represent a key to the understanding of mammalian distribution patterns. Integration of this knowledge into a GIS database provides unique information not only for current research, but also for future analyses when new information becomes available. Conservation applications for this research include identification of precise patterns in threatened taxa and knowledge of possible future distribution patterns due to climatic change.

This paper describes the methods that were used to measure geographic range distributions of all mammal species. The motivation here, similar to related problems in ecology (Brown, 1995; Rosenzweig, 1995), is that to have rigorous explanations for large-scale patterns of geographic range distributions, it is necessary to describe geographic ranges accurately. With this solid spatial database, comparative analyses are used to evaluate patterns of geographic ranges. Conceptually and methodologically this study links our current understanding of the nature of geographic ranges with applications to conservation biology and biodiversity research.

\section{Methods}

One of the most critical aspects of biodiversity research is to identify, measure and describe the patterns of species' distributions. This study has concentrated on the distribution of all species of mammals. The following text describes data collection 
techniques, as well as the analytical components utilized in subsequent research (Chapters 3-6).

Taxonomy

Mammalian taxonomic classification has followed Mammal Species of the World (MSW), Second Edition (Wilson and Reeder, 1993). Modifications have been incorporated from the latest taxonomic information from draft chapters of MSW, Third Edition (D. Reeder and D. Wilson, pers. comm.). The Second Edition of MSW lists 4,629 species of mammals divided into 26 orders. The class Mammalia is divided into three main groups of extant mammals; monotremes, marsupials, and placentals. The mammal Orders are the monotremes (Monotremata); seven orders of marsupial mammals (Didelphimorphia, Paucituberculata, Microbiotheria, Dasyuromorphia, Peramelemorphia, Notoryctemorphia, Diprotodontia) and placental mammals (Xenarthra, Insectivora, Scandentia, Dermoptera, Primates, Carnivora, Proboscidea, Perissodactyla, Hyracoidea, Tubulidentata, Artiodactyla, Pholidota, Rodentia, Chiroptera, Lagomorpha, and Macroscelidea, Cetacea, Sirenia).

The revised number of species considered is over 5,000 using the preliminary chapters of MSW, Third Edition (Table 1a). Some higher taxonomic levels have also been changed; the primary changes included the division of the Order Xenarthra into the Orders Cingulata and Pilosa, and the division of the Order Insectivora into Lipotyphla, Afrosoricida, and Erinaceomorpha, for a total of 29 Orders of mammals considered. The total number of mammal species considered is 5,035 (this does not include 54 species removed in the Third Edition that were included in the Second Edition). In this study, I 
exclude any species that are extinct, as classified by the World Conservation Union (IUCN) (Hilton-Taylor, 2002), or human commensals. Also excluded are 58 species that were described in the text of Mammal Species of the World and other expert sources as having taxonomic and distribution uncertainty. Since the focus is on biodiversity patterns and human impacts across terrestrial systems, marine mammals (Cetacea, Sirenia and marine Carnivora) also were not used in the analyses. Therefore, the total number of mammal species under consideration is 4,740 species (Table $1 \mathrm{~b}$ ).

Since the unit of most biodiversity and biogeographic research is the species, accurate taxonomic information at the species level is critical. Synonym data were used to establish congruence among different sources, which often use different names for the same species. Even among vertebrate groups, new species are still being discovered, and revisions of taxonomy are still made. However, all efforts were made to assure that the taxonomic information used here is the most recent and rigorous available.

\section{Data sources}

Spatial data were compiled from primary and secondary literature (e.g. taxonomic accounts, regional atlas projects, Mammalian Species Accounts), museum records and other scientific reports and documents. The initial step involved researching the latest literature on mammals and their distributions. This was done either taxonomically or geographically. Sources were reviewed and assessed for their relevance, and for each species one or more maps were selected for the process of mapping the species' range into a GIS. The review and assessment was necessarily subjective, but followed consistent criteria based on scale, measurement, methods, and time period over which the 
data were collected. Over 1,700 sources were consulted for information on species distributions. For many species, recent sources provided a good compilation of previous research, and these were used for mapping the range or to provide a basis for further data compilation (Table 2). More extensive research and use of primary literature was required for other species, especially among Chiroptera, Rodentia, and Lipotyphla.

Distribution information for each species within a taxonomic group, typically the Family, was gathered. This information was evaluated to match consistency with the taxonomy used (Wilson and Reeder, 1993; D. Reeder and D. Wilson and Reeder, pers. comm.). Each species has descriptive textual information associated with it from these sources, and this was used in addition to other available published distribution information. For each species, this was used to assess the taxonomic and distributional content from one or more maps, which were then selected. Preference is given for more recent sources, as well as sources that have comprehensive information for the entire species' range. I used the many available synthetic sources completed by relevant taxonomic experts. For species with little information available, I attempted to use all the available primary sources. This includes new species, restricted range species, and species from poorly studied geographic regions.

Data were preferred that were either from the most recent primary source, based on a mapping method showing range extents and point locality data, or at the finest mapping resolution and based on the greatest amount of information (in terms of the extent of temporal coverage as well as amount of museum, field and literature research). Where data were of similar quality, the maximum possible extent of occurrence was calculated. Where necessary, sources that only contain information for part of the 
species' entire range were combined to estimate the extent of occurrence for that species. Data quality was quantified from each spatial source as follows: (A) mapping detail and method: 1) extent of occurrence map that depicts range disjuncts and elevation information, with point locality data marked, 2) extent of occurrence map that depicts range disjuncts and altitudinal information, without point locality data marked, 3) extent of occurrence map without detailed information (no disjuncts, altitudinal information, etc.), 4) mapped point locality data with no extrapolated extent of occurrence estimated, 5) mapped point locality data recorded as presence/absence in grids of a predetermined size, 6) textual range or point locality information (i.e. county, province, island); (B) publication date and/or time period of point locality data used; (C) data quantity: for spatial information with point locality data, the number of records were recorded.

The digitized extent of occurrence range for each species was linked to its sources, source quality and details of how sources were combined to construct the range (Figure 1 and 2). This makes it possible to consider the variability in quality within the database, allowing subsequent analyses of the effect of biases in the data quality such as mapping method, detail and date, data quantity and biogeographic region on the patterns observed in the spatial data. Tracking data sources and quality was also crucial so that additions of new and higher quality sources can be easily incorporated into the database. For example, different means of measuring distributions may affect the patterns and correlations seen within the geographic data (Gaston, 1994), although how important these possible confounding factors are on subsequent analyses is unknown. There is some evidence to suggest that variability in measurement method is unlikely to be a substantial 
confounding factor as different estimates of geographic extent of occurrence have been found to be broadly interchangeable.

Published species distribution information in the form of georeferenced point localities, which are often either field or museum records. Although point locality data are the critical data on which all other spatial information is estimated, there are at present several drawbacks to using only these data. For example, rapid changes in distributions due to human activities may nullify the accuracy of some historical information (Channell and Lomolino, 2000). Additionally, it would ignore information from local regional expert opinion. Localities are incorporated as latitude and longitude coordinates, which are either as decimal degrees (DD) or degrees-minutes-seconds (DMS). Where information is necessarily only based on point locality data or point locality data in binary grids, an area based on a minimum area convex polygon (MACP) following major landscape features (e.g. water, mountains) was calculated from those points. The range is interpolated from known localities, using information on habitat association to delineate the extent of occurrence. When there are too few point localities to calculate a MACP (under 3 point localities) a set circular range of $100 \mathrm{~km}^{2}$ was assigned to each point locality, or if the area is on an island then the entire area of the island (whichever is smaller). The final extent of occurrence produced for each species was checked using complete country, island and regional species lists in published sources (e.g. Wilson and Reeder, 1993; Nowak, 1999; IUCN, 2000).

This study generated the first complete digital geographic database of the mammals. Extent of occurrence maps have been generated for each species from the literature as a basis for refinement using further field and museum locality records, 
population density and persistence information, along with the many probable future taxonomic species revisions. In cases where there is more than one data source for a species, the highest quality of information was selected, based on the previously outlined criteria. This approach is similar to an independently developed methodology that was used for the African Mammal Databank project, the first to assemble extent of occurrence maps and model area of occupancy for large mammals in Africa (Boitani et al., 1999). All available data compiled for each species were then used to generate an extent of occurrence map. These maps were digitized into a spatial geographic information system (GIS) database (ArcView version 3.2 for Windows). There are many ways to measure a species geographic range. However, species exhibit varying levels of density and distribution within their EO. Models of area of occupancy can be used to remove unsuitable habitat from a species range map. Comprehensive point records and population information across the range of most species of mammals is unknown. The EO is important in delineating the range boundaries, including large internal range absences, so that AO models can account for history, competition, and other factors that cannot be modeled using habitat and ecology alone. Here I consider published extent of occurrence maps as the best estimate of overall geographic range size. I consider these ranges as a framework for further refinement based on additional mapped or textual point locality information, which can be used for models of area of occupancy (following Boitani et al., 1999).

The designation of current range was indicated for the most recently compiled distribution maps, preferably within the last two decades, that reflect current distributions (extent of occurrence). For a limited number of species it was possible to quantify their 
historical distribution. Historical ranges were defined as the largest range known for a species within the last two centuries, which follows a similar methodology employed by BirdLife International in classifying restricted range species (Stattersfield et al., 1998). Geographic range data from before the early 1800's were not used; although humans have affected geographic distributions since prehistoric times, quantifying historical ranges relies on subfossil or fossil information, which is often scarce and imprecise (Stattersfield et al., 1998). This is limited by the amount of historical data on individual species, though a range that recently contracted was considered as a historical estimation. Historical range size data were collected for a subset of mammalian species, which are biased towards larger bodied, temperate species that have better historical records (411 species).

\section{Database}

The database, created in Microsoft Access, contains all of the relevant species information. The database included all taxonomic information as well as specific data on island status, range area, latitudinal and longitudinal extent. This information all conformed to standards for each category, to make the data as uniform as possible across species (Table 3). Information was recorded for general regions (Table 4) including continents and island groups that a species occurs on.

\section{Mapping ranges}

The following is a description of several aspects of compiling a database of geographic ranges in a GIS using published information. A digital copy of a distribution 
map is needed to complete the digitizing procedure using this technique. If there are digital copies available, then the only step needed is to convert them into a Tagged Information Format (tif) file if they are not in this format. There are multiple ways of batch converting image files into tif files. If there are no digital copies of the maps, then a manual procedure must be used. If the maps are all on single pieces of paper, an automatic document feeder can be used in conjunction with the scanner to scan multiple maps. The equipment needed include a standard flatbed scanner and a desktop computer, along with the appropriate scanning and image software.

Digitization of distribution maps was performed using either of two methods. Available maps from secondary sources were scanned in using a standard flatbed scanner. These images were scanned into the program Adobe Photoshop (version 5.0 for Windows), as tif files. Data transformation included removing information to digitally transfer the range map into ArcView. For maps that were difficult to scan, such as those at poor resolution or with hatched boundaries, a digitizing tablet was used.

The following section describes the methods used to digitize species distributions. The software ArcView GIS, a widely available computer program, was utilized. The tiff file was transferred into ArcView using the Image Analysis Extension and was georeferenced using the image rectification tool to adjust the projection and scale of the original map to that of Digital Chart of the World. For each image a minimum of 10 control points were used. My analyses have shown that the root mean square (RMS) error between the original and the geo-referenced image is very low (typically less than 1). The geo-referenced image was then converted into an ArcView vector shapefile. Textual spatial information was digitized onto the Digital Chart of the World manually. As 
described above, an MACP was drawn in ArcView for those maps that contained only point locality data, and a circular set range of $100 \mathrm{~km}^{2}$ was calculated for maps for species that contain less than 3 point localities or the entire area of the island for island species (whichever is smaller). Multiple shapefile images were merged to create an extent of occurrence map for each species. Importantly, the final Arcview shapefile precisely represents the source map or maps, as they are vector base range-filling (extent of occurrence) maps, not presence/absence grid based maps.

\section{Shapefile Table Layout}

The shapefile table layout contains relevant information. Each record (either point or polygon) is referenced directly to the source used, and contains other information that applies to the record. Thus, each species range is composed of one or more records, each of which contains information in the shapefile's table (dbf). Categories are used to describe a species' range in a GIS shapefile, and can be applied to polygon or point records (Appendix 1). Each species' shapefile table includes all of these categories, though not all need be filled in. The scientific name field refers to the species, so that any information in the associated databases can be referenced. The other fields refer directly to the polygon (or point record) that a row in the table represents. Information such as comments, references, compiler etc. refer directly to the specific polygon or point. Information that applies to the entire distribution is stored in the associated database, so that only information unique to each individual polygon or point is stored in the shapefile table. 
Gridding polygon ranges

The digital geographic database contains vector-based files for each species, which allows the ArcView shapefiles to be easily manipulated when new information becomes available. Also, subsequent analyses these data are not limited to any predetermined spatial scale. However, for many analyses of the geographic range data conversion of the shapefiles to a grid-based map of set resolutions is necessary. The Spatial Analyst Extension is used to convert the shapefiles into grid format. The database has several advantages: real boundaries are drawn using shapefiles, the grid system can be easily used at different scales, and the data in shapefiles can be manipulated when new information becomes available.

Data Analysis

All analyses were performed using ESRI products, including ArcView and ArcGIS. A program was developed at the University of Virginia to manipulate and analyze the large amount of geographic data. The program links the database containing species information with the geographic shapefile of each species. This allowed for sorting and querying the database to analyze subsections of the dataset. Grid based analyses were performed the same way, using grid overlays in ArcGIS to produce density maps. In addition, calculations on grid cells, such as range size rarity, were performed using the developed program. 


\section{Conclusions}

The development of a database on geographic ranges of all species of mammals forms the basis the following chapters. The methods followed allowed for flexible, quantitative analyses to be performed on large amounts of geographic data. Data quality and consistency were also analyzed to identify possible errors in results. Overall, the quality of the database was crucial to describing and analyzing patterns of diversity across mammals. 


\section{References}

Brown, J.H. 1995. Macroecology. University of Chicago Press, Chicago.

Brown, J.H., G.C. Stevens, and D.M. Kaufman. 1996. The geographic range: size, shape, boundaries, and internal structure. Annual Review of Ecology and Systematics 27:597-623.

Ceballos, G. and J.H. Brown. 1995. Global patterns of mammalian diversity, endemism, and endangerment. Conservation Biology 9:559-568.

Channell, R., and M. V. Lomolino. 2000. Dynamic biogeography and the conservation of endangered species. Nature 403:84-86.

ESRI. 1993. Digital Chart of the World, Environmental Systems research Institute, Inc.

Gaston, K.J. 1994. Measuring geographic range sizes. Ecography 17:198-205.

Gaston, K.J. 1996. Species-range-size distributions: patterns, mechanisms and implications. Trends in Ecology and Evolution 11:197-201.

Hilton-Taylor, compiler. 2002. 2002 IUCN Red List of Threatened Animals. IUCN, Gland, Switzerland.

Hutchinson, G. E. 1957. Concluding remarks. Cold Spring Harbor Symposia on Quantitative Biology 22:415-427.

Lawes, M.J. and S.E. Piper. 1998. There is less to binary maps than meets the eye: The use of species distribution data in the southern African sub-region. South African Journal of Science 94:207-210.

Letcher, A. J., and P. H. Harvey. 1994. Variation in geographical range size among mammals of the Palearctic. The American Naturalist 144:30-42.

Mace, G. M., and A. Balmford. 2000. Patterns and processes in contemporary 
mammalian extinction. in A. Entwistle and N. Dunstone, editors. Future Priorities for the Conservation of Mammalian Diversity. Cambridge University Press, Cambridge.

McKenna, M. C., and S. K. Bell. 1997. Classification of Mammals Above the Species Level. Columbia University Press, New York.

Nowak, R.M. 1999. Walker's mammals of the world, sixth edition. Johns Hopkins University Press, Baltimore.

Pagel, M.D., R.M. May, and A.R. Collie. 1991. Ecological aspects of the geographical distribution and diversity of mammalian species. American Naturalist 137:791815.

Rosenzweig, M.L. 1995. Species Diversity in Space and Time. Cambridge University Press, Cambridge.

van Jaarsveld, A.S., K.J. Gaston, S.L. Chown, and S. Freitag. 1998. Throwingbiodiversity out with the binary data? South African Journal of Science 94:210-215.

Wilson, D. E., and D. M. Reeder (eds). 1993. Mammal Species of the World. Smithsonian Institution Press, Washington, DC. 


\begin{tabular}{|l|c|}
\hline & Number of species \\
\hline Species included in the analyses & 4740 \\
\hline $\begin{array}{l}\text { Domesticated or commensal species (including } \\
\text { Homo sapiens) }\end{array}$ & 13 \\
\hline Marine (Cetacea, Sirenia, marine Carnivora) & 121 \\
\hline Extinct & 103 \\
\hline Uncertain species ${ }^{2}$ & 58 \\
\hline \hline Total (all mammal species globally) & 5035 \\
\hline
\end{tabular}

1 Not Applicable

${ }^{2}$ No range information available or uncertain taxonomic status

Table 1a: Mammal species of the world. 


\begin{tabular}{|c|c|}
\hline Order & $\begin{array}{l}\text { Number of } \\
\text { Species }\end{array}$ \\
\hline Afrosoricida & 51 \\
\hline Artiodactyla & 211 \\
\hline Carnivora & 238 \\
\hline Chiroptera & 1077 \\
\hline Cingulata & 20 \\
\hline Dasyuromorphia & 71 \\
\hline Dermoptera & 2 \\
\hline Didelphimorphia & 63 \\
\hline Diprotodontia & 134 \\
\hline Erinaceomorpha & 22 \\
\hline Hyracoidea & 4 \\
\hline Lagomorpha & 90 \\
\hline Lipotyphla & 354 \\
\hline Macroscelidea & 15 \\
\hline Microbiotheria & 1 \\
\hline Monotremata & 5 \\
\hline Notoryctemorphia & 2 \\
\hline Paucituberculata & 6 \\
\hline Peramelemorphia & 18 \\
\hline Perissodactyla & 14 \\
\hline Pholidota & 8 \\
\hline Pilosa & 10 \\
\hline Primates & 361 \\
\hline Proboscidea & 3 \\
\hline Rodentia & 1939 \\
\hline Scandentia & 20 \\
\hline Tubulidentata & 1 \\
\hline Total & 4740 \\
\hline
\end{tabular}

Table 1b: Number of species considered, per order. 
Region

North America

West Indies

Central America

South America

Madagascar

Africa

Europe

Asia

Philipine Islands

New Guinea

Australian Region

Southeast Asian, Pacific Islands

\section{Main References}

Hall, 1981; Wilson and Ruff, 1999

Woods, 1989; Woods and Sergile, 2001

Hall, 1981; Reid, 1997

Eisenberg, 1989; Redford and Eisenberg, 1992; Eisenberg and Redfored, 1999; Emmons and Feer, 1997

Garbutt, 1999

Kingdon, 1997; Boitani et al., 1999

Mitchell-Jones et al., 1999

Corbet, 1978; Harrison and Bates, 1991; Corbet and Hill, 1992; Zhang et al. 1997

Heaney et al., 1998

Flannery, $1995 \mathrm{~A}$

Strahan, 1996

Corbet and Hill, 1992; Flannery, 1995 B

Table 2: List of main sources for range data by regions (see Appendix 3 for full references). 


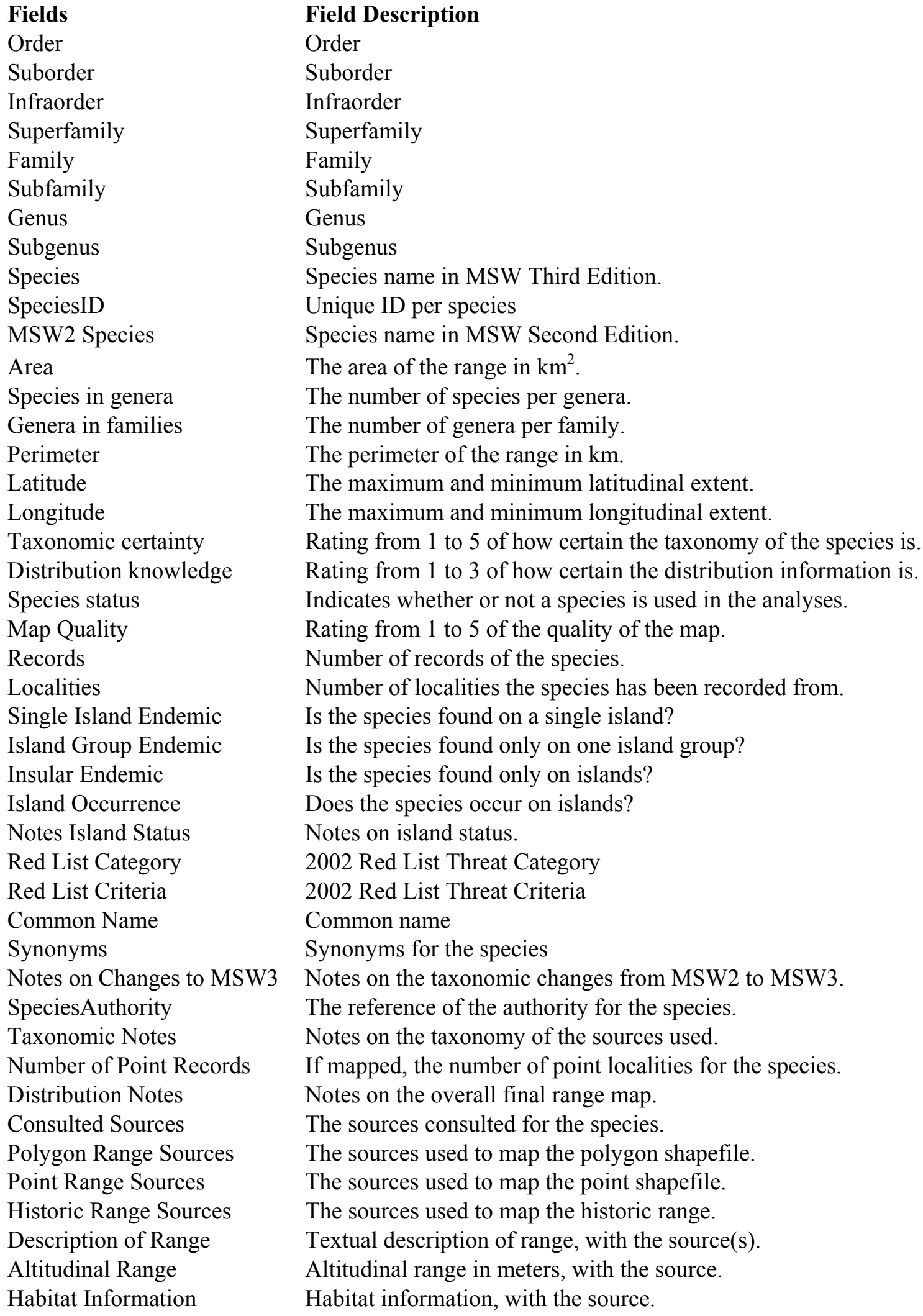

Table 3: Description of fields per species in the range database. 


\author{
Regional Records \\ North America \\ Caribbean \\ South America \\ Madagascar \\ Africa \\ Europe \\ Asia \\ Southeast Asian islands \\ Philippines \\ New Guinea \\ Australia \\ New Zealand \\ Pacific \\ Marine
}

Table 4: Broad regions used in the analyses. 
Species Taxonomic Certainty

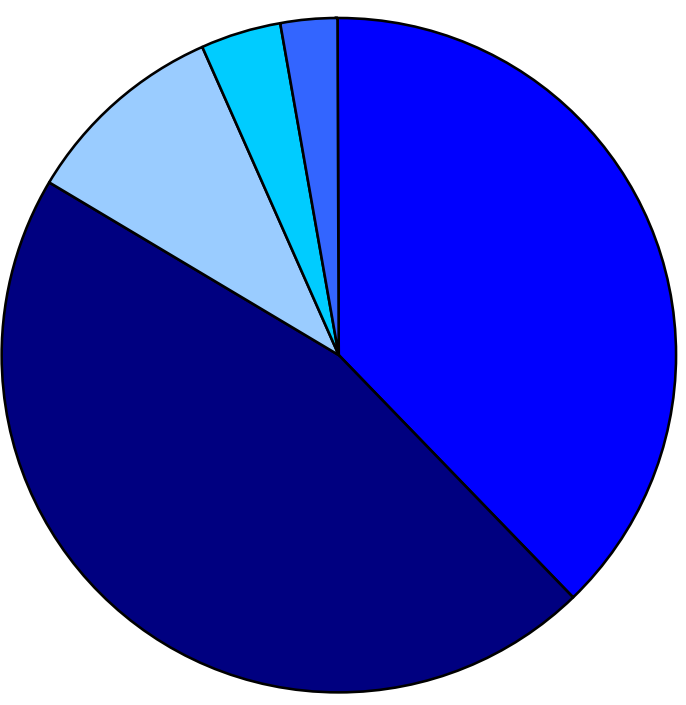

Figure 1: Proportion of taxonomic certainty rated across all mammal species considered. 
Species Distributional Certainty

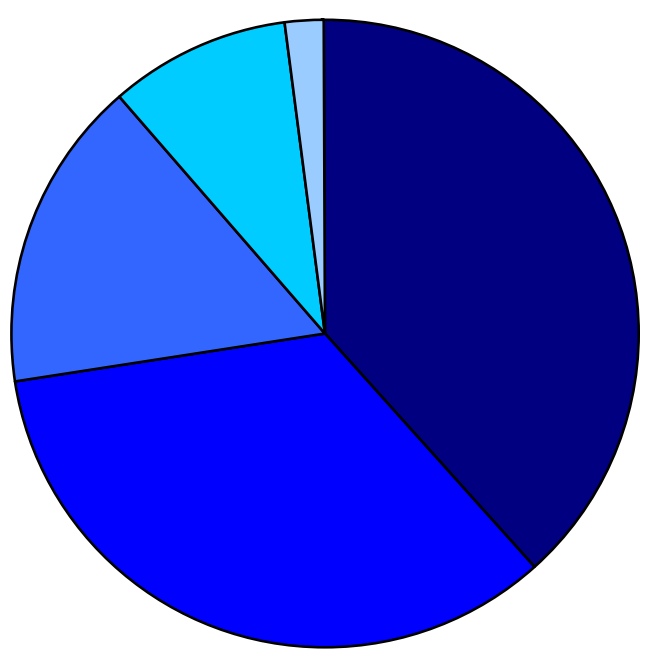

Certain

Somewhat certain

Moderat ely certain

$\square$ Somewhat uncertain

口Uncertain

Figure 2: Proportion of distributional certainty rated across all mammal species considered 


\section{APPENDIX 1}

\section{Shapefile Tables}

\section{Shapefile Fields}

*Shape - Polygon or Point

*ID - Unique number identification for each polygon or point record.

*SCI_NAME - Scientific name of the species mapped.

*PRESENCE - Is/Was the species in the area (see table below).

*ORIGIN - Why/How is the species in the area (see table below).

*COMPILER - Organization(s) or individual(s) that compiled the polygon or point. TAX_COMMEN - Taxonomic comments that refer directly to the polygon or point. DIST_COMM - Distribution comments that refer directly to the polygon or point.

*REFERENCES - Literature or expert reference for the polygon or point. A number code is used which codes for a source in the reference database (such as EndNote).

REVIEWERS - Experts and dates of review.

ISLAND - Name of the island the polygon or point is on.

SUBSPECIES - Subspecies the polygon or point is referred to.

* These fields are required to be filled for each polygon or point. 


\section{Presence}

\begin{tabular}{|l|l|}
\hline 1 & Extant \\
\hline 2 & Possibly present \\
\hline 3 & Not likely present \\
\hline 4 & Probably extirpated \\
\hline 5 & Extirpated \\
\hline 6 & Extirpated, subfossil \\
\hline 7 & Eradicated - refers only to introduced spp. \\
\hline 8 & Not present, possibly existed previously \\
\hline 9 & Absent \\
\hline 10 & Fossil \\
\hline 11 & Possible subfossil/fossil \\
\hline 12 & Island group * \\
\hline
\end{tabular}

Extant - The species is known to occur presently in the area.

Possibly present - The species presence is possible, either from extrapolations or possible records, within the area.

Not likely present - The species presence is unlikely, either from expert knowledge or dubious records, though it could occur in the area.

Probably extirpated - The species presence was previously confirmed, but it is most likely extirpated from the area.

Extirpated - The species presence was previously confirmed, but it is known to have been extirpated from the area.

Extirpated, subfossil - The species presence was previously confirmed with subfossil information, but it is known to have been extirpated from the area.

Eradicated - The species was previously introduced into an area, but it is known to have been eradicated from the area.

Not present, possibly existed previously - The species presence was previously possibly confirmed, but it is known to not presently be found in the area.

Absent - The species is known to be absent from the area. This category is used for large absences within a species' known range limits.

Fossil - The species is known from fossil records for an area.

Possible subfossil/fossil - The species possibly existed previously based on possible subfossil or fossil information.

Island group - Little or no specific island info exists, but the species known to occur on an island group. This is used mainly for atolls or small island groups. 
Origin

\begin{tabular}{|l|l|}
\hline 1 & Native (year round) \\
\hline 2 & Native (during breeding season only) \\
\hline 3 & Native (during non-breeding season only) \\
\hline 4 & Native (as passage migrant) \\
\hline 5 & Native (seasonal permanence uncertain) \\
\hline 6 & Introduced \\
\hline 7 & Either introduced or native \\
\hline 8 & Reintroduced \\
\hline 9 & Either reintroduced or introduced \\
\hline 10 & Vagrant \\
\hline 11 & Unknown \\
\hline 12 & Prehistorically introduced \\
\hline 13 & Absent \\
\hline
\end{tabular}

Native (year round) - The species is/was native to the area throughout the year. Native (during breeding season only) - The species is/was present only during its breeding season.

Native (during non-breeding season only) - The species is/was present only during its non-breeding season.

Native (as passage migrant) - The species is/was present only as a passage migrant. Native (seasonal permanence uncertain) - The species is/was present, but it is not known if it is present during part or all of the year.

Introduced - The species is/was introduced through either direct or indirect human activity.

Either introduced or native - The species is/was known to be in the area, but it is not known whether it is native or introduced through either direct or indirect human activity. Reintroduced - The species is/was reintroduced through either direct or indirect human activity.

Either reintroduced or introduced - The species is/was known to be in the area, but it is not known whether it has been reintroduced or introduced through either direct or indirect human activity.

Vagrant - The species is/was recorded once or sporadically, but it is known not to be native to the area.

Unknown - The species provenance in an area is unknown.

Prehistorically introduced - The species is/was introduced through either direct or indirect human activity in prehistoric times. This is specifically for species that have been introduced prior to 1800 .

Absent - The species has never been recorded in the area, and is known to be absent. 
APPENDIX 2

Boitani, L., F. Corsi, A. De Biase, I. D'Inzillo Caranza, M. Ravagli, G. Reggiani, I. Sinibaldi, and P. Trapanese. 1999. African Mammals Databank: A Databank for the Conservation and Management of the African Mammals. Instituto di Ecologia Applicata, Rome.

Corbet, G. B. 1978. The Mammals of the Palaearctic Region: a taxonomic review. British Museum (Natural History) Cornell University Press, London.

Corbet, G. B., and J. E. Hill. 1992. The Mammals of the Indomalayan Region: A Systematic Review. Oxford University Press, Oxford.

Eisenberg, J. F. 1989. Mammals of the Neotropics: The Northern Neotropics. University of Chicago Press, Chicago.

Eisenberg, J. F., and K. H. Redford. 1999. Mammals of the Neotropics: The Central Neotropics. University of Chicago Press, Chicago.

Emmons, L. H., and F. Feer. 1997. Neotropical Rainforest Mammals: A Field Guide. University of Chicago Press, Chicago.

Flannery, T. F. 1995. Mammals of New Guinea, Second edition. Cornell University Press, Ithaca, NY.

Flannery, T. F. 1995. Mammals of the South-West Pacific and Moluccan Islands. Comstock/Cornell, Ithaca, N.Y.

Garbutt, N. 1999. Mammals of Madagascar. Yale University Press, New Haven.

Hall, E. R. 1981. The Mammals of North America, Second edition. John Wiley and Sons, New York. 
Harrison, D. L., and P. J. J. Bates. 1991. The Mammals of Arabia. The Harrison Zoological Museum, Kent, England.

Heaney, L. R., D. S. Balete, L. Dolar, A. C. Alcala, A. Dans, P. C. Gonzales, N. Ingle, M. Lepiten, W. Oliver, E. A. Rickart, J. Tabaranza, B. R., and R. C. B. Utzurrum. 1998. A synopsis of the mamalian fauna of the Philippine islands. Fieldania Zoology new series 88:1-61.

Kingdon, J. 1997. The Kingdon Field Guide to African Mammals. Academic Press, London.

Mitchell-Jones, A. J., G. Amori, W. Bogdanowicz, B. Krystufek, P. J. K. Reijnders, F. Spitzenberger, M. Stubbe, J. B. M. Thissen, V. Vohralik, and J. Zima. 1999. The Atlas of European Mammals. Academic Press, Orlando, FL.

Redford, K. H., and J. F. Eisenberg. 1992. Mammals of the Neotropics: The Southern Cone. University of Chicago Press, Chicago.

Reid, F. A. 1997. A Field Guide to the Mammals of Central America and Southeast Mexico. Oxford University Press, New York.

Strahan, R. 1995. The Mammals of Australia. The Australian Museum/Reed Books, Chatswood, NSW.

Wilson, D. E., and S. Ruff. 1999. The Smithsonian Book of North American Mammals. Smithsonian Institution Press, Washington, D. C.

Woods, C. A. 1989. Biogeography of the West Indies, Past, Present and Future. Sandhill Crane Press, Gainesville, Florida.

Woods, C. A., and F. E. Sergile. 2001. Biogeography of the West Indies: Patterns and Perspectives, Second edition. CRC Press, Washington, D.C. 
Zhang, Y. Z ., S. K. Jin, G. Q. Quan, S. H. Li, Z. Y. Ye, F. G. Wang, and M. L. Zhang. 1997. Distribution of Mammalian Species in China. Cites Management Authority of China, China Forestry Publishing House, Beijing. 


\section{Chapter 3}

\section{Global Biogeography of the World's Mammal Species}

\section{Introduction}

The origin, spatial distribution, and maintenance of biological diversity have received considerable attention over the past several decades (Ricklefs and Schluter, 1993; Heywood, 1995; Gaston and Spicer, 1996). The importance of biogeography in ecology, evolution, and conservation biology has been established over the last century and a half (Darwin, 1859; Murray, 1866; Wallace, 1876; Willis, 1922; MacArthur and Wilson, 1967; MacArthur, 1972). Biogeography research ultimately relies on the knowledge of what species exist and where they are found. This information, in the form of species' geographic ranges, provides the basis of research on biodiversity and macroecological patterns (Brown et al., 1996). Any spatial analysis of biodiversity is initially constrained by the characterization of species and their geographic ranges, and to obtain relevant results both aspects must be accurately defined and measured. Such information is crucial for establishing a rigorous scientific basis for many conservation decisions and actions.

The geographic range of a species is determined by its physiology, ecology and evolutionary history. Every species can tolerate a certain range of physical factors, such as temperature and precipitation, which determine where individuals can survive. A species is thus constrained to live within its fundamental niche, the areas within its physiological tolerances. However, the area where a species actually occurs, its realized 
niche, also takes into account ecology and evolution (Brown, 1995). For example, a species may be excluded from certain areas because of a combination of biological and environmental factors, such as competition with other organisms or physical barriers to dispersal. These factors can vary dramatically among species and regions (Gaston and Blackburn, 1997). Measurement of a species' geographic range can be accomplished using various methods, but is often characterized by its extent of occurrence or area of occupancy (see Chapter 2). Extent of occurrence encompasses the outermost limits of a species' distribution and area of occupancy is the area within this where the species is actually found (Gaston, 1994). Extent of occurrence measures the maximum extent of a species, while the measurement of area of occupancy is dependent on the scale used. Since the purpose of this paper is to study global trends in species distributions, geographic ranges were defined as a species' extent of occurrence.

There is often a large amount of variation in the size of species geographical ranges. Some fish species are restricted to a single small pond, in contrast to the blue whale (Balaenoptera musculus) that ranges over $300,000,000 \mathrm{~km}^{2}$ of ocean (Brown et al., 1996). In general, frequency distributions of the areas of geographic ranges across a taxonomic group are strongly right-skewed (Willis, 1922), so that most species have small ranges and relatively few have very large ranges (Rapoport, 1982; Gaston, 1994; Gaston, 1998; Brown, 1995). Thus, when species' range sizes for a taxonomic group are plotted a 'hollow curve' is often observed (Willis 1922; Rapoport 1982; Gaston 1994; Gaston 1998). When range size is logarithmically transformed and plotted, an approximate lognormal distribution is typically seen (Pagel et al. 1991; Gaston 1998). Recent analyses have been undertaken to explain this pattern, using comparisons of 
ecological, evolutionary, environmental, and other factors that may affect the range size of species in a given taxonomic group (Brown, 1995; Gaston, 1996; Gaston 1998). This pattern has implications for current and past biodiversity patterns, including the underlying processes of speciation, extinction, and transformation (Gaston, 1996; Gaston, 1998). With a complete data set of the Class Mammalia, it is possible to achieve a much clearer picture of the frequency distribution of range sizes.

Rapoport (1982) originally observed that mean latitude of a species range correlates with range size, such that range size increases with increasing latitude (Simpson, 1964; Schall and Pianka, 1978; Rapoport, 1982; Stevens, 1989; Gaston and Williams, 1996). The climatic variability hypothesis set forth by Stevens (1989), which holds that species experience a narrowing range of climatic conditions with decreasing latitude, attempted to explain Rapoport's rule. Individuals of species found at higher latitudes (or higher altitudes) must be able to survive broad climatic variation, so that these species tend to have larger geographic ranges (Stevens, 1989; Stevens, 1992). Other mechanisms set forth to explain this pattern include biological determinants such as competition, predation, mutualism, etc. as well as environmental determinants such as habitat heterogeneity, productivity, environmental stability or predictability, and geographic area. Rapoport's rule has not been consistently found across taxa, most likely due to taxonomic groups exhibiting different biogeographic patterns across different landmasses (Rohde, 1992; Rohde, 1996; Gaston, 1999). This includes differences in species' biology as well as variation in the environment across geographic areas. Recent research on species richness patterns by latitude has focused on answering questions concerning the extent to which patterns reflect random patterns and to what extent the 
patterns are caused by underlying ecological or evolutionary mechanisms (Colwell and Hurtt, 1994; Willig and Lyons, 1998; Colwell and Lees, 2000; Bokma et al., 2001).

Patterns of global biodiversity today have not only been influenced by natural processes, but also by the activity of humans. Humans have had a profound effect on global ecology and biodiversity. Prehistorically, humans have directly or indirectly influenced the extinction of many large vertebrates, including 23 of 24 terrestrial vertebrate genera over 40 kilograms in Australia, around 46,000 B.P. (Roberts et al., 2001). Since the beginning of agriculture, and through the development of industrial human society, humans have had an increasing impact on the distribution of organisms. Presently, many formerly wide-ranging species are confined to small segments of their range. Many species are on the verge of extinction across their entire range, while others have already become extinct (Hilton-Taylor, 2002). Patterns of species distribution are thus inextricably linked with past and present biological and physical processes, presently including intense human activity across the planet (see Chapter 5). Therefore, it is no surprise that patterns of mammalian biodiversity are different today than they were a hundred years ago. Unfortunately, however, there is no consistent source for historical range data across all mammals, or even a large proportion of mammals. Research to date includes many case studies as well as several global studies of spatial extents of range loss across a handful of taxonomic groups (Lomolino and Channell, 1995; Channell and Lomolino, 2000a; Channell and Lomolino, 2000b; Ceballos and Ehrlich, 2002). However, many of these studies dramatically underestimate the true declines in mammals, largely because information is extremely inconsistent across taxa and regions. For instance, Ceballos and Erhlich (2002) show that there are large losses across mammal 
ranges in North Africa, which is heavily biased because of the inclusion of large mammals, mostly ungulates. These species have suffered losses across their ranges due to human hunting, but inhabit areas of relatively low species diversity. Since fossil information is patchy at best, and certainly is influenced by biological and physical processes, I have not included it in my analyses. For the overall patterns of mammal diversity, I have therefore concentrated on evaluation of current distribution information for all species, with the knowledge that many factors, including anthropogenic ones, have influenced the current picture.

Biogeography, the study of the distribution of organisms (Brown and Lomolino, 1998), has developed gradually over the last few centuries. In order to conduct a rigorous biogeographical analysis of mammals, or any taxonomic group, the distributions of species biodiversity must be accurately described. Presently, the amount of data and recent technological advances provide, for the first time, a systematic and quantitative description of species-level biogeographic patterns for an entire group of terrestrial organisms (Chapter 2). This allows for more quantitative analyses that can be applied to questions in ecology and conservation science. Presently, few quantitative studies have been carried out at a global scale. Amongst terrestrial systems, most analyses have addressed North America, Europe and Australia, some Africa (e.g. Balmford et al., 2001; Brooks et al., 2001), and relatively few Asia or South America (e.g. Ruggiero et al., 1998). As a result, there is no comprehensive knowledge of global patterns of species richness and diversity (Rosenzweig, 1995). Indeed, we still do not know why patterns of geography, including endemism, species richness, and complementarity, vary significantly across taxa at global scales (Pimm and Lawton, 1998; Howard et al., 1998). 
The goal of this paper is to address this paucity of knowledge by utilizing a complete, spatially explicit dataset to analyze global patterns of mammalian diversity. This effort represents the first comprehensive analysis for any large taxonomic group.

Comprising over 5,000 species, from marine to terrestrial to flying species, mammals represent an impressive diversity (Wilson and Reeder 1993; Nowak, 1999). Species of mammals exist throughout the globe, though their diversity varies tremendously across regions. Many biogeographical patterns of mammals have been extensively researched, but a significant number of patterns have not been examined, especially using explicit spatial data on ranges. Indeed, mammalian biogeography has been and is currently a hallmark of ecology and evolution. The first attempt at a comprehensive picture of global geographical patterns in mammals dates back to 1866 (Murray, 1866). Research on mammal biogeography continued through Darwin and Wallace, both of whom used data on mammals for their groundbreaking works in ecology and evolution (Darwin, 1859; Wallace, 1876). Darlington (1957) developed and refined much of the previous knowledge on the biogeography of mammals (and other groups of vertebrates). Other early work includes analyses of vertebrate faunas from the United States and Australia (Schall and Pianka, 1978). Recently, Ceballos and Brown (1995) used data from 155 countries to examine species richness, endemicity, and endangerment. They found that total species richness was correlated with country land area, whereas endemicity was not strongly correlated with country land area or species richness. These patterns were explained by differences in topography, habitats, and history. The Ceballos and Brown (1995) study, though accomplished at the level of countries, was able to differentiate some broad ecological and biogeographic patterns of 
mammalian diversity. Dobson et al. (1997) spatially analyzed the distribution of endangered species in the United States and found hotspots of endangerment. Gaston and Williams (1996) suggest that mammals deviate from the general pattern of the Neotropics having the greatest species richness, as the Afrotropics (sub-Saharan Africa and Madagascar) have more families and genera (Cole et al., 1994). From Murray's (1866) first comprehensive study until now, knowledge on the ecology and evolution of mammals has gradually increased with these biogeographic approaches. However, there remain fundamental weaknesses in most past studies, especially in the accuracy, resolution and completeness of species range data.

Here, I present the most rigorous and comprehensive description of mammal diversity and biogeography across the globe. First, I examine the patterns of range size, including the overall distribution of range sizes, across regions and taxonomic groups. These patterns are predicted to generally map to known patterns of mammal diversity, with higher species richness in tropical regions, though this will vary among taxonomic groups. Second, I examine to what extent the global distribution of mammal species coincides with previous studies on latitudinal patterns of range size and species numbers. Then, I examine global diversity patterns across all mammals, and among the major orders. The results form the basis for describing diversity patterns in mammals, and are used in the subsequent chapters on endemism, threat, and evolutionary history. 


\section{Methods}

I compiled a database on the ranges of all species within an entire Class of vertebrates, the Mammalia. The underlying unit for analysis is the species, and for each species I collected the most current and quantitative information on their distribution. The result is the most complete species-level distribution database for any large group of organisms to date.

\section{Taxonomic information}

The taxonomy followed that provided in Mammal Species of the World, Second Edition (Wilson and Reeder, 1993). The taxonomic information has been updated for most orders, excluding some of the small mammals, using draft chapters of the Third Edition (D. Reeder and D. Wilson, pers. comm.). The higher taxonomic levels follow the changes in the latest edition. The total number of mammal species in this taxonomic listing is 5,035 (Figure 1) (excluding 54 species removed in the Third Edition that were included in the Second Edition). I have excluded species that are extinct, live commensally with humans, inhabit marine environments (Cetacea, Sirenia and marine Carnivora), as well as some species with taxonomic problems for a total consideration of 4,740 mammal species (Table 1) (see Chapter 2). There are vast differences in numbers of species per order, as over $60 \%$ of mammal species are rodents or bats (Figure 1). 
Distribution information

Data were compiled from published sources, including primary and secondary sources such as field studies, museum studies, field guides, regional and taxonomic works, Mammalian Species Accounts (American Society of Mammalogists), and reports such as World Conservation Union (IUCN) Species Survival Commission (SSC) Action Plans. Over 1,700 data sources were consulted, and over 1,000 sources were subsequently used (see Chapter 2). Data for each species were gathered and evaluated for three types of information: accuracy, currency, and sources. The types of information included point localities, polygon range maps, modeled ranges, and species lists for countries, islands, and biogeographic regions. The most accurate and updated distribution information available for every species was then digitized into a GIS (see Chapter 2). Information such as point localities and expert opinion were used to estimate ranges when no adequate range maps were available. The end product for each species was one map of its geographic range, given as its extent of occurrence.

\section{Analytical methods}

The data analysis was performed using the ESRI ArcGIS 8.2 platform by linking the geographic ranges with a database, created in Microsoft Access, containing all of the relevant species information. The database included all taxonomic information as well as specific data on island status, range area, and latitudinal and longitudinal extent. Information was recorded for general regions including continents and island groups where a species occurs. Overlays were performed using the spatial tools through ArcGIS 
8.2. Statistical analyses were performed using a PC based statistical packages, SPSS (SPSS, 2001).

All spatial analyses used information in the Behrmann equal area projection. Range maps were in the form of polygon shapefiles for range size based analyses, including measuring of each range size and extent. For the richness analyses, a gridbased database was created using the range maps. All grid-based analyses were performed using grid cells of $100 \mathrm{~km}$ by $100 \mathrm{~km}$ size $\left(10,000 \mathrm{~km}^{2}\right)$.

\section{Results}

Geographic range size distributions

The average range size for mammals is over 1.5 million square kilometers (mean $\pm \mathrm{SE}=1,683,755 \pm 3,757,291 \mathrm{~km}^{2}, \mathrm{n}=4740$ species), while the median range size is $245,005 \mathrm{~km}^{2}$. Orders of mammals exhibit different range sizes and variations, with mean range sizes varying over several orders of magnitude in some cases (Figure 2 and Table 2). Mean (ln transformed) range size differed significantly among families within orders and among genera within families (Nested ANOVA, $\mathrm{F}_{98,4615}=4.31, \mathrm{p}<0.001$ and $\mathrm{F}$ $26,4713=16.53, \mathrm{p}<0.001$, respectively)

The frequency distribution of mammal range sizes shows a strong right skew, in other words most mammals have small ranges (Figure 3a-b). Under natural logarithmic transformation, the data are more normally distributed, but there is a strong left skew $($ skewness ratio $=138.42, \mathrm{p}<0.001)($ Figure 4$)$. The skewness of most orders show a strong left skew, with the exception of two orders, Perissodactyla (14 species) and 
Hyracoidea (5 species) which have a small number of species. The mean (logtransformed) range sizes differ significantly within the diverse ordinal groups of mammals (ANOVA, $\mathrm{F}_{26,4713}=16.53, \mathrm{p}<0.001$ ) (Figure 4).

\section{Geographic patterns}

Continental patterns were examined amongst North America, South America, Africa, Eurasia, and Australia. However, some species occur on more than one continent, so will alter continental patterns if the entire range is considered. Analyses were therefore performed on species that occurred only on one continent due to the confounding effects

of shared species occurrence among continents. However, all analyses were repeated including all species that occur on more than one continent, and these analyses produced statistically similar results. Mean (ln transformed) range size was significantly different among continents (ANOVA, $\mathrm{F}=14.50, \mathrm{p}<0.001$ ) (Figure 5). Multiple comparisons (Tukey-Kramer) indicated that mean range size in North American mammals was significantly smaller than Africa $(\mathrm{p}<0.001)$, and Eurasia $(\mathrm{p}<0.001)$, but no differences were found compared to Australia $(\mathrm{p}=0.483)$. Mean range size in Africa was significantly greater than the other four continental areas considered, South America $(\mathrm{p}=$ $0.015)$, Eurasia $(p=0.026)$, and Australia $(p=0.003)$. Mean range size in Australia only differed from Africa, while mean range size in Eurasia and South America differed only from mean range size in North America and Africa.

A significant proportion of mammals are concentrated on oceanic and continental islands and island groups. Across extant mammals, there are 599 species that are endemic to only one island. Another 371 species do not range on continents, and are only found 
across multiple islands. There are several main areas that hold high numbers of insular mammals, including the Caribbean, Madagascar, New Guinea, the Philippines, Pacific islands, and the Southeast Asian archipelago (Table 4).

\section{Latitudinal patterns}

Latitudinal and longitudinal extents were calculated for all species using a geographic projection. A plot of number of species per 5-degree latitudinal band reveals that most species are centered in the tropics (Figure 6a). Continental landmass was plotted by 5-degree latitudinal bands, and this was used to scale species per latitude band by available land area (Figure 6 b-c). The bimodal pattern observed was an artifact of the use of 5-degree bands over the small area in the southern hemisphere that contained a similar complement of species as in the next band. Maximum north to south and east to west extents were calculated from species range maps in the GIS. These extents were plotted for each species (Figure $7 \mathrm{a}-\mathrm{b}$ ). Mean range size increases with increasing median latitude, though latitude does not explain much of the variation $\left(\mathrm{R}^{2}=0.07\right)$. The number of species peaked around 15 degrees north and south latitude. When controlling for available landmass, however, the number of species (per area) was greatest from around -20 to 5 , with another peak at the extreme south, due to small land mass area at the southern edge of species ranges in South America and Australia. For each species, range size was plotted against latitudinal minimum, maximum, and median (Figure 8 a-c).

The number of mammal species is highest around the equator, with the majority of species distributed within this zone (Figure 6 a). A corresponding increase in species diversity is seen in the tropics, with a strong correlation with latitude, independent of 
available land mass (Figure 6b and c). Of all mammal species, 34\% (1621 of 4740) range through the tropics, and extend above the tropics. A similar pattern was found for higher taxonomic groups, with ordinal and familial richness highest in tropical Africa, along with the Neotropics for families (Figure 14a and b). Patterns of genera mapped closely to species richness patterns (Figure 14c).

I tested the variation in geographic range size with latitude. In mammals, there is a general increase of geographic range size from the equator to the poles (Figure 8 a-c). Examining patterns on different continents further refines this global pattern. For example, species occurring in Africa show a positive relationship between range size and latitude $(\mathrm{p}<0.001)$. Similar results have been found in other groups (Lyons and Willig, 1997).

Species diversity patterns

Species diversity patterns were examined using spatial overlay grid maps to produce a map of species richness. The global map of mammal species richness varied from 0 to 273 species per grid cell (100 $\mathrm{km}^{2}$ equal-area) (Figures 9 and 10). The richest areas were consistently within the tropics. Africa and the Neotropics exhibit that highest diversity, with Southeast Asia also having high diversity.

Species richness patterns varied across different taxonomic levels and groups within them. Richness maps for the six most speciose (over 200 species) orders (Artiodactyla, Carnivora, Chiroptera, Lipotyphla, Primates, and Rodentia) were created and examined. Species richness for the Artiodactyla and Carnivora showed very similar 
patterns, with the highest diversity reached across sub-Saharan tropical Africa and Southeast Asia, particularly for the carnivores (Figure $11 \mathrm{a}-\mathrm{g}$ ). The frequency of species richness values varied among the groups as well (Figure $12 \mathrm{a}-\mathrm{g}$ ).

Species richness maps were produced for different range size classes. Species were divided into quartiles to examine differences in richness (Figure 13 a-d). The patterns revealed very strong differences among the quartiles, with the widest ranging quartile driving much of the pattern seen in overall mammal species richness. This widest ranging quartile contained the majority of species per area (grid cell) record, and therefore created most of the overall patterns of species richness.

\section{Higher taxonomic level diversity patterns}

Comparisons were made on richness maps of orders, families, genera, and species. The ordinal richness map had grid cell values that ranged from 0 to 15 (out of a total of 27 orders, excluding Cetacea and Sirenia). The map for familial richness varied from 0 to 43 families per cell (out of a total 146 families), while the generic richness varied from 0 to 149 genera per cell (out of a total 1183 genera) (Figures 14 a-c, respectively). Species values (ln transformed) for each grid cell were regressed against values for each of the other taxonomic levels (also ln transformed). Grid cell species richness was highly correlated with grid cell richness of the other taxonomic levels $\left(\mathrm{R}^{2}=\right.$ 99.4 sp vs. genera; $\mathrm{R}^{2}=95.4 \mathrm{sp}$ vs. families; $\mathrm{R}^{2}=89.3 \mathrm{sp}$ vs. orders). Tests for spatial autocorrelation indicate that species richness values are spatially correlated (Moran's I, p $=0.035)$. A spatial regression using species values produced qualitatively similar results. 
Comparisons were made to test the spatial variability of higher-level diversity. This was done by dividing the number of different taxonomic levels represented in a cell by the number of species in the cell. The product is a proportion of higher-level diversity compared to species, which is essentially a measure of the proportion of unique species per grid cell. The number of species versus the number of unique genera per area was then plotted and mapped (Figure 15 and 16, respectively). If most species in an area do not have congeners, then the proportion of genera to species will approach unity, while the proportion decreases in areas with many congeneric species. Broad areas include Patagonia, the Sahara, central Australia, the Saudi Arabian Desert, and island groups including the Caribbean islands and notably western Madagascar. For areas of increased species diversity, there is a trend towards lower generic uniqueness, as a higher proportion of species co-occur with other congeners (Figure 16).

\section{Discussion}

A complete dataset of mammal ranges has allowed the evaluation of many patterns within this Class that until now have not been sufficiently addressed. This underlying dataset, which is the only global dataset of its kind with thousands of species, provides the basis for this research. In addition, the use of a powerful GIS platform has allowed more flexible and complex analyses of biodiversity patterns. The quality of the data and the methods employed are necessary for correct spatial analyses, which helps avoid the weaknesses of most previous research (Brown et al., 1996). These include 
examining the distribution of range sizes, patterns of species richness, latitudinal patterns in range size and richness, and higher taxon richness and distributional extent.

\section{Distribution of Range Sizes}

The distribution of range sizes shows a similar pattern to other groups (Willis 1922; Rapoport 1982; Gaston 1994; Gaston 1998), as most species of mammals have small ranges. Range sizes for mammals vary over seven orders of magnitude from a low of around $1 \mathrm{~km}^{2}$ for some species known from small islands, such as the Ryukyu mole (Nesoscaptor uchidai), which is monotypic to its genus and only found on the west coast of Uotsuri-jima in Senkaku Islands, to tens of millions of $\mathrm{km}^{2}$ for some of the widest ranging species, such as the Holarctic red fox (Vulpes vulpes). Half of all mammal species have a total range under $250,000 \mathrm{~km}^{2}$, which is less than the total land area of Italy. When insular species are removed, the median range size for continental species is $475,000 \mathrm{~km}^{2}$. This pattern is similar to that seen in other studies. One study determined that the median range size of North American mammals was only around $1 \%$ of the North American landmass (Pagel et al., 1991). When calculated globally, the median range size extends to only $0.38 \%$ of the world's surface for non-insular species $(0.2 \%$ if insular species are included). The mean range size differs significantly between orders, and is much larger for Carnivora than for small-bodied Orders including Rodentia and Lipotyphla. Species of large mammals, such as carnivores, tend to range over wide areas because of their distinct ecology, such as large home range size, high trophic level, and general habitat requirements (Hunt, 1996). These patterns are as yet undescribed for any 
other major group of vertebrates, or other speciose taxonomic group, so cannot be compared globally.

\section{Latitudinal Patterns}

Species' latitudinal and longitudinal extents were plotted against each other to examine the relationship between a species' north-south and east-west extent (Figure 7a and $b$ ). A species with equal extents would lie along the diagonal (e.g. if its range shape were close to a square or circle). Most species are above the diagonal, especially smaller ranging species, which show an increased latitudinal versus longitudinal extent, whereas the opposite holds true for the majority of wide-ranging species. These species range into the northern latitudes, particularly those occurring above around $10^{\circ}$-north latitude. There is not nearly as strong of a pattern when maximum southern latitude is used. Median latitude reveals an almost bimodal distribution of points, with wide ranging species clustered from $-30^{\circ}$ to $15^{\circ}$ and $30^{\circ}$ to $50^{\circ}$. This pattern was seen in North American mammals previously, hypothesized to be accounted for by environmental variation such as topology and available landmass (Brown and Maurer, 1989). Most species that range over wide longitudes are Holarctic species such as the arctic fox (Vulpes alopex) and the ermine (Mustela erminea). There are few mammals that have large latitudinal extents, but notable among them is the cougar (Puma concolor), spanning the widest latitudinal extent of all terrestrial mammals. 
Species Richness Patterns

The pattern of species richness in mammals has previously only been examined across some taxonomic groups and in some regions (Murray, 1866; Darlington, 1957; Simpson, 1964; Brooks et al., 2001; Baquero and Telleria, 2001; Cole et al., 1994). For instance species richness was found to range from 13 to 163 species per $150,000 \mathrm{~km}^{2}$ quadrats across North America (Simpson, 1964). This global analysis extends and refines previous analyses of species richness patterns in mammals. The reasons for the observed patterns in species richness are not well known, but revealing the patterns is the necessary first step to understanding the processes behind them.

The general pattern of species richness reveals some broad generalizations that were already known (Rosenzweig, 1995), most notably that the highest species richness areas are almost exclusively in tropical areas (Figure 5a). Comparison of mean richness inside and outside the Tropics reveals a significantly higher richness within the Tropics as compared to subtropical, temperate, and arctic regions. Only 864 species are found exclusively north of the Tropic of Cancer and 225 south of the Tropic of Capricorn, whereas over half of all included mammal species (2,488 species) are confined exclusively to the tropics. Another 1,163 species reside in both temperate and tropical regions. The regions outside of the tropics that are relatively diverse include montane regions in North America (e.g. the Rockies) and Eurasia (e.g. the Alps, Caucasus and Mongolian plateau). The southern hemisphere, without as diverse a topography or as much landmass, does not reveal these same patterns. Similar patterns generally hold for other terrestrial vertebrates, as regions of high diversity and endemism are generally found in the tropics, while diverse regions outside of the tropics are generally in montane 
areas or Mediterranean systems (Myers et al., 2000). Groups such as reptiles do not hold similar patterns, with some high diversity in arid regions, though only regional species comparisons have been researched. However, there are no comprehensive global spatial analyses of other groups, so global comparisons of different regions cannot be done.

Species richness patterns vary globally among the different orders and families. I examined richness patterns across the six largest orders; Artiodactyla, Carnivora, Chiroptera, Lipotyphla, Primates, and Rodentia. Canivora and Artiodactyla show strong richness patterns in Africa, but are found at a low to moderate richness across most of the areas they occur in. Primate species, the majority of which are distributed within the tropics, show patterns of high diversity in the Congo and Amazon basins as well as Madagascar. For bats, by far the highest richness is in the Neotropics, with moderately high richness in tropical Africa and Asia. For the shrews and moles (Lipotyphla), the areas of highest richness include West Africa, the Cameroon lowlands and highlands, and the Alberine rift area to the montane regions of East Africa. Central and south-central China also exhibit high species richness, while temperate forests in Eurasia, with a diversity of Sorex species, are also moderately rich. Marsupials exhibit the highest diversity along the eastern areas of Australia as well as New Guinea. In the New World marsupials (which includes the didelphids, shrew possums, and the monotypic Monito del Monte), richness is concentrated along the Andes. Patterns of vertebrates in Africa have shown some similarities and differences between different vertebrate groups, such as high diversity of mammals and birds in the Eastern Arc Mountains (Brooks et al., 2001). 
Species richness analyses provide basic biodiversity knowledge for areas, such as the composition, distribution and number of species. When all species are treated equally, patterns of species richness have the greatest effect on patterns of geographical rarity. One of the clear patterns is that widespread species drive the overall species richness of mammals. Over $80 \%$ of the widest ranging quartile of species are found in four orders; rodents $(27.6 \%)$, bats $(33.8 \%)$, carnivores $(11.6 \%)$, and artiodactyls $(7.8 \%)$. The fact that a few species drive the overall richness pattern is amplified by fact that there are a large number of very restricted range species of mammals. The strong skew in range size distributions of mammals and other groups results in richness patterns that are heavily driven by low numbers of geographically common species. It is important to note the striking differences in patterns among the quartile richness maps, and the very different areas that reveal high diversity. For the overall richness, the tropics as a whole are extremely rich in species numbers. This pattern remains for the widest ranging quartile, with little effect on the richness of most areas. The third quartile shows a very different picture, as species in this range class are found mostly in Central America, along the Andes in South America, central China and the Himalayas through Southeast Asia, the Sundas, New Guinea, east Australia, West Africa, Cameroon and Gabon, and some of the highlands in east Africa. Certainly habitat plays a large role in species within this range class, as visually many of the richest areas encompass continuous habitat types. For instance, the long chain of the Andes is very rich, most likely due to all the intermediate range species that are restricted to the higher elevations. The lowest two quartiles, the geographically rare species, reveal endemic rich areas (see Chapter 4). These patterns 
have never been examined quantitatively across the globe in any other large group of organisms, so comparisons cannot be made with other research.

Taxonomic covariance was analyzed to determine if species richness of one higher taxon is correlated with richness of other levels. The order, family, and generic richness values correlated highly with species richness, and this pattern was consistent across most geographic areas. This is evidence for relatively even distribution of higher taxonomic levels across the globe, similar to that found in other research (Williams and Gaston, 1994).

An interesting pattern was revealed when plotting the grid cell higher-level diversity calculation, which represents the proportion of species in an area (measured here as grid cells) to the number of genera represented. There are several broad areas with close to $100 \%$ of species without congeners, including many low species diversity areas such as deserts and island groups. Although many of these regions, such as the Sahara, are exceptionally poor in overall species numbers, the species that do occur have only a few or no congenerics (per grid cell). This does not indicate uniqueness for these genera, but rather that these areas do not hold many species of similar relatedness. The reasons for this can include isolation, in the case of islands, where there are small chances for dispersal and establishment. In areas of low productivity such as deserts, the availability of different ecological niches may produce this pattern. 


\section{Conclusions}

Biological diversity is distributed across the globe in many complex patterns. Mammal diversity shows strong differences among taxonomic groups and regions. Latitudinal patterns showing higher numbers of species in the tropics are supported by this global dataset. There is weak support for range size increase in species at higher latitudes, however there is a need to bring in the processes, whether biological, environmental, or stochastic that produce these patterns. Higher taxonomic richness patterns are broadly concordant with species richness patterns, especially at the family and genus levels. As shown elsewhere with other groups, I show a strong concentration of species in tropical areas, including islands and montane regions. While the diversity patterns are certainly different from other groups, mammals, as a globally distributed group of thousands of species, allow testing of biogeographic patterns. The examination of large-scale patterns in mammal diversity can be used as a framework for more detailed research on the processes behind these patterns, and the relevance for the conservation of the world's biodiversity. 


\section{References}

Balmford, A., J. L. Moore, T. Brooks, N. Burgess, L. A. Hansen, P. Williams, and C. Rahbek. 2001. Conservation conflicts across Africa. Science 291:2616-2619.

Baquero, R. A., and J. L. Telleria. 2001. Species richness, rarity and endemicity of European mammals: a biogeographical approach. Biodiversity and Conservation $10: 29-44$.

Bokma, F., J. Bokma, and M. Monkkonen. 2001. Random processes and geographic species richness patterns: why so few species in the north? Ecography 24:43-49.

Brooks, T., A. Balmford, N. Burgess, J. Fjeldså, L. A. Hansen, J. Moore, C. Rahbek, and P. Williams. 2001. Toward a blueprint for conservation in Africa. Bioscience 51:613-624.

Brown, J. H. 1995. Macroecology. University of Chicago Press, Chicago.

Brown, J. H., and M. V. Lomolino. 1998. Biogeography, Second edition. Sinauer Associates Inc., Sunderlands, Massachusetts.

Brown, J. H., and B. A. Maurer. 1989. Macroecology: The division of food and space among species on continents. Science 243:1145-1150.

Brown, J.H., G.C. Stevens, and D.M. Kaufman. 1996. The geographic range: size, shape, boundaries, and internal structure. Annual Review of Ecology and Systematics 27:597-623.

Ceballos, G., and J. H. Brown. 1995. Global patterns of mammalian diversity, endemism, and endangerment. Conservation Biology 9:559-568.

Ceballos, G., and P. R. Ehrlich. 2002. Mammal population losses and the extinction crisis. Science 296:904-907. 
Channell, R. and M. V. Lomolino. 2000a. Dynamic biogeography and the conservation of endangered species. Nature 403:84-86.

Channell, R., and M. V. Lomolino. 2000b. Trajectories to extinction: spatial dynamics of the contraction of geographical ranges. Journal of Biogeography 27:169-179.

Cole, F. R., D. M. Reeder, and D. E. Wilson. 1994. A synopsis of distribution patterns and the conservation of mammal species. Journal of Mammalogy 75:266-276.

Colwell, R. K., and G. C. Hurtt. 1994. Nonbiological gradients in species richness and a spurious Rapoport effect. American Naturalist 144:570-595.

Colwell, R.K. and D.C. Lees. 2000. The mid-domain effect: geometric constraints on the geography of species richness. Trends in Ecology and Evolution 15:70-76.

Darwin, C. 1859. On the Origin of Species by Means of Natural Selection, or, The Preservation of Favoured Races in the Struggle for Life. John Murray, London.

Darlington, P. J., Jr. 1957. Zoogeography: The Geographical Distribution of Animals. John Wiley and Sons, New York.

Dobson, A.P., J.P. Rodriguez, W.M. Roberts, and D.S. Wilcove. 1997. Geographic distribution of endangered species in the United States. Science 275:550-553.

Gaston, K. J. 1994. Measuring geographic range sizes. Ecography 17:198-205.

Gaston, K. J. 1996. Species-range-size distributions: patterns, mechanisms and implications. Trends in Ecology and Evolution 11:197-201.

Gaston, K. J. 1998. Species-range size distributions: products of speciation, extinction and transformation. Philosophical Transactions of the Royal Society of London B $353: 219-230$

Gaston, K. J. 1999. Why Rapoport's Rule does not generalise. Oikos 84:309-312. 
Gaston, K.J. and T.M. Blackurn. 1997. Age, area and avian diversification. Biological Journal of the Linnean Society 62:239-253.

Gaston, K. J., and P. H. Williams. 1996. Spatial patterns in taxonomic diversity. Pages 202-229 in K. J. Gaston, editor. Biodiversity: A Biology of Numbers and Difference. Cambridge University Press, Cambridge.

Gaston, K. D., and J. I. Spicer. 1996. Biodiversity: an introduction. Blackwell Science.

Heywood, V. H. 1995. Global Biodiversity Assessment. Cambridge University Press for the United Nations Environment Programme, Cambridge.

Hilton-Taylor, C., compiler. 2002. 2002 IUCN Red List of Threatened Species. IUCN, Gland, Switzerland.

Howard, P. C., P. Viskanic, T. R. B. Davenport, F. W. Kigenyi, M. Baltzer, C. J. Dickinson, J. S. Lwanga, R. A. Matthews, and A. Balmford. 1998. Complementarity and the use of indicator groups for reserve selection in Uganda. Nature 394:472-475.

Hunt, RM, Jr., 1996. Biogeography of the Order Carnivora. in J. L. Gittleman, editor. Carnivore Behavior, Ecology, and Evolution, Volume 2. pp 485-541. Cornell University Press, Ithaca.

Lomolino, M. V., and R. Channell. 1995. Splendid isolation: Patterns of geographic range collapse in endangered mammals. Journal of Mammalogy 76:335-347.

Lyons, S. K., and M. R. Willig. 1997. Latitudinal patterns of range size: methodological concerns and empirical evaluations for New World bats and marsupials. Oikos 79:568-580.

MacArthur, R. H., and E. O. Wilson. 1967. The Theory of Island Biogeography. 
Princeton University Press, Princeton, NJ.

MacArthur, R. H. 1972. Geographical Ecology; Patterns in the Distribution of Species. Harper and Row, Publishers, New York.

Murray, A. 1866. The Geographical Distribution of Mammals. London: Day and Son.

Myers, N., R. A. Mittermeier, C. G. Mittermeier, G. A. B. d. Fonseca, and J. Kent. 2000. Biodiversity hotspots for conservation priorities. Nature 403:853-858.

Owen, R. 1859. On the Classification and Geographical Distribution of the Mammalia. London: John W. Parker \& Son. 103 pp.

Nowak, R. M. 1999. Walker's Mammals of the World, 6th Ed. Johns Hopkins University Press, Baltimore.

Pagel, M. D., R. M. May, and A. R. Collie. 1991. Ecological aspects of the geographical distribution and diversity of mammalian species. American Naturalist 137:791815.

Pimm, S. L., and J. H. Lawton. 1998. Planning for biodiversity. Science 279:2068-2069.

Rapoport, E.H. 1982. Areography: Geographical strategies of species. Pergamon Press, New York.

Ricklefs, R. E., and D. Schluter. 1993. Species Diversity in Ecological Communities, Historical and Geographic Perspectives. University of Chicago Press, Chicago.

Roberts, R. G., T. F. Flannery, L. K. Ayliffe, H. Yoshida, J. M. Olley, G. J. Prideaux, G. M. Laslett, A. Baynes, M. A. Smith, R. Jones, and B. L. Smith. 2001. New ages for the last Australian megafauna: Continent-wide extinction about 46,000 years ago. Science 292:1888-1892.

Rohde, K. 1992. Latitudinal gradients in species diversity: the search for the primary 
cause. Oikos 65:514-527.

Rohde, K. 1996. Rapoport's Rule is a local phenomenon and cannot explain latitudinal gradients in species diversity. Biodiversity Letters 3:10-13.

Rosenzweig, M. L. 1995. Species Diversity in Space and Time. Cambridge University Press, Cambridge.

Ruggiero, A., J. H. Lawton, and T. M. Blackburn. 1998. The geographic ranges of mammalian species in South America: spatial patterns in environmental resistance and anisotropy. Journal of Biogeography 25:1093-1103.

Schall, J. J., and E. R. Pianka. 1978. Geographical trends in numbers of species. Science 201:679-686.

Simpson, G. G. 1964. Species density of North American mammals. Systematic Zoology $13: 57-73$.

SPSS. 2001. SPSS 11.0 for Windows. SPSS Inc.

Stevens, G.C. 1989. The latitudinal gradient in geographical range: how so many species coexist in the tropics. American Naturalist 133:240-256.

Stevens, G.C. 1992. The elevational gradient in altitudinal range: an extension of Rapoport's latitudinal rule to altitude. American Naturalist 140:893-911.

Wallace, A. R. 1876. The Geographical Distribution of Animals; With a Study of the Relations of Living and Extinct Faunas as Elucidating the Past Changes of the Earth's Surface. New York: Harper and Brothers.

Williams, P. H., and K. J. Gaston. 1994. Measuring more of biodiversity: can highertaxon richness predict wholesale species richness? Biological Conservation $67: 211-217$ 
Willig, M. R., and S. K. Lyons. 1998. An analytical model of latitudinal gradients of species richness with an empirical test for marsupials and bats in the New World. Oikos 81:93-98.

Willis, J.C. 1922. Age and Area; A Study in Geographical Distribution and Origin of Species. Cambridge, U.K.: Cambridge University Press.

Wilson, D. E., and D. M. Reeder. 1993. Mammal Species of the World. Smithsonian Institution Press, Washington. 


\begin{tabular}{|l|c|}
\hline & $\begin{array}{c}\text { Number of } \\
\text { species }\end{array}$ \\
\hline Species included in the analyses & 4740 \\
\hline Domesticated or commensal species (including Homo sapiens) & 13 \\
\hline Marine (Cetacea, Sirenia, marine Carnivora) & 121 \\
\hline Extinct & 103 \\
\hline Uncertain species ${ }^{2}$ & 58 \\
\hline \hline Total (all mammal species globally) & 5035 \\
\hline
\end{tabular}

${ }^{1}$ Not Applicable

${ }^{2}$ No range information available or uncertain taxonomic status

Table 1: Mammal species of the world. 


\begin{tabular}{|c|c|c|c|c|c|c|}
\hline \multirow[t]{2}{*}{ Order } & \multirow{2}{*}{$\begin{array}{c}\text { \# of } \\
\text { Species }\end{array}$} & \multicolumn{3}{|c|}{ Geographic Range Size $\left(\mathrm{km}^{2}\right)$} & \multicolumn{2}{|c|}{$\begin{array}{c}\text { Range Midpoint } \\
\text { (deg. latitude) }\end{array}$} \\
\hline & & Median & Mean & SD & Mean & SD \\
\hline Afrosoricida & 51 & 60,892 & 171,209 & 640,911 & -20.3 & 9.2 \\
\hline Artiodactyla & 211 & $1,082,859$ & $2,579,533$ & $4,107,148$ & 11.4 & 21.4 \\
\hline Carnivora & 238 & $2,624,352$ & $6,373,986$ & $8,960,129$ & 8.7 & 22.9 \\
\hline Chiroptera & 1077 & 553,949 & $2,575,470$ & $4,268,552$ & 3.8 & 16.9 \\
\hline Cingulata & 20 & $2,121,842$ & $3,766,041$ & $4,228,928$ & -15.5 & 13.7 \\
\hline Dasyuromorphia & 71 & 142,052 & 501,574 & 910,593 & -22.2 & 10.9 \\
\hline Dermoptera & 2 & 755,883 & 755,883 & 899,252 & 6.1 & 4.3 \\
\hline Didelphimorphia & 63 & 502,135 & $1,642,043$ & $2,442,214$ & -8.0 & 13.6 \\
\hline Diprotodontia & 134 & 83,122 & 343,743 & 842,216 & -16.3 & 11.6 \\
\hline Erinaceomorpha & 22 & 764,170 & $2,501,209$ & $3,778,021$ & 20.9 & 18.5 \\
\hline Hyracoidea & 4 & $5,099,460$ & $9,181,260$ & $10,052,764$ & -2.1 & 9.5 \\
\hline Lagomorpha & 90 & 426,060 & $1,868,305$ & $3,853,302$ & 28.8 & 19.6 \\
\hline Lipotyphla & 354 & 132,605 & $1,115,219$ & $2,671,018$ & 18.2 & 20.7 \\
\hline Macroscelidea & 15 & 845,291 & $1,110,246$ & $1,306,417$ & -9.2 & 16.7 \\
\hline Microbiotheria & 1 & 58,833 & 58,833 & $\mathrm{n} / \mathrm{a}$ & -39.9 & $\mathrm{n} / \mathrm{a}$ \\
\hline Monotremata & 5 & 130,889 & $1,699,958$ & $3,415,385$ & -12.7 & 12.7 \\
\hline Notoryctemorphia & 2 & 923,004 & 923,004 & $1,200,517$ & -22.8 & 2.4 \\
\hline Paucituberculata & 6 & 13,633 & 45,792 & 56,234 & -9.6 & 17.0 \\
\hline Peramelemorphia & 18 & 70,227 & 293,635 & 417,752 & -13.8 & 11.0 \\
\hline Perissodactyla & 14 & 563,761 & $2,631,207$ & $4,404,236$ & 3.8 & 18.0 \\
\hline Pholidota & 8 & $2,897,935$ & $3,413,720$ & $2,195,013$ & 7.3 & 10.4 \\
\hline Pilosa & 10 & $2,834,886$ & $4,835,098$ & $4,883,182$ & -1.8 & 8.5 \\
\hline Primates & 361 & 120,516 & 606,386 & $1,243,698$ & -2.1 & 12.7 \\
\hline Proboscidea & 3 & $4,208,860$ & $3,416,632$ & $1,740,468$ & 1.5 & 10.5 \\
\hline Rodentia & 1939 & 147,774 & 937,469 & $2,166,421$ & 9.5 & 23.9 \\
\hline Scandentia & 20 & 235,701 & 530,205 & 689,811 & 4.9 & 6.2 \\
\hline Tubulidentata & 1 & $17,928,254$ & $17,928,254$ & $\mathrm{n} / \mathrm{a}$ & -5.7 & $\mathrm{n} / \mathrm{a}$ \\
\hline Total & 4740 & 245,005 & $1,683,755$ & $3,757,291$ & 6.3 & 22.1 \\
\hline
\end{tabular}

Table 2: Number of species, mean, standard deviation, median, and mean and standard deviation of the latitudinal midpoint across all orders. 


\begin{tabular}{|l|r|r|r|}
\hline Region & $\begin{array}{c}\text { Single Island } \\
\text { Endemic }\end{array}$ & $\begin{array}{c}\text { Restricted to } \\
\text { islands }\end{array}$ & $\begin{array}{c}\text { Total in the } \\
\text { region }\end{array}$ \\
\hline Caribbean & 18 & 26 & 74 \\
\hline Madagascar & 117 & 11 & 139 \\
\hline Philippines & 43 & 67 & 159 \\
\hline New Guinea & 125 & 70 & 250 \\
\hline Southeast Asian region & 172 & 123 & 494 \\
\hline Pacific & 17 & 44 & 71 \\
\hline Others & 107 & 30 & 4740 \\
\hline \hline World Total & 599 & 371 & \\
\hline
\end{tabular}

Table 3: Island species distributions. 


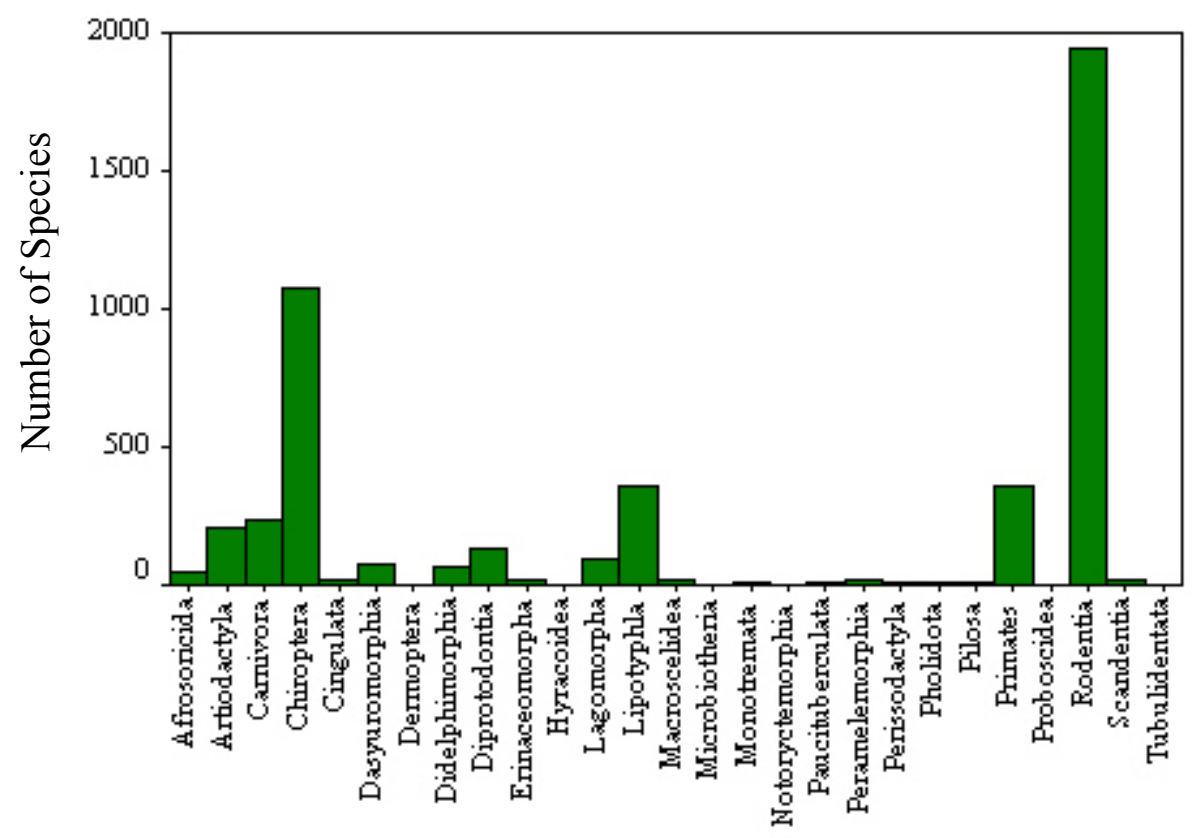

Order Name

Figure 1: Number of extant terrestrial species per order. 


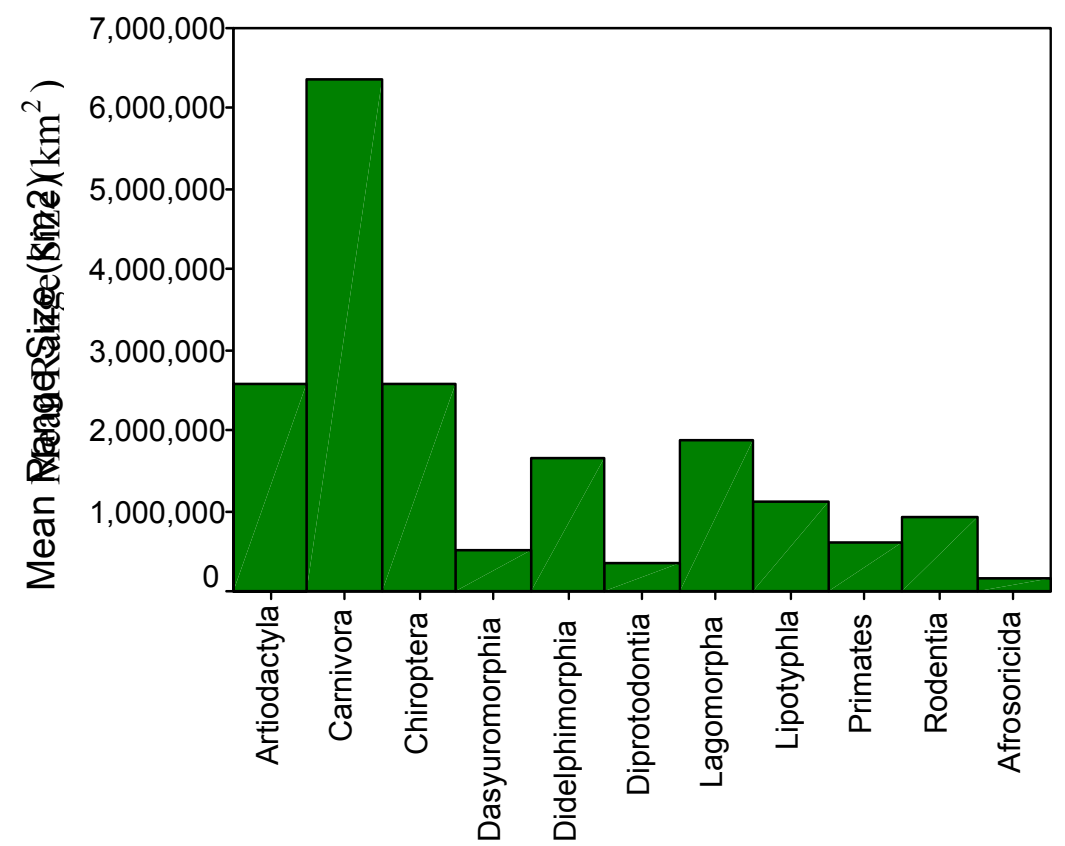

Order Name

Figure 2: Mean range size variation among orders containing over 50 recognized species. 

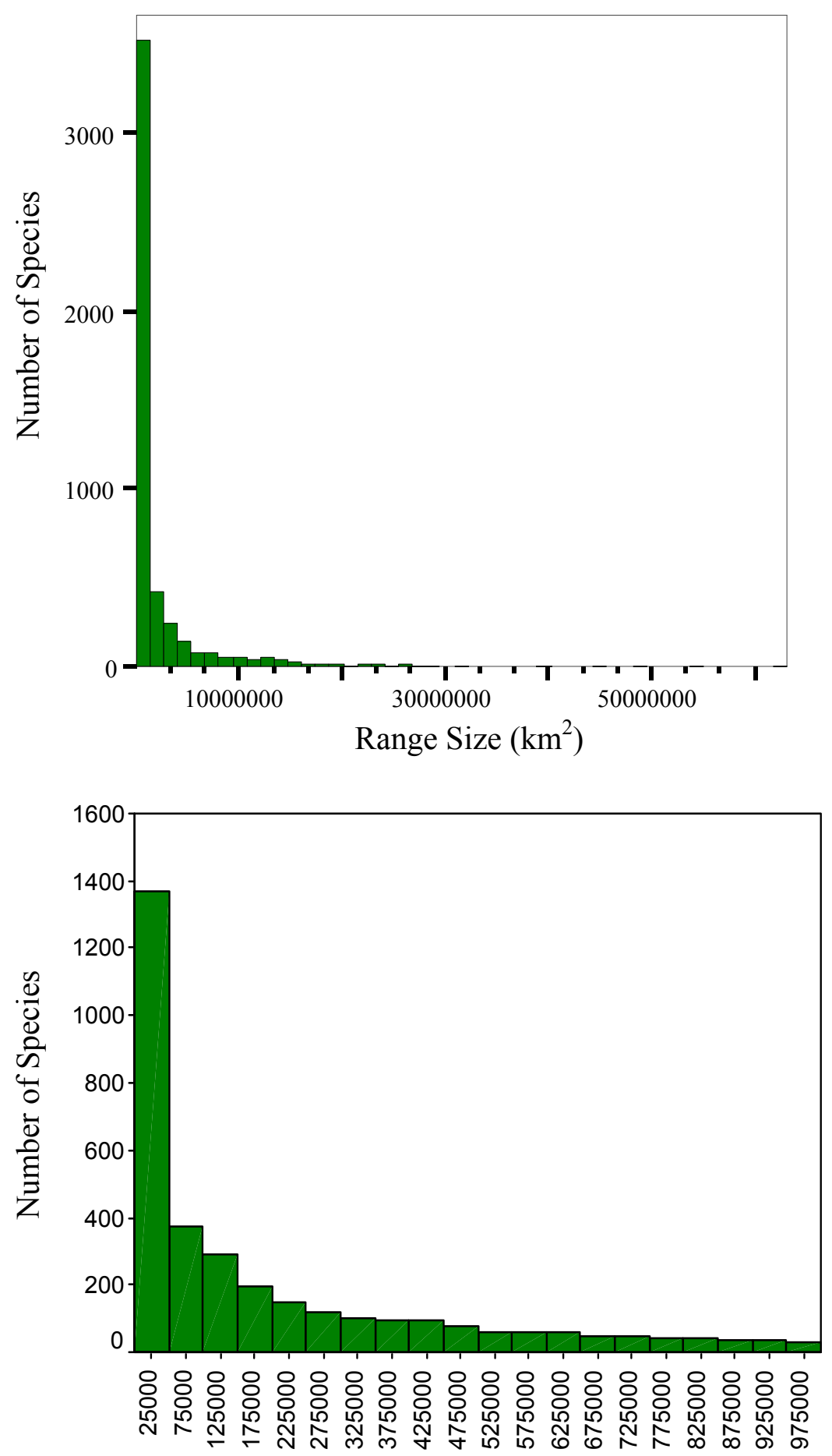

Figure 3a and b: Range size distribution for all mammals. Bottom graph is a magnification of the lower left portion of the top graph. 


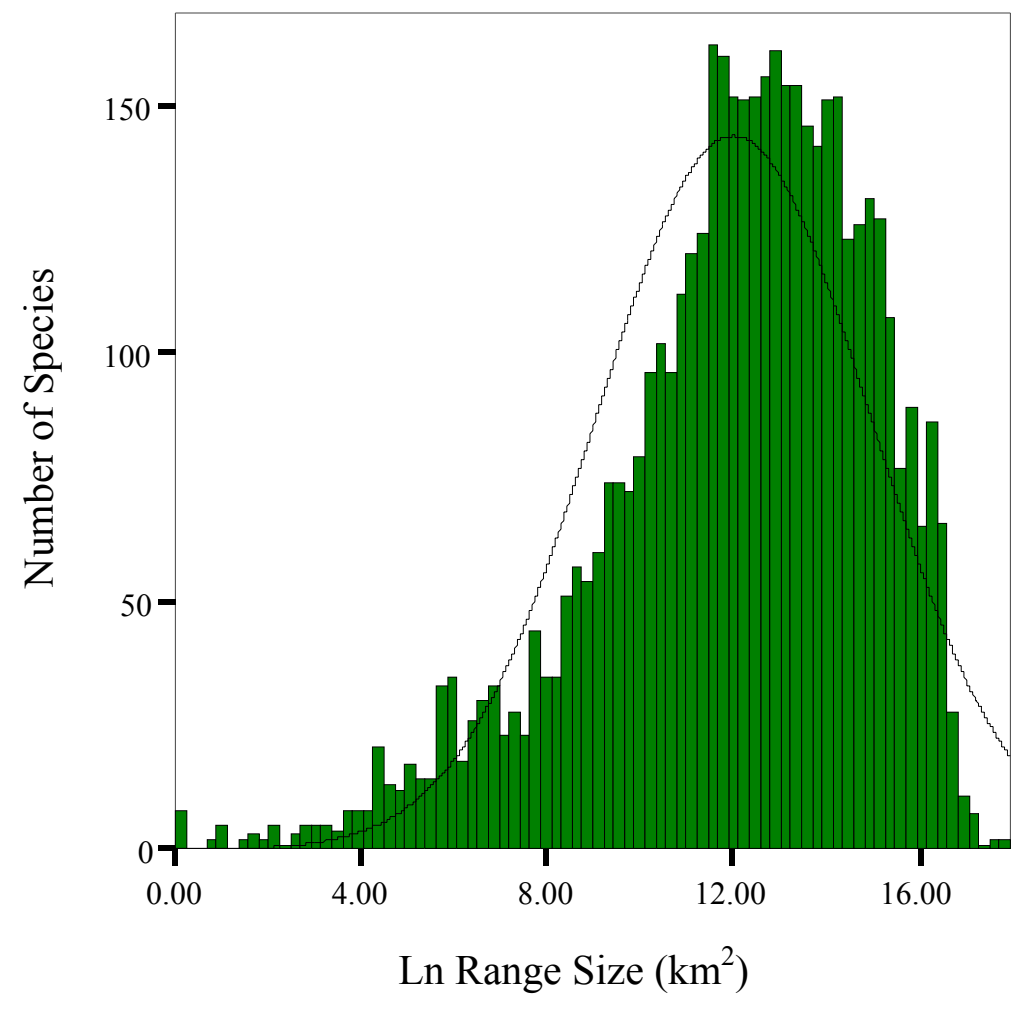

Figure 4: $\operatorname{Ln}($ Range size) distribution for all mammals. 


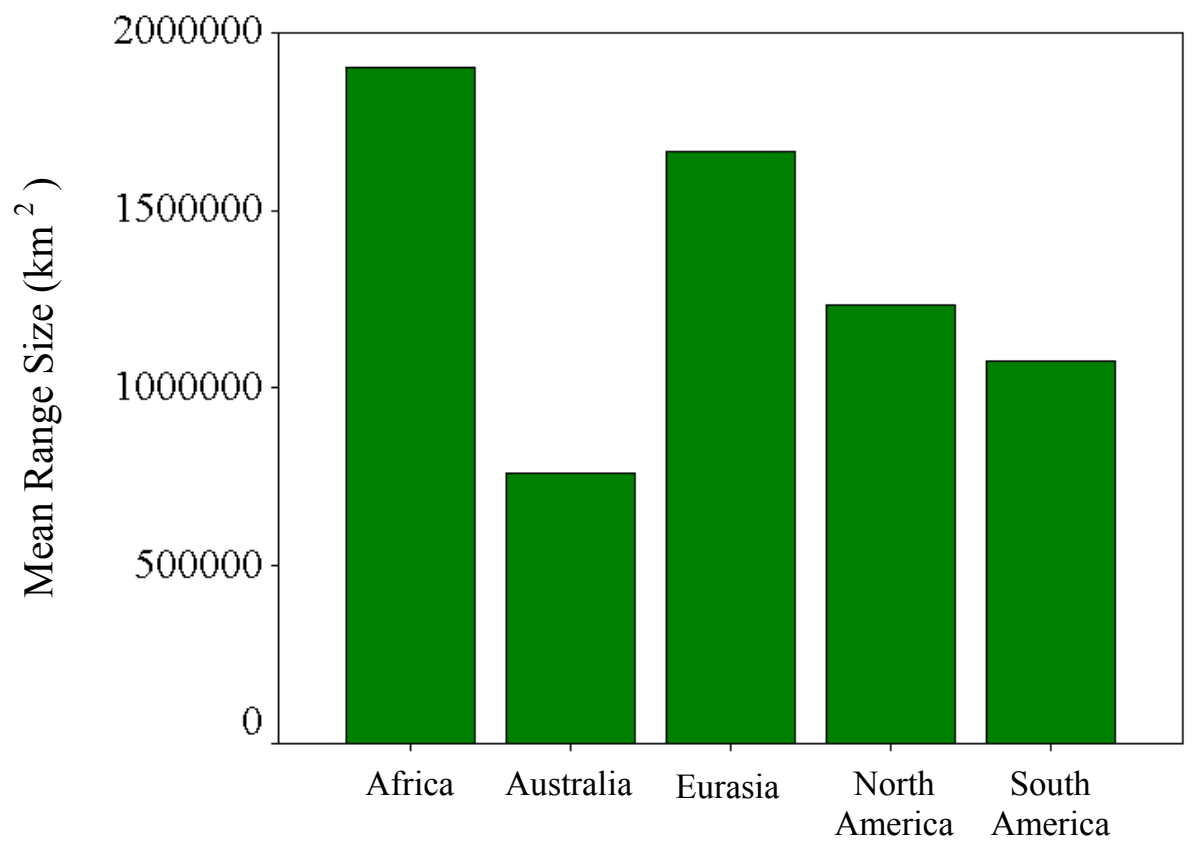

Continent

Figure 5: Mean range size per continent. Species ranging between continents were excluded. 


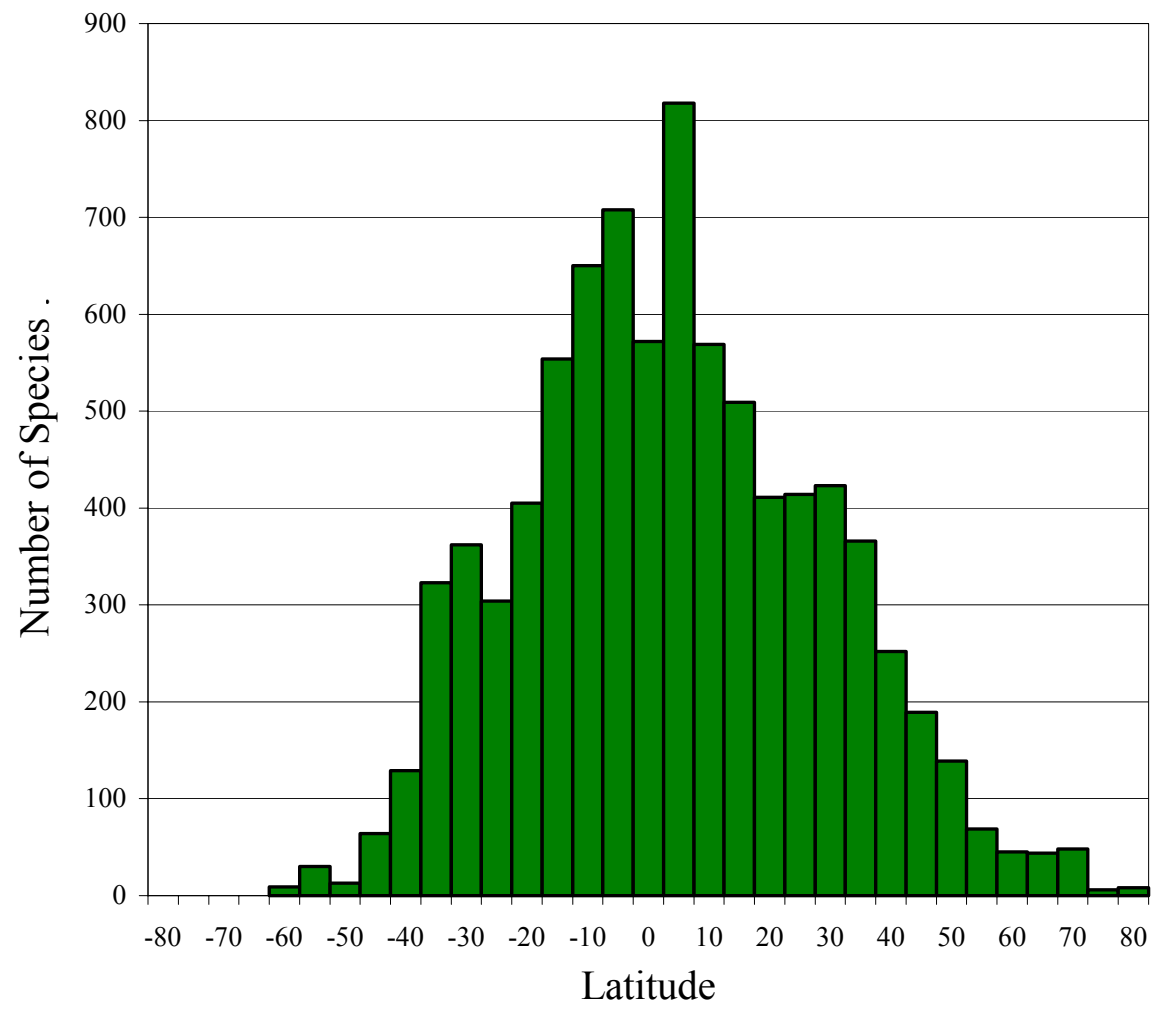

Figure 6a: Number of species per 5 degree latitude band. 


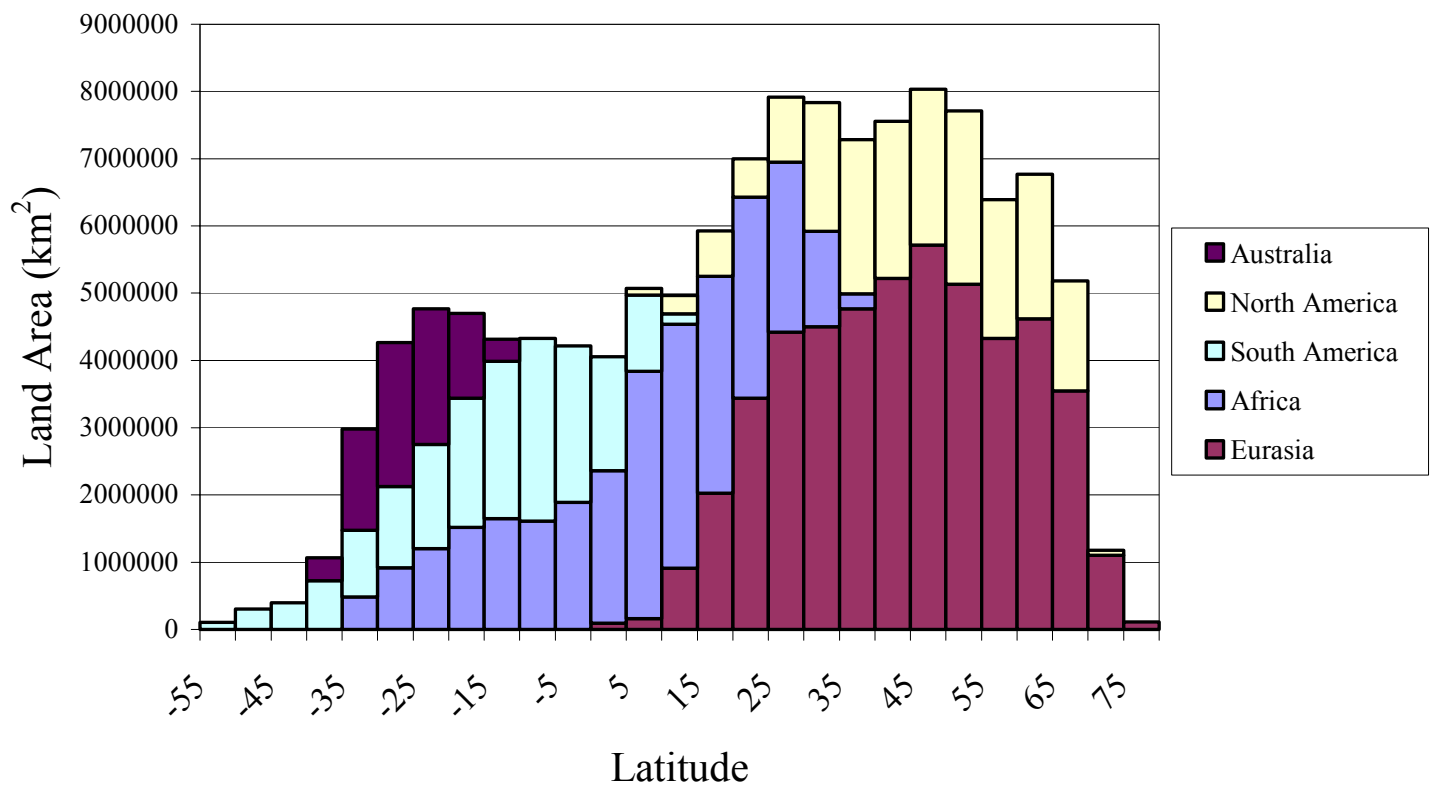

Figure 6b: Global continental land area by latitude.

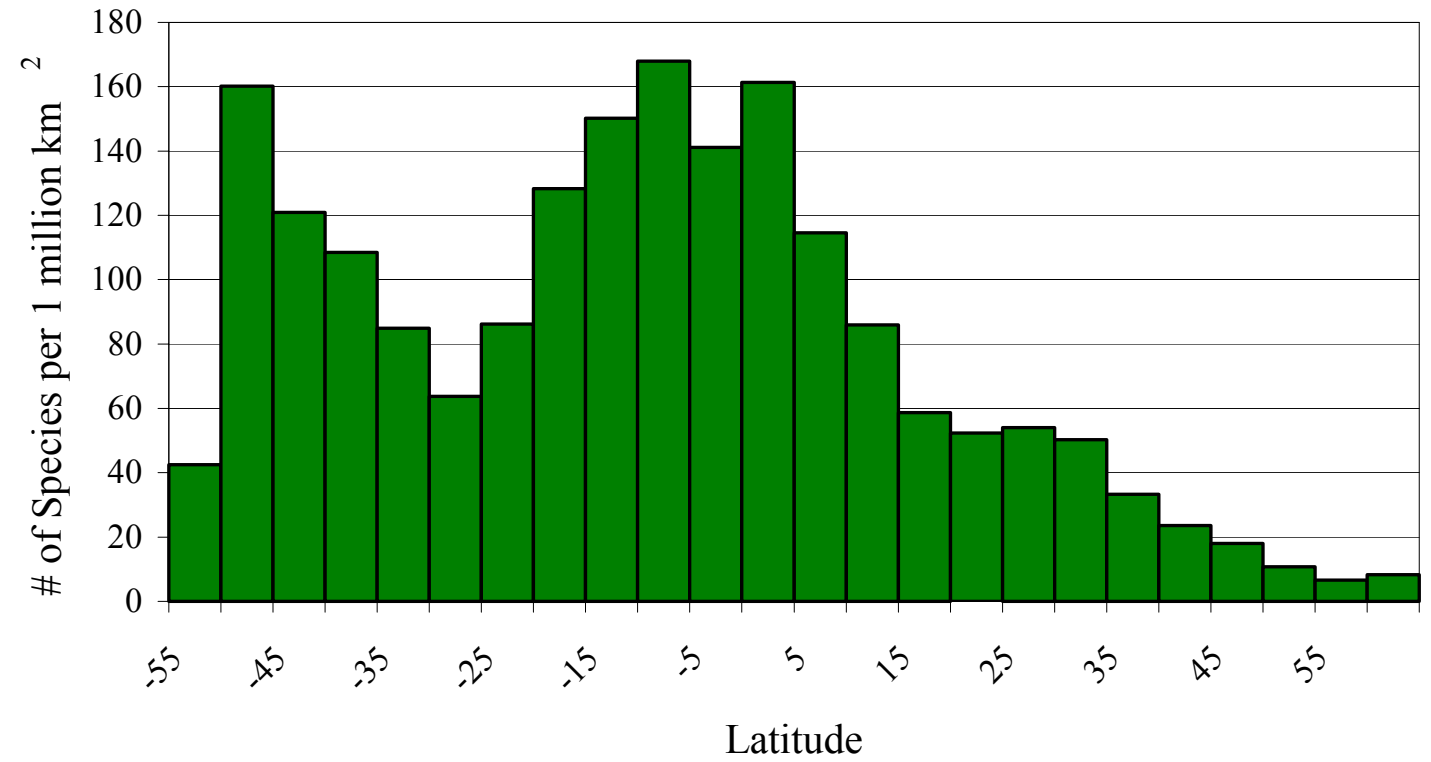

Figure 6c: Species per area across latitudes (5 degree bands). 


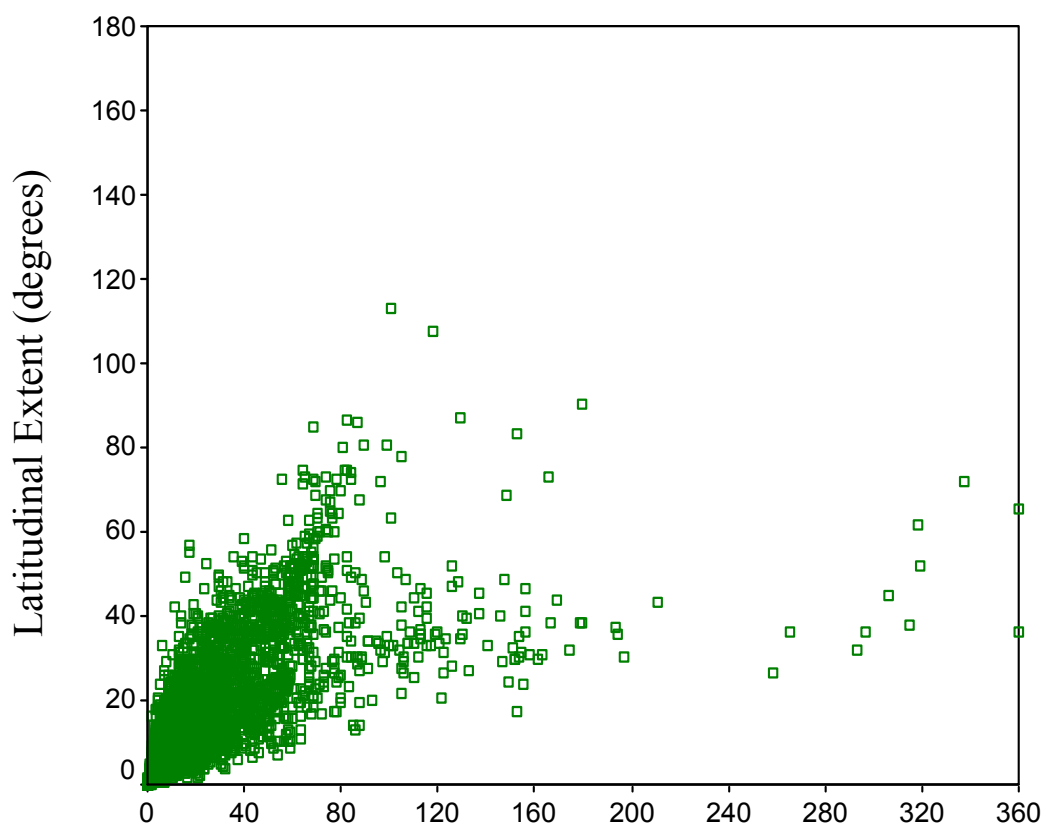

Longitudinal Extent (degrees)

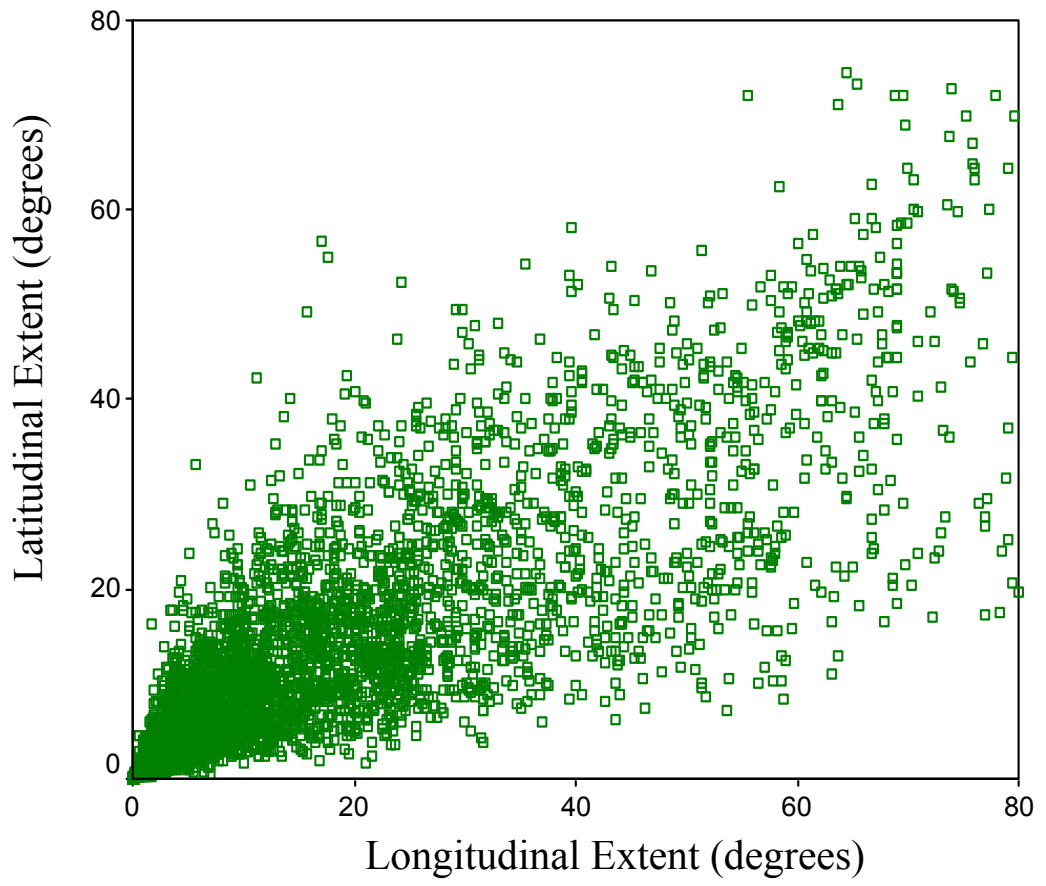

Figure 7a and b: Latitudinal versus longitudinal extent. Figure $6 \mathrm{~b}$ is a blow-up of the lower left portion of the graph. 


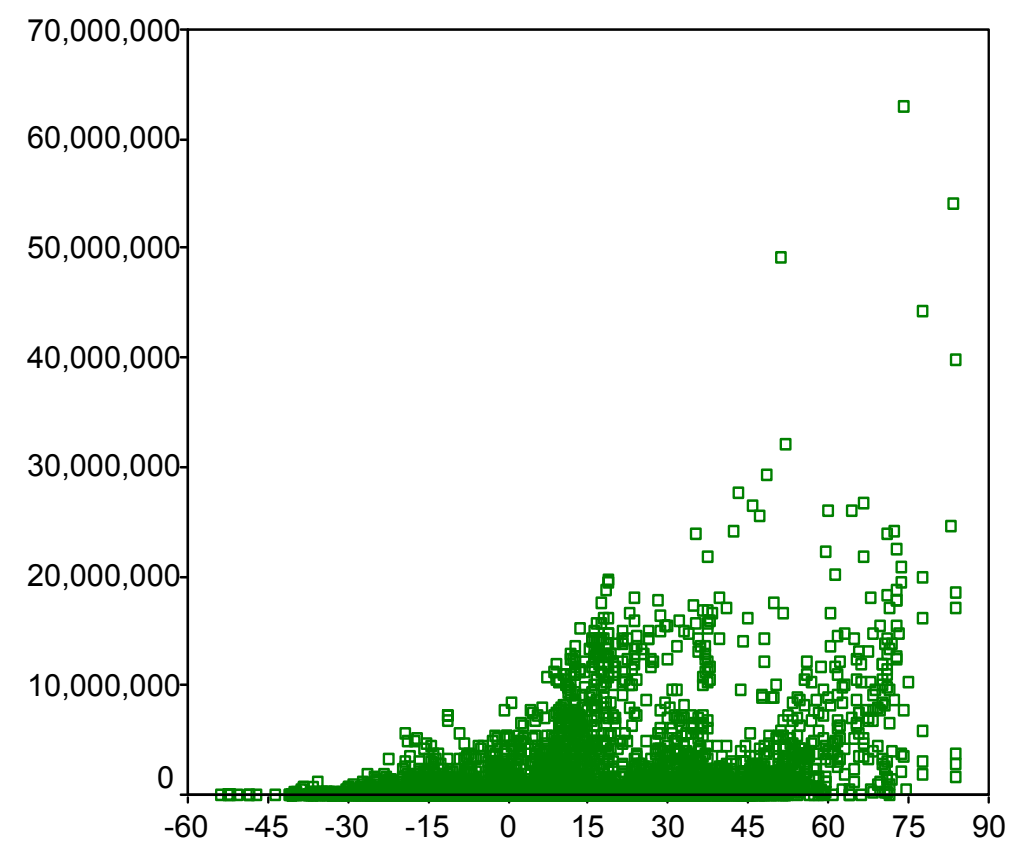

Figure 8a: Species geograpnıc range sıze versus maxımum ratıtude of occurrence.

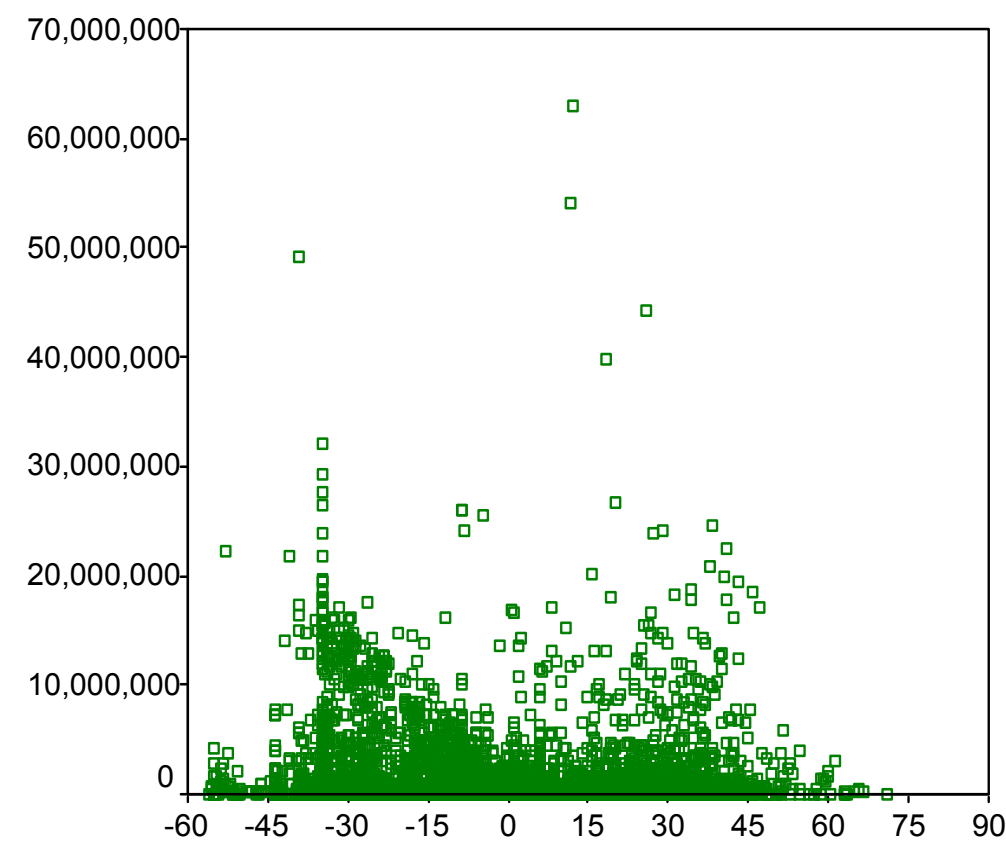

Figure 8b: Species' geographic range size versus minımum latıtude of occurrence. 


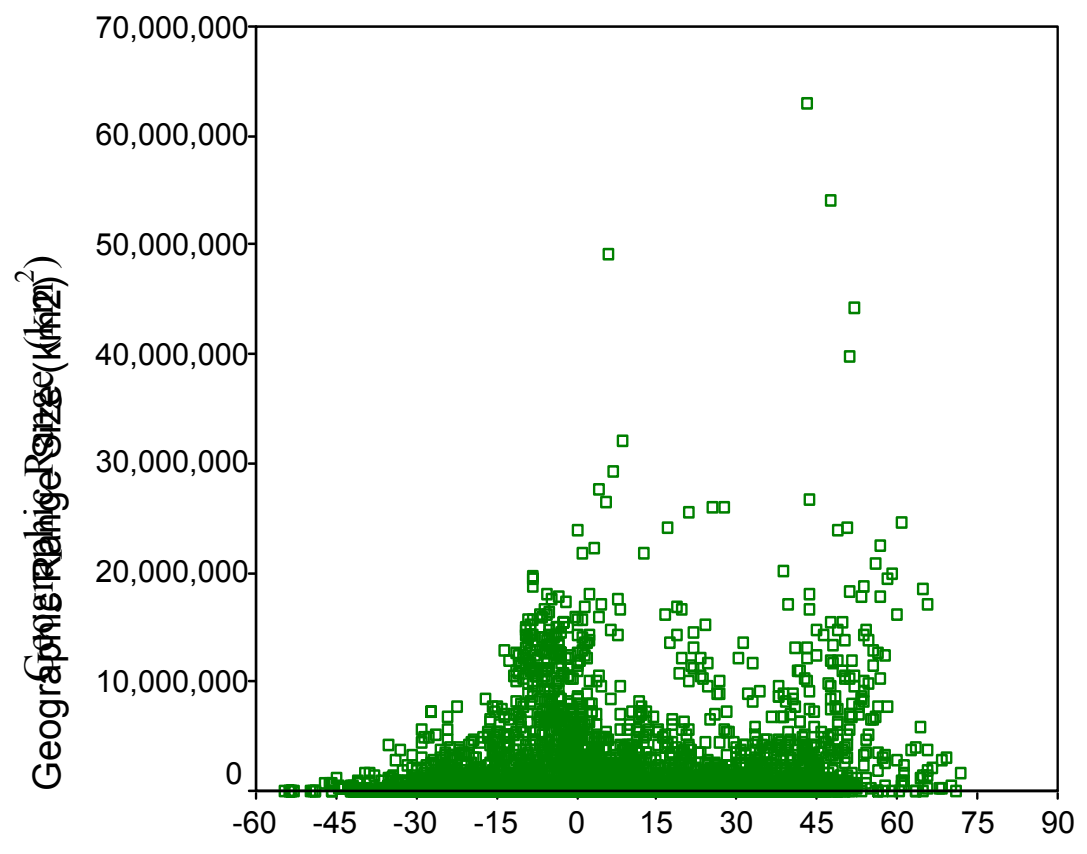

Median Latitude

Figure 8c: Species' geographic range size versus median latitude of occurrence. 


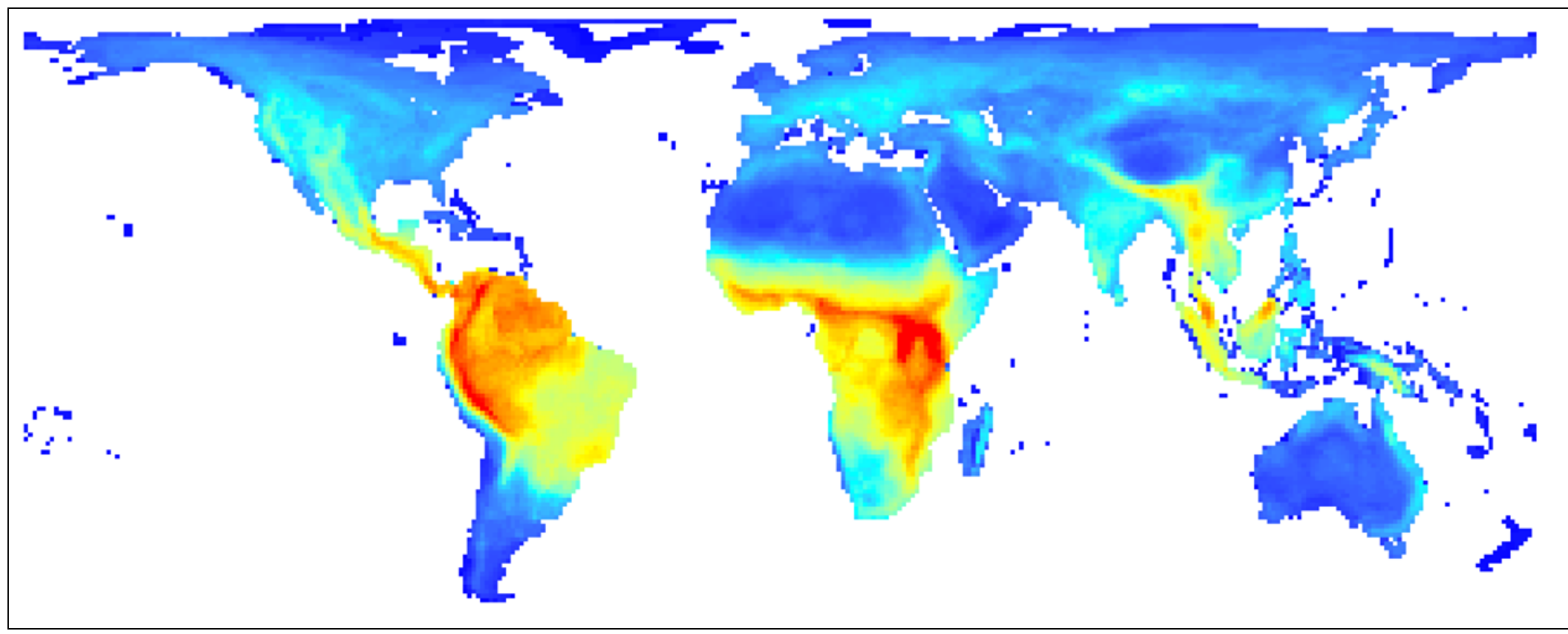

Figure 9: Global Mammal Species richness.

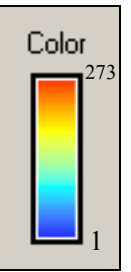




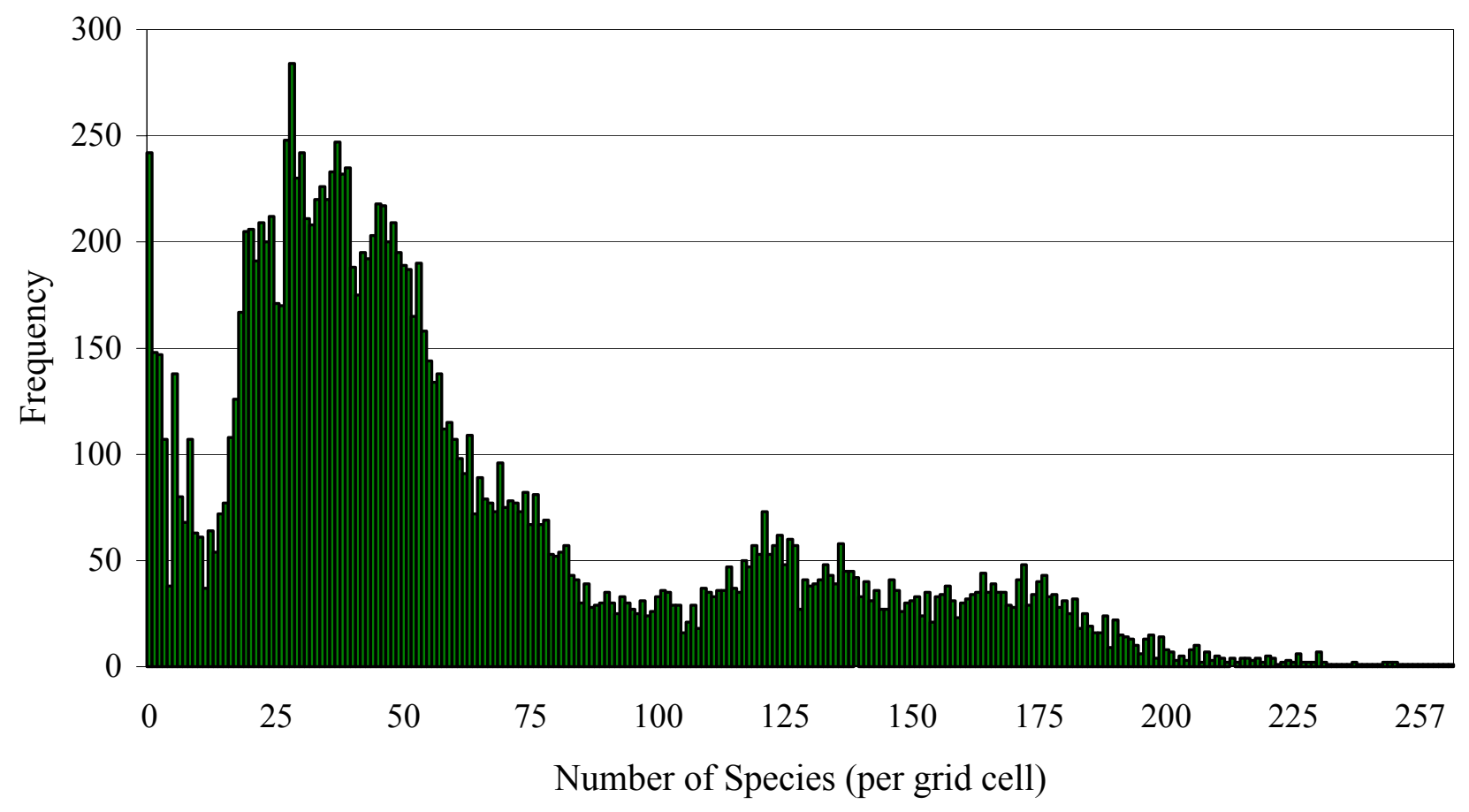

Figure 10: Frequency of richness across grid cells: All terrestrial mammals. 


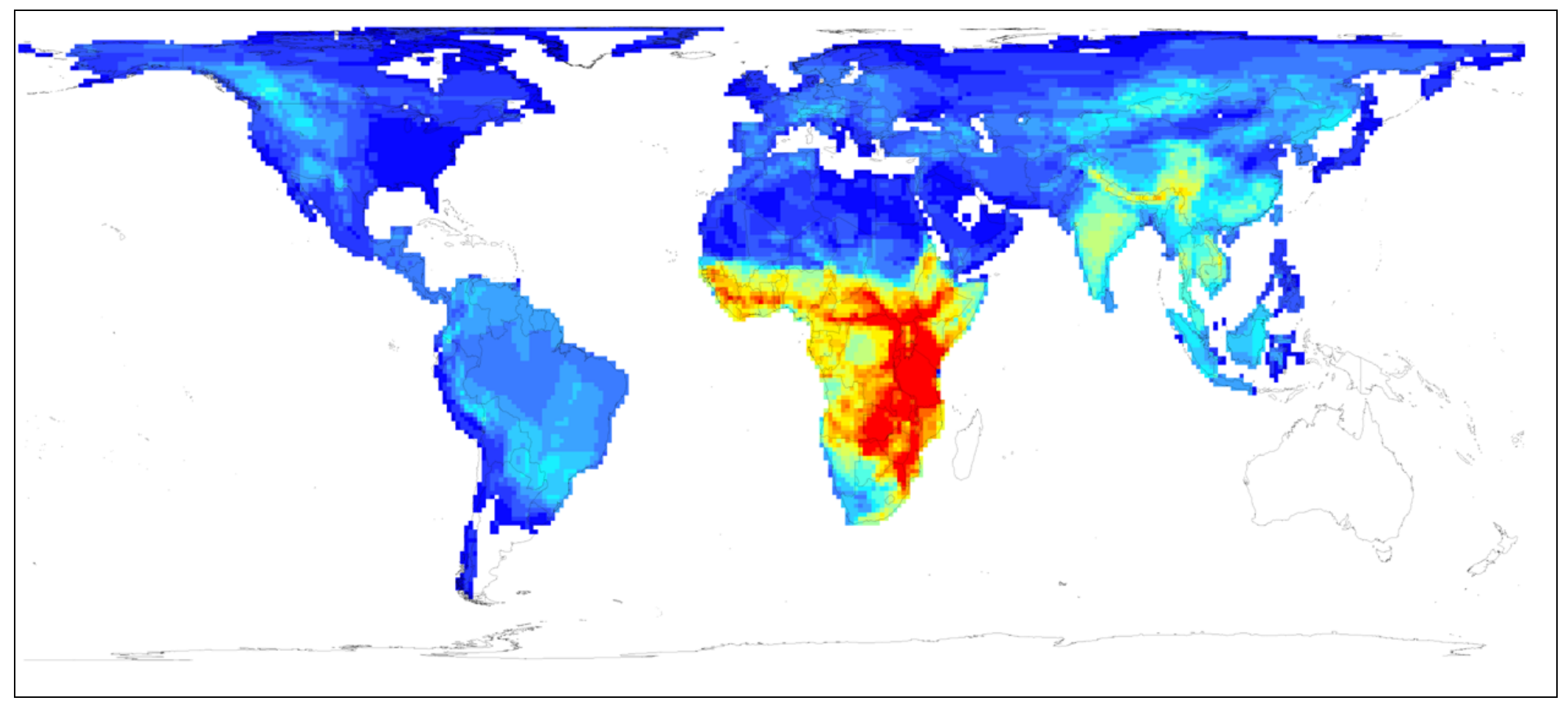

Figure 11a: Species richness: Artiodactyla

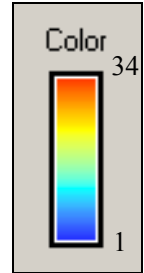




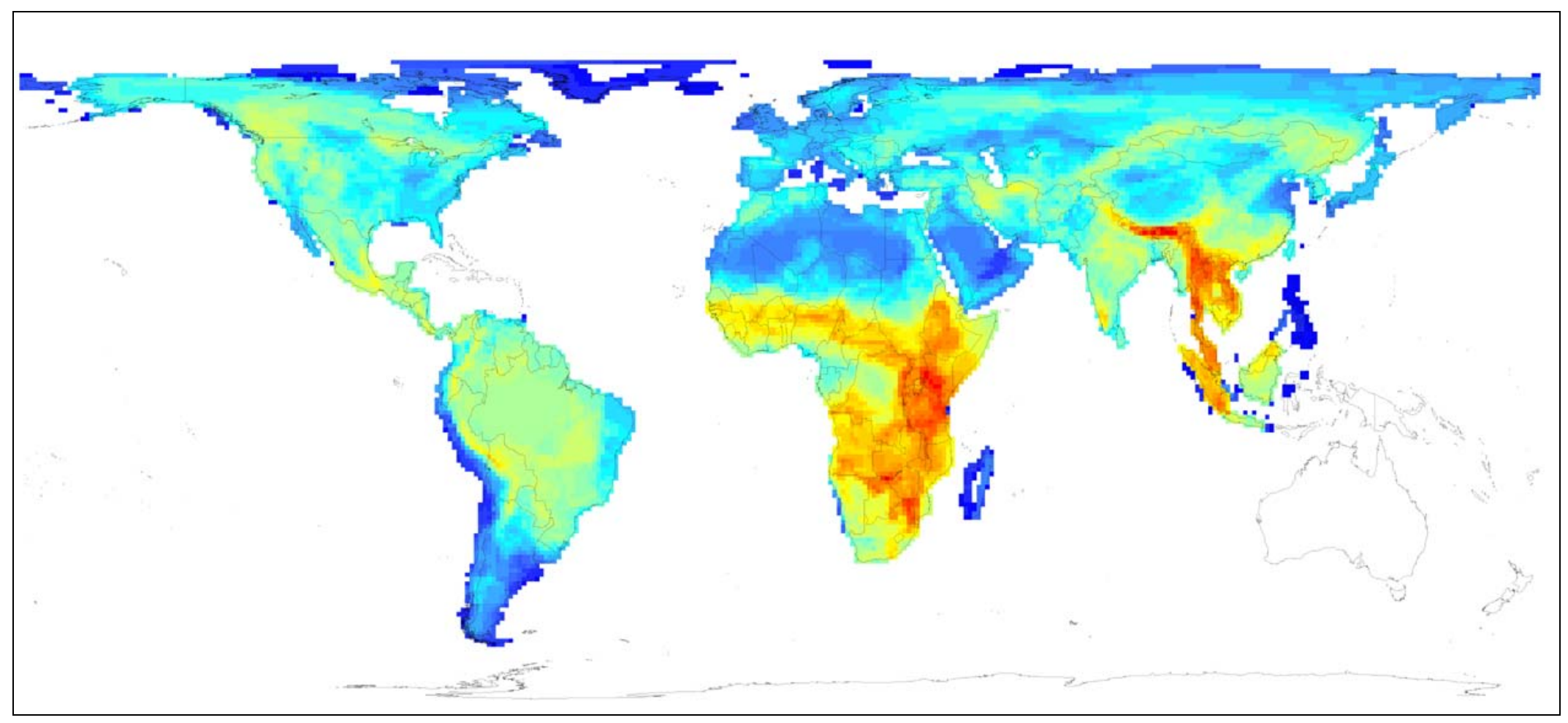

Figure 11b: Species richness: Carnivora

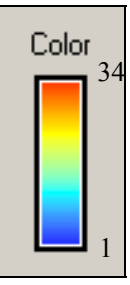




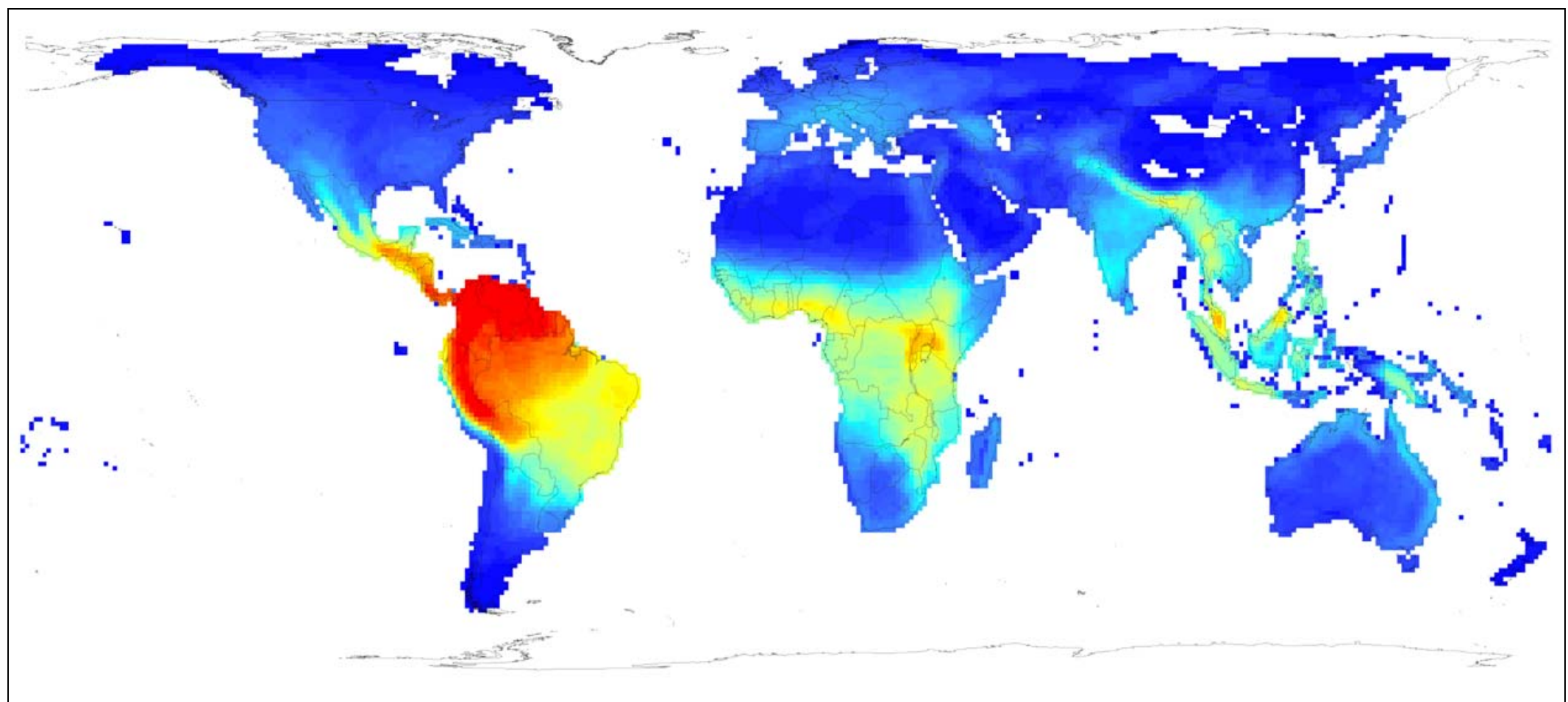

Figure 11c: Species richness: Chiroptera

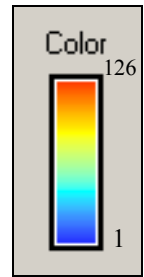




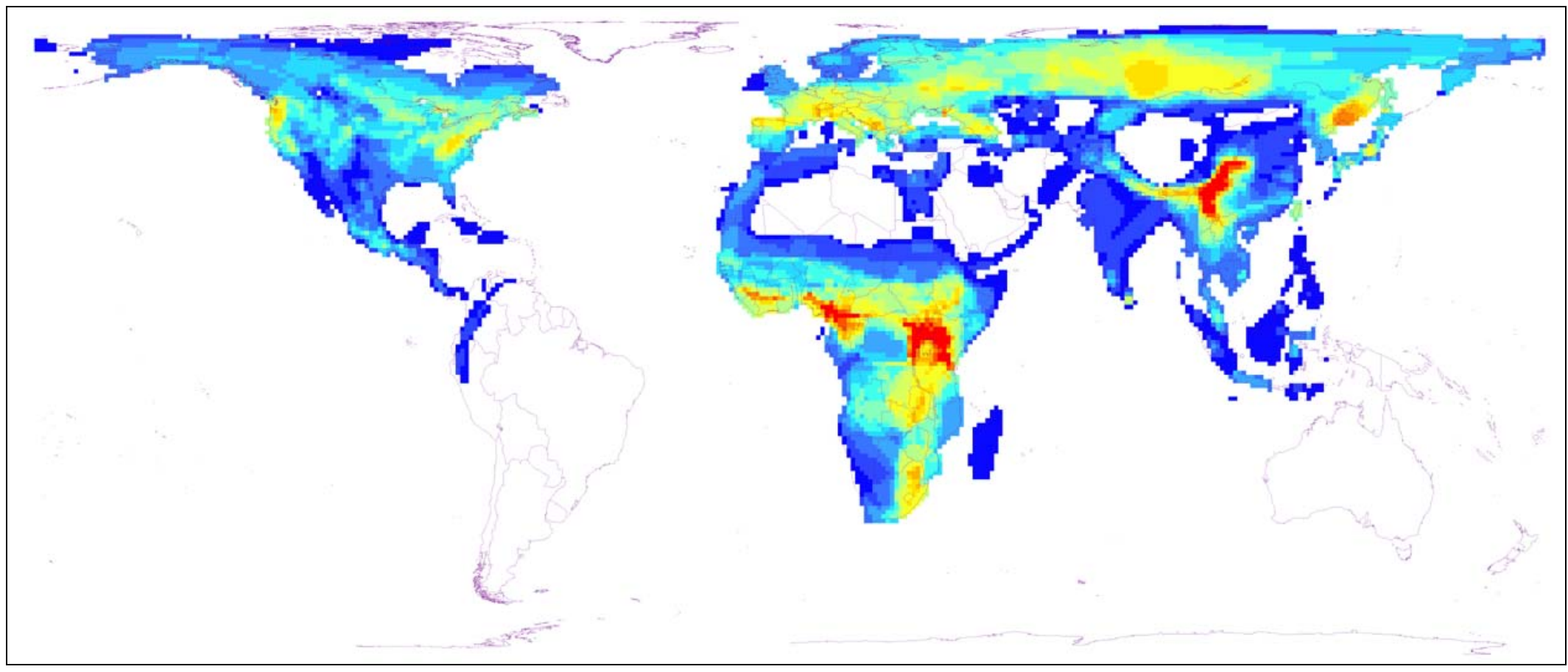

Figure 11d: Species richness: Lipotyphla

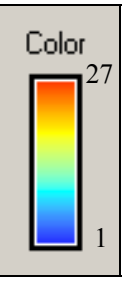




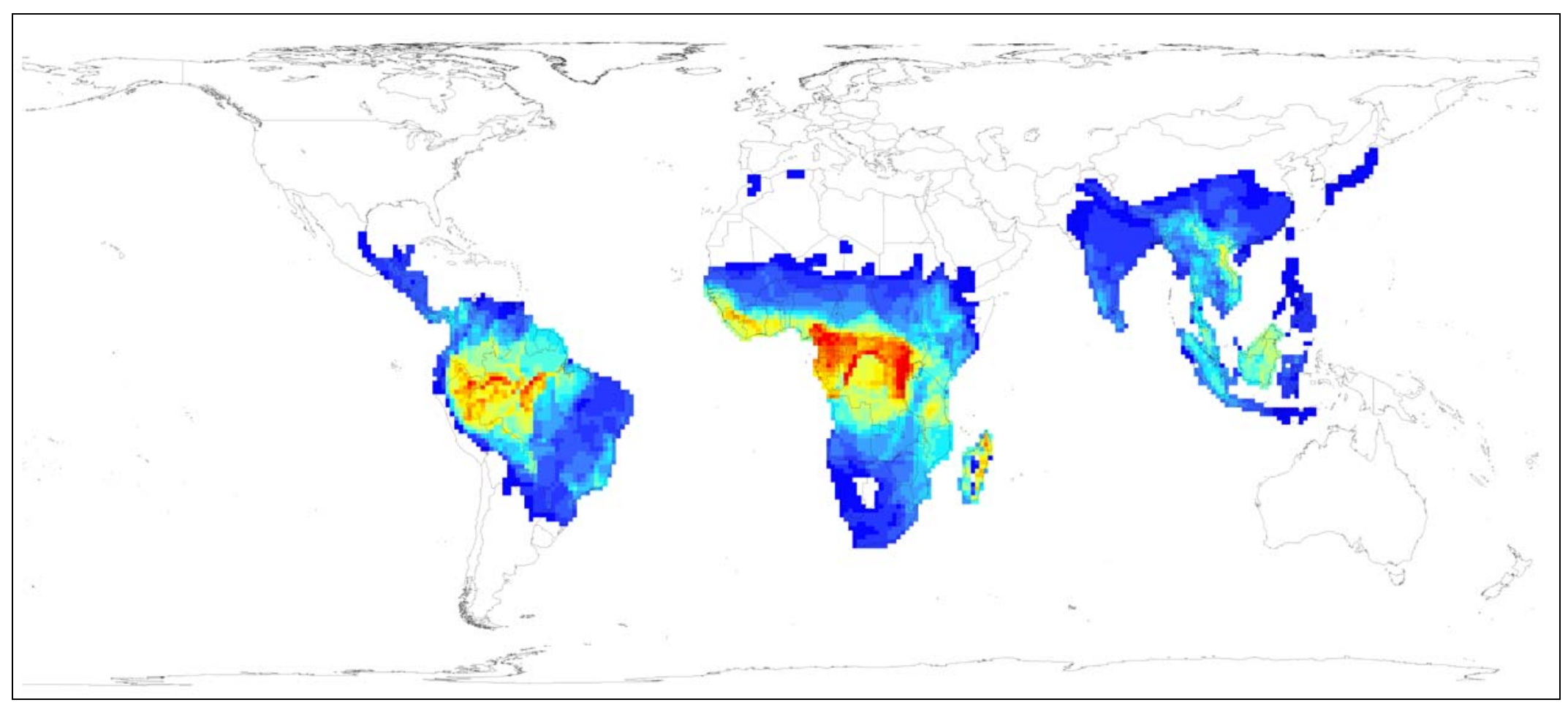

Figure 11e: Species richness: Primates

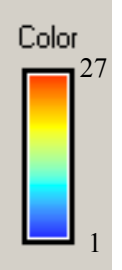




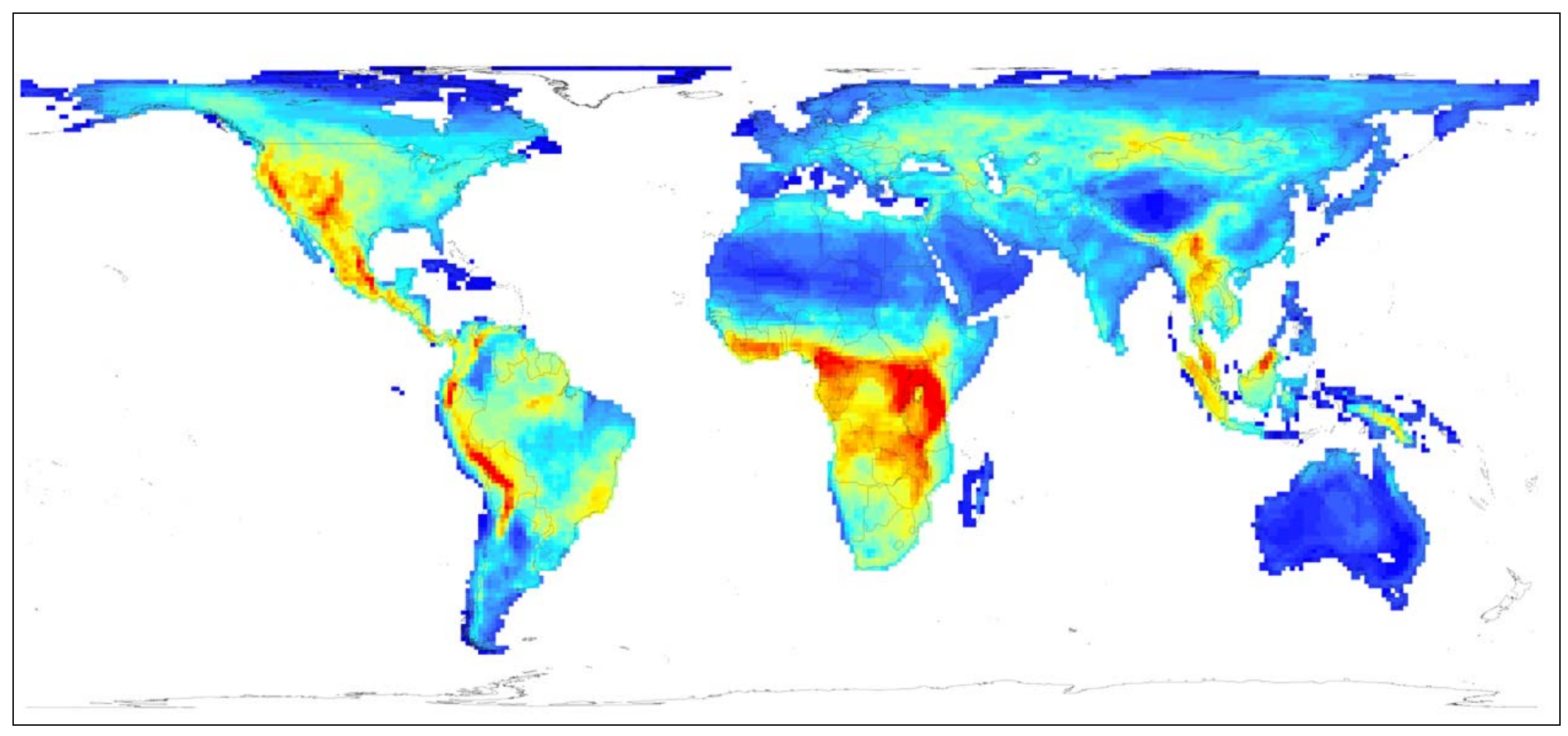

Figure 11f: Species richness: Rodentia.

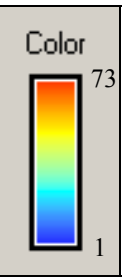




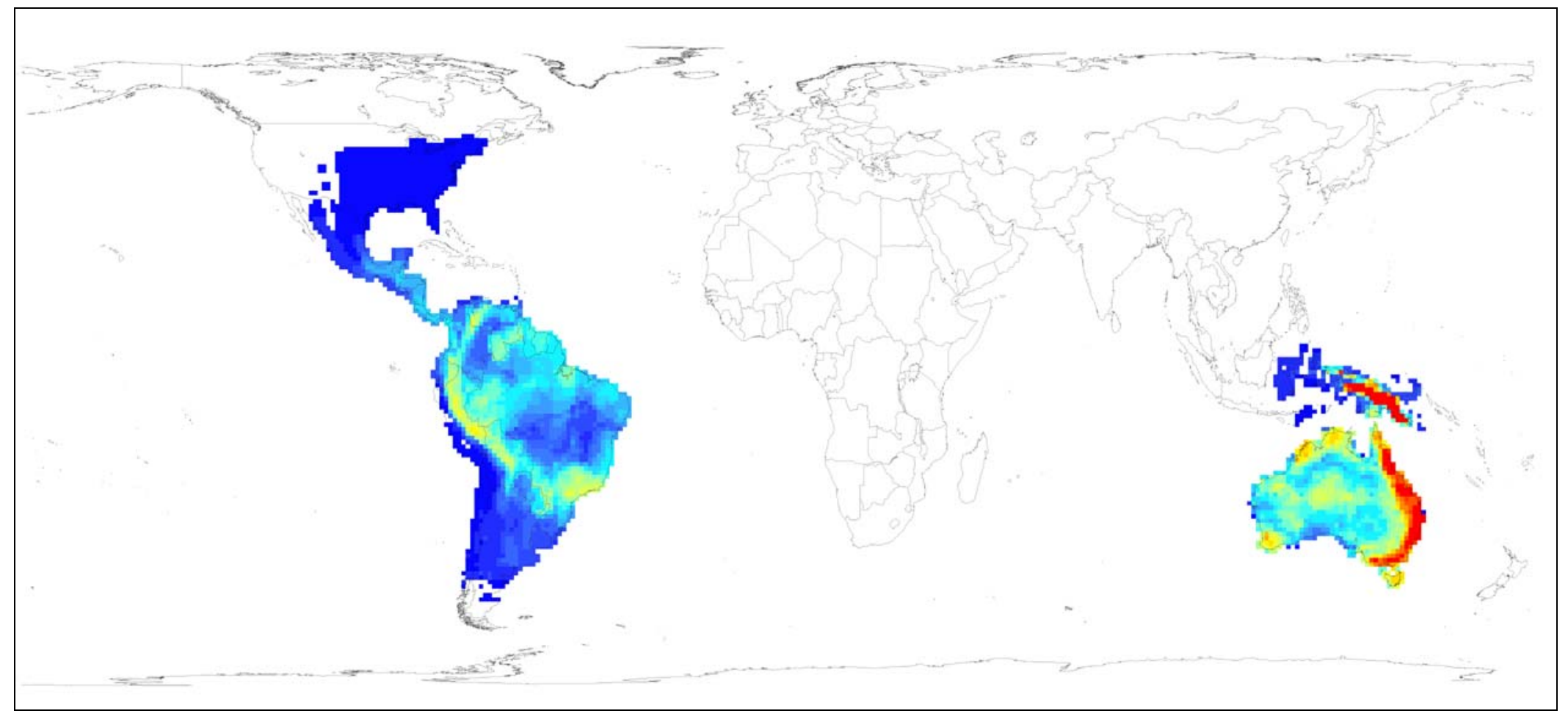

Figure 11g: Species richness: Marsupials

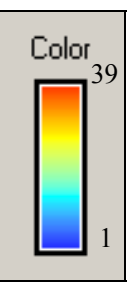




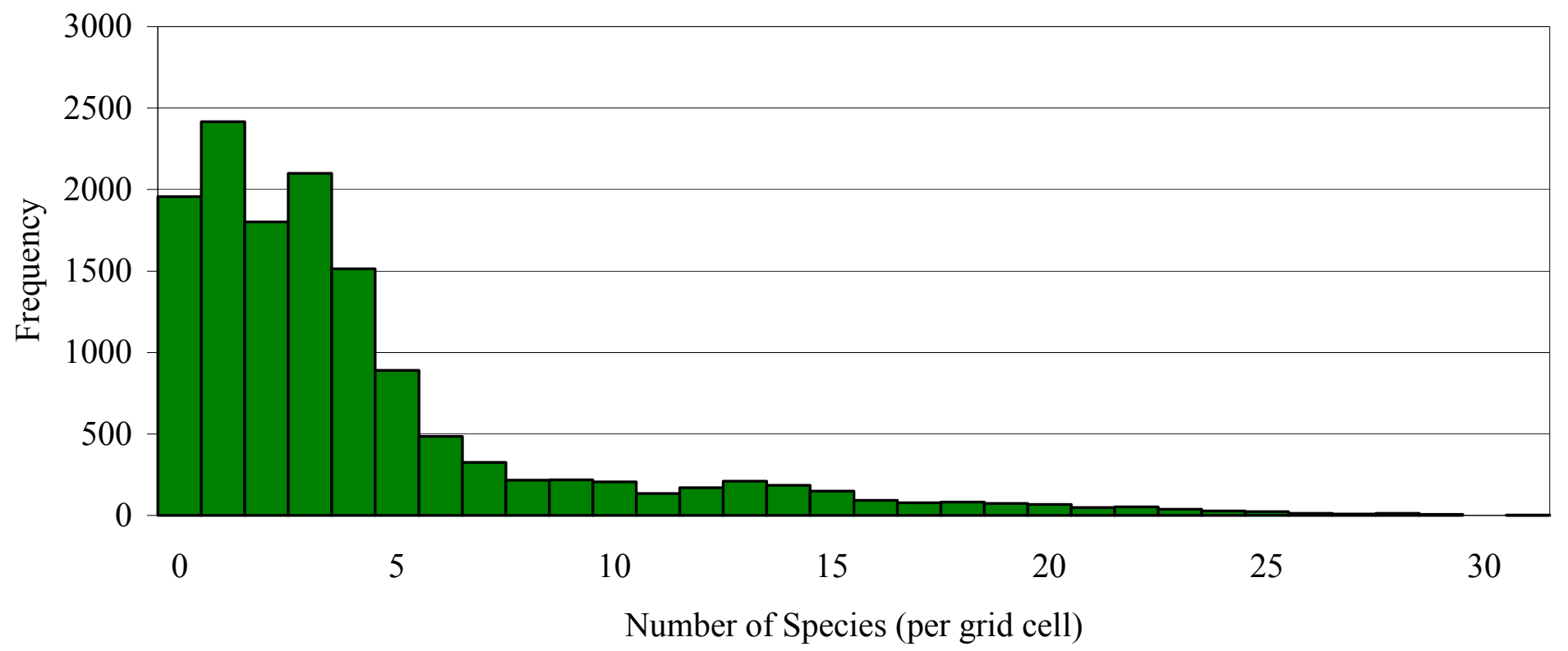

Figure 12a: Frequency of richness across grid cells: Artiodactyla 


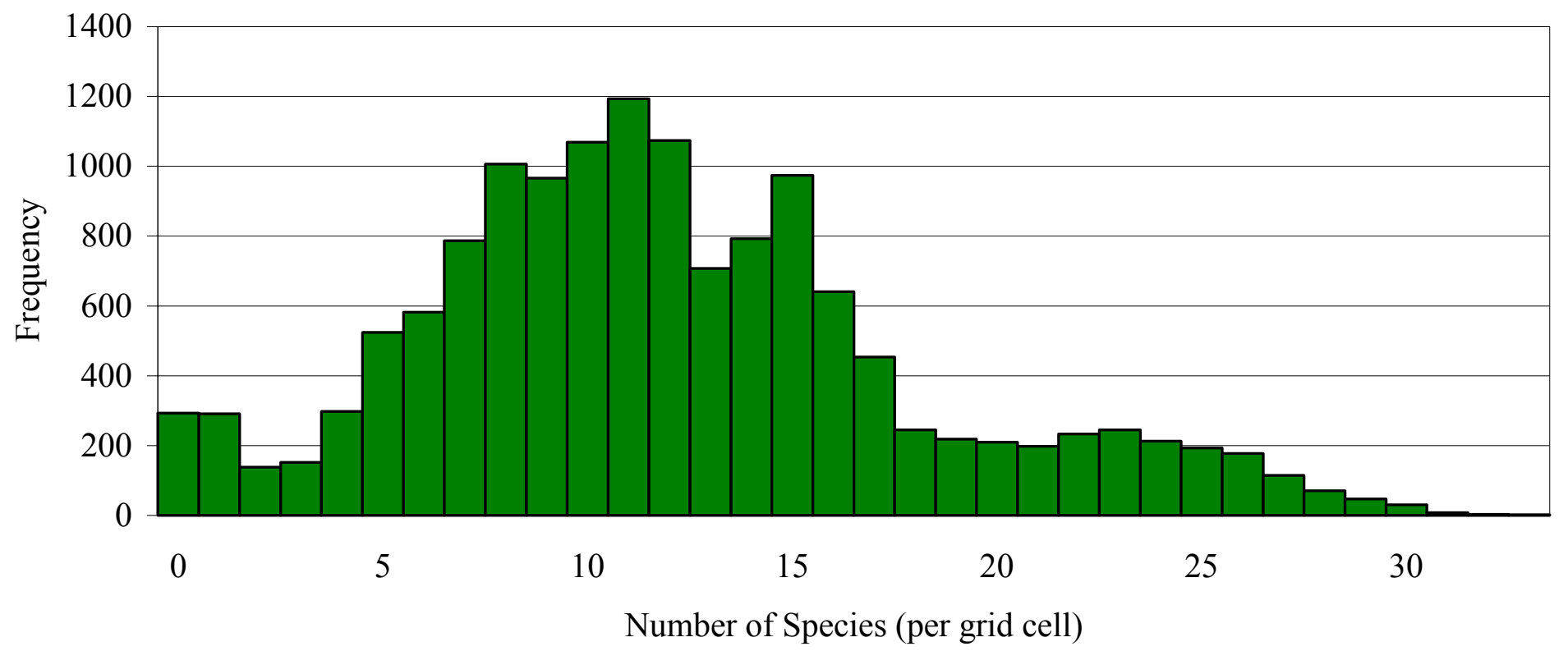

Figure 12b: Frequency of richness across grid cells: Carnivora 


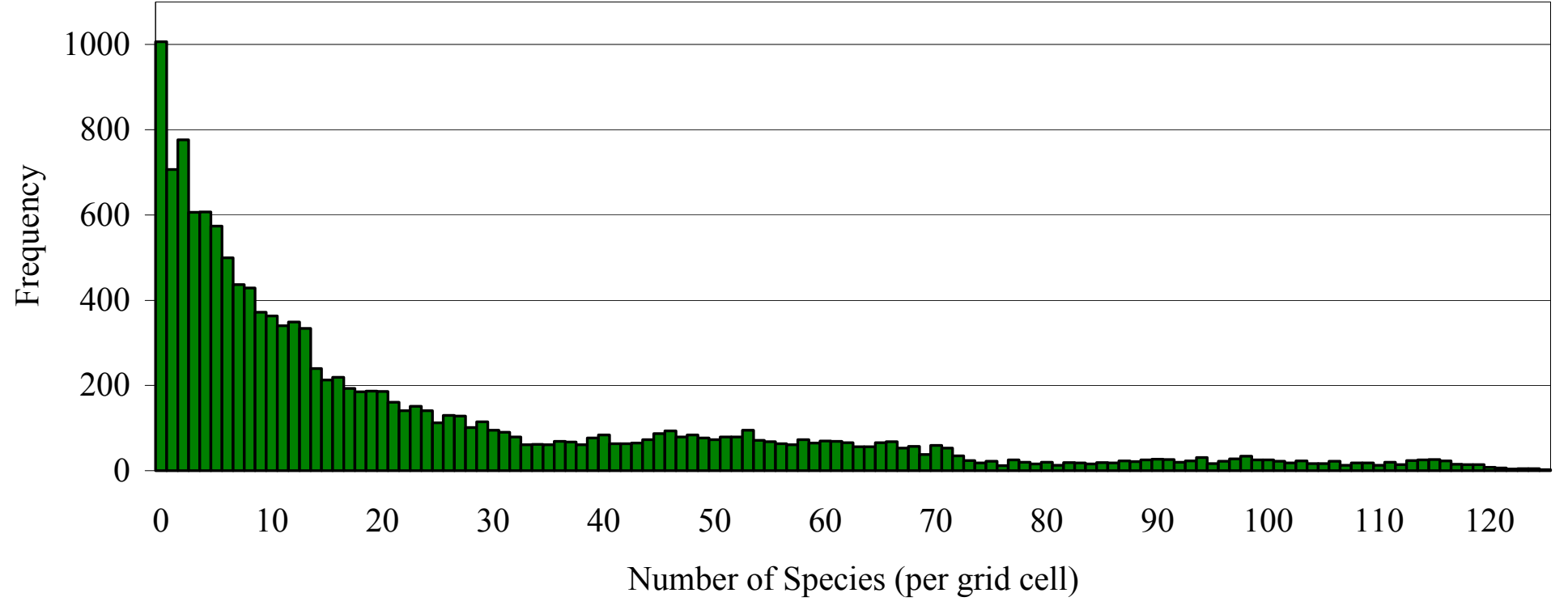

Figure 12c: Frequency of richness across grid cells: Chiroptera. 


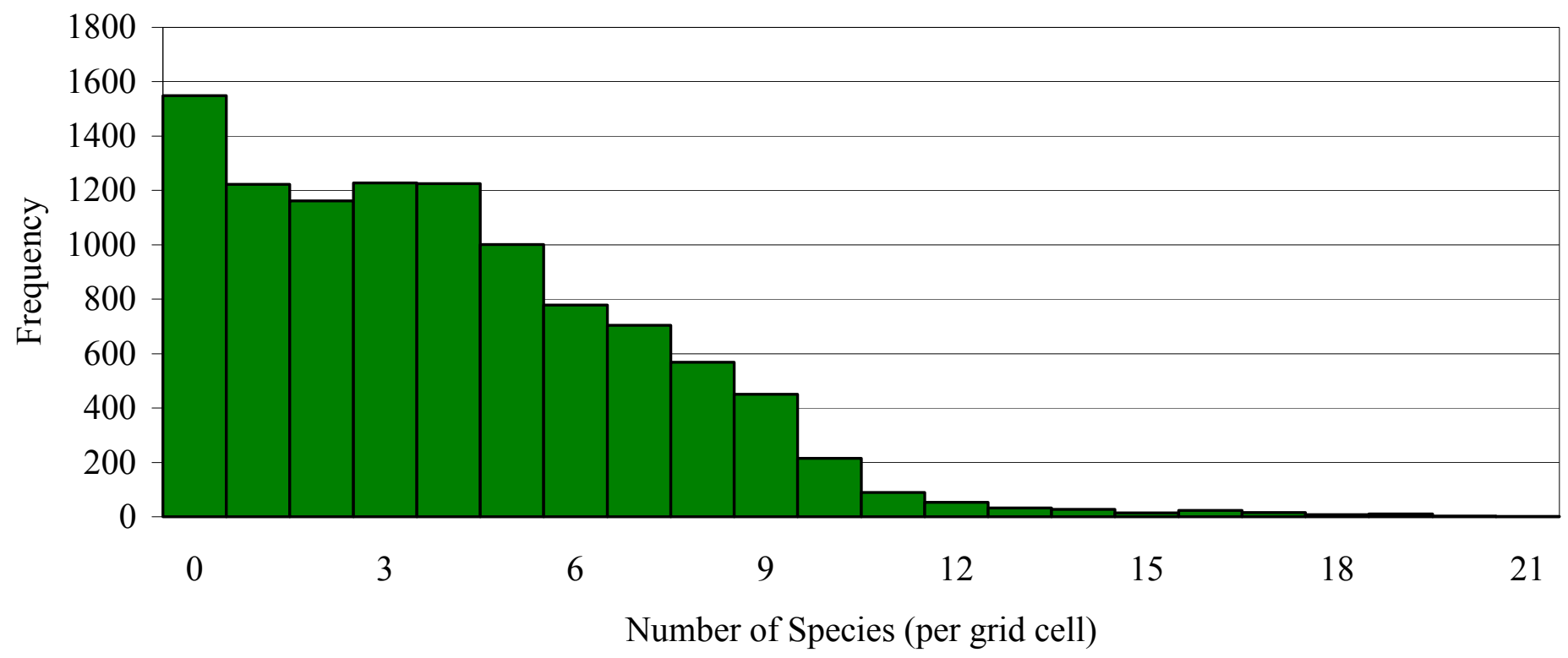

Figure 12d: Frequency of richness across grid cells: Lipotyphla 


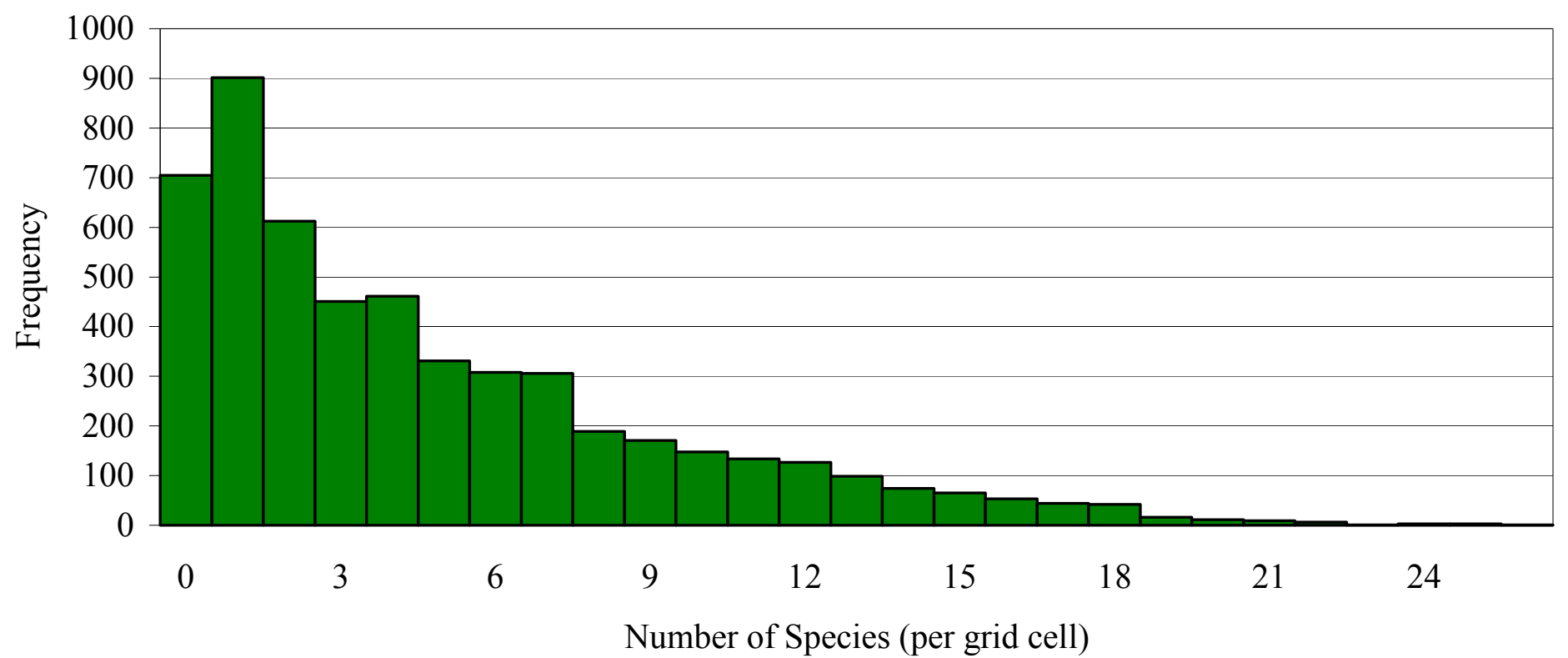

Figure 12e: Frequency of richness across grid cells: Primates 


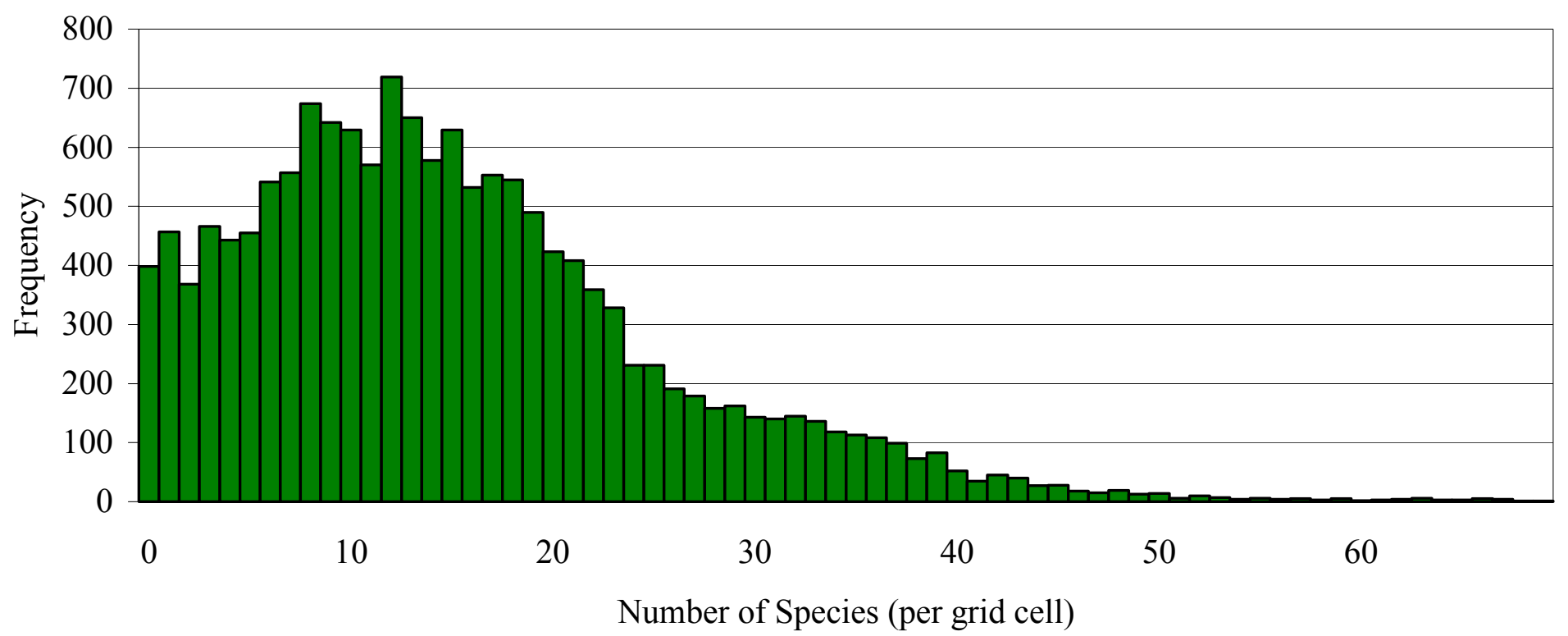

Figure 12f: Frequency of richness across grid cells: Rodentia. 


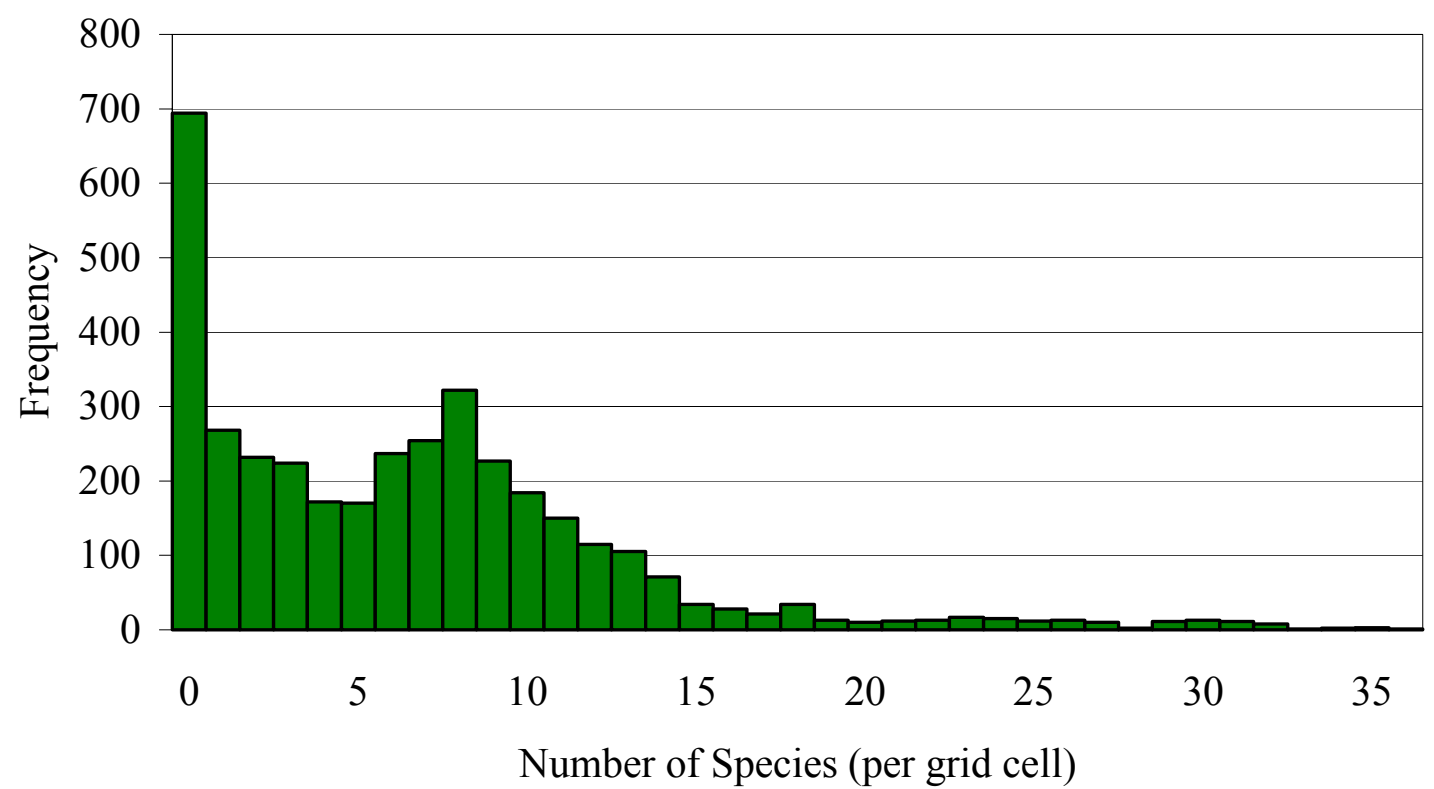

Figure 12g: Frequency of richness across grid cells: Marsupials 


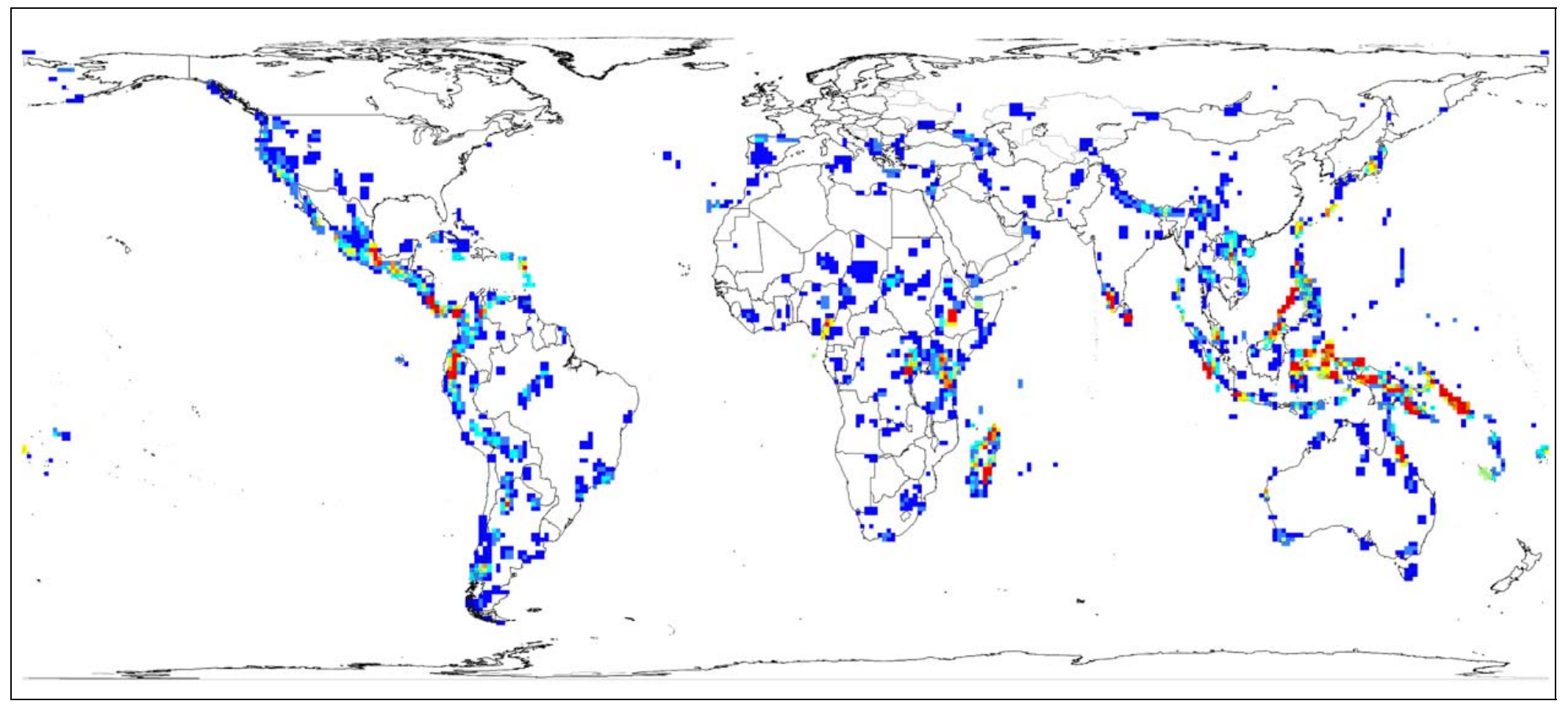

Figure 13a: Species richness based on range size cutoff; first quartile.

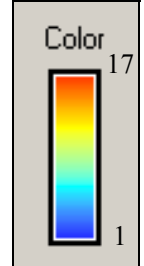




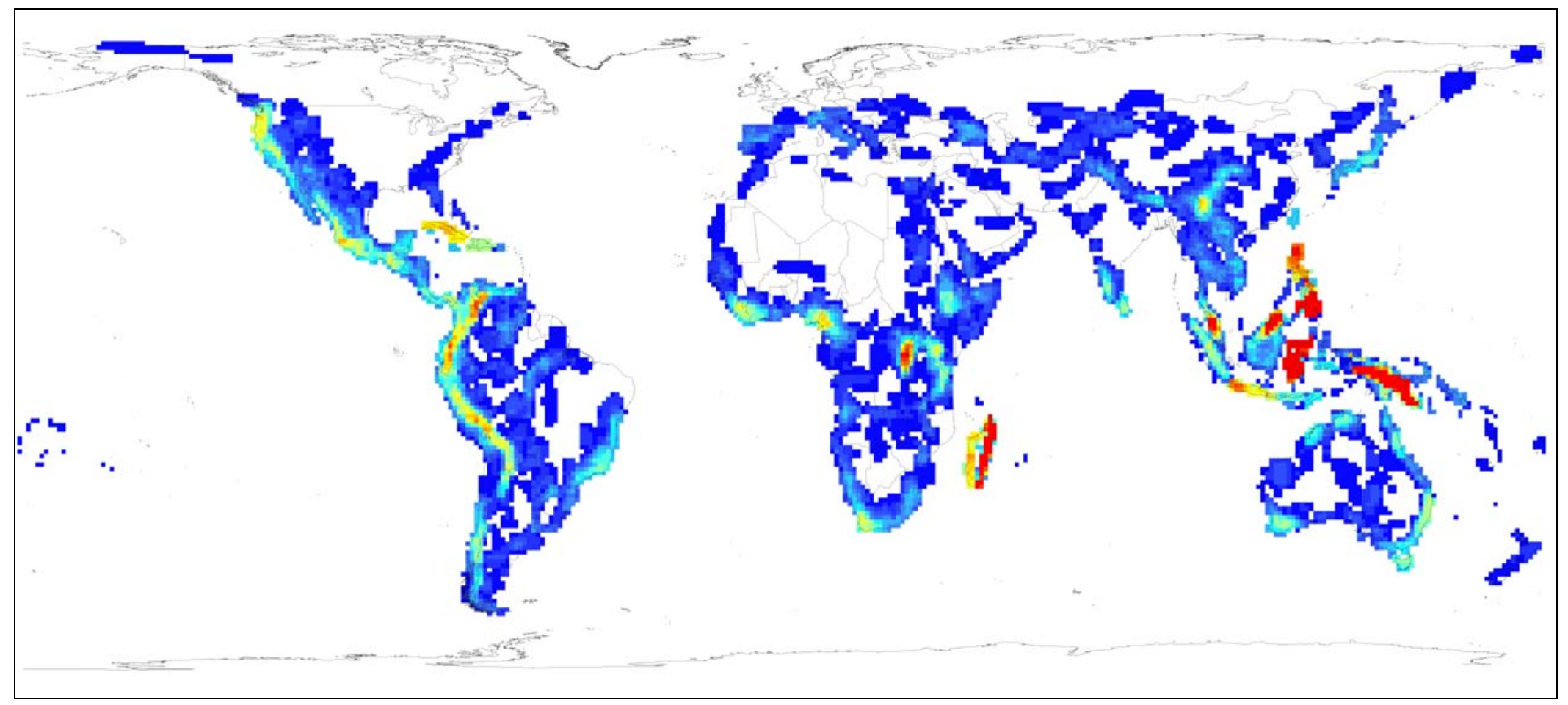

Figure 13b: Species richness based on range size cutoff; second quartile.

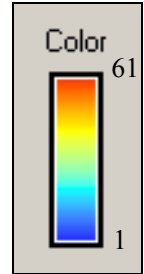




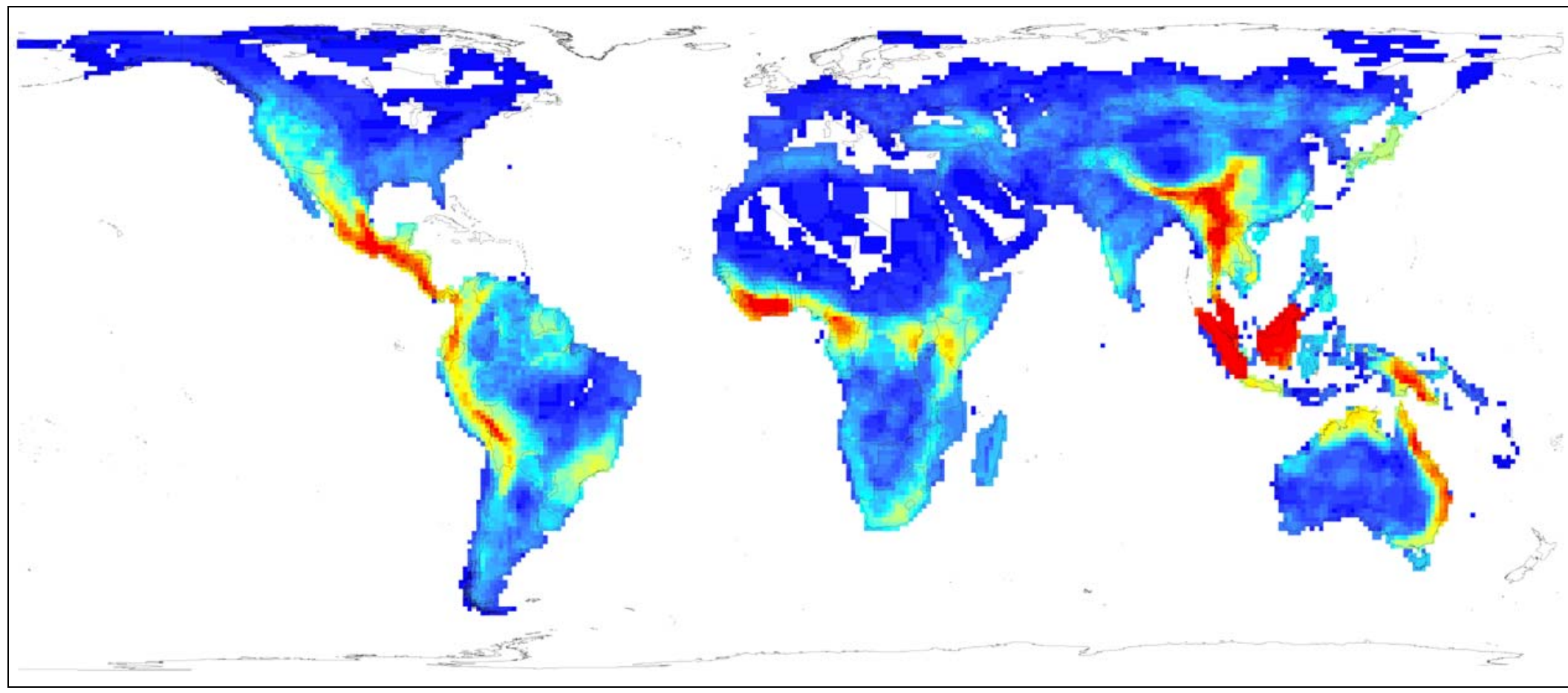

Figure 13c: Species richness based on range size cutoff; third quartile.

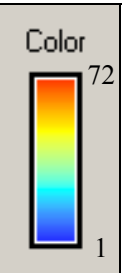




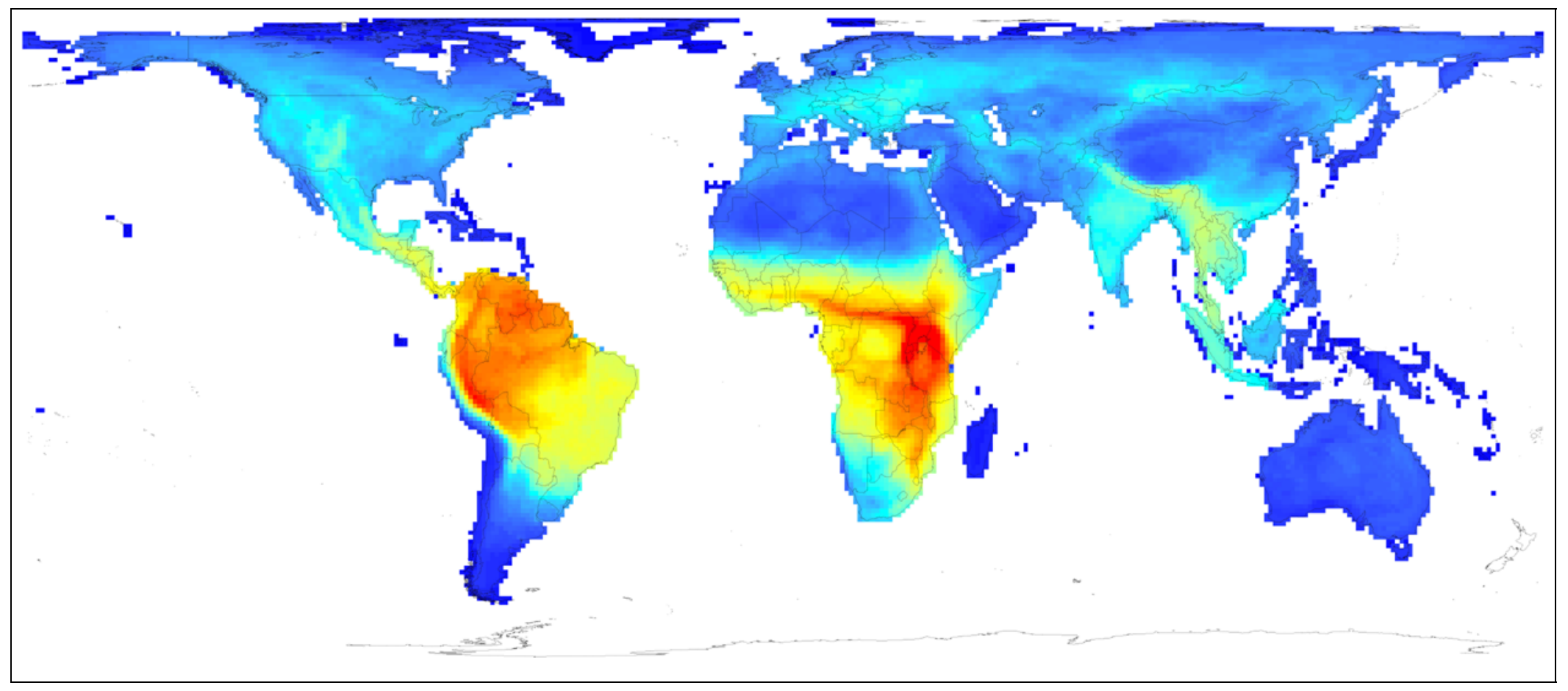

Figure 13d: Species richness based on range size cutoff; last quartile

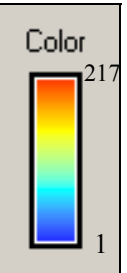




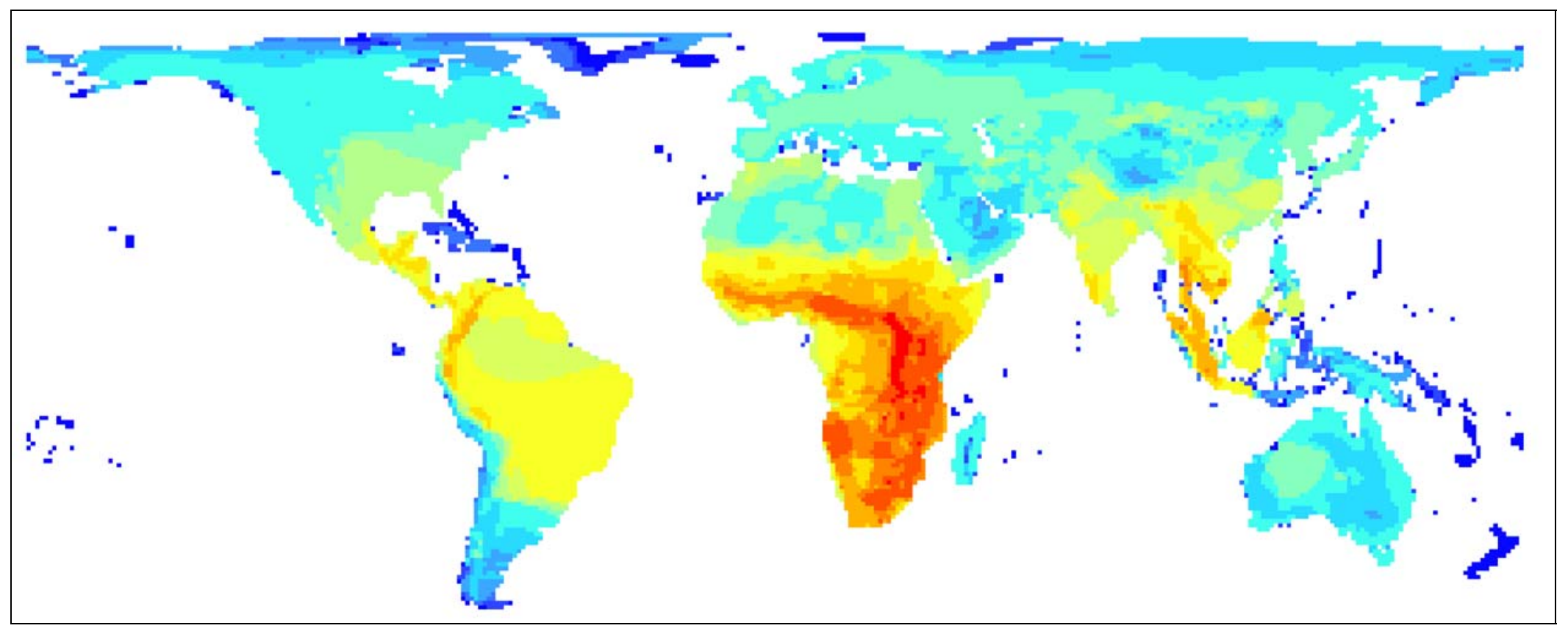

Figure 14a: Global Mammal Ordinal richness. Species ranges were consolidated into one range per order.

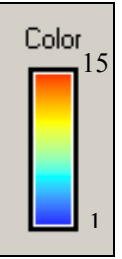




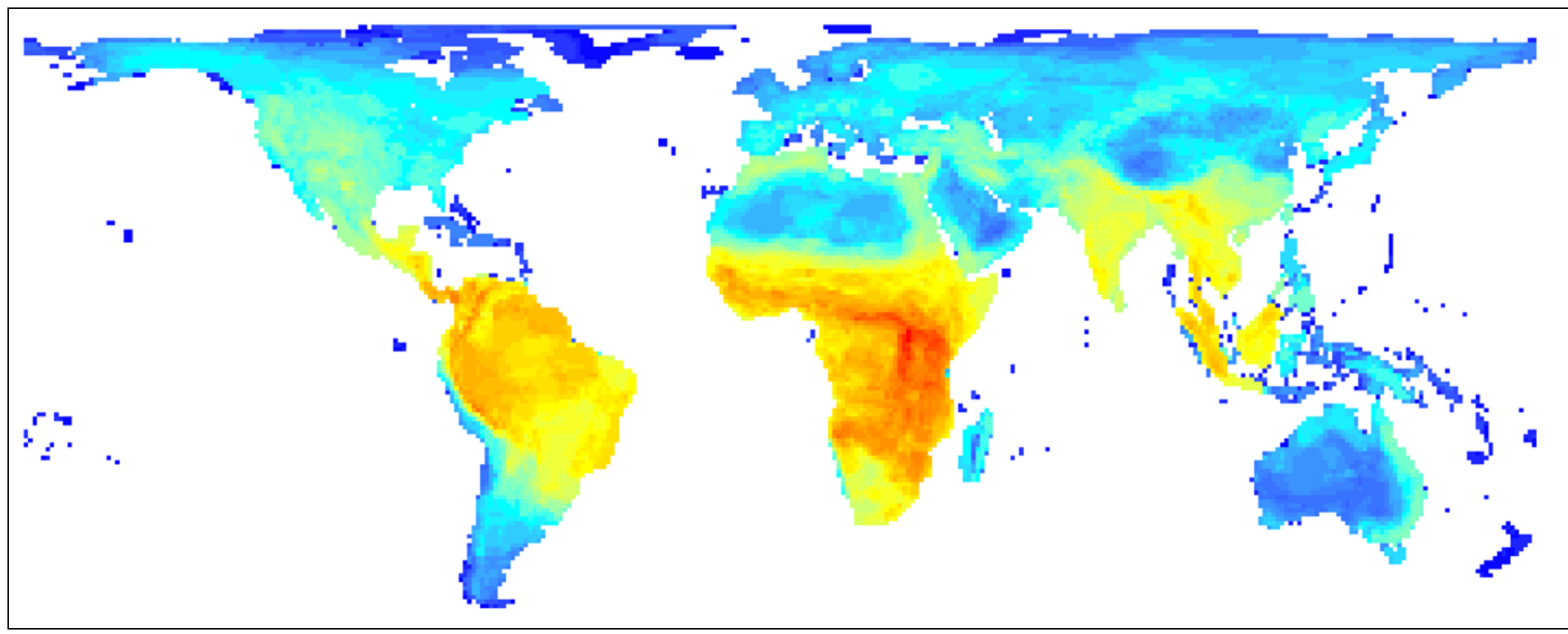

Figure 14b: Global Mammal Familial richness.

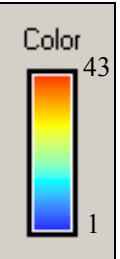




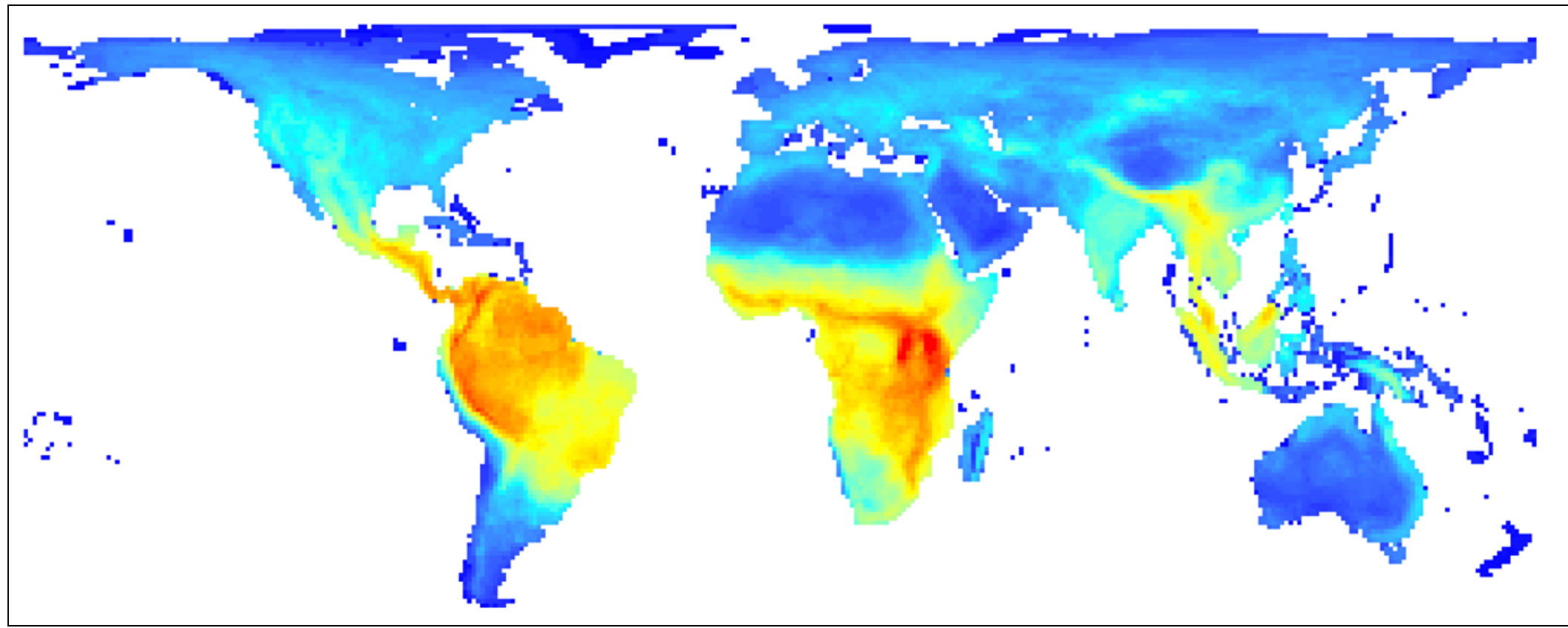

Figure 14c: Global Mammal Generic richness.

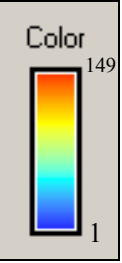




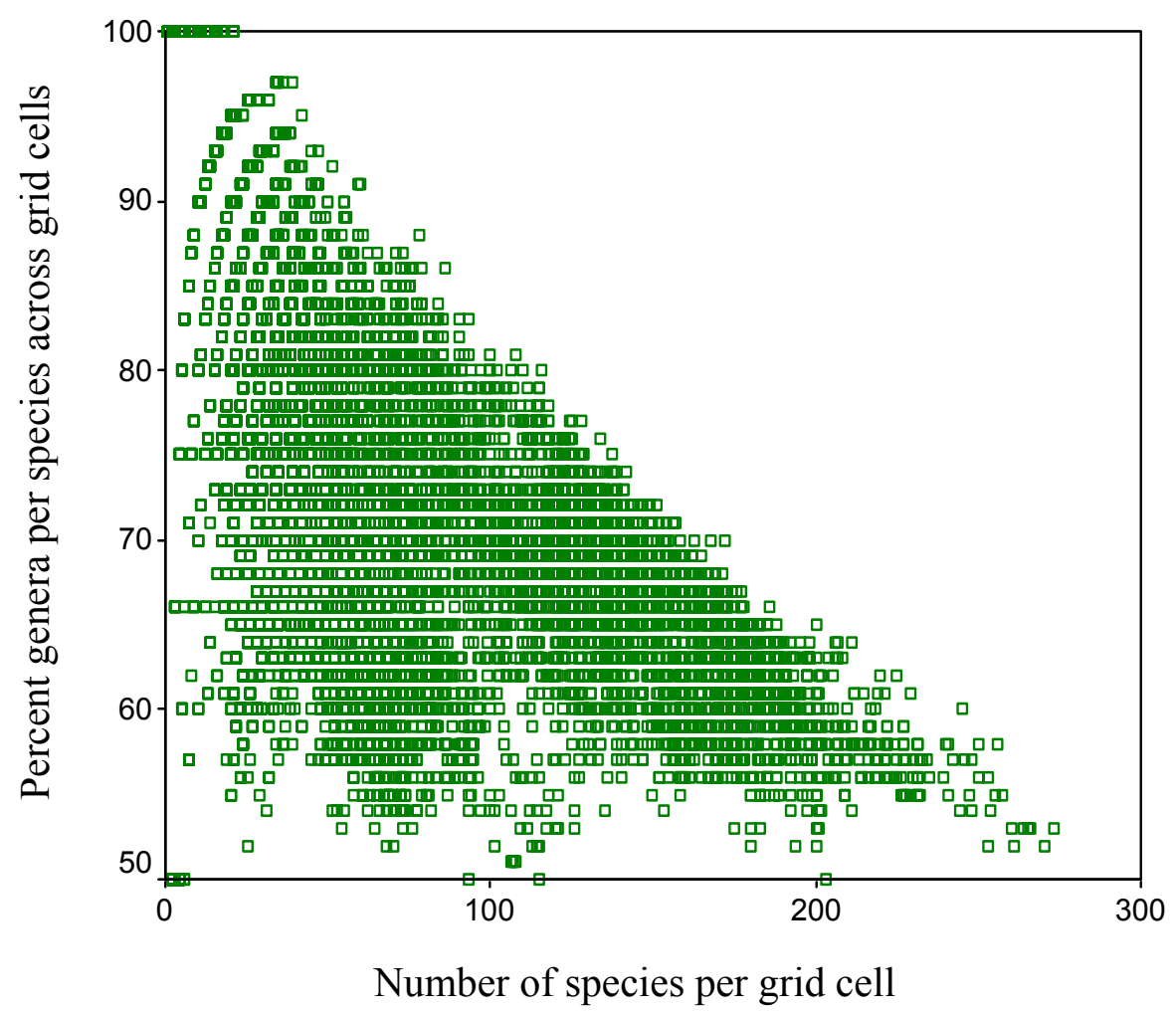

Figure 15: Proportion of genera per species across grid cells, versus number of species per grid cell. 


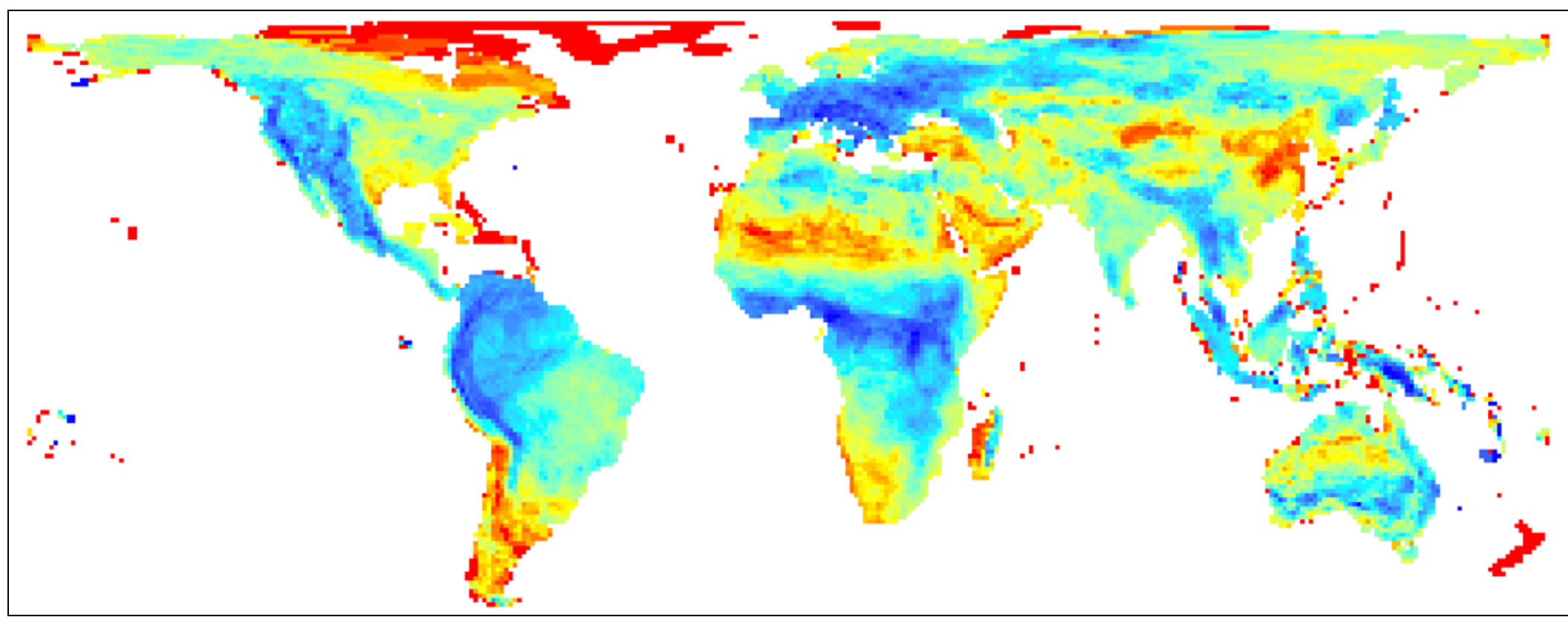

Figure 16: Percent of genera per species across grid cells.

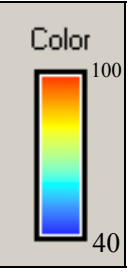




\section{Chapter 4}

\section{Global Mammalian Endemism}

\section{Introduction}

Our knowledge of the world's biodiversity remains incomplete. Tens of millions of species have yet to be described by science (May, 1988). The majority of the world's species are thought to be narrowly distributed (Thirgood and Heath, 1994; Gaston, 1998b; Cowling and Samways, 1995). However, comprehensive distributional data are scarce for even relatively well-known groups of organisms (Heywood, 1995). This paucity of knowledge is an enormous challenge for conservation biology. A clear priority is to improve our knowledge of species distributions, especially for rare species, which can provide a sound scientific basis to develop and implement conservation strategies and tactics.

Identifying species restricted to small geographic areas is essential, since these regions are prone to small-scale disturbances. Species occurring in small areas are naturally vulnerable to local extinction, due to both environmental (e.g., storms, volcanism) and biological (e.g., disease, increased competition) causes (Gaston, 1994a). Over time periods of hundreds or thousands of years, this is unlikely to lead to many extinctions, even for restricted range species, since natural extinction rates are relatively low and not easily detectable (May et al., 1995). However, virtually all recent extinctions are driven by human activity; humans have driven extinctions rates to at least three orders of magnitude above the "background" rate (Pimm et al., 1995). A species restricted to a 
small area that is completely destroyed by human activity would, once its population in the area is lost, become globally extinct. All else being equal, a widespread species from the same area would undergo a local extinction, reducing the species' overall genetic and population level diversity, but would still retain extant populations in other areas.

In addition to the increased vulnerability of species with small ranges, there is evidence that these same species may be additionally prone to extinction by having smaller populations (Lawton, 1993; Gaston, 1998a). For most species groups, the relationship between range size and abundance is a positive one (Brown, 1984; Gaston et al., 1997). Thus, species with small geographic ranges tend to not only have lower total population sizes, but also lower local densities than wide ranging species. An exception to this tendency was found among Australian marsupials greater than 4 million years old (Johnson, 1998). Conversely, the same study confirms a positive relationship among evolutionarily younger marsupial species and attributes the unusual results among older species to differential extinction of those species with small ranges and low local abundances (Johnson, 1998).

Rarity, which is a general term applicable not only to geographic range but also to population and ecological requirements, is quantifiable (Rabinowitz, 1981; Rabinowitz et al. 1986; Gaston, 1994b; Kunin and Gaston, 1997). In this paper, I examine the former: geographically rare species, or restricted range species. The definition of a restricted range species is necessarily subjective, although quantitative measures may use either absolute range size cutoffs (for example, less than a certain area or latitudinal extent) or proportions based on the lower range sizes within a given taxonomic group. Those species solely confined to a certain geographic feature or a political entity are called 
endemic species, although the term is also used widely to describe species that are narrow endemics, or restricted range species (Anderson, 1994; Harold and Mooi, 1994). A center of endemism is generally defined as a small area that holds many species found exclusively within its boundaries (Anderson, 1994).

Mammals provide an ideal group to examine patterns of endemism, because they contain species that are extremely varied in their ecologies (e.g. flying, burrowing, arboreal) and evolution (Nowak, 1999), and are found in most areas across the globe. Mammals also play large ecological roles in many ecosystems, and are often critical components of major guilds such as carnivores and herbivores (Terborgh, 1988). Previous studies of mammal endemism by continent, country, and biogeographic region have found that endemic species are not randomly distributed but are highly clumped (Ceballos and Brown, 1995; Mace and Balmford, 2000; Baquero and Telleria, 2001; Dannell and Aava-Olsson, 2002). The distribution of mammals at the scale of continental and biogeographic regions yield insights into biogeography, and country level lists of endemic species are important to promote awareness and political support for the protection of a nation's unique biodiversity (Mittermeier et al., 1998).

Many centers of endemism, however, are smaller than continents and do not conform to country boundaries. The most obvious examples are islands that contain large numbers of unique species, but are politically part of a larger country. Ceballos and Brown (1995) account for species endemic to islands by separating island nations from continental nations. Unfortunately, the contribution of single island species to countries with many islands is lost. For instance, the large island nation of Indonesia contains many 'endemic' species of mammals, with some that are widely distributed across the Sunda 
Archipelago, while others are restricted to very small areas, such as the Pig-tailed Langur, (Simias concolor), endemic to the Mentawai Islands (Fuentes, 1998). Furthermore, geographic features containing unique species that happen to straddle two or more countries, such as mountain ranges, are ignored by country level endemism approaches. An example of this is the Talamancan Small-eared Shrew (Cryptotis gracilis), which occurs only in the Talamancan Mountains (Choate, 1970). This mountain range spans the border of Costa Rica and Panama, thus the shrew is not 'endemic' to either country. Species reside in areas for biological and evolutionary reasons, and thus do not conform to artificial human defined boundaries.

Analyses of distributional rarity in a group of species can also be accomplished using calculations of range size rarity. This measures the contribution of every species within the group, with each contributing a value proportional to their range size (Williams, 1998). The choice of calculations used is inherently subjective, with common equations including taking the sum of the reciprocals of range sizes for all species in a cell or taking the square root of the inverse of range size for all species in a cell (Williams et al., 1996). These measurements seek to have all species represent the value for rarity across a given region, taken analytically as a grid cell.

With the knowledge that restricted range species face a "double jeopardy" due to both small population and small range size, conservation efforts have sought to locate centers of endemism (Gaston, 1998a). For example, Myers et al. (2000) designated the planet's 25 most threatened centers of endemism as "biodiversity hotspots". Each hotspot contains, as endemics, at least $0.5 \%$ of the world's vascular plants and has lost over $70 \%$ of its primary vegetation (Myers et al., 2000). Collectively, hotspots contain $44 \%$ of 
vascular plants and $35 \%$ of vertebrates as endemics within just $1.4 \%$ of the world's land surface (Myers et al., 2000).

Other measures of endemism seek to identify species that have restricted ranges (Peterson and Watson, 1998). Under this approach, endemism is a relative measurement where a threshold for what qualifies as a restricted range species can, in theory, be set at any spatial amount. For example, an early study of rare African birds defined endemics as species extending less than $250 \mathrm{~km}$ in any direction, i.e. with a maximum possible range being a circle of radius $125 \mathrm{~km}$ (Hall and Moreau, 1962). Instead of a maximum extent, Terborgh and Winter (1983) used an area threshold of $50,000 \mathrm{~km}^{2}$ for defining restricted range bird species in South America. BirdLife International subsequently carried out the first global assessment of a major taxonomic group, birds, using the same $50,000 \mathrm{~km}^{2}$ threshold (ICBP, 1992; Stattersfield et al., 1998). Under this approach, "Endemic Bird Areas" (EBAs) were defined as areas encompassing the entire collective ranges of two or more overlapping restricted range species. A total of 218 Endemic Bird Areas (EBAs) were thus defined, with 138 'Secondary Areas' delimited as holding only one endemic restricted range species.

The BirdLife initiative was important in focusing attention on where centers of restricted range species are found and what species are found within them, and many conservation decisions have been driven by this important work (Brooks, 1998). There remains an urgent need for complete spatial information on other taxonomic groups. The methodology for defining species and areas on the basis of geographical rarity needs to be improved, including the use of biologically and spatially relevant measures, which are needed to allow flexibility for use on varying scales and taxonomic groups. Research has 
also shown that many groups do not show similar diversity patterns. The usefulness of surrogates for biodiversity measurement and protection is inconsistent across taxa and areas (Howard et al., 1998). However, there is a pressing need for more data to thoroughly test the utility of this approach, especially across large taxonomic groups at different scales.

For this analysis of mammals, I use the term "range restricted" to describe species with ranges of less than $50,000 \mathrm{~km}^{2}$. I describe the number and location of all known extant terrestrial mammal species with restricted ranges. The availability of comprehensive distribution information for all species, not just those with small ranges, allows for unprecedented flexibility in how restricted ranges were defined. This quantitative information is used to examine the results from defining other range size thresholds. Altogether, these results are used to identify areas across the globe that hold restricted range mammal species. The results of this study reveal many patterns concerning which terrestrial areas hold restricted range species, and of these the areas that contain a high number of restricted range endemics.

\section{Methods}

\section{Taxonomic information}

Mammal species classification, as well as higher-level taxonomy, follows the second edition of Mammal Species of the World (MSW) (Wilson and Reeder, 1993). For certain mammal orders (all except for Lipotyphla, Didelphimorphia, and some speciose families of Rodentia), draft chapters of the forthcoming third edition were used, kindly 
provided by D. Reeder and D. Wilson (pers. comm.). The total number of mammal species considered is 5,035; this does not include 54 species listed by Wilson \& Reeder (1993) but removed in the draft chapters of the third edition. In this study, I exclude all 103 species that are extinct (as classified by the World Conservation Union) (HiltonTaylor, 2002), humans and their domestics and commensals (13 species), and species that live in marine environments ( 80 species of Cetacea, four species of Sirenia, and 37 species of marine Carnivora). In addition, I excluded 58 species that were described in the text of MSW and other sources as having serious taxonomic and distribution uncertainty. After these modifications, the total number of mammal species remaining under consideration is 4,740 species (Table 1; also see Chapter 2).

\section{Species' range data}

The species database created for this analysis contains information on the spatial aspects of each species' range (Chapter 3). Broad regions are listed where each species occurs including the continents and several large island groupings (Madagascar, New Guinea, South-east Asian islands, Caribbean). Additionally, species' island status is recorded, including whether the species occurs on islands, is found only on islands, is found only in one island group, or is confined to a single island.

Species range information was compiled from published literature sources, including books, journal articles, government reports, and IUCN/SSC Action Plans (Chapter 3). Distribution data, including polygon range maps and point localities, were georeferenced and digitized into a geographic information system (GIS). For species known only from point localities, ranges were conservatively estimated using published 
information on ecology and habitat preferences. All species included a final polygon map of their geographic range, or extent of occurrence (EO) (Gaston, 1994c). The range size of each species was determined using its EO measured in the Behrmann equal-area projection.

\section{Classification of restricted range species}

A GIS platform was used for all spatial analyses (ArcGIS 8.2). Information on range size was then used to identify species based on both total EO areas and also for proportional thresholds, such as lowest deciles. Here, mammal ranges were separated in 5 increments beginning with $50,000 \mathrm{~km}^{2}$ up to $250,000 \mathrm{~km}^{2}$ (which is the median range size for mammals). A few mammal species (27 species) were not considered range restricted even though their EO is less than $50,000 \mathrm{~km}^{2}$. These are species that have undergone recent range contractions (since 1800) due to humans; their exclusion follows the methodology of Stattersfield et al. (1998). The 1800 cutoff for classifying such species was set arbitrarily because there is little reliable data for most species' distributions until relatively recently. Thus, the analysis of current human impacts on species with restricted ranges refers to those species that are naturally small ranging, and not those whose ranges have recently been severely reduced into the restricted range class.

Richness maps of restricted range species were calculated using a gridded onetenth degree geographic projection. All analyses were repeated using an equal-area projection, Behrmann cylindrical, with similar qualitative results not reported. Another calculation of restricted range status, range-size rarity, was analyzed following previous 
studies (Williams and Gaston, 1998). For each grid cell, the range-size rarity value equals the square root of the reciprocal of a species range size, summed for all species in the cell.

The patterns of restricted range species were compared with a random model assuming that there should be an equal distribution of these species across the globe. This was performed once across the entire globe, and also assuming higher species numbers in the tropics following Chapter 3. The distribution of restricted range species was randomized 100 times to determine whether the observed pattern was significantly different from random.

\section{Results}

\section{Range size distributions}

The frequency distribution of mammal range sizes shows a strong right skew, i.e. most mammals have small ranges (Figure 1a). Under natural logarithmic transformation, there is a strong left skew (skewness ratio $=138, \mathrm{p}<0.001$ ) (Figure $1 \mathrm{~b}$ ). The average range size for mammals is over 1.5 million $\mathrm{km}^{2}($ mean $(\mathrm{std})=1,683,755 \pm 3,757,291$ $\mathrm{km}^{2}, \mathrm{n}=4,740$ species) (Chapter 2). There is considerable variation in range sizes across orders (Figure 1c). Species with range size less than $50,000 \mathrm{~km}^{2}$ show a similar hollow curve pattern (Figure 1d). Most classified restricted range mammals are not found in highly disjunct areas (i.e. less than 43 out of 1,369 species have a latitudinal or longitudinal extent of over 10 degrees latitude, with most well under this). 
Endemic Patterns

A map of the 'Endemic Mammal Areas' of the world was made using the Stattersfield et al. (1998) criteria (Figure 2). Species richness of 'Endemic Mammal Areas' was calculated, and here those areas that are classified as 'Secondary Areas' were included. Richness was calculated over a total of five different cutoffs, at $50,000 \mathrm{~km}^{2}$ intervals up to $250,000 \mathrm{~km}^{2}$ (Figures 3a-f). The different range size thresholds show different patterns, with some areas not represented when the lowest threshold is used. An example is seen with the absence of the Northwest region of the United States in the range size rarity measurement; this appears rich in restricted range species for the median cutoff $\left(250,000 \mathrm{~km}^{2}\right)$.

The comparison of range size rarity for all mammals with the richness of restricted range species over predicts areas of high endemism, especially using lower cutoffs $\left(50,000 \mathrm{~km}^{2}\right)$. The range size rarity map closer predicts richness maps using larger range size cutoffs (e.g., $250,000 \mathrm{~km}^{2}$ ). The results of these calculations are qualitatively similar, though analytically the results are variable (Figure $4 \mathrm{a}-\mathrm{b})$. Here, I concentrate on using $50,000 \mathrm{~km}^{2}$ as the measurement of rarity, as this method allows for more refined details, and also follows the only other previous global study on vertebrate endemism.

\section{Taxonomic Patterns}

The proportion of restricted range species varied between orders, with some containing much higher proportions than others $\left(\mathrm{F}_{19,1349}=2.96, \mathrm{p}<0.001\right.$, respectively). The range size skew differs across orders, though all but two orders with less than 25 species (Perissodactyla and Hyracoidea) have strong left skews (see Chapter 3). The 
majority of species that are restricted in range are found in the speciose groups of small mammals: Rodentia, Chiroptera, and Lipotyphla. Additionally, Primates contain a large number of restricted range species (Figure $5 \mathrm{a}-\mathrm{b}$ ). Eleven of the 28 Orders of mammals (not counting Cetacea) have more than 50 recognized species. Of these, Afrosoricida, Dasyuromorphia, Diprotodontia, Lipotyphla, Rodentia, and Primates all have over a quarter of their species as restricted range, with Chiroptera and Lagomorpha just over a fifth of their species. Only Artiodactyla, Carnivora, and Didelphimorphia have under onefifth their species as restricted range. The patterns for the less speciose groups were not examined in detail due to the small sample sizes.

Narrow endemics are found across all the major groups of mammals. The patterns vary across taxonomic groups, both in number of species and proportion of species (Figure $5 \mathrm{a}-\mathrm{b}$ ). Among orders, Rodentia comprise the highest proportion of restricted range species (47\%), the others with large numbers being Chiroptera (18\%), Lipotyphla $(10 \%)$ and Primates $(9 \%)$, whereas all other orders represent fewer than $5 \%$ of restricted range species. The small orders of Cingulata and Hyracoidea, and all the orders with 3 species or less, have no restricted range species (Figure 5b).

\section{Geographic patterns}

The distribution of restricted range species varies across both taxonomic groups and geographic regions. The number of endemic mammal species varies across continents from 226 in Africa to 197 in North America to only 58 in Australia $\left(F_{4,876}=\right.$ 6.65, $\mathrm{p}<0.001$; Figure 7). Islands, even those as small as the Mentawai Islands (under $5,000 \mathrm{~km}^{2}$ ) account for many restricted range species (Figure 8). Regions [i.e., EMAs] 
were classified as having a 'high diversity of endemics' if they contain 5 or more restricted-range species. The reason behind this was that many areas contain only one or a few species. This threshold was chosen due to the fact that the frequency by area (in this case, a grid cell), showed that $94 \%$ of cells held 4 or less species. Changing the threshold to 4 species added only 5 more continental regions (Table 2). There are additional areas of high diversity of restricted range species occurring in island regions (over 20 depending on splits between adjacent island regions). All of these EMAs with a 'high diversity of endemics' are confined entirely to the tropics (Figure 3a). The majority of these areas are on either actual islands or 'islands' of montane habitat. Some high biodiversity EMAs in the tropics include the western Ghats, the Albertine Rift, the Talamancan highlands, and the Queensland tropical rainforest (Table 2). Several areas in the Andes, from Venezuela to Argentina, also hold large numbers of endemics. There are other distinct areas that contain a moderate diversity of restricted range species, including areas not in the tropics or on islands, such as the Caucasus, Rocky Mountains, Chilean temperate forests (Armesto et al. 1998), and southwest Australia.

The overall global patterns of restricted range species were compared with random models, and the richness patterns were significantly different from random (100 randomizations, $\mathrm{p}<0.001$, reject null hypothesis of random spatial distribution). The statistical results validate readily apparent patterns seen on the richness map of restricted range species, that the distribution of restricted range species is highly non-random, with a large proportion found in tropical areas, especially montane and island regions (Figure 9). The degree of overlap between these restricted range species is also non-random, such 
that certain areas hold high proportions of restricted range species, as many restricted range species overlap each other.

\section{Discussion}

In most taxonomic groups, a high proportion of species are found in small areas, relative to the group in question (Gaston, 1998b). Mammals are no different in this respect. Half of all known species of extant, terrestrial mammals are restricted to areas under $250,000 \mathrm{~km}^{2}$. This means that fully 2,370 species of mammals (of 4,740 total) are found in areas just smaller than the land area of California. In total, 1,369 species (29\%) of mammals were measured to have range sizes of less than $50,000 \mathrm{~km}^{2}$. For the global analysis of terrestrial birds (Stattersfield et al., 1998), 28\% of all landbird species (27\% of all species) were measured to have ranges under $50,000 \mathrm{~km}^{2}$. At this range size threshold, mammals show a similar proportion of endemism to birds. The extent to which this holds across other taxonomic groups is unknown, though groups such as the amphibians that have many restricted range species (Duellman, 1999; Frost, 2002) are expected to have higher proportions under this range. Further research on other groups is essential towards understanding the ecological and evolutionary factors leading to range restrictions.

Across the globe, island regions hold high numbers of restricted range species, with the islands from southeast Asia to New Guinea and the Solomons holding the most, along with the island nation of Madagascar (Figure 2a). Continental areas with large numbers of endemics include areas in all three major tropical regions. This pattern is very similar to restricted range bird species, with over $77 \%$ of EBAs located in the tropics and 
subtropics (Stattersfield et al., 1998). For mammals, the vast majority of restricted range species are in the tropics, over 78\% (not including the subtropics). Physical barriers and topography are the most important features for delineating areas of restricted range mammals.

How strong are the patterns of mammal endemism on oceanic islands and those on continental shelves? The percentage of restricted range bird species on islands is $53 \%$, of which $70 \%$ are oceanic islands and $30 \%$ are continental (Stattersfield et al., 1998). There are 27 islands in the world that have land areas over $50,000 \mathrm{~km}^{2}$ (Dahl, 1991) and only 15 of these hold endemic mammals, of which 11 are in the tropics. As with the birds, a high percentage of mammals restricted to small areas are found on islands (45\%). This proportion may well be even higher, given that knowledge of mammal distributions is especially poor on tropical islands larger than $50,000 \mathrm{~km}^{2}$ (e.g., Luzon, Sumatra, Borneo, New Guinea). The distributions of some species did not, therefore, fall below the threshold because often all that was known for a given species was presence on an island. Islands harbor diverse endemics across most groups; unlike birds, mammals are not found on many of the isolated oceanic archipelagos. Only the bats, the sole flying mammals, have naturally dispersed to distant oceanic archipelagos such as New Zealand and the Hawaiian Islands, though at very low diversity. There are only two bat species endemic to New Zealand (not including one recently extinct) (King, 1990) and only the widespread Hoary Bat (Lasiurus cinereus) reaches Hawai'i (Kepler, 1990). Across mammals, the insular restricted range species are composed mostly of bats (171 species; $69 \%$ of all restricted-range bat species) and rodents (235 species; $36 \%$ of all restrictedrange rodent species), with larger bodied species comprising almost none of the insular 
endemism in mammals (Figure 8). This pattern mirrors the overall diversity patterns of these groups, as a much higher number and proportion of all bat and rodent species are found on islands (Chapter 2). However, islands have experienced disproportionate extinction of medium to large bodied vertebrates, including carnivorous species and large herbivores (Alcover and McMinn, 1994), mostly in the orders Carnivora and Artiodactyla, but also species in the orders Proboscidea, the extinct Bibymalagasia, Perissodactyla and Pilosa (Alcover, 1998). In fact, endemic insular Carnivores exist only on Borneo (Catopuma badia), Sulawesi (Macrogalidia musschenbroekii), Madagascar (8 species of herpestids and vivverids), and the California Channel Islands (Urocyon littoralis).

In addition to the uneven distribution of species, taxonomic groups are also unevenly distributed across the world. Some taxonomic groups, including orders, families, and genera are cosmopolitan and others are confined to certain continental or island regions. This is true for mammals, with strong differences among Eurasia, Africa, Australia, and the Americas. Taxonomic groups also show highly divergent patterns of large-scale diversity (Chapter 2). This unequal distribution of species is translated into the composition of endemic areas; some regions and taxonomic groups are very well represented, whereas others are not. The difference between taxonomic groups reflects several qualities, including, for example, differing ecologies and evolution (Nowak, 1999). The Carnivora have few restricted range species, most likely due to their biology, for example large body sizes, high trophic levels, and large home range sizes (Hunt, 1996). Interestingly, there are many insular restricted range bat species (69\%), but only a small number of continental species restricted in range, many of which are poorly known 
and may be more widespread. This pattern is different from the other group of flying vertebrates, the birds, which have only $53 \%$ restricted range species as insular, and indeed are found more widely on islands in general.

Restricted range species often have overlapping ranges (Stattersfield et al., 1998), and hence high proportions exist in centers of endemism. Identifying the causes of nonrandom spatial clumping of restricted range species remains a major question in ecology and evolutionary biology. Endemic areas exist for mammals, with many restricted range species found in the same area as other restricted range species - this pattern increases with higher range size thresholds, but is evident even at the a threshold of $50,000 \mathrm{~km}^{2}$ (Figure 2 a-f). Some of these areas have been previously identified for other taxonomic groups, such as the Albertine Rift for birds, plants, and other groups (Stattersfield et al., 1998). This could result from the narrow amount of available areas suitable for holding large numbers of small ranging species, such as mountains, islands, and other small areas distinct from adjacent areas. Some species do not overlap with other narrow ranging species; the reasons for this could be due to unique biology or evolutionary history, or could be mostly due to either taxonomic or distributional uncertainty. The reasons for the existence of both isolated and clumped restricted range species are still unknown for most groups.

There is probably poor knowledge of a relatively high proportion of restricted range species, though this bias has not been extensively researched (Hall and Moreau, 1962; Kruckeberg and Rabinowitz, 1985). Distributional and taxonomic uncertainty contribute some proportion of endemic species, though by no means the majority in wellknown groups such as mammals (in this study less than one tenth of species under 50,000 
$\mathrm{km}^{2}$ were evaluated to have serious uncertainties). There are a number of mammals that are only known from one or a few localities or individuals, and most of these have received very little research (Patterson, 2001). Other species are better described as subspecies or populations of an existing species. However, there remains a significant proportion that can be classified as truly endemic species, and these deserve scientific attention. Study of areas containing high numbers of endemic species is useful, in that these areas are unlikely to change with the addition or subtraction of a few species after more knowledge is gained. For instance, there are several areas that hold several mammals with small known ranges, though this is only due to a sampling bias, especially for small mammals in tropical rainforests. Certain places in the tropics, such as near accessible rivers or settled areas, have been extensively surveyed, though the surrounding landscape has not (Nelson et al., 1990). Many species identified from localities such as these will inevitably be found to be more widespread, and most will not meet the criteria of a restricted range species. These biases can only be indicated in the present dataset, and cannot be overcome until more systematic and field research is done.

Other difficulties in the classification of restricted range species are due to either recent human-induced range reductions. Some of the apparently restricted range species found in lowland continental areas have been severely impacted by humans, including species such as the giant panda (Ailuropoda melanoleuca) in China, the Spanish lynx (Lynx pardinus) (Rodriguez and Delibes, 2003) from the Iberian Peninsula, and the golden bandicoot (Isoodon auratus) (Maxwell et al., 1996) in Australia. Other species that were extinct in the wild and have recently been reintroduced into small areas include the black-footed ferret (Mustela nigripes) (Clark, 1989; Wisely et al., 2003) and Père 
David's deer (Elaphurus davidianus) (Hu and Jiang, 2002). Species were not included in the analyses when historical reductions were known, but there are likely some species with present small ranges that have suffered unknown range reductions by past human activity. Taxonomic identity is crucial towards understanding which species are restricted in range. Some cases are probably artifacts of minimal taxonomic or geographic knowledge, for example, some shrews of the genus Crocidura in Africa (Nicoll et al., 1990). Some species have not been intensively studied in the field, and hence their range boundaries are unclear. This includes species in most tropical regions, including the newly described Annamite Striped Rabbit (Nesolagus timminsi) from Ha Tinh Province, Vietnam (Averianov et al., 2000) as well as several recently described bushbabies (Galago sp.) from Africa identified solely on vocalization (Groves, 2001).

Understanding the spatial distribution of the world's biodiversity is critical for efficient conservation action. Conservation strategies have increasingly been applied that focus on species as the unit of biodiversity conservation. The patterns, once revealed, can be used to set and implement priorities (ICBP 1992; Adno et al., 1998; Margules and Pressey, 2000; Myers et al., 2000). One strategy seeks to identify areas of high biodiversity, often by evaluating areas that contain high proportions of rare species. This is appropriate, as research has indicated that geographically rare species occur together in centers of endemism (Fjeldså and Lovett, 1997). The tendency for restricted range species to be biologically rare (in population size), along with the tendency for cooccurrence of these species, allows for conservation efforts to target small areas that hold a disproportionate amount of the planet's biodiversity. This enables efficient conservation priorities to be set and implemented. Indeed, some research has shown that species 
richness and endemism are not necessarily correlated (Prendergast et al., 1993; but see Kerr, 1997). Further, these patterns are essential for determining the ecological and evolutionary processes that drive areas to hold large amounts of endemics. Knowledge of endemism in mammals, combined with other groups such as birds, can be used to evaluate areas that hold species, both known and unknown, that are found in small areas of the planet's land. Further research into the causes of endemism and the degree to which centers of endemism are congruent is necessary for effective conservation strategies, both on a global and regional scale. The coincidence of these areas for other major taxonomic groups, while certainly at least somewhat variable between groups, needs to be tested to see whether there are broadly applicable areas of endemism across groups. Identifying restricted range species, and the areas where they occur, is a necessary initial step towards directing conservation focus to a large proportion of the world's biodiversity. 


\section{References}

Adno, A., J. Camm, S. Polasky, and A. Solow. 1998. Species distributions, land values, and efficient conservation. Science 219:2126-2128.

Alcover, J. A., and M. McMinn. 1994. Predators of vertebrates on islands. Bioscience 44:12-18.

Alcover, J. A., A. Sans, and M. Palmer. 1998. The extent of extinctions of mammals on islands. Journal of Biogeography 25:913-918.

Anderson, S. 1994. Area and endemism. Quarterly Review of Biology 69:451-471.

Armesto, J. J., R. Rozzi, C. Smith-Ramirez, and M. T. K. Arroyo. 1998. Conservation targets in South American temperate forests. Science 282:1271-1272.

Averianov, A. O., A. V. Abramov, and A. N. Tikhonov. 2000. A new species of Nesolagus from Vietnam with osteological description. Contributions from the Zoological Institue, St. Peteresburg, 3:1-22.

Baquero, R. A., and J. L. Telleria. 2001. Species richness, rarity and endemicity of European mammals: a biogeographical approach. Biodiversity and Conservation 10:29-44

Brooks, T. 1998. Endemic Bird Areas of the World: Priorities for Biodiversity Conservation (Book Review). Condor 102:770-771.

Brown, J. H. 1984. On the relationship between abundance and distribution of species. The American Naturalist 124:255-279.

Ceballos, G., and J. H. Brown. 1995. Global patterns of mammalian diversity, endemism, and endangerment. Conservation Biology 9:559-568. 
Choate, J. R. 1970. Systematics and zoogeography of the Middle American shrews of the genus Cryptotis. University of Kansas Publ., Museum of Natural History 19:195317.

Clark, T.W. 1989. Conservation Biology of the Black-footed ferret, Mustela nigripes. Wildlife Preservation Trust International. Special scientific report No. 3.175 pages.

Cowling, R. M. and M. J. Samways. 1995. Endemism and biodiversity. In Global Biodiversity Assessment, V.H. Heywood (ed.). pp 174-191. Cambridge University Press, Cambridge, United Kingdom.

Dahl, Arthur Lyon. 1991. Island Directory. UNEP Regional Seas Directories and Bibliographies No. 35. UNEP, Nairobi (573 pp.)

Dannell, K., and B. Aava-Olsson. 2002. Endemic mammal genera: are they really unique? Journal of Biogeography 29:457-464.

Duellman, W. E. 1999. Patterns of Distributions of Amphibians: A Global Perspective. Johns Hopkins University Press, Baltimore, Maryland.

Fjeldså, J. and J. Lovett. 1997. Geographical patterns of old and young species in African forest biota: the significance of specific montane areas as evolutionary centers. Biodiversity and Conservation 6:325-346.

Frost, D. R. 2002. Amphibian Species of the World: an online reference. V2.21 (15 July 2002). Electronic database available at http://research.amnh.org/herpetology/amphibia/index.html. The American Museum of Natural History.

Fuentes, A. 1998. Current status and future viability for the Mentawai Primates. Primate 
Conservation 17:111-116.

Gaston, K. J. 1994a. Geographic range sizes and trajectories to extinction. Biodiversity Letters 2:163-170.

Gaston, K. J. 1994b. Rarity. Chapman and Hall, London.

Gaston, K. J. 1994c. Measuring geographic range sizes. Ecography 17:198-205.

Gaston, K. J., T. M. Blackburn, and J. H. Lawton. 1997. Interspecific abundance-range size relationships: an appraisal of mechanisms. Journal of Animal Ecology $66: 579-601$

Gaston, K. 1998a. Rarity as double jeopardy. Nature 394:229-230.

Gaston, K. J. 1998b. Species-range size distributions: products of speciation, extinction and transformation. Philosophical Transactions of the Royal Society of London B $353: 219-230$

Groves, C. P. 2001. Primate Taxonomy. Smithsonian Institution Press, Washington, DC. Hall, B. L., and R. E. Moreau. 1962. A study of the rare birds of Africa. Bulletin of the British Museum (Natural History) Zoology 8:313-378.

Harold, A. S., and R. D. Mooi. 1994. Areas of endemism: Definition and recognition criteria. Systematic Biology 43:261-266.

Heywood, V. H. 1995. Global Biodiversity Assessment. Cambridge University Press, Cambridge.

Hilton-Taylor, C. 2000. 2000 IUCN Red List of Threatened Species. IUCN, Gland, Switzerland.

Howard, P. C., P. Viskanic, T. R. B. Davenport, F. W. Kigenyi, M. Baltzer, C. J. 
Dickinson, J. S. Lwanga, R. A. Matthews, and A. Balmford. 1998.

Complementarity and the use of indicator groups for reserve selection in Uganda. Nature 394:472-475.

Hu, H. J., and Z. G. Jiang. 2002. Trial release of Père David's deer Elaphurus davidianus in the Dafeng Reserve, China. Oryx 36:196-199.

Hunt, RM, Jr., 1996. Biogeography of the Order Carnivora. in J. L. Gittleman, editor. Carnivore Behavior, Ecology, and Evolution, Volume 2. pp 485-541. Cornell University Press, Ithaca.

ICBP. 1992. Putting Biodiversity on the Map: Global Priorities for Conservation. ICBP, Cambridge.

Johnson, C. 1998. Species extinction and the relationship between distribution and abundance. Nature 394:272-274.

Kepler, C. M., and J. M. Scott. 1990. Notes on the distribution and behavior of the endangered Hawaiian hoary bat (Lasiurus cinereus semotus). 'Elepaio 50:59-64.

Kerr, J. T. 1997. Species richness, endemism, and the choice of areas for conservation. Conservation Biology 11:1094-1100.

King, C. M. 1990. The Handbook of New Zealand Mammals. Oxford University Press, Auckland.

Kruckeberg, A. R., and D. Rabinowitz. 1985. Biological aspects of endemism in higher plants. Annual Review of Ecology and Systematics 16:447-479.

Kunin, W. E., and K. J. Gaston (eds.). 1997. The Biology of Rarity. Causes and Consequences of Rare-Common Differences. Chapman and Hall, London. Lawton, J. H. 1993. Range, population abundance and conservation. Trends in Ecology 
and Evolution 8:409-413.

Mace, G. M., and A. Balmford. 2000. Patterns and processes in contemporary mammalian extinction. In Priorities for the Conservation of Mammalian Diversity: Has the Panda had its Day? Pages 27-52 in A. Entwistle and N. Dunstone, editors. Cambridge University Press, Cambridge.

Margules, C. R., and R. L. Pressey. 2000. Systematic conservation planning. Nature 405:243-253.

Maxwell, S., A. A. Burbidge, and K. Morris. 1996. The 1996 Action Plan for Australian Marsupials and Monotremes. Australasian Marsupial and Monotreme Specialist Group, IUCN Species Survival Commission, Gland, Switzerland.

Mittermeier, R. A., N. Myers, J. B. Thomsen, G. A. B. d. Fonseca, and S. Olivieri. 1998. Biodiversity hotspots and major tropical wilderness areas: Approaches to setting conservation priorities. Conservation Biology 12:516-520.

May, R. M. 1988. How many species are there on Earth? Science 241:1441-1449.

May, R. M., J. H. Lawton, and N. E. Stork. 1995. Assessing extinction rates. in J. H. Lawton and R. M. May, editors. Extinction Rates. Oxford University Press, Oxford.

Myers, N., R. A. Mittermeier, C. G. Mittermeier, G. A. B. d. Fonseca, and J. Kent. 2000. Biodiversity hotspots for conservation priorities. Nature 403:853-858.

Nelson, B. W., C. A. C. Ferreira, M. F. da Silva, and M. L. Kawasaki. 1990. Endemism centers, refugia and botanical collection density in Brazilian Amazonia. Nature 345:714-716.

Nicoll, M. E., G. B. Rathbun, and the IUCN/SSC Insectivore, Tree-Shrew and Elephant- 
Shrew Specialist Group. 1990. Insectivora and Elephant-Shrews. An Action Plan for their Conservation. IUCN, Gland, Switzerland.

Nowak, R. M. 1999. Walker's Mammals of the World, 6th Ed. Johns Hopkins University Press, Baltimore.

Patterson, B. D. 2001. Fathoming tropical biodiversity: the continuing discovery of Neotropical mammals. Diversity and Distributions 7:191-196.

Peterson, A. T. and D. M. Watson. 1998. Problems with areal definitions of endemism: the effects of spatial scaling. Diversity and Distributions 4:189-194.

Pimm, S. L., G. J. Russell, J. L. Gittleman, and T. M. Brooks. 1995. The future of biodiversity. Science 269:347-350.

Prendergast, J. R., R. M. Quinn, J. H. Lawton, B. C. Eversham, and D. W. Gibbons. 1993. Rare species, the coincidence of diversity hotspots and conservation strategies. Nature 365:335-337.

Rabinowitz, D. 1981. Seven forms of rarity. Pages 205-217 in H. Synge, editor. The Biological Aspects of Rare Plant Conservation. John Wiley and Sons, New York, NY.

Rabinowitz, D., S. Cairns, and T. Dillon. 1986. Seven forms of rarity and their frequency in the flora of the British Isles. Pages 182-204 in M. Soule, editor. Conservation Biology: The Science of Scarcity and Diversity. Sinauer Associates, Sunderland, MA.

Rodriguez, A., and M. Delibes. 2003. Population fragmentation and extinction in the Iberian lynx. Biological Conservation 109:321-331.

Stattersfield, A.J., M.J. Crosby, A.J. Long, and D.C. Wege. 1998. Endemic Bird Areas of 
the World: Priorities for Biodiversity Conservation. BirdLife International, Cambridge.

Terborgh, J., and B. Winter. 1983. A method for siting parks and reserves with special reference to Colombia and Ecuador. Biological Conservation 27:45-58.

Terborgh, J. 1988. The big things that run the world: a sequel to E. O. Wilson. Conservation Biology 2:402-403.

Thirgood, S. J., and M. F. Heath. 1994. Global patterns of endemism and the conservation of biodiversity. Pages 207-227 in P. L. Forey, C. J. Humphries, and R. I. Vane-Wright, editors. Systematics and Conservation Evaluation. Clarendon Press, Oxford.

Williams, P. H. 1998. Key sites for conservation: area-selection methods for biodiversity. in G. M. Mace, A. Balmford, and J. Ginsberg, editors. Conservation in a Changing World. Cambridge University Press, Cambridge.

Williams, P. H., and K. J. Gaston. 1998. Biodiversity indicators: Graphical techniques, smoothing and searching for what makes relationships work. Ecography 21:559568.

Williams, P., D. Gibbons, C. Margules, A. Rebelo, C. Humphries, and R. Pressey. 1996. A comparison of richness hotspots, rarity hotspots, and complementary areas for conserving diversity of British birds. Conservation Biology 10:155-174.

Wilson, D. E., and D. M. Reeder. 1993. Mammal Species of the World. Smithsonian Institution Press, Washington. 
Wisely, S. M., D. B. McDonald, and S. W. Buskirk. 2003. Evaluation of the species survival plan and captive breeding program for the black-footed ferret. Zoo Biology 22:1-12. 


\begin{tabular}{|l|c|}
\cline { 2 - 2 } \multicolumn{1}{l|}{} & Number of species \\
\hline Species included in the analyses & 4740 \\
\hline $\begin{array}{l}\text { Domesticated or commensal species (including } \\
\text { Homo sapiens) }\end{array}$ & 13 \\
\hline Marine (Cetacea, Sirenia, marine Carnivora) & 121 \\
\hline Extinct & 103 \\
\hline Uncertain species ${ }^{1}$ & 58 \\
\hline \hline Total (all mammal species globally) & 5035 \\
\hline
\end{tabular}

${ }^{1}$ No range information available or uncertain taxonomic status

Table 1: Mammal species of the world. 


North America
Talamancan highlands
Veracruz Moist Forests*
Guatemala/Mexico border
Panama/Colombia border

South America

Ecuadoran Andes

Venzuelan Andes
Australia
Queensland
tropical
Eurasia
Western
Ghats
montane
forests
Peninsular
Malaysian
montane
forests*

Africa

rainforest* Albertine Rift Montane Forest*

Usambara Mountains

Kenyan highlands

Ethiopian highlands

Cameroon highlands

\author{
Islands \\ Taiwan \\ Sri Lanka \\ Eastern Madagascar \\ Java \\ Sulawesi \\ Northern Borneo \\ Central Honshu Highlands \\ Lesser Sundas \\ Palawan \\ Sumatran Highlands \\ Mentawai Islands \\ Mindinao \\ Luzon \\ Solomon Islands
}

Table 2: Geographic regions with high levels of endemism.

* Regional name taken from World Wildlife Fund Ecoregions. 


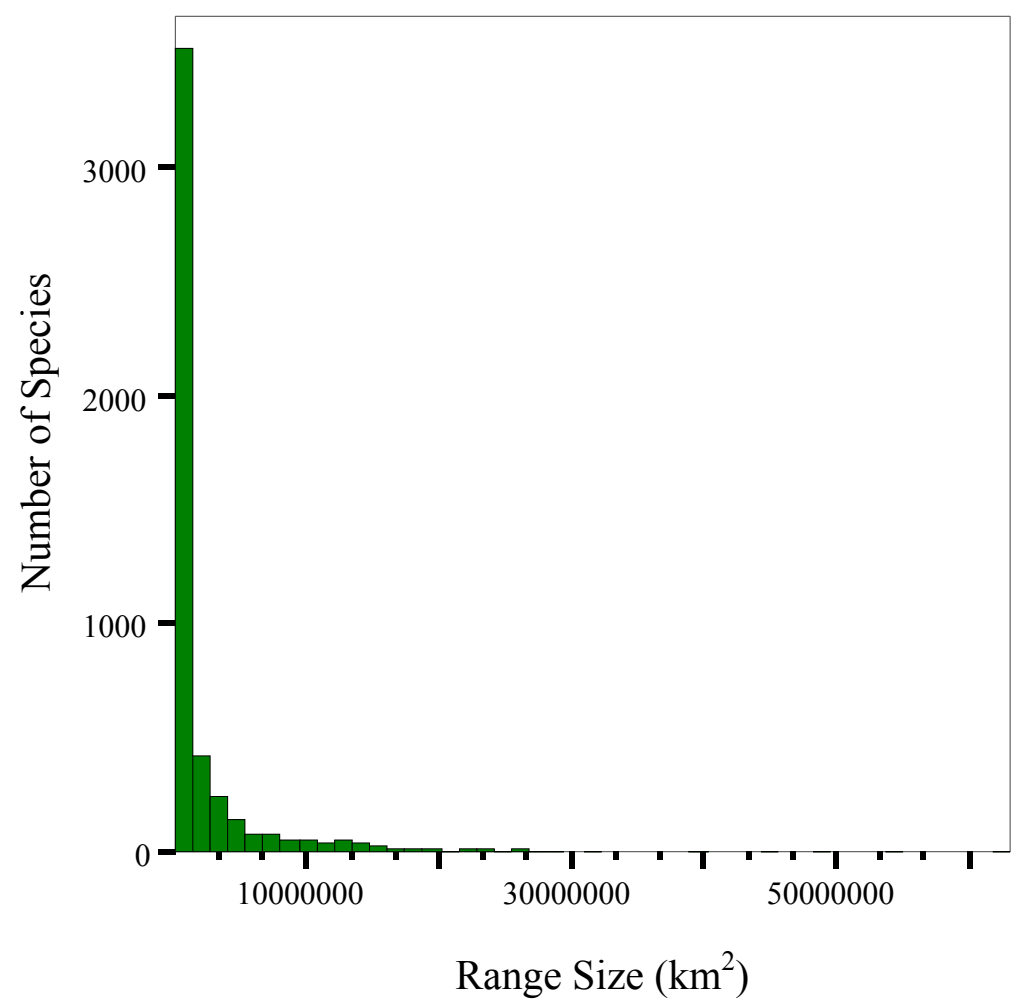

Figure 1a: The distribution of range sizes for all extant terrestrial mammal species.

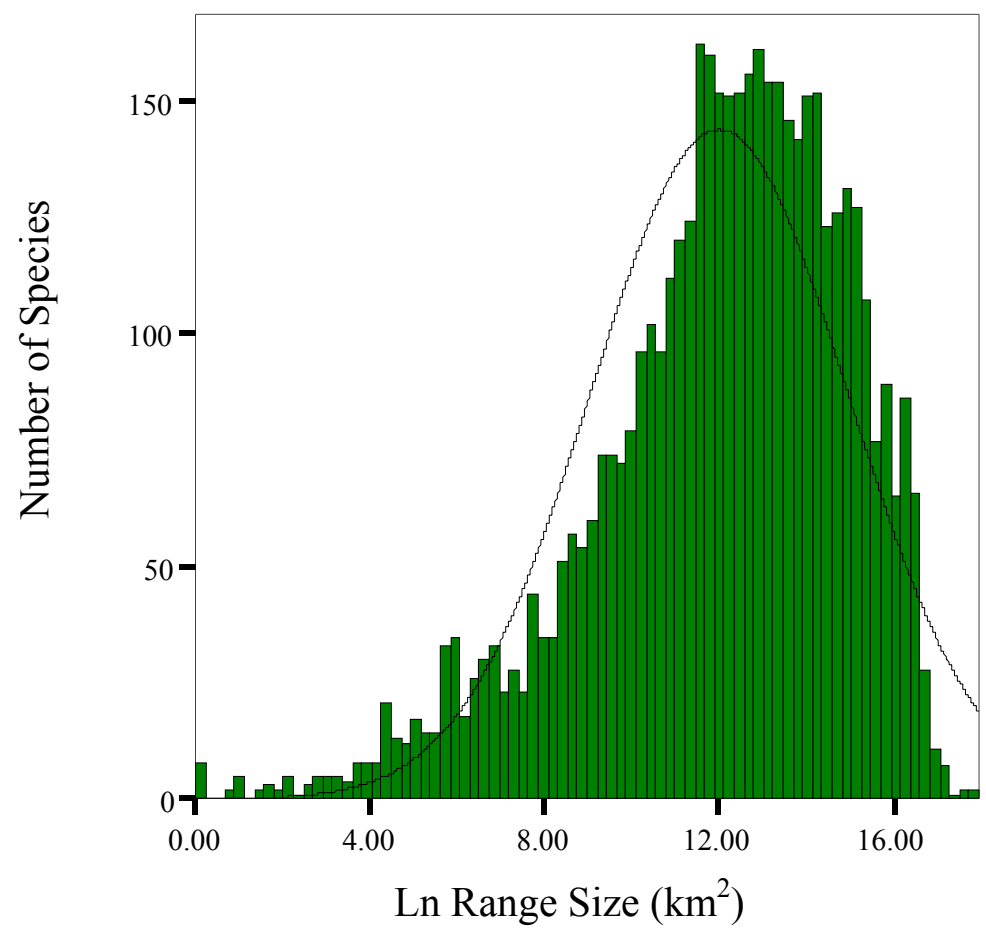

Figure 1b: The logarithmic distribution of range sizes for all extant terrestrial mammal species. 


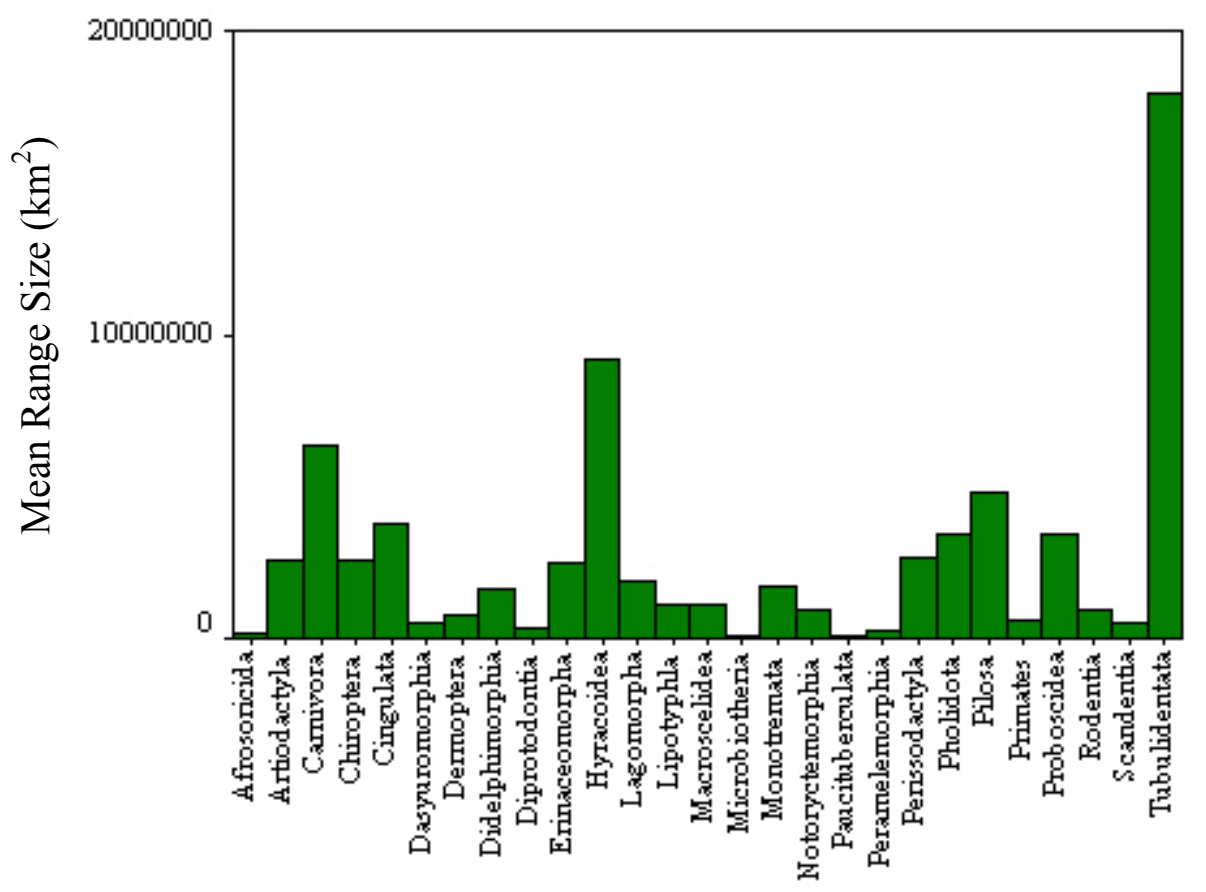

Order Name

Figure 1c: Mean range size distribution by order for all extant terrestrial mammals.

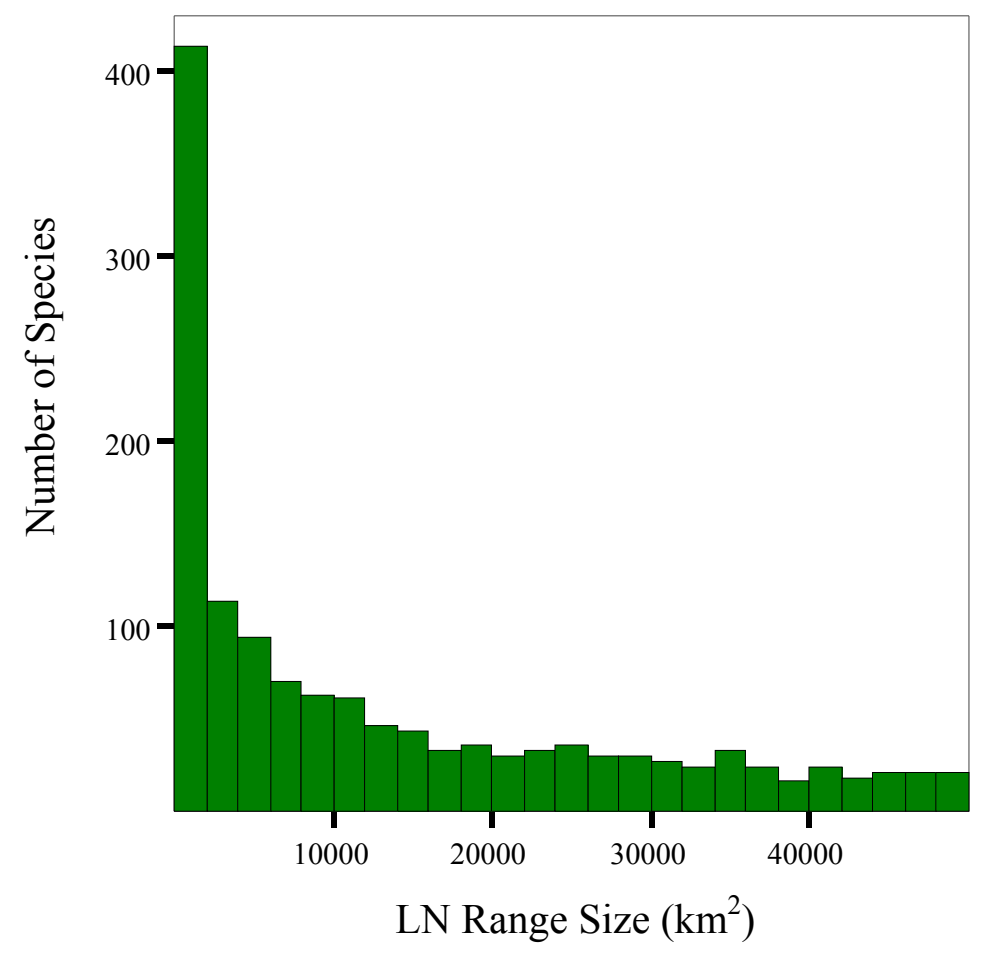

Figure 1d: The distribution of range sizes for all extant terrestrial mammal species with range size under $50,000 \mathrm{~km}^{2}$. 


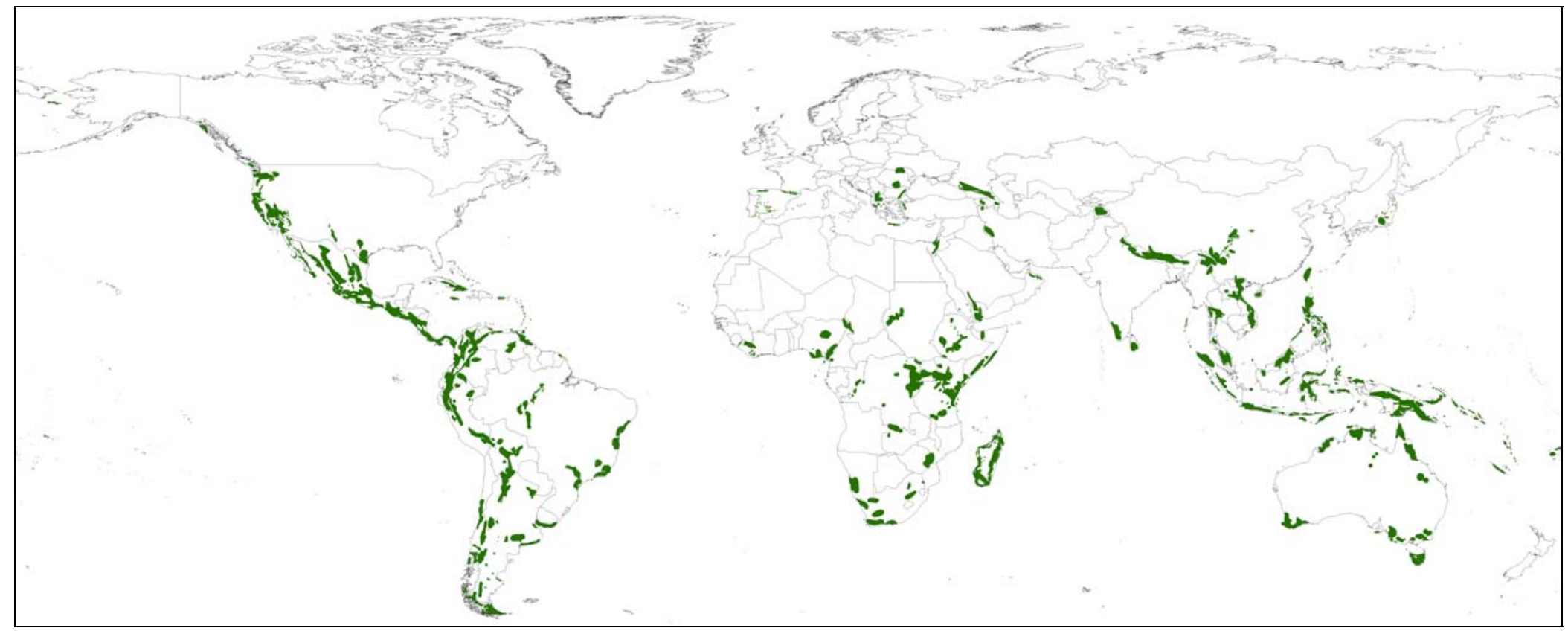

Figure 2: Endemic Mammal Areas of the World.

The classification of these areas follows Stattersfield et al. (1998). 


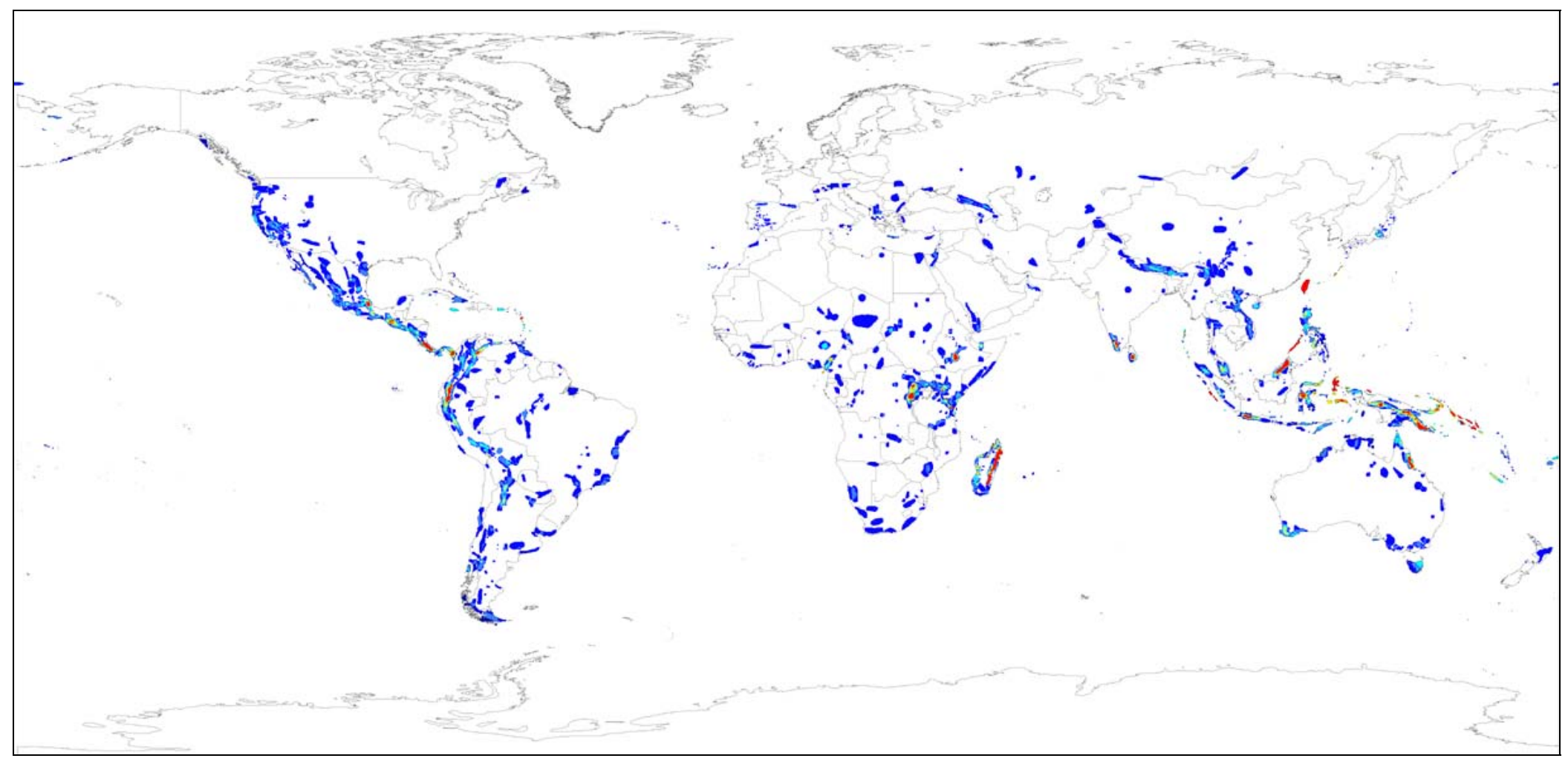

Figure 3a: Species richness of restricted range species (range size under 50,000 km²). $1369 \mathrm{spp}$

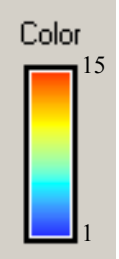




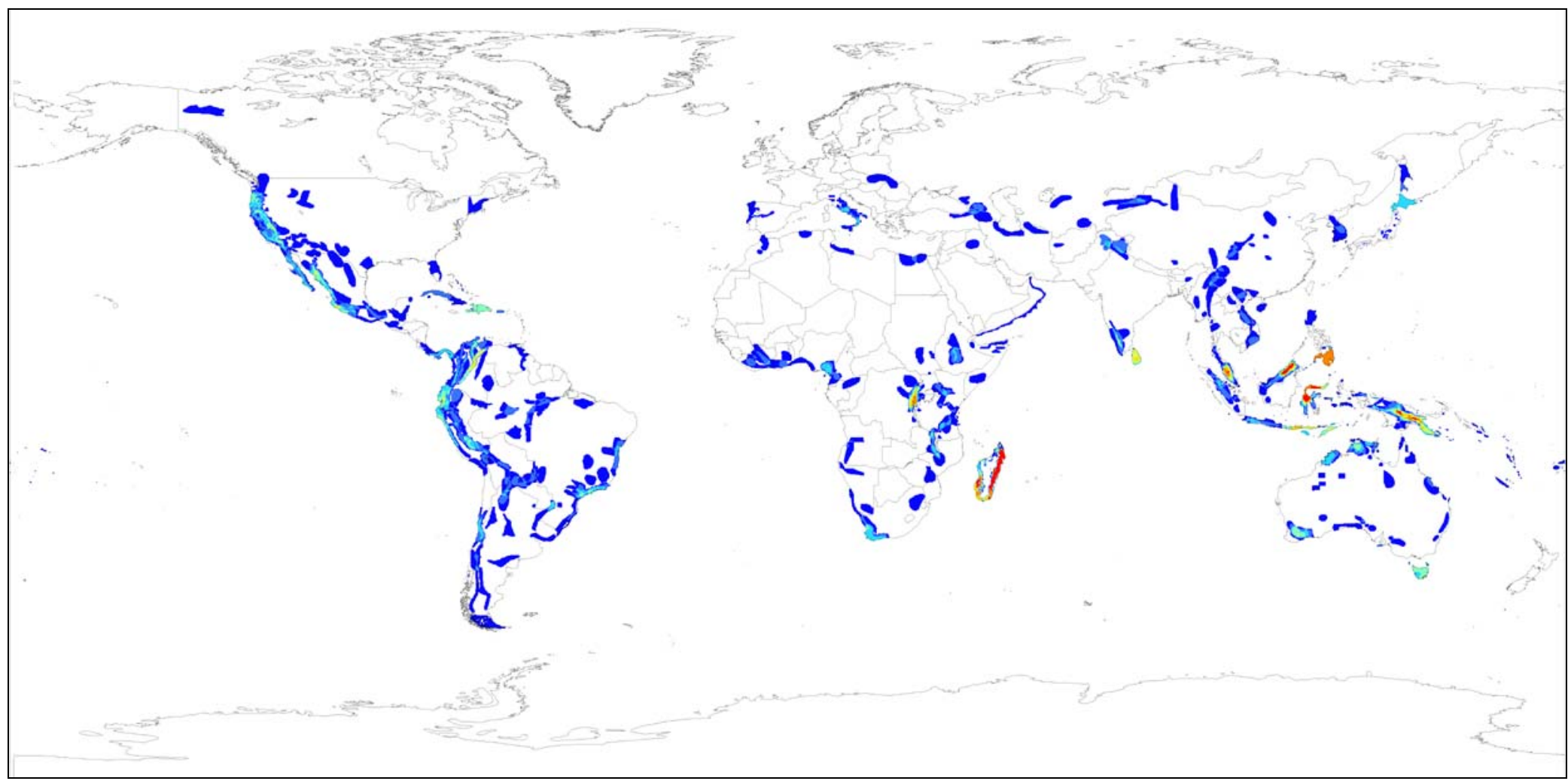

Figure 3b: Species richness of restricted range species (range size between 50,000 and 100,000 km²). $375 \mathrm{spp}$

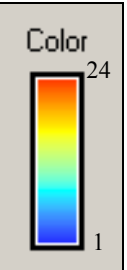




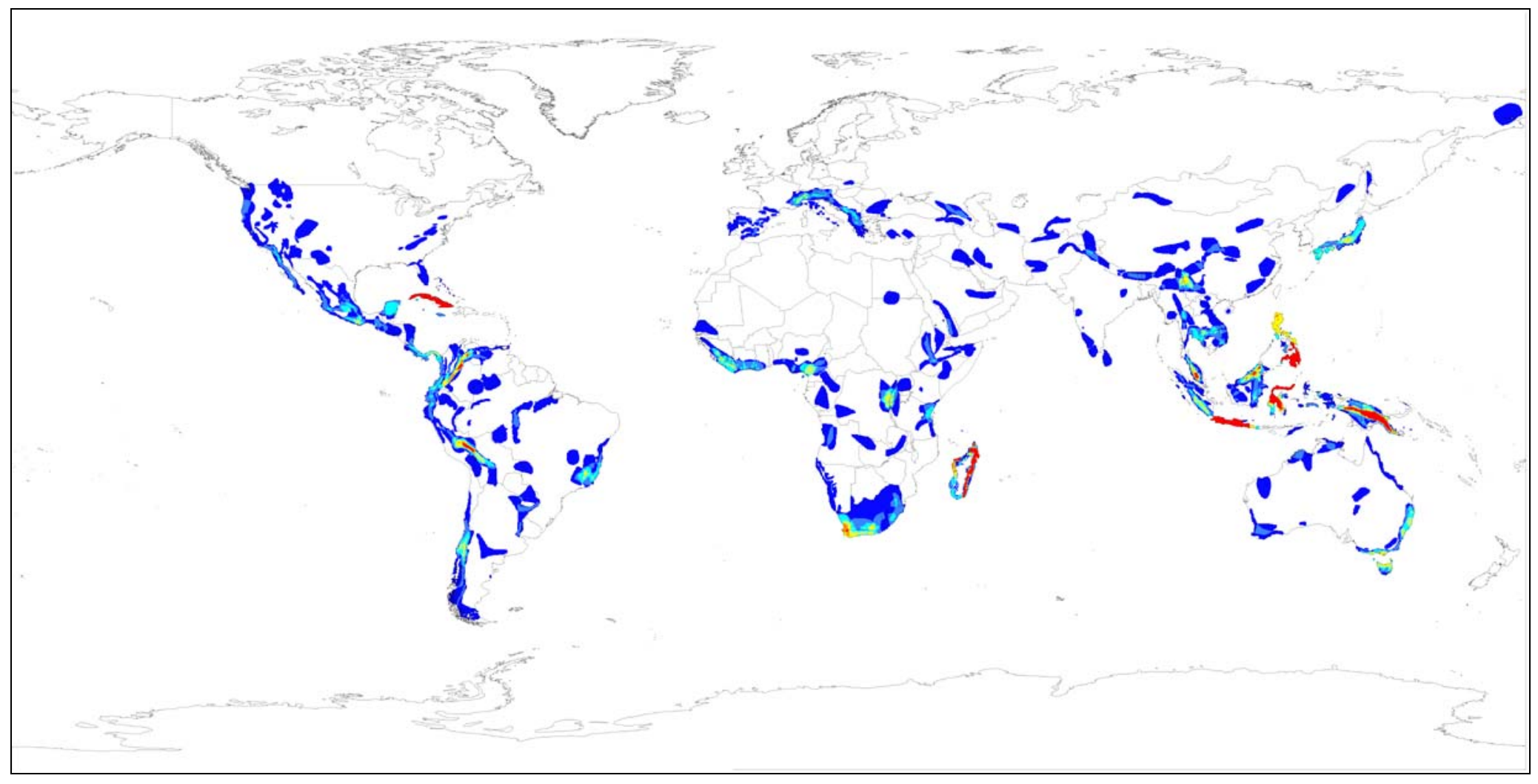

Figure 3c: Species richness of restricted range species (range size between 100,000 and 150,000 km²). 290 spp

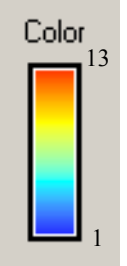




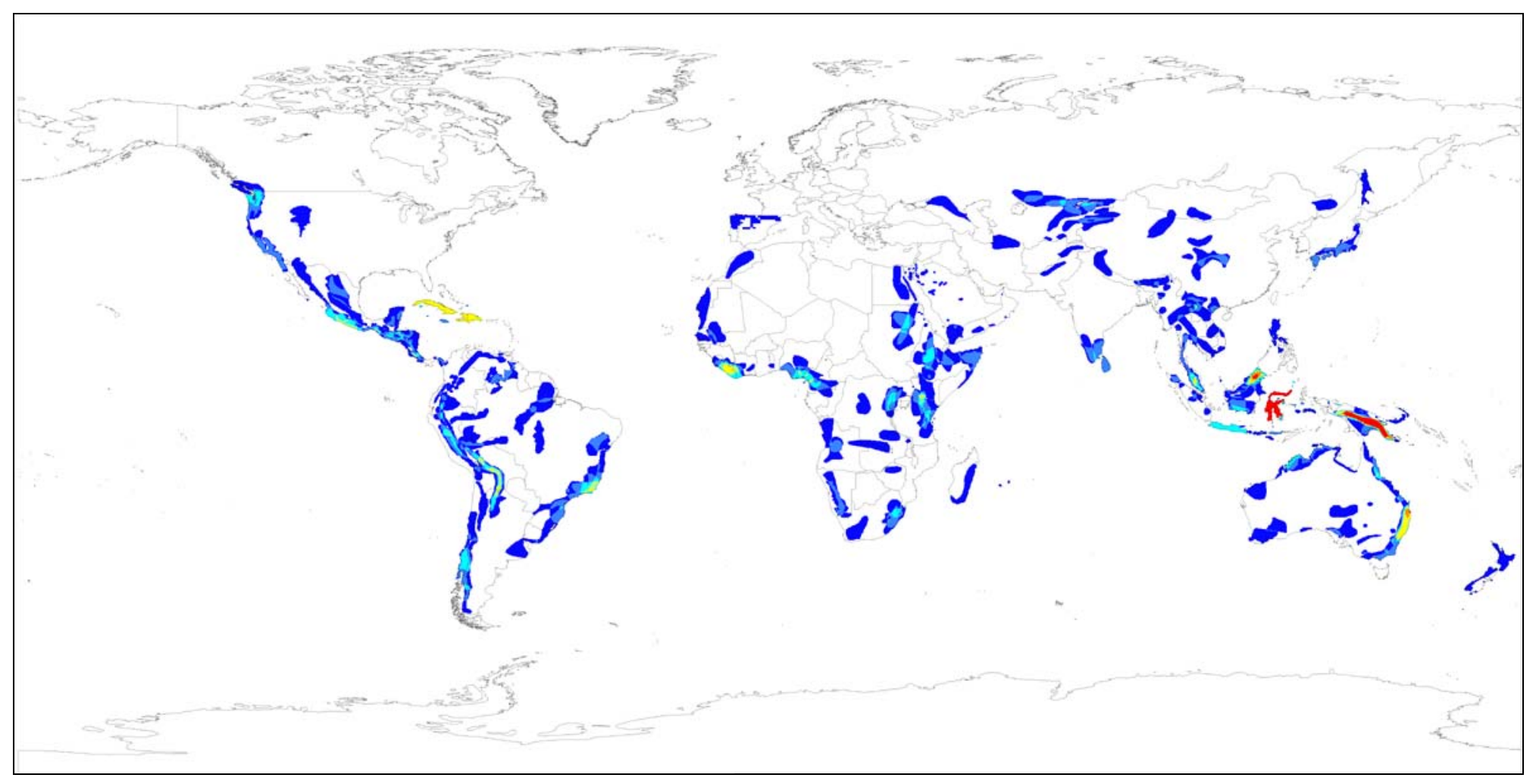

Figure 3d: Species richness of restricted range species (range size between 150,000 and 200,000 km²). $197 \mathrm{spp}$

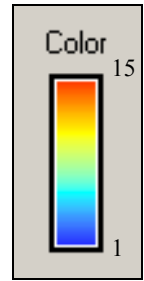




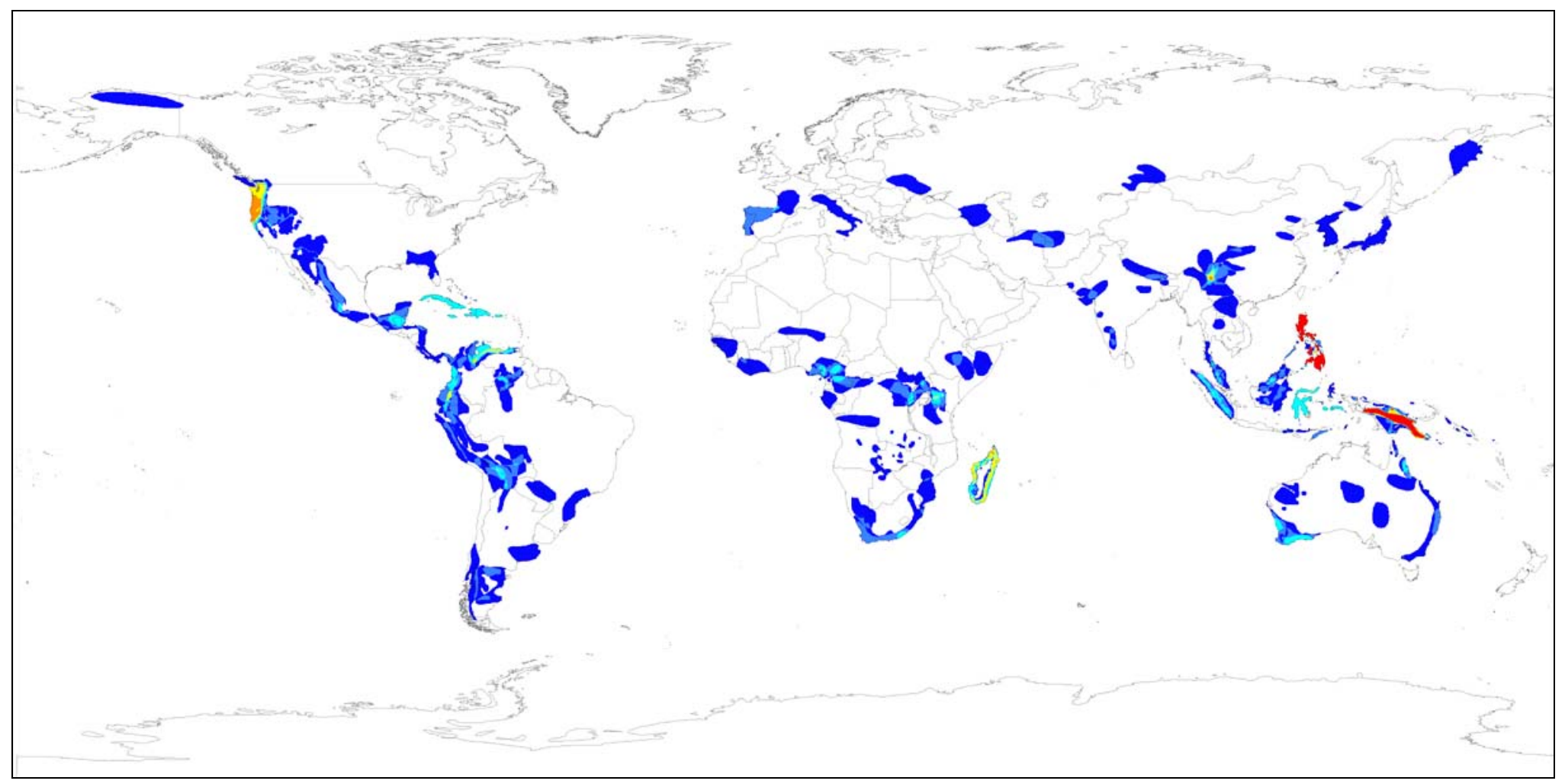

Figure 3e: Species richness of restricted range species (range size between 200,000 and 250,000 km²). 150 spp

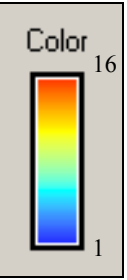




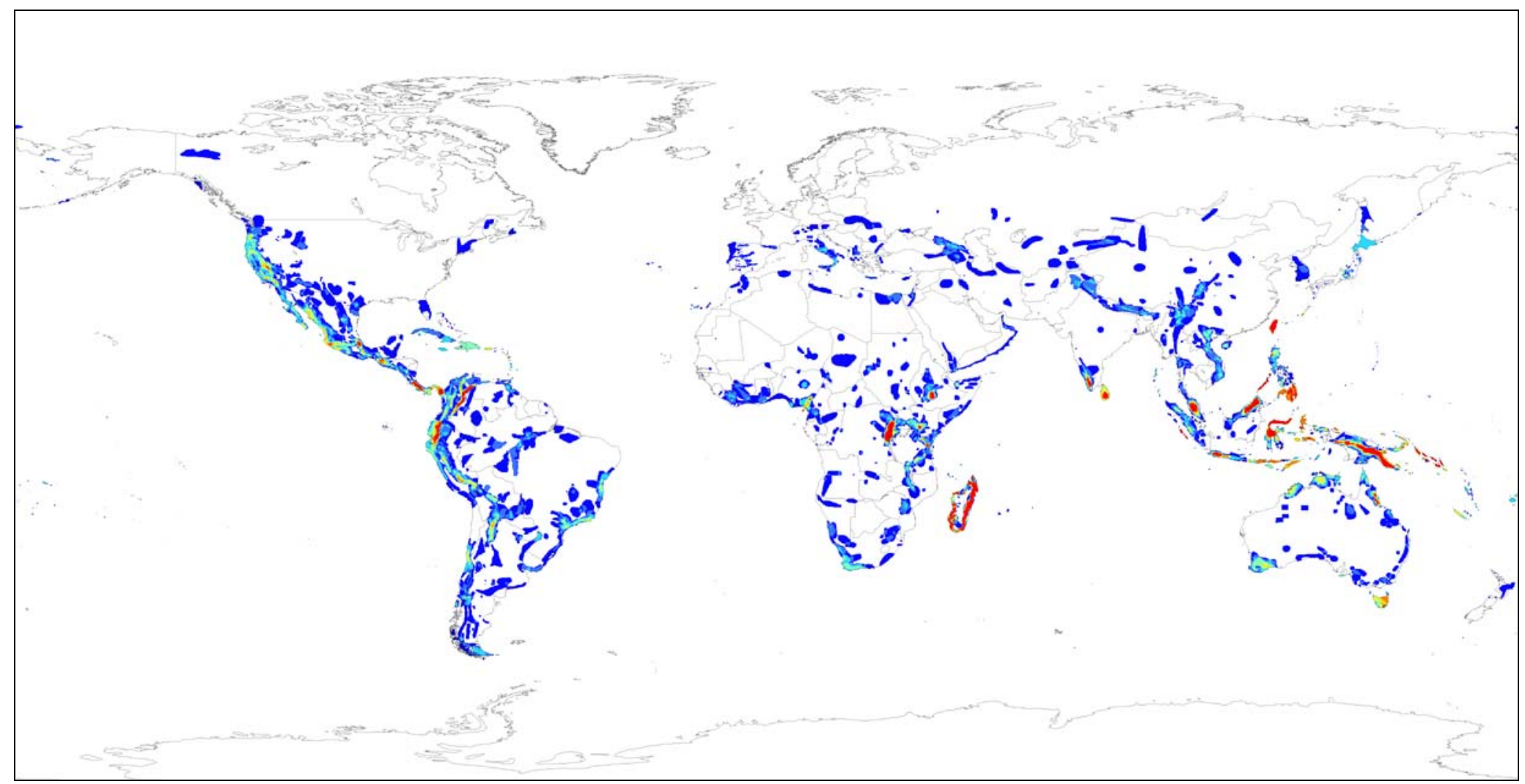

Figure 3f: Species richness of restricted range species (range size under 100,000 km²). $1744 \mathrm{spp}$

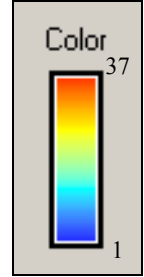




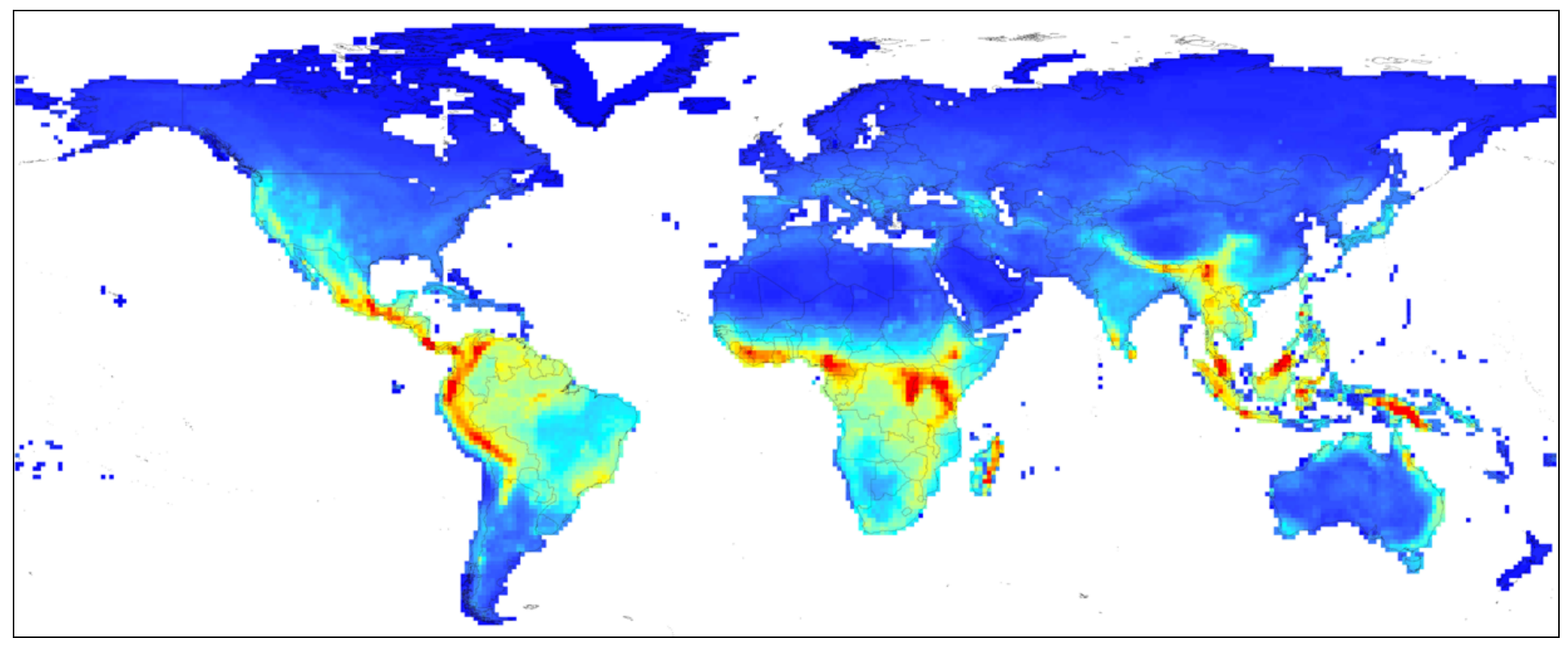

Figure 4a: Range size rarity of all mammals.

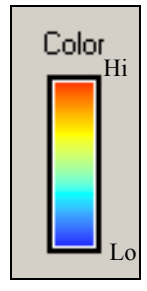




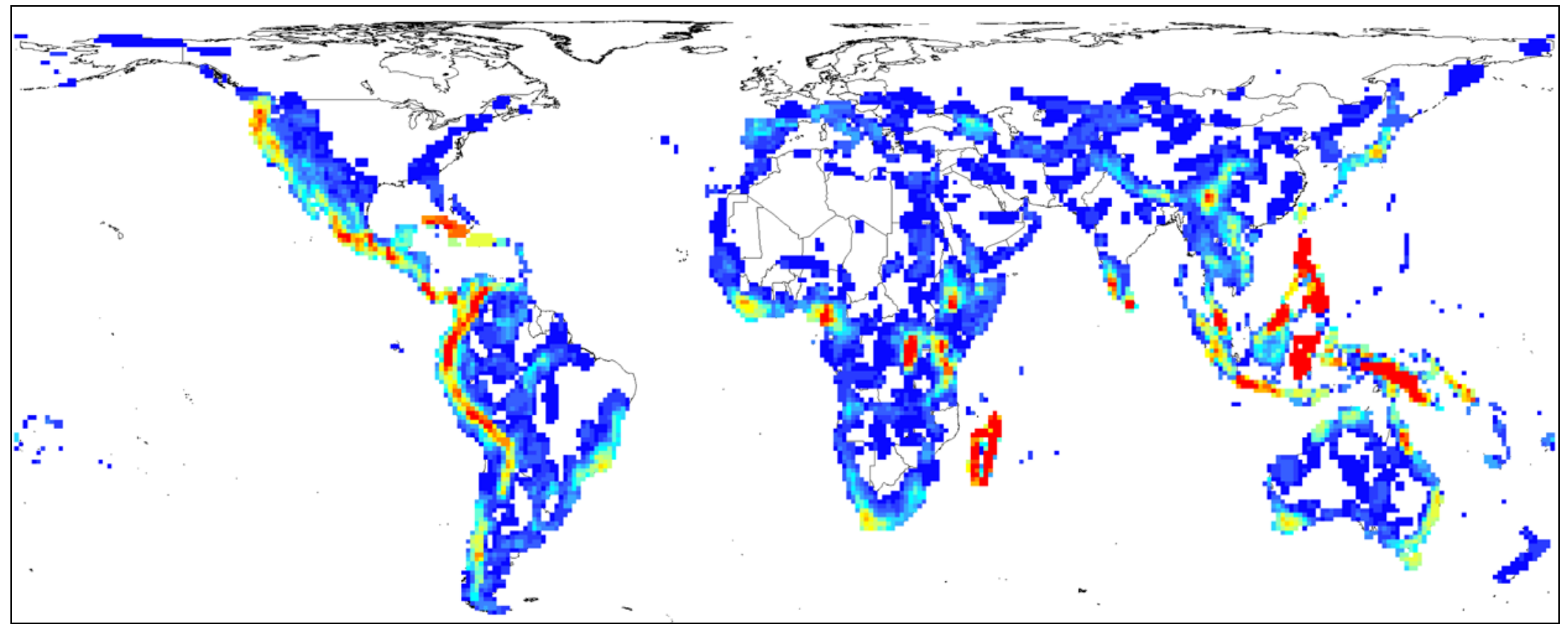

Figure 4b: Species richness of restricted range species (range size under 250,000 km²).

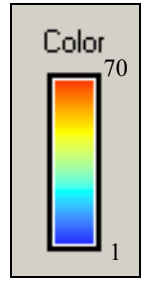




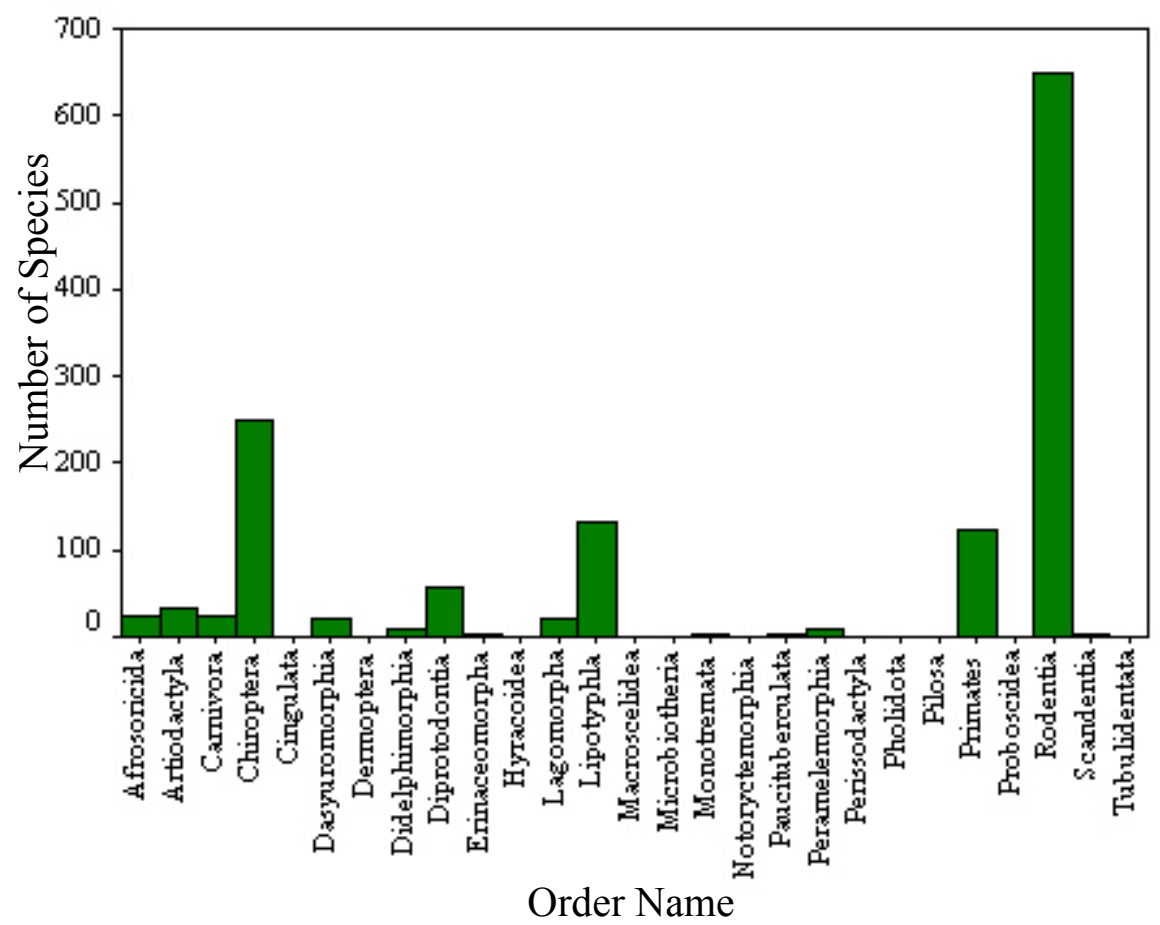

Figure 5a: Restricted range mammal species distribution by order (range $<50,000 \mathrm{~km}^{2}$ ).

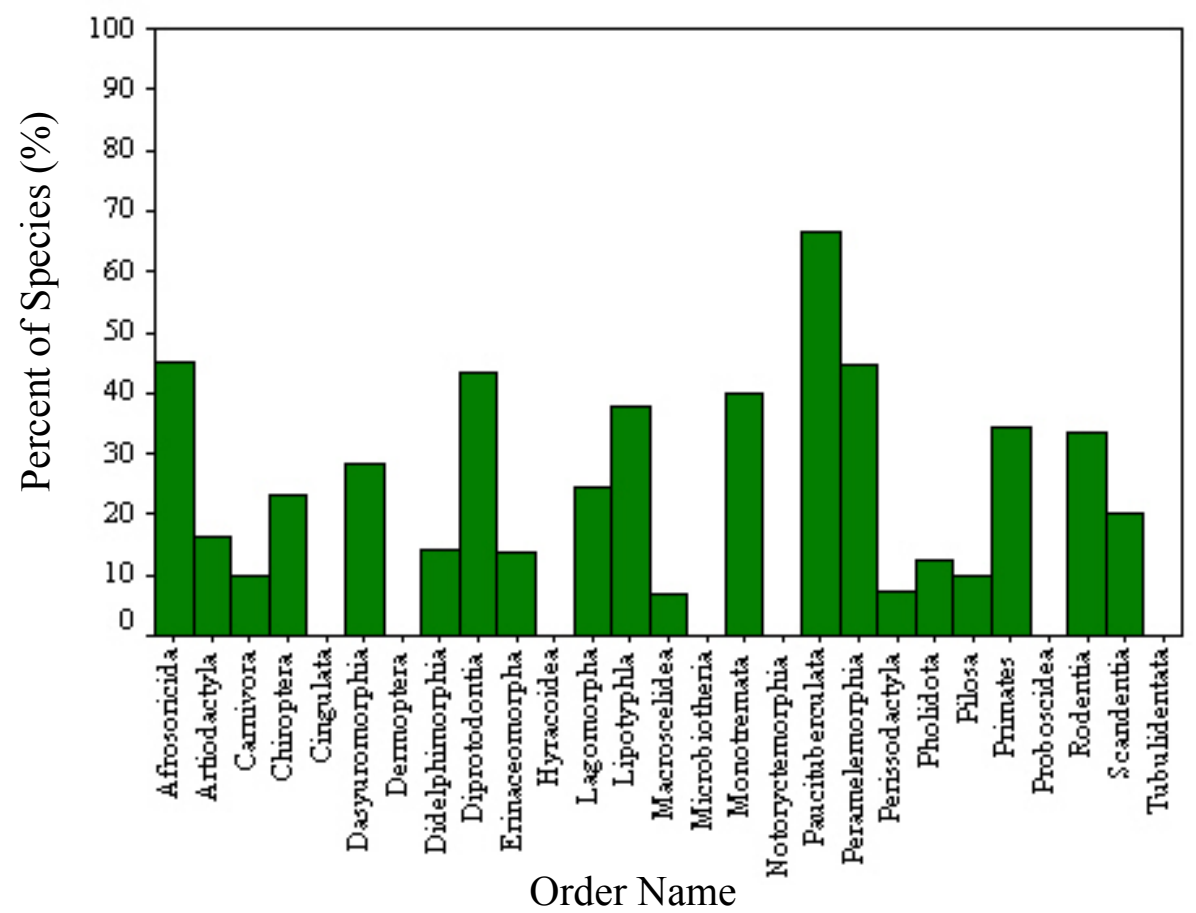

Figure 5b: Percent of restricted range mammal species by order $\left(\right.$ range $\left.<50,000 \mathrm{~km}^{2}\right)$. 


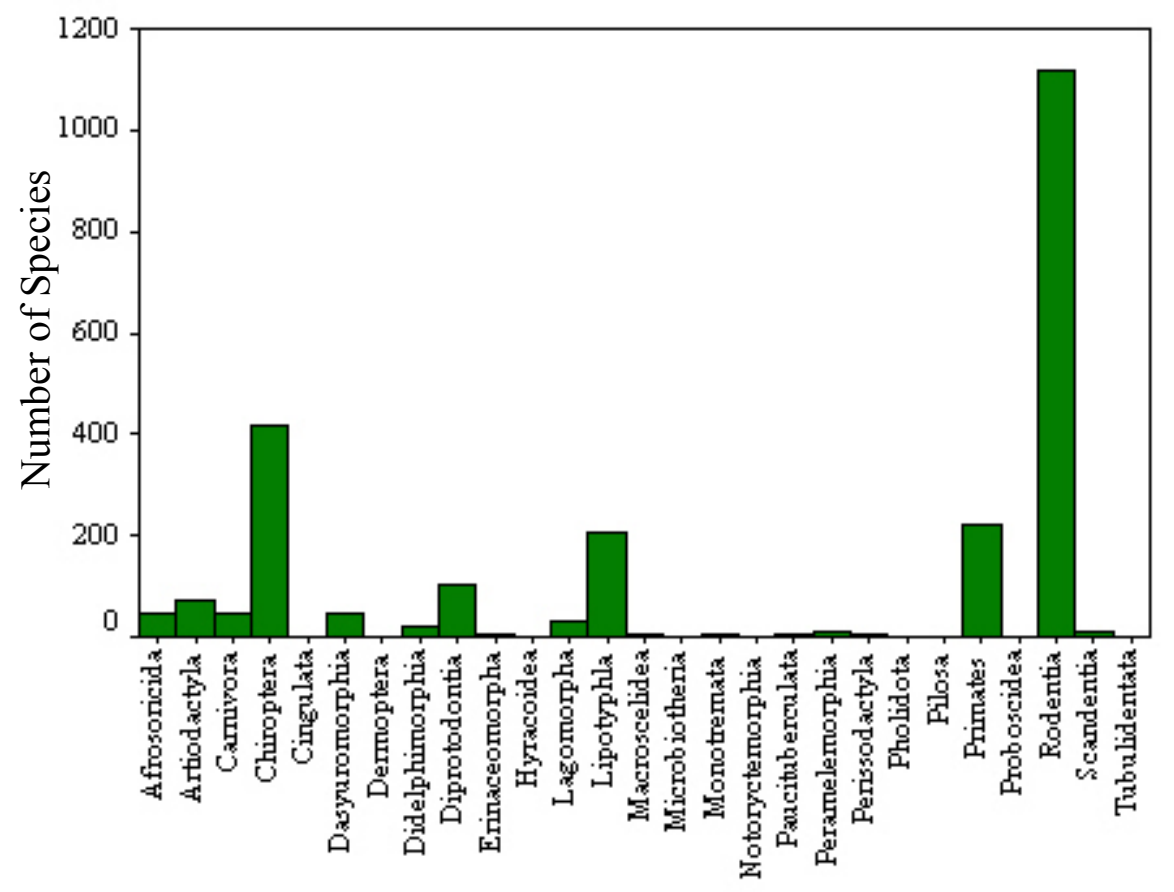

Order Name

Figure 6a: Mammal species distribution by order with less than the median range size (range $\left.<250,000 \mathrm{~km}^{2}\right)$.

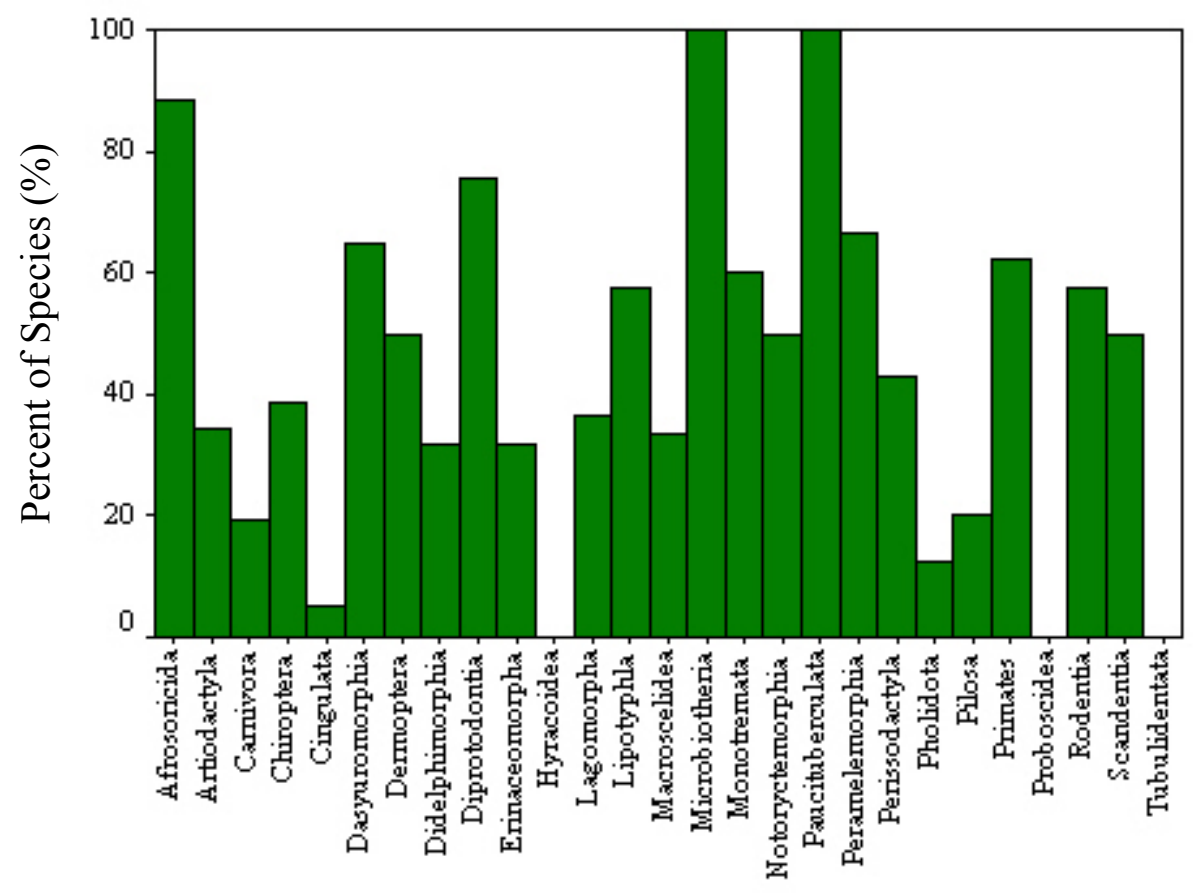

Order Name

Figure 6b: Percent mammal species by order with less than the median range size (range $<250,000 \mathrm{~km}^{2}$ ). 


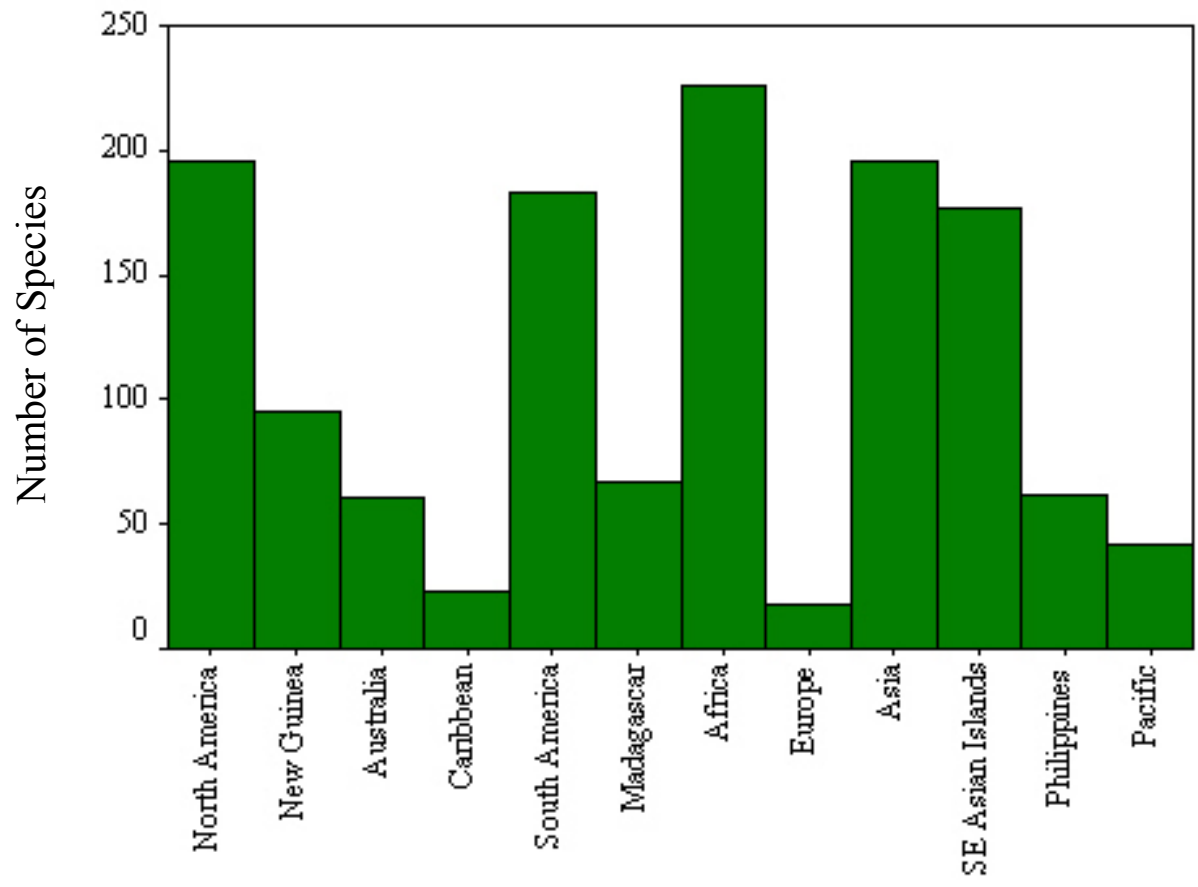

Order Name

Figure 7: Endemic mammal species distribution by geographic region (range < $\left.50,000 \mathrm{~km}^{2}\right)$.

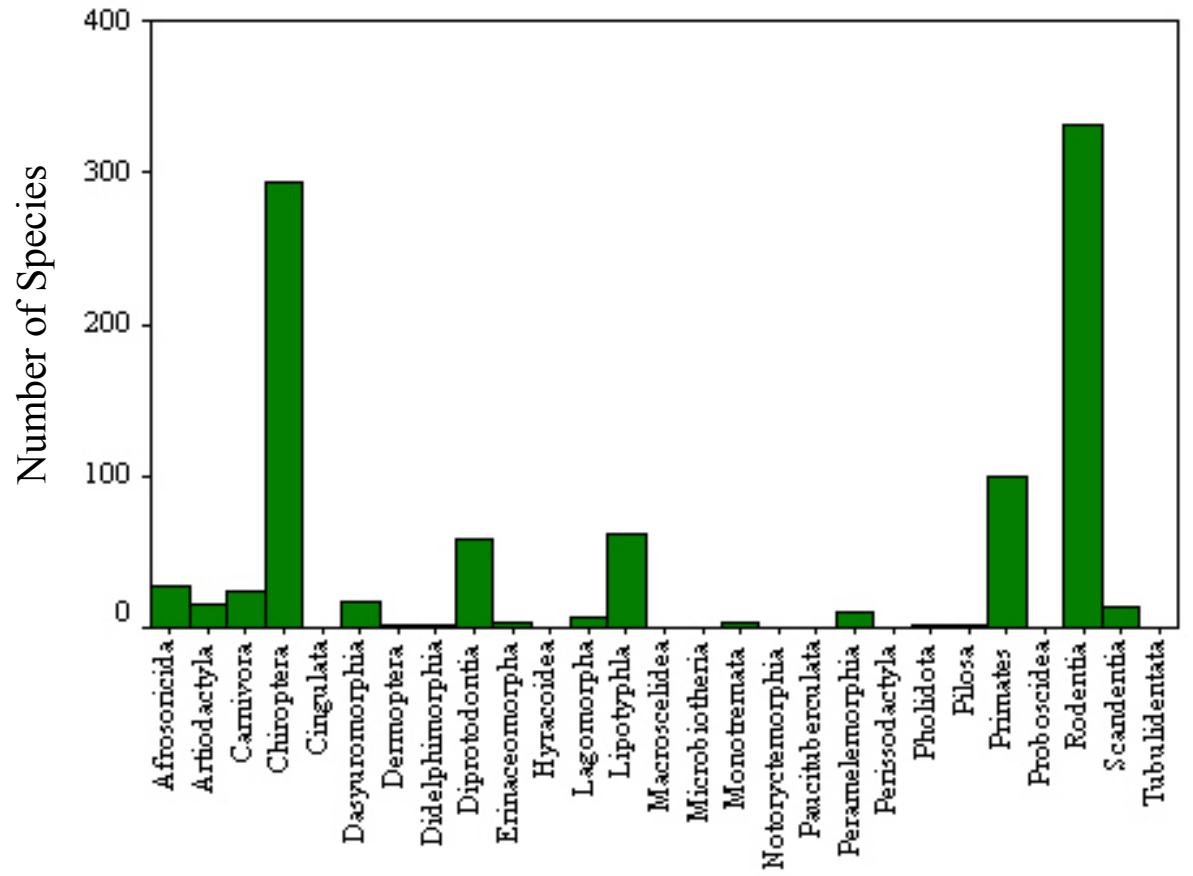

Order Name

Figure 8: Insular endemic mammal species distribution by order. 


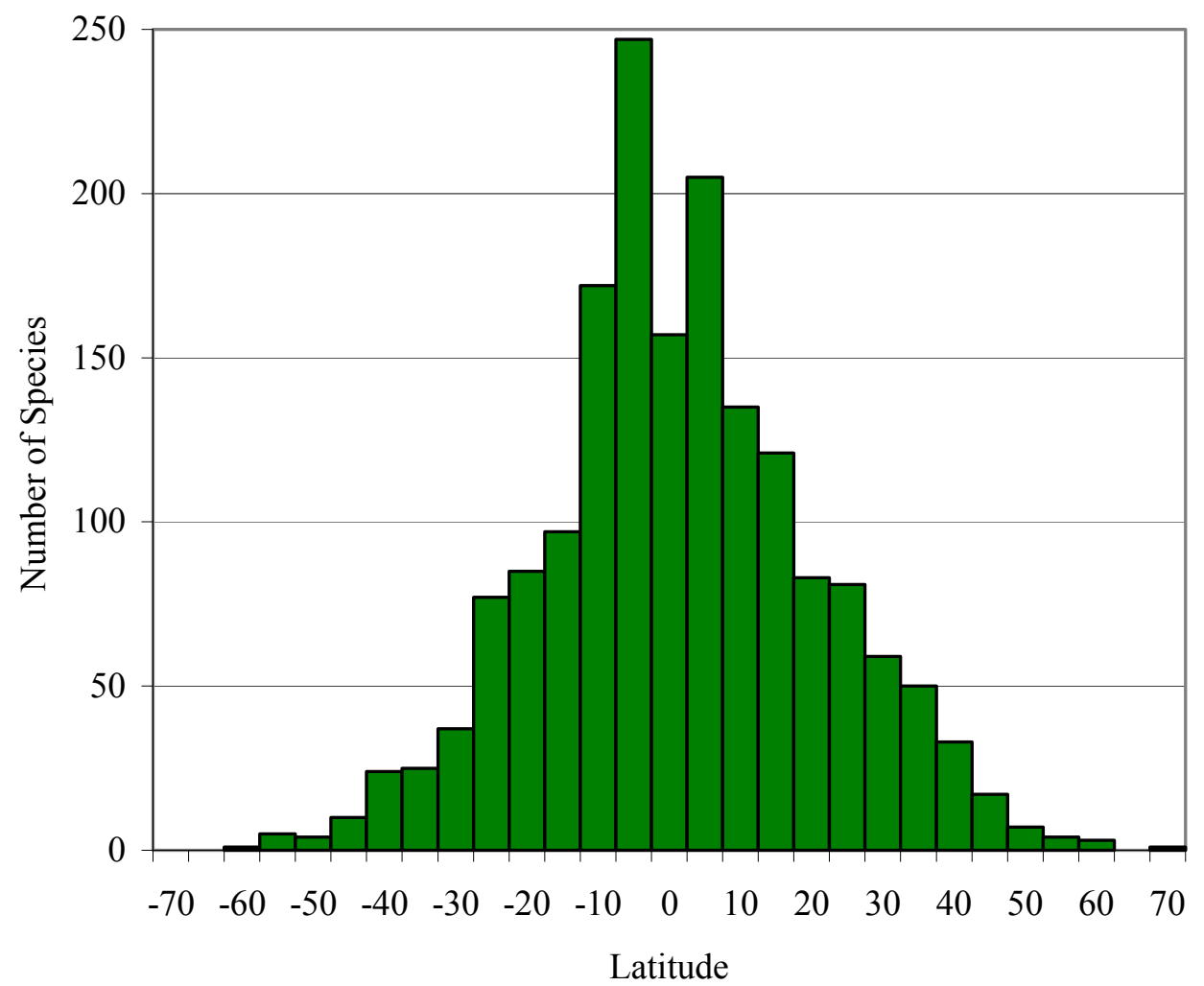

Figure 9: Number of species per 5 degree latitudinal band (range size $<50,000 \mathrm{~km}^{2}$ ). 


\section{Chapter 5}

\section{The Geography of Human Threats to Mammals}

\section{Introduction}

Certain ecosystems such as tropical rain forests and coral reefs are well known for containing a disproportionate amount of the world's biodiversity (Gaston, 2000; Myers et al., 2000; Roberts et al., 2002). Unfortunately, these areas also face greater than average human population pressures and habitat destruction (Balmford et al., 2002). This fact has raised concerns among scientists about the rate at which species are going extinct (Pimm et al., 2001). Efforts have been made to describe biodiversity rich areas, and document their species and associated threats (Myers et al., 2000). Results of these efforts have identified biodiversity hotspots, which have been shown to contain a high proportion of the world's threatened taxa, with $57 \%$ of all threatened terrestrial vertebrates as endemics (Brooks et al., 2002). Since there is a time lag in extinction events, many of the species that still survive are doomed unless the remaining habitat is protected and other land is restored (Brooks et al., 1999). Overall, recent extinction rates are from 100 to 1000 times (May et al., 1995; Pimm et al., 1995) and even possibly up to 10,000 times (May and Tregonning, 1998) the background rate. To mitigate threats, comprehensive information on the distribution of all threatened species is critical to their conservation, yet complete global data are only currently available for birds (BirdLife International, 2000).

Current extinction threats include first and foremost, habitat destruction, in addition to introduced species, exploitation, and some combination of anthropogenic 
climate change and pollution (Chapin et al., 2000; Sala et al., 2000; Walther et al., 2002). Human land-use has been a direct threat to biodiversity (Tilman et al., 2001), with the accompanied habitat loss being a primary driver of extinctions in many areas of the globe. The biodiversity hotspots, which have all lost over $70 \%$ of their original vegetation, stand to lose at least $18 \%$ of their species even if all remaining habitat is conserved based on species-area relationships (Pimm and Raven, 2000). However, if deforestation rates continue, over $40 \%$ of the species will be eventually lost $(20 \%$ in the next 50 years), though this is an underestimate as it does not account for other factors such as exploitation, introduced species, and global climate change (Pimm and Raven, 2000). In addition to intensive human land-use, biodiversity hotspots contain high human population densities (Cincotta et al., 2000), which can serve as a surrogate for human impact, although threats do not necessarily scale directly with human densities, and may be very different across regions. Liu et al. (2003) also show that the number of households, over and above human numbers, is significantly greater in hotspots, thus suggesting that the link of exploitation affecting biodiversity is considerable. Further, these estimates do not account for further impacts, including exploitation, introduced species, and global climate change, for which global data either do not exist or are still being refined. Despite recent improvements in technology and information, anthropogenic factors are only now being included in regional and global biodiversity analyses.

Present mammalian diversity, although impressive, is incomparable to the diversity exhibited in most terrestrial biomes prior to modern human colonization. Indeed, greater than two-thirds of mammals and other megafauna greater than $44 \mathrm{~kg}$ 
mean body weight were lost during the last 40,000 years, an extinction process linked with modern human colonization (Martin and Steadman, 1999; Flannery, 1999). Recent research implicates humans, most likely through overkill or possibly other mechanisms, such as environmental modification, as agents of megafaunal extinctions in North America, New Zealand and Australia (Alroy, 2001; Holdaway and Jacomb, 2000; Miller et al., 1999; Roberts et al., 2001). Other extinctions occurred through relatively recent times, such as that of the last known surviving population of mammoths around 4,000 B. P. on Wrangel Island (Vartanyan et al., 1993) and the extinctions of giant lemurs, some larger than gorillas, and other large species on Madagascar over the last several thousand years (Dewer, 1997). These extinctions greatly reduced the diversity of mammals, and likely caused widespread ecological and environmental changes (Burchard, 1998). More recent, "historical" extinctions (since 1500 AD) have claimed at least 88 species of mammals, perhaps well over 100 if unverified extinctions are included (MacPhee and Flemming, 1999). Interestingly, none of the major natural climatic oscillations of the last several centuries, including the Little Ice Age, which caused decreased average temperatures for almost four centuries, have caused any documented mammalian or bird extinctions (MacPhee and Flemming, 1999). These previous climatic changes altered species distributions, as evidenced in reconstructions of past species distribution (Pielou,1991). Although prehistoric extinctions have been attributed to overhunting or disease transmission, historic extinctions have a variety of causes, including, for instance, introduced species, as well as overkill and habitat destruction. Historic extinctions overwhelmingly occurred on islands, accounting for over three-quarters of mammalian species losses since 1500 AD. This can be viewed as an extinction filter, 
where species in areas previously heavily altered by humans are less vulnerable than their extinct counterparts (Balmford, 1996). This could mean that the most threatened taxa are in areas that have experienced relatively recent human disturbance (McKinney, 1997).

The geographic ranges of many mammal species have decreased, particularly in the last century, due to anthropogenic factors such as hunting, habitat destruction, and introduction of exotic species (Channell and Lomolino, 2000). All known mammalian species have been evaluated by the Species Survival Commission (SSC) World Conservation Union (IUCN) in the IUCN Red List of Threatened Animals, which provides an updated analysis based on quantitative evaluation of extinction risk (Baillie and Groombridge, 1996; Hilton-Taylor, 2000; Hilton-Taylor, 2002). The Red List provides a global assessment of the threats to a species, and a critical framework for more detailed data collection and analyses. Recently, threat status was analyzed in New World passerine birds, which represent nearly a quarter of the total worldwide avian diversity. Accounting for range size, continental species are more vulnerable to extinction than island species (Manne et al., 1999). Lowland continental species have a relatively higher current vulnerability than island species, perhaps as a result of two factors: depletion of island bird fauna in past human-induced extinctions and the current existence of disproportionate human pressure on lowland species (Manne et al., 1999). Further evidence of biased island extinction includes prehistoric bird extinctions on tropical Pacific islands that are conservatively estimated to have reduced global avian diversity by greater than one-fifth (Steadman, 1995). An analysis of global patterns of IUCN threat across mammals found that $26.2 \%$ of species (excluding Data Deficient species) are threatened with extinction or recently became Extinct or Extinct in the Wild (Mace and 
Balmford, 2000). Island species were more threatened than continental species, presumably because of their relatively smaller geographic ranges and their historically lower exposure to anthropogenic threats. Also, Old World mammals are more threatened than New World mammals, most likely due to more original habitat left in the New World, or perhaps because more vulnerable species in the New World have previously succumbed to human pressure (Mace and Balmford, 2000). Here, I extend this research and provide an explicit spatial analysis to examine these patterns in endangerment across global mammals.

A global scale analysis of extinction risk in birds and mammals assessed the effects of human activity in different countries (Kerr and Currie, 1995). Correcting for land area, a significant correlation was found between human population density, birth rate and per capita GNP, and proportion of threatened birds and mammals within the countries with sufficient data (Kerr and Currie, 1995). An extension of this research on country level patterns across the tropics found that mammals were generally more threatened than birds (Kerr and Burkey, 2002). These studies have provided broad understanding of human factors, but there is a need for explicit spatial information to test hypotheses that are in themselves spatially oriented.

Here, I analyze current human threats to all mammal species. I use a comprehensive dataset on species distributions and IUCN threat status, combined with two direct measures of human impact, human population density and land-use (Repetto, 1994; Myers 1994; Hannah et al., 1995; Sanderson et al., 2002). Human population density and land-use intensity are hypothesized to be greater across the ranges of threatened species than unthreatened species. Furthermore, following on several studies 
that have examined patterns of richness in relation to human populations (Kerr and Burkey 2002; Balmford et al., 2001), areas rich in species are predicted to also have dense human populations. In addition, human population density, which is could be used as a surrogate for magnitude of human impact, is hypothesized to be higher in areas with the greatest number of threatened species. This study illustrates, for the first time, the distribution of human threats to the biodiversity of a large group of organisms, using a spatially explicit global dataset.

\section{Methods}

\section{Data}

\section{Taxonomic information}

Mammal species classification, as well as higher-level taxonomy for this analysis follows Mammal Species of the World, Second Edition (Wilson and Reeder, 1993). If available, mammal orders were revised using updated draft chapters of Mammal Species

of the World, Third Edition (D. Reeder and D. Wilson, pers. comm.). The total number of mammal species considered is 5,035 (this does not include 54 species removed in the Third Edition that were included in the Second Edition). In this study, I exclude any species that are extinct, as classified by the World Conservation Union (IUCN) (HiltonTaylor, 2002), as well as human commensals. Also excluded are 58 species that were described in the text of Mammal Species of the World and other expert sources as having serious taxonomic and distribution uncertainty. Since the focus is on human impacts to terrestrial systems, marine mammals (Cetacea, Sirenia and marine Carnivora) also were 
not used in the analyses (see Chapter 3). Therefore, the total number of mammal species under consideration is 4,740 species (see Chapter 2).

\section{Species' range data}

Species range information was compiled from published literature sources, including books, journal articles, government reports, and IUCN/SSC Action Plans (Chapter 3). Distribution information, including polygon range maps and point localities, was georeferenced and digitized into a geographic information system (GIS). For species known only from point localities, ranges were estimated using published information on ecology and habitat preferences. All species included a final polygon map of their geographic range, or extent of occurrence (EO). The range information used in this analysis included only known present range extents, and did not consider historical or prehistorical ranges. The combination of poor knowledge of species historical distributions, as well as the focus on current threats, precluded the use of these data.

The species database created for this analysis contains information on the spatial aspects of each species' range (Chapter 3). Broad regions are listed where each species occurs including the continents and several large island groupings (Madagascar, New Guinea, Southeast Asian islands, Caribbean islands). Additionally, species' island status is recorded, including whether the species occurs on islands, is found only on islands, is found only across one island group, or is confined to a single island.

All spatial analyses were conducted using the ESRI products ArcGIS and ArcView. The range size of each species was determined using its EO measured in the Behrmann equal-area projection. All grid-based calculations were performed using 
$100 \mathrm{~km}^{2}$ equal-area grids to minimize the effect of projections on area estimates (see Chapter 2).

\section{Threat data}

Species threat data were used from the 2002 Red List of Threatened Species, produced by the IUCN - The World Conservation Union's Species Survival Commission (SSC) (Hilton-Taylor, 2002). The Red List is a quantitative assessment based on relative risk of extinction. There are three categories of threat - Critically Endangered, Endangered and Vulnerable, each of which classifies a species extinction probability (Hilton-Taylor, 2002). The Red List also details information on species that are Data Deficient, Extinct, Extinct in the Wild, Lower Risk Near Threatened, Lower Risk Least Concern, and those that are Not Evaluated (Table 1, Figure 1). There are efforts underway to have a comprehensive assessment of all known species, but currently the only two groups covered fully are birds and mammals (Hilton-Taylor, 2002). This provides a unique opportunity to quantitativatively assess threat in relation to human impacts. The number of species in each threat category, and mean and median range sizes for each category are represented in Table 2.

\section{Human population data}

The Gridded Population of the World (GPW) data set, version 2, was used to obtain estimates of human population density (CEISIN et al., 2000). The dataset has both gridded population estimates and population growth rates for 1990 and 1995. For this analysis, the 1995 human population density data was used. There are some errors 
identified in the source for the human population density map, including the use of census data from irregular political boundaries, extrapolation of all densities to the year 1995, and general errors assumed with census data. This source provides the most comprehensive and uniform source for global human density, so was used as an indicator of human impact across all areas. The human population grid map was divided into 7 classes following the system employed by Cincotta et al. (2000) (Figure 2). There are many areas with relatively low human populations, but there are also a high proportion of areas with high human populations (Figure 3).

\section{Land-use data}

Human land-use data were used to evaluate areas of disturbance, obtained from the U.S. Geological Survey's (USGS) Earth Resources Observation System (EROS) Data Center. The dataset, the Global Land-Cover Characteristics Database (GLCC), is a 1-km resolution global land cover characteristics data base (Loveland et al., 2000), derived from 1-km Advanced Very High Resolution Radiometer (AVHRR) data spanning a 12month period (April 1992-March 1993). There are 22 classes of land cover (Figure 4 and 5), of which 5 are explicitly measured human land-uses; urban, dry cropland, irrigated cropland, cropland/grassland and cropland/woodland systems. These five land-uses were utilized in the analyses as the areas with high human land-use intensity. Although many of the other land classes certainly have some degree of human land-use impact, this cannot be quantified on a global scale and hence the other classes were not included in any of the analyses. 
Spatial analyses

Species were analyzed initially by classifying all species as threatened within the 3 classes of IUCN: CR, EN, and VU. Species that were DD, LRlc, and LRnt were excluded from the analyses. First, human population density was overlaid with richness maps of threatened species on a gridded equal-area map (Behrmann projection) with a resolution of $100 \mathrm{~km}^{2}$. Analysis of spatial neighbors was performed to use in a test of spatial autocorrelation using Moran's I . A spatial regression was performed comparing human population density (ln transformed) versus threatened species richness.

The second part of the analyses used individual species ranges, and calculated the values of human impact across each range. Human population density was summarized across the range of each species to use in the analyses. The percentage of each class of human population density within each species' range was used to compare threatened and non-threatened species.

Land use was also summarized using the five classes outlined previously. The amount of impacted land across each species' range was calculated. These measurements were used to compare threatened species with unthreatened species. Human population density was compared in areas classified as impacted and less-impacted.

\section{Results}

Human impacts and species richness

Analysis of spatial neighbors for a test of spatial autocorrelation using Moran's I indicated that the richness data (both all species and threatened species only), on this 
scale, were spatially autocorrelated $(\mathrm{p}<0.001)$. Thus spatial regression models were used in all of the analyses using species richness. The richness of all species of mammals was compared to human population density; there was a strong positive correlation $\left(\mathrm{R}^{2} 0.07, \mathrm{t}\right.$ $=31.32, \mathrm{p}<0.001$ ), although not much of the variation is explained (Figure 6). Species richness of all threatened species (CR, EN, and VU) was compared with human population density, with the resulting strong positive correlation $\left(\mathrm{R}^{2} 0.12, \mathrm{t}=42.46, \mathrm{p}<\right.$ 0.001), though high human population density did not predict much of the variation in threat. Human population density was significantly higher in impacted areas than in lower-impacted areas $(\mathrm{t}=54.51, \mathrm{p}<0.001)$.

A global density map of threatened species was made to analyze broad geographic patterns (Figure 7). The analysis of areas with high numbers of threatened species showed that impacted areas had a significantly higher number of threatened species $(\mathrm{t}=$ 17.27, $\mathrm{p}<0.001)$. Areas of human impact contain on average 6 species per grid cell, while lower-impacted areas contain on average 4.4 species per grid cell.

\section{Human impacts across individual species ranges}

The geographic range of each species was analyzed in relation to human population density and land-use. Both these measures were given proportional values for analytical purposes - results were output as percentage of each class within the range. The analysis showed significant differences of species' range covered by high human population densities comparing threatened and unlisted species (Figure 8). Species that were not listed exhibited higher percentages of their ranges covered by low human populations. In contrast, the percent of the range of threatened species increases up to a 
maximum at 15-50 people per square kilometer, after which it declines (ANOVA, all classes significant at the $\mathrm{p}<0.001$ level) comparing all threatened versus all nonthreatened. The analysis of human population density across the ranges of threatened species showed a significantly higher proportion of the four highest human population densities across their ranges as compared to unlisted species (Figure 8). Unlisted species have significantly more of their ranges within areas of lower human density ( 0 to 15 people per square kilometer), while threatened species have significantly more of their ranges within highly populated areas

Human land-use was used to analyze impact across species' ranges. The results indicate that threatened species show a greater human impact of habitat than those that are currently non-threatened (Figure 9). Overall, the amount of impacted habitat averaged $24.6 \%$ of the range for non-threatened species, and $28.6 \%$ of the range for all threatened species $(t=4.26, \mathrm{p}<0.001)$. Two classes are especially high for threatened species. Cropland/woodland mosaic habitats make up $7.8 \%$ of the land area of unlisted species, while these habitats comprise $10.3 \%$ of threatened species. Irrigated cropland and pasture comprise $5.7 \%$ and $4.1 \%$ of threatened and unthreatened species' ranges, respectively.

\section{Discussion}

The current distributions of mammals have been widely affected by anthropogenic factors, through prehistorical times to the recent past, and into the present. The existence of both comprehensive spatial distribution data across mammal species, along with comprehensive quantitative threat assessments, allows broad analyses of 
human impacts to threatened species. Here, human population density and land-use were used as indicators of anthropogenic effect. Among geographic areas containing high human population densities and or land use intensity, there are hypothesized to be a corresponding high proportion of threatened taxa. There have been many studies linking various human activities to threatened status (Dobson et al., 1997; Kerr and Burkey, 2002), however there have been few comprehensive global studies that have examined spatial components of threat.

The global map of threatened species shows patterns that were broadly realized in the literature (Ceballos and Brown, 1995; Mace and Balmford, 2000). However, this analysis greatly extends upon these country level analyses to link biogeographic species data to spatial components of human threats. The tropics, which hold by far the greatest overall species numbers (Chapter 3) and restricted range species (Chapter 4), also contain some of the areas most heavily impacted by humans. Southeast Asia, with its high diversity of species across both large and small bodied groups, is the most heavily impacted in terms of absolute numbers of threatened species. Other heavily impacted areas include the Atlantic Forest of Brazil, the Andes from Bolivia through Venezuela, the highlands of east Africa, the west African rainforest, and many diverse island systems such as the Greater Sundas (Figure 2 and 7).

The United States and Canada, and Australia are surprisingly devoid of threatened species. These areas are heavily impacted, mostly through habitat loss in the former, through introduced species in the latter. Species have decreased in range in Australia in recent times (Strahan, 1995), and these patterns of range loss are, of course, not revealed by this analysis of current ranges. Similar large losses in ranges have occurred in North 
America, affecting almost all large bodied species, such as Wolves (Canis lupus), Cougars (Puma concolor), and Bison (Bison bison), as well as smaller species such as American Marten (Martes americana) and the New England Cottontail (Sylvilagus transitionalis) in North America (Chapman and Flux, 1990; Nowell and Jackson, 1996; Wilson and Ruff, 1999). This is of critical importance to maintenance of biological diversity, as any loss of population or genetic diversity can be translated to a loss of biological diversity (Hughes et al. 1997). This can be more drastic for some species that play critical roles in their native ecosystems, for example large herbivores and carnivores that are lost over much of their ranges, with a corresponding cascade of negative effects on areas that have sustained losses (Terborgh et al., 2001). However, it is important to note that these data which are not available for most mammal species, and the skewed representation of species from certain areas (i.e. Australia and the United States) and certain groups (e.g. Carnivora and Artiodactyla), preclude their inclusion in a global analysis. One study that attempted to map this globally shows a biased geographical pattern in range losses, and hence does not accurately map either current threats or actual range losses (Ceballos and Ehrlich, 2002). If data on range losses are available and accurate for individual species, then this information can be used to estimate areas and mechanisms behind the range loss for the species in question. However, a global comparative analysis across all mammals cannot be accomplished using range losses, as these data are not presently available. There remains a strong need to link current patterns of threat across taxonomic groups, as I have outlined here, with recent historical and prehistorical patterns. 
Mammal species show a great degree of variation in the amount of their distributions that contain high human populations and large amounts of human altered land. Examining the spread of these measures of human impact across species ranges reveals several broad patterns. Areas of exceptionally high human populations, such as China and India, tend to also contain high proportions of threatened species (Figure 2 and 7). While the number of humans in an area does not necessarily correspond directly to impacts on natural areas, and hence species, all else being equal, more humans mean a greater magnitude and rate of impact. There is evidence that human population size is a critical factor. For example, in six West African reserves, the human population density along with the size of the reserve accounted for $98 \%$ of the variation in extinction rates among 41 species of large mammals (Brashares et al., 2001). In addition, human land-use can provide an important assessment of threat status. Many areas have undergone extensive transformations for cropland and rangeland, although they hold relatively low human populations. Intensive agriculture and areas with high deforestation are a major threat to most species (Tilman et al., 2001), which rely on intact natural habitat for shortterm and long-term persistence.

Human land use, as characterized by the GLCC, correlates across threatened species ranges. Species that are listed as threatened by the IUCN show higher proportions of their ranges covering areas of high human impact (Figure 9). The total proportion of impacted land across species' ranges is significantly higher for all threatened versus unlisted species $(\mathrm{t}=4.26, \mathrm{p}<0.001)$. While the difference is only around $4 \%$ of the area covered by human land-use, this was found to be significantly different across the almost 5,000 species analyzed, which have vast differences in biology, ecology, as well as range 
size and location. There are interesting differences among impacted land classes, with threatened species' ranges containing higher proportions of both irrigated cropland and cropland/woodland classes, with equivocal amounts cropland/grassland and dry cropland. Much of this can be attributed to the higher amount of the former two classes in tropical regions, which hold high amounts of threatened species. These amounts are necessarily an underestimation, as many threatened species have already been lost from those areas that have extremely high human impact, such as the case with many threatened species on the island of Madagascar, which has been denuded of the vast majority of its native vegetation (Goodman and Patterson, 1997; Garbutt et al., 1999). This said, many more widespread species, which are not threatened, are also usually mapped generally within their recent historical distributions. Most of these species have experienced local and regional population extinctions, many of which are as yet unrecorded. More research and monitoring of natural populations, along with accurate models of population responses to human impact, are needed to determine how extensive losses are across most ranges.

Individual species show differential responses to human activities, so any broad generalization based on variables such as human population or land-use intensity cannot fully explain the degree of impact. For instance, biological characteristics, such as reproductive rate, can help a species resist certain human threats (Purvis et al., 2000). However, human activities that alter the distribution, abundance, ecology and behavior of a species inevitably have an impact on some level of diversity, be it species diversity (extinctions) to population and genetic diversity. The magnitude of this impact remains the critical variable, as minimizing human activities that are most detrimental to natural biodiversity can prevent major losses of biodiversity. Unfortunately, many of the current 
extinction drivers are both widespread and temporally rapid. In fact, there were some species with their entire ranges covered by human population densities of over 300 per $\mathrm{km}^{2}$, including many critically endangered species such as Muennink's Spiny Rat (Tokudaia muenninki) of Okinawa (Tsuchiya et al., 1989) and the Seychelles Sheathtailed Bat (Coleura seychellensis) (Hutson et al., 2001). Even widespread species, such as the Bengal Fox (Vulpes bengalensis), show heavy human populations across their ranges, in this case the heavily populated Indian subcontinent (Ginsberg and MacDonald, 1990). This is an example of a species that is ranked as Data Deficient by the IUCN, as the full impact of human pressures have not been sufficiently addressed across its range. Clearly, the natural distributions of species, combined with the global distribution of human threats, including human population and land-use, can offer a spatially explicit examination of the differential threats that species are undergoing.

Global patterns of threatened mammals are necessary for refinement of conservation actions. Like global patterns in species richness and endemism, the distribution of threatened mammals is highly clumped in some geographic areas. Areas of high threat are predicted to some extent by areas of high species richness. However, many areas of the world hold low numbers or no threatened mammals. It is important to note that this does not imply that these areas and the species that occur there are somehow immune to threat. Species that are not categorized as globally threatened are still susceptible to various human activities, and many suffer large losses across their ranges. In these areas with low numbers of threatened species, there are differential rates of human disturbance. 
There is one clear fact; humans have precipitated a mass extinction event - just how massive is still unknown (Pimm and Brooks, 2001). The recovery from just the historic and prehistoric extinctions is likely to take on the order of 10 million years, the recovery time that has been demonstrated in the geological record after both the five previous mass extinctions, and also other 'background' extinction events (Kirchner and Weil, 2000; Erwin, 2000). Many species will not be replaced by congeners, due to evolutionary adaptations that are not easily replaced - it is not yet understood how the evolutionary process has been disrupted (Myers, 1997). Mammals are no exception - the results of this study indicate that many species range over areas with high human population density and land use, and many threatened species overlap with disproportionate numbers of humans. The sheer magnitude of human impacts provides a compelling and immediate reason to protect and manage the world's biodiversity. 


\section{References}

Alroy, J. 2001. A multispecies overkill simulation of the end-Pleistocene megafaunal mass extinction. Science 292:1893-1896.

Baillie, J., and B. Groombridge. 1996. 1996 IUCN red list of threatened animals. World Conservation Union, Gland, Switzerland.

Balmford, A. 1996. Extinction filters and current resilience: the significance of past selection pressures for conservation biology. Trends in Ecology and Evolution 11:193-196.

Balmford, A., J. L. Moore, T. Brooks, N. Burgess, L. A. Hansen, P. Williams, and C. Rahbek. 2001. Conservation conflicts across Africa. Science 291:2616-2619.

BirdLife International. 2000. Threatened birds of the world: the official source for birds on the IUCN red list. Cambridge, UK : BirdLife International.

Brashares, J. S., P. Arcese, and M. K. Sam. 2001. Human demography and reserve size predict wildlife extinction in West Africa. Proceedings of the Royal Society of London, Series B 268:2473-2478.

Brooks, T. M., R. A. Mittermeier, C. G. Mittermeier, G. A. B. d. Fonseca, A. B. Rylands, W. R. Konstant, P. Flick, J. Pilgrim, S. Oldfield, G. Magin, and C. Hilton-Taylor. 2002. Habitat loss and extinction in the hotspots of biodiversity. Conservation Biology 16:909-923.

Brooks, T. M., S. L. Pimm, and J. O. Oyugi. 1999. Time lag between deforestation and bird extinction in tropical forest fragments. Conservation Biology 13:1140-1150.

Burchard, I. 1998. Anthropogenic impact on the climate since man began to hunt. Palaeogeography, Palaeoclimatology, Palaeoecology 139:1-14. 
Ceballos, G., and J. H. Brown. 1995. Global patterns of mammalian diversity, endemism, and endangerment. Conservation Biology 9:559-568.

Ceballos, G., and P. R. Ehrlich. 2002. Mammal population losses and the extinction crisis. Science 296:904-907.

Center for International Earth Science Information Network (CIESIN), Columbia University; International Food Policy Research Institute (IFPRI); and World Resources Institute (WRI). 2000. Gridded Population of the World (GPW), Version 2. Palisades, NY: CIESIN, Columbia University. Available at http://sedac.ciesin.columbia.edu/plue/gpw.

Channell, R., and M. V. Lomolino. 2000. Dynamic biogeography and the conservation of endangered species. Nature 403:84-86.

Chapin, F. S., III, E. S. Zavaleta, V. T. Eviner, R. L. Naylor, P. M. Vitousek, H. L. Reynolds, D. U. Hooper, S. Lavorel, O. E. Sala, S. E. Hobbie, M. C. Mack, and S. Díaz. 2000. Consequences of changing biodiversity. Nature 405:234-242.

Chapman, J. A., and J. E. C. Flux. 1990. Rabbits, Hares, and Pikas. IUCN Lagomorph Specialist Group, IUCN, Gland, Switzerland.

Cincotta, R. P., J. Wisnewski, and R. Engelman. 2000. Human population in the biodiversity hotspots. Nature 404:990-992.

Dewer, R. E. 1997. Were people responsible for the extinction of Madagascar's subfossils, and how will we ever know? In S.M. Goodman and B.D. Patterson (eds.) Natural Change and Human Impact in Madagascar, p. 364-377. Smithsonian Institution Press, Washington.

Dobson, A. P., J. P. Rodriguez, W. M. Roberts, and D. S. Wilcove. 1997. Geographic 
distribution of endangered species in the United States. Science 275:550-553.

Erwin, D. 2000. Life's downs and ups. Nature 404:129-130.

Flannery, T.F. 1999. Debating extinction. Science 283:182-183.

Garbutt, N. 1999. Mammals of Madagascar. Yale University Press, New Haven.

Gaston, K. J. 2000. Global patterns in biodiversity. Nature 405:220-227.

Ginsberg, J. R., and D. W. MacDonald. 1990. Foxes, Wolves, Jackals, and Dogs: An Action Plan for the Conservation of Canids. IUCN/SSC Canid Specialist Group, IUCN, Gland, Switzerland.

Goodman, S. M., and B. D. Patterson. 1997. Natural Change and Human Impact in Madagascar. Smithsonian, Washington.

Hannah, L., J. L. Carr, and A. Lankerani. 1995. Human disturbance and natural habitat: a biome level analysis of a global data set. Biodiversity and Conservation 4:128155.

Hilton-Taylor, C., compiler. 2000. 2000 IUCN Red List of Threatened Species. IUCN, Gland, Switzerland.

Hilton-Taylor, C., compiler. 2002. 2002 IUCN Red List of Threatened Species. IUCN, Gland, Switzerland.

Holdaway, R. N., and C. Jacomb. 2000. Rapid extinction of the Moas (Aves: Dinornithiformes): Model, test, and implications. Science 287:2250-2254.

Hughes, J. B., G. C. Daily, and P. R. Ehrlich. 1997. Population diversity: its extent and extinction. Science 278:689-692.

Hutson, A. M., S. P. Mickleburgh, and P. A. Racey. 2001. Microchiropteran bats: global status, survey and conservation action plan. IUCN, Gland, Switzerland. 
Kerr, J. T., and T. V. Burkey. 2002. Endemism, diversity, and the threat of tropical moist forest extinctions. Biodiversity and Conservation 11:695-704.

Kerr, J. T. and D. J. Currie. 1995. Effects of human activity on global extinction risk. Conservation Biology 9:1528-1538.

Kirchner, J. W., and A. Weil. 2000. Delayed biological recovery from extinctions throughout the fossil record. Nature 404:177-180.

Liu, J., G. C. Daily, P. R. Ehrlich, and G. W. Luck. 2003. Effects of household dynamics on resource consumption and biodiversity. Nature 421:530-533.

Loveland, T.R., Reed, B.C., Brown, J.F., Ohlen, D.O., Zhu, J, Yang, L., and Merchant, J.W., 2000, Development of a Global Land Cover Characteristics Database and IGBP DISCover from 1-km AVHRR Data: International Journal of Remote Sensing , v. 21, no. 6/7, p. 1,303-1,330.

Mace, G. M., and A. Balmford. 2000. Patterns and processes in contemporary mammalian extinction. in A. Entwistle and N. Dunstone, editors. Future Priorities for the Conservation of Mammalian Diversity. Cambridge University Press, Cambridge.

MacPhee, R. D. E. and C. Flemming. 1999. Requiem Aeternam; The last five hundred years of mammalian species extinctions. In R. D. E. MacPhee (ed.) Extinctions in Near Time; Causes, Contexts, and Consequences. Kluwer Academic/Plenum Publishers.

Martin, P. S. and D. W. Steadman. 1999. Prehistoric extinctions on islands and continents. In R. D. E. MacPhee (ed.) Extinctions in Near Time; Causes, Contexts, and Consequences. Kluwer Academic/Plenum Publishers. 
Manne, L.L., T.M. Brooks, and S.L. Pimm. 1999. Relative risk of extinction of passerine birds on continents and islands. Nature 399:258-261.

May, R. M., J. H. Lawton, and N. E. Stork. 1995. Assessing extinction rates. in J. H. Lawton and R. M. May, editors. Extinction Rates. Pp 1-24. Oxford University Press, Oxford.

May, R. M., and K. Tregonning. 1998. Global conservation and UK government policy. Pages 287-301 in G. M. Mace, A. Balmford, and J. Ginsberg, editors. Conservation in a Changing World. Cambridge University Press, London. McKinney, M. L. 1997. Extinction vulnerability and selectivity: Combining ecological and paleontological views. Annual Review of Ecology and Systematics 28:495516.

Miller, G. H., J. W. Magee, B. J. Johnson, M. L. Fogel, N. A. Spooner, M. T. McCulloch, and L. K. Ayliffe. 1999. Pleistocene extinction of Genyornis newtoni: Human impact on Australian megafauna. Science 283:205-208.

Myers, N. 1994. Population and biodiversity. Pages 117-135 in F. Graham-Smith, editor. Population - The Complex Reality. Royal Society of London, London.

Myers, N. 1997. Mass extinction and evolution. Science 278:597-598.

Myers, N., R. A. Mittermeier, C. G. Mittermeier, G. A. B. d. Fonseca, and J. Kent. 2000. Biodiversity hotspots for conservation priorities. Nature 403:853-858.

Nowell, K., and P. Jackson. 1996. Wild Cats: Status Survey and Conservation Action Plan. IUCN/SSC Cat Specialist Group, IUCN, Gland, Switzerland.

Olson, D. M., and E. Dinerstein. 1998. The Global 200: A representation approach to 
conserving the Earth's most biologically valuable ecoregions. Conservation Biology 12:502-515.

Pimm, S. L., G. J. Russell, J. L. Gittleman, and T. M. Brooks. 1995. The future of biodiversity. Science 269:347-350.

Pimm, S. L., and T. M. Brooks. 2000. The sixth extinction: how large, how soon, and where? in P. H. Raven and T. Williams, editors. Nature and Human Society: the Quest for a Sustainable World. National Academy Press, Washington, D. C.

Pimm, S. L., and P. Raven. 2000. Extinction by numbers. Nature 403:843-845.

Pimm, S. L. et al. 2001. Can we defy nature's end? Science 293:2207-2208.

Purvis, A., J. L. Gittleman, G. Cowlishaw, and G. M. Mace. 2000. Predicting extinction risk in declining species. Proceedings of the Royal Society of London B 267:1947-1952.

Repetto, R. 1994. The "Second India" Revisited: Population, Poverty, and Environmental Stress Over Two Decades. World Resources Institute, Washington, DC.

Roberts, C. M., C. J. McClean, J. E. N. Veron, J. P. Hawkins, G. R. Allen, D. E. McAllister, C. G. Mittermeier, F. W. Schueler, M. Spalding, F. Wells, C. Vynne, and T. B. Werner. 2002. Marine biodiversity hotspots and conservation priorities for tropical reefs. Science 295:1280-1284.

Roberts, R. G., T. F. Flannery, L. K. Ayliffe, H. Yoshida, J. M. Olley, G. J. Prideaux, G. M. Laslett, A. Baynes, M. A. Smith, R. Jones, and B. L. Smith. 2001. New ages for the last Australian megafauna: Continent-wide extinction about 46,000 years ago. Science 292:1888-1892.

Sala, O. E., F. S. Chapin III, J. J. Armesto, E. Berlow, J. Bloomfield, R. Dirzo, E. Huber- 
Sanwald, L. F. Huenneke, R. B. Jackson, A. Kinzig, R. Leemans, D. M. Lodge, H. A. Mooney, M. Oesterheld, N. L. Poff, M. T. Sykes, B. H. Walker, M. Walker, and D. H. Wall. 2000. Global biodiversity scenarios for the year 2100. Science 287:1770-1774.

Sanderson, E. W., M. Jaiteh, M. A. Levy, K. H. Redford, A. V. Wannebo, and G.

Woolmer. 2002. The human footprint and the last of the wild. Bioscience 52:891904.

Steadman, D.W. 1995. Prehistoric extinctions of Pacific island birds: biodiversity meets zooarchaeology. Science 267:1123-1131.

Strahan, R. 1995. The Mammals of Australia. Reed Books.

Terborgh, J., L. Lopez, P. Nuñez, M. Rao, G. Shahabuddin, G. Orihuela, M. Riveros, R. Ascanio, G. H. Adler, T. D. Lambert, and L. Balbas. 2001. Ecological meltdown in predator-free forest fragments. Science 294:1923-1926.

Tilman, D., J. Fargione, B. Wolff, C. D'Antonio, A. Dobson, R. Howarth, D. Schindler, W. H. Schlesinger, D. Simberloff, and D. Swackhamer. 2001. Forecasting agriculturally driven global environmental change. Science 292:281-284.

Tsuchiya, K., S. Wakana, H. Suzuki, S. Hattori, and Y. Hayashi. 1989. Taxonomic study of Tokudaia (Rodentia: Muridae): I. Genetic differentiation. Memoirs of the National Science Museum, Tokyo 22:227-234.

Vartanyan, S. L., V. E. Garrut, and A. V. Sher. 1993. Holocene dwarf mammoths from Wrangel Island in the Siberian Arctic. Nature 382:337-340.

Walther, G.-R., E. Post, P. Convey, A. Menzel, C. Parmesan, T. J. C. Beebee, J.-M. 
Fromentin, O. Hoegh-Guldberg, and F. Bairlein. 2002. Ecological responses to recent climate change. Nature 416:389-395.

Wilson, D. E., and D. M. Reeder. 1993. Mammal Species of the World. Smithsonian Institution Press, Washington.

Wilson, D. E., and S. Ruff. 1999. The Smithsonian Book of North American Mammals. Smithsonian Institution Press, Washington, D. C. 


\section{Red List Categories}

Extinct

Extinct in the wild

Critically endangered

Endangered

Vulnerable

Near threatened

Least concern

Data deficient

Not evaluated
No reasonable doubt that the last individual has died.

Survives only in captivity or as a naturalized population outside its range.

Extremely high risk of extinction.

Very high risk of extinction.

High risk of extinction.

Close to qualifying for a threatened category.

Widespread and abundant.

Inadequate information to make an assessment.

Not yet evaluated against the criteria.

Table 1: Red list categories. More information is available from the IUCN SSC, www.redlist.org 


\begin{tabular}{|l|r|r|r|r|r|r|r|r|}
\hline & \multicolumn{7}{|c|}{ IUCN 2002 Red List threat classes } \\
\cline { 2 - 9 } & \multicolumn{1}{|c|}{$\mathrm{CR}^{1}$} & \multicolumn{1}{c|}{$\mathrm{EN}^{2}$} & \multicolumn{1}{c|}{$\mathrm{VU}^{3}$} & \multicolumn{1}{c|}{$\mathrm{LR}^{2} \mathrm{~cd}^{4}$} & \multicolumn{1}{c|}{$\mathrm{LR}^{5} \mathrm{nt}^{5}$} & \multicolumn{1}{c|}{$\mathrm{DD}^{6}$} & Unlisted $^{7}$ & \multicolumn{1}{c|}{ Total } \\
\hline Number of Species & 168 & 315 & 582 & 58 & 592 & 174 & 2,851 & 4,740 \\
\hline Mean & 92,548 & 281,178 & 586,618 & $2,629,256$ & $1,195,870$ & 941,472 & $2,283,830$ & $1,683,755$ \\
\hline Std. Deviation & 883,203 & $1,063,363$ & $2,098,676$ & $3,106,954$ & $3,345,501$ & $2,251,537$ & $4,302,365$ & $3,757,291$ \\
\hline Median & 1,192 & 14,152 & 48,663 & $1,593,317$ & 196,291 & 78,351 & 54,0472 & 245,005 \\
\hline \% of Total Species & $3.50 \%$ & $6.60 \%$ & $12.30 \%$ & $1.20 \%$ & $12.50 \%$ & $3.70 \%$ & $60.10 \%$ & $100.00 \%$ \\
\hline
\end{tabular}

${ }^{1}$ Critically endangered

2 Endangered

3 Vulnerable

${ }^{4}$ Lower risk / conservation dependent

${ }^{5}$ Lower risk / near-threatened

6 Data deficient

${ }^{7}$ Unlisted

Table 2: Range size descriptive statistics across IUCN Red List threat class. 


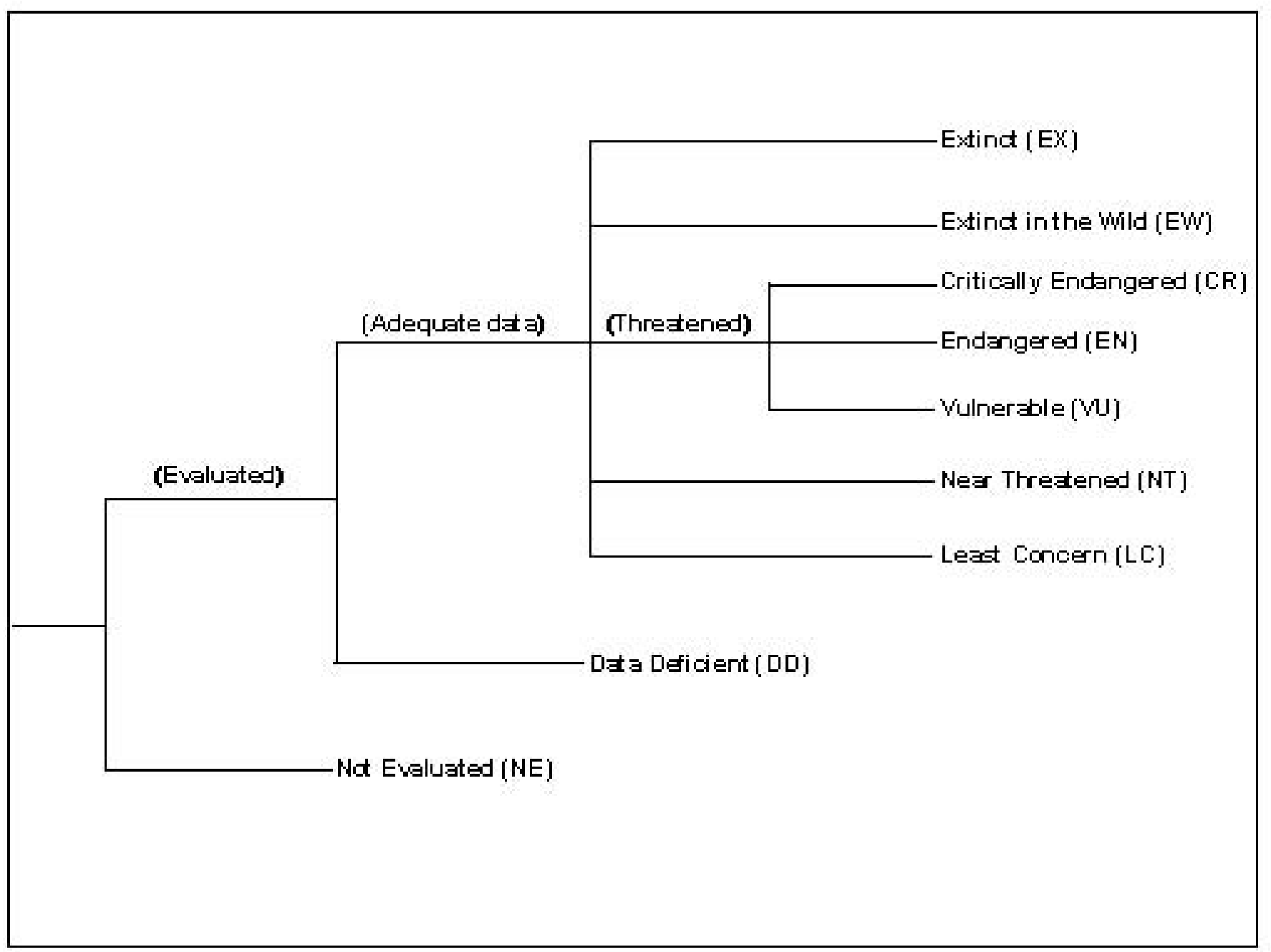

Figure 1: The structure used by the IUCN to assign threat categories (Hilton-Taylor, 2002). 


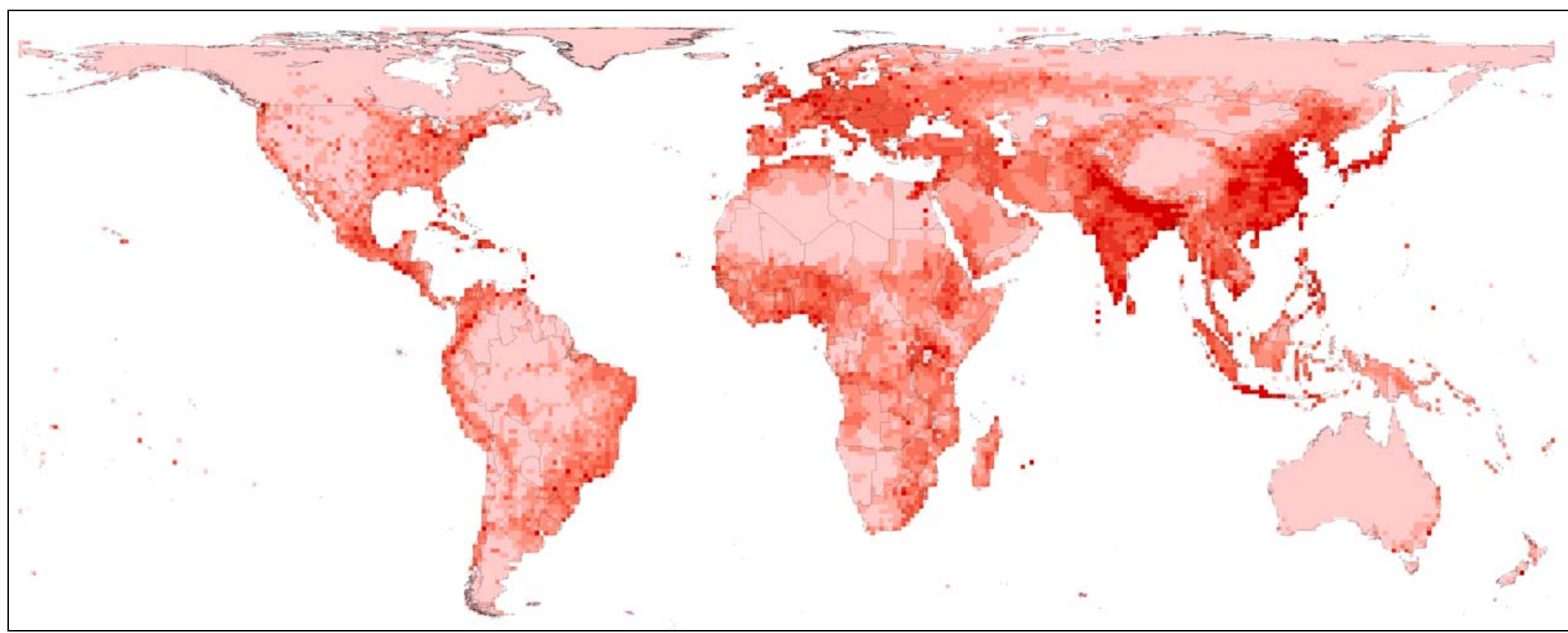
$\square 0-1$
$\square 1-5$
$\square 5-15$
$15-50$
$50-150$
$150-300$
300 and up

Figure 2: The map of human population density, produced from data provided by CEISIN (2000). 


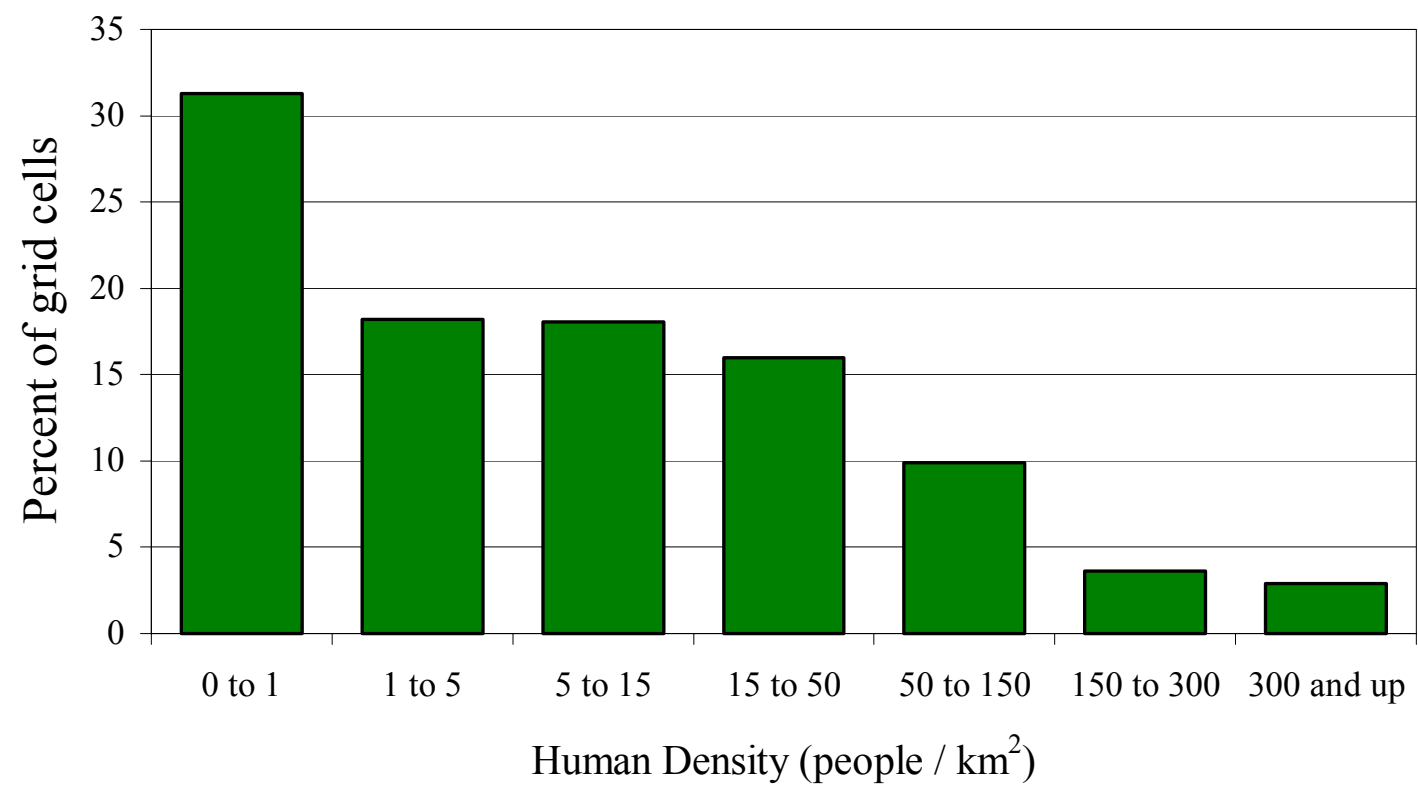

Figure 3: Percent of grid cells ( $100 \mathrm{~km}^{2}$ equal-area grid cells) for given human population density. 


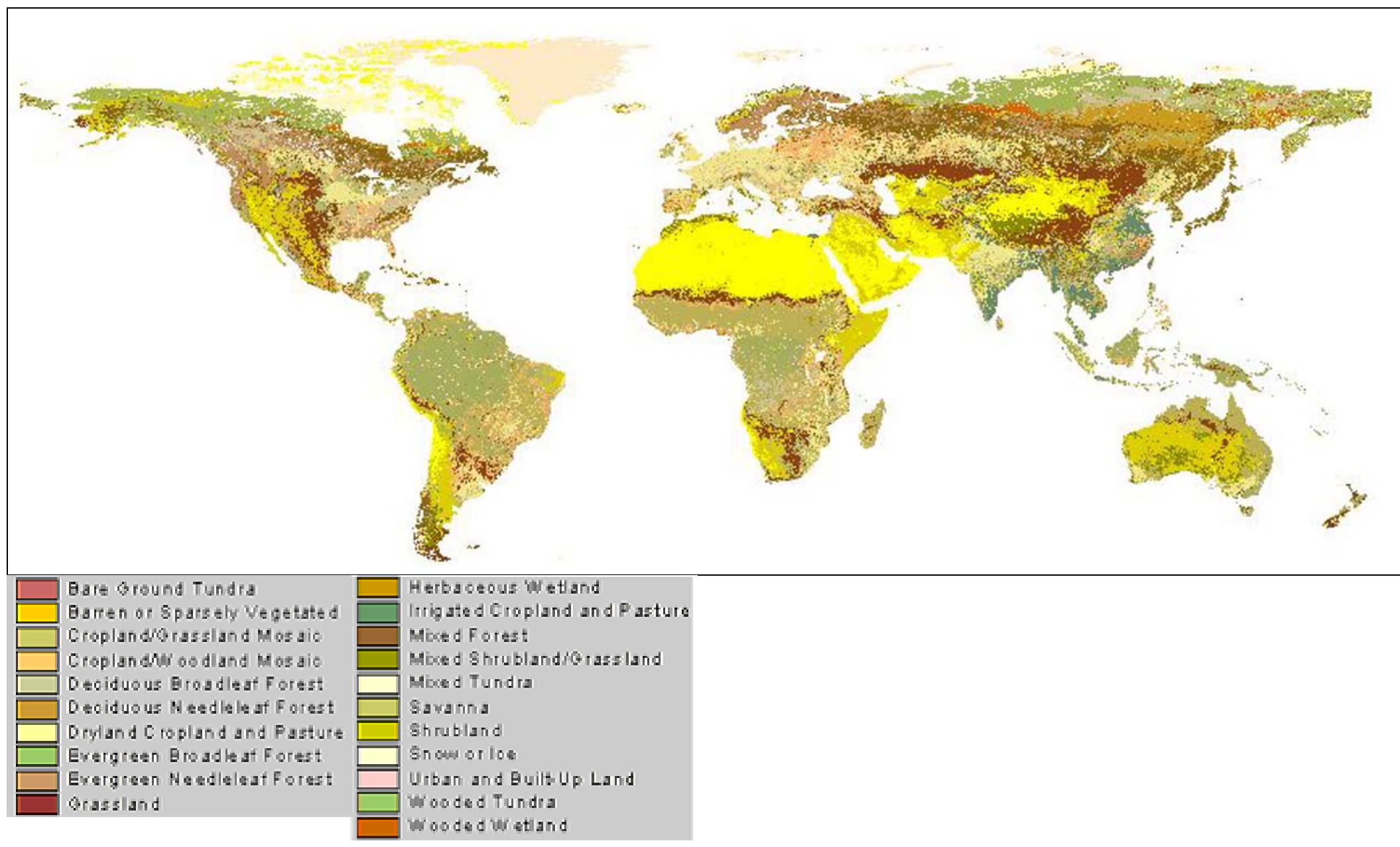

Figure 4: Map of global land cover classes (Adapted from Loveland et al., 2000). 


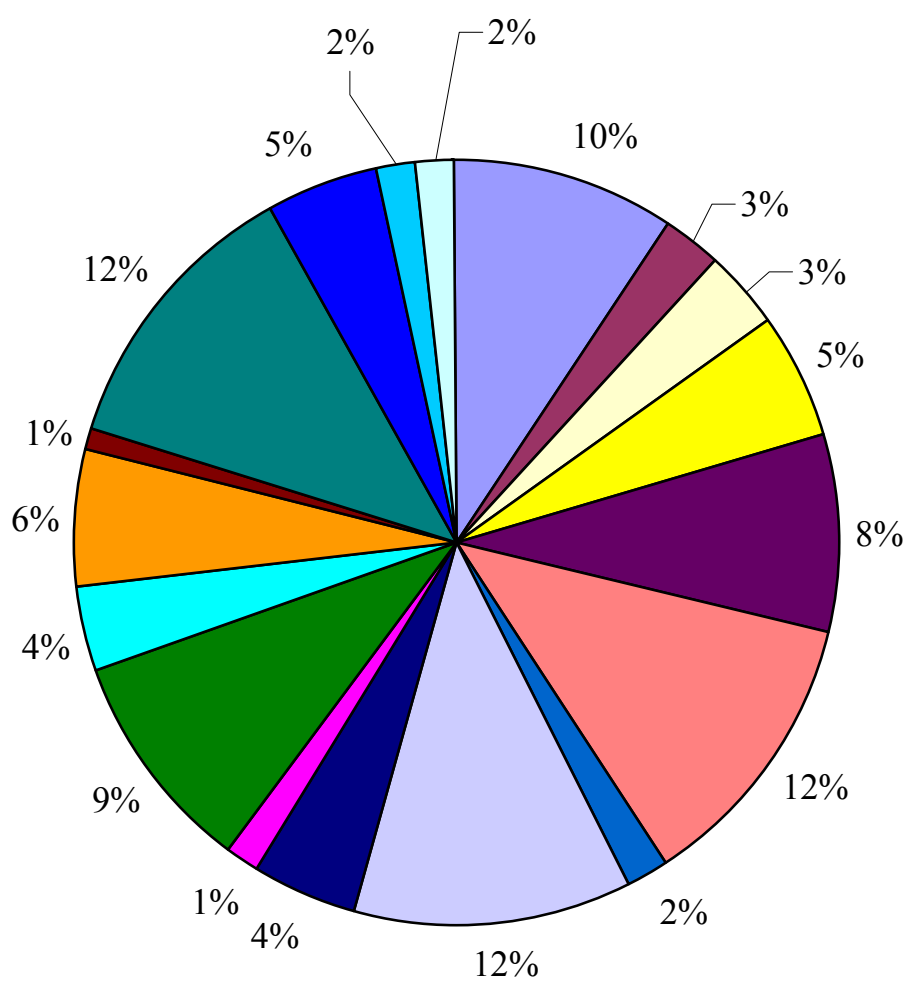

\begin{tabular}{|c|c|}
\hline $\begin{array}{l}\square \text { Dryland Cropland and Pasture } \\
\square \text { Cropland/Grassland Mosaic } \\
\square \text { Grassland } \\
\square \text { Mixed Shrubland/Grassland } \\
\square \text { Deciduous Broadleaf Forest } \\
\square \text { Evergreen Broadleaf Forest } \\
\square \text { Mixed Forest } \\
\square \text { Barren or Sparsely Vegetated } \\
\square \text { Mixed Tundra }\end{array}$ & $\begin{array}{l}\square \text { Irrigated Cropland and Pasture } \\
\square \text { Cropland/Woodland Mosaic } \\
\square \text { Shrubland } \\
\square \text { Savanna } \\
\square \text { Deciduous Needleleaf Forest } \\
\square \text { Evergreen Needleleaf Forest } \\
\square \text { Wooded Wetland } \\
\square \text { Wooded Tundra } \\
\square \text { Snow or Ice }\end{array}$ \\
\hline
\end{tabular}

Figure 5: The global distribution of land cover types (based on the GLCC) (Adapted from Loveland et al., 2000). 


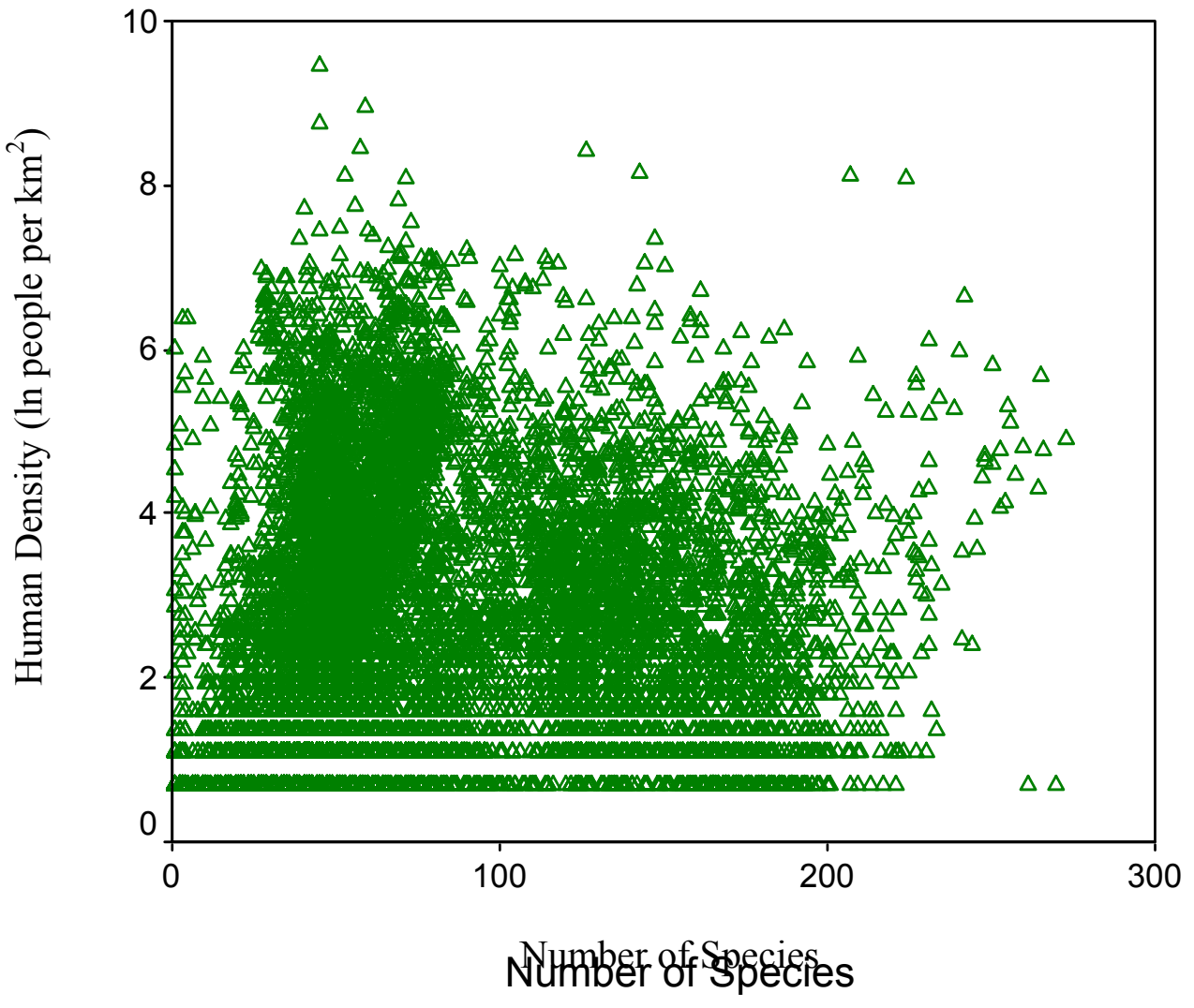

Figure 6: Human population density $\left(\mathrm{ln}\right.$ people per $\mathrm{km}^{2}$ ) versus species richness. 


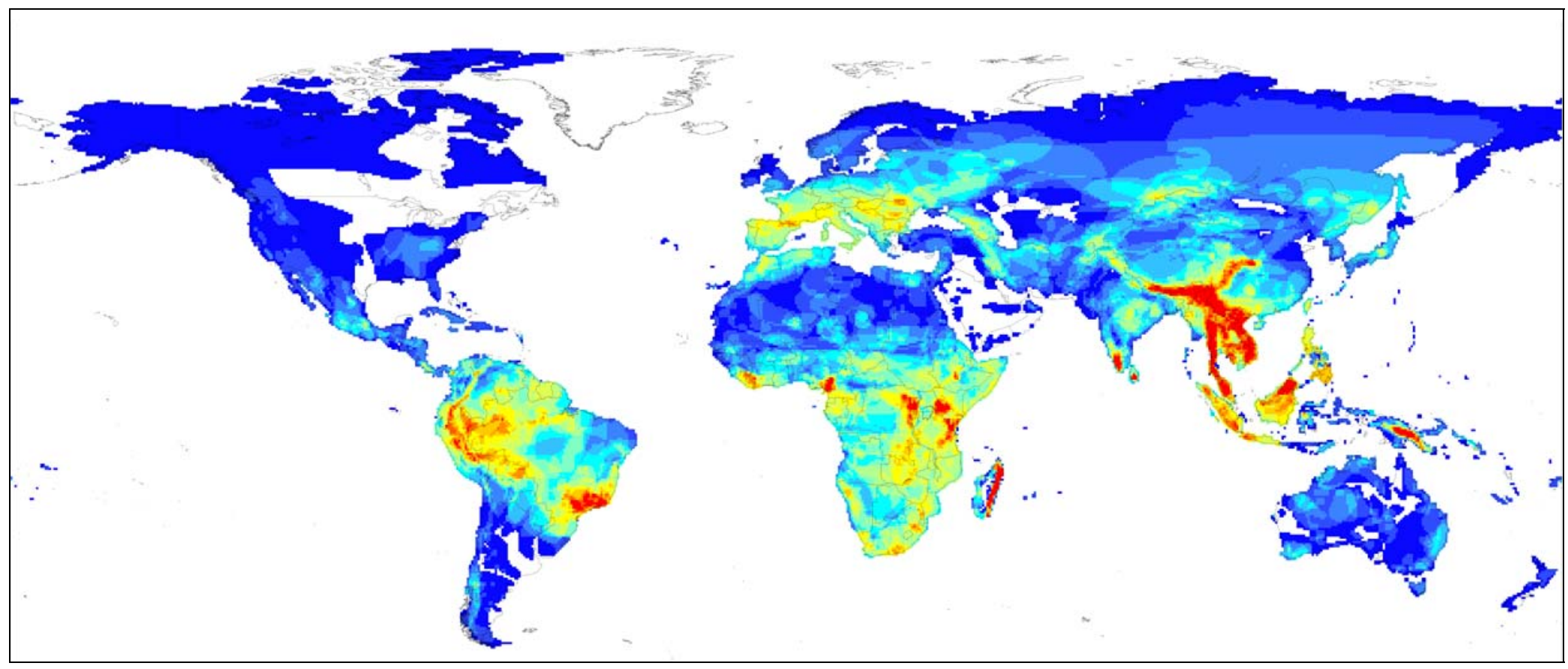

Figure 7: Richness of threatened species ( $\mathrm{n}=1065$ species).

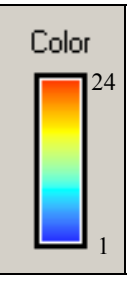




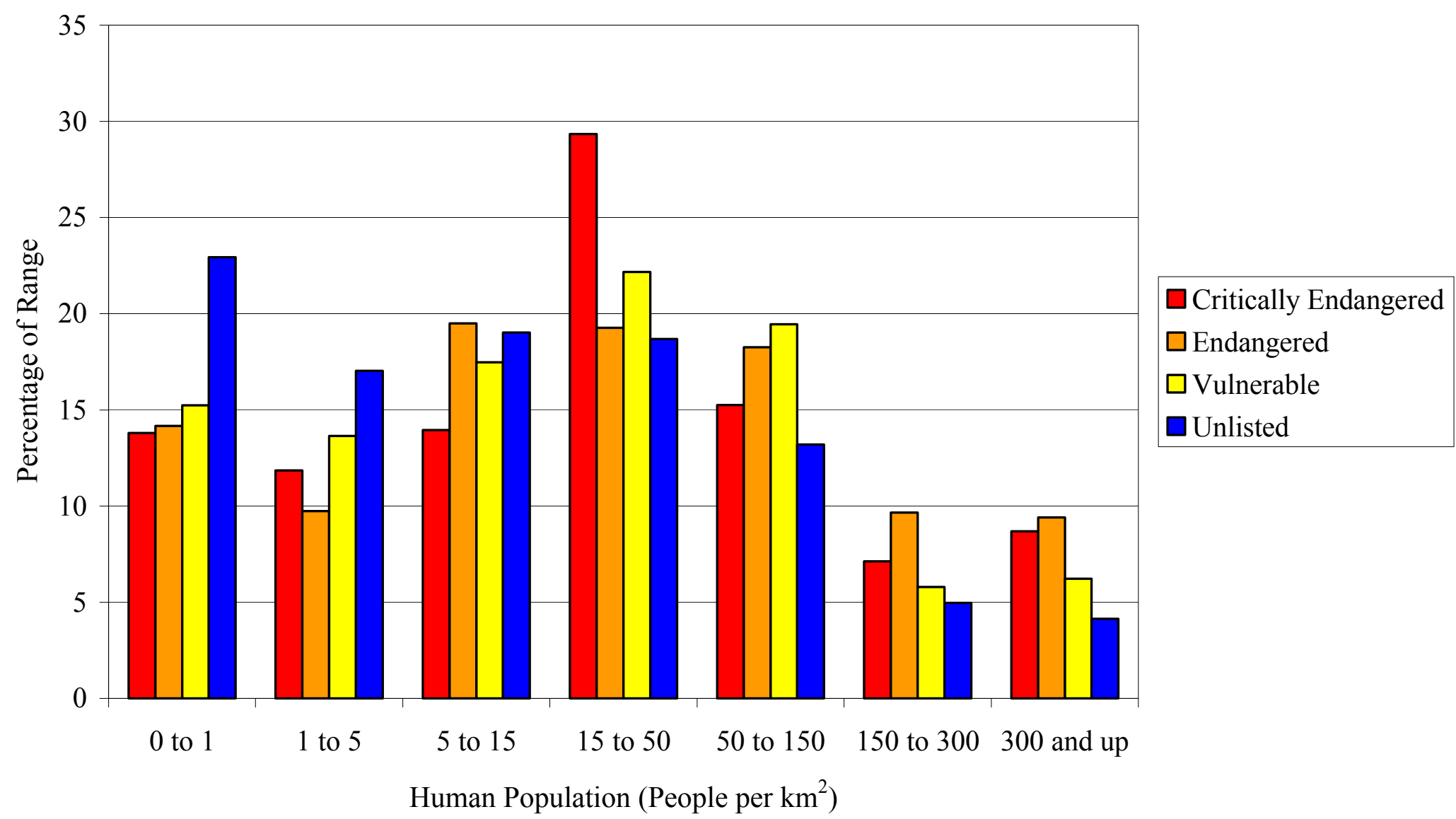

Figure 8: Human population density across the ranges of threatened mammals. 


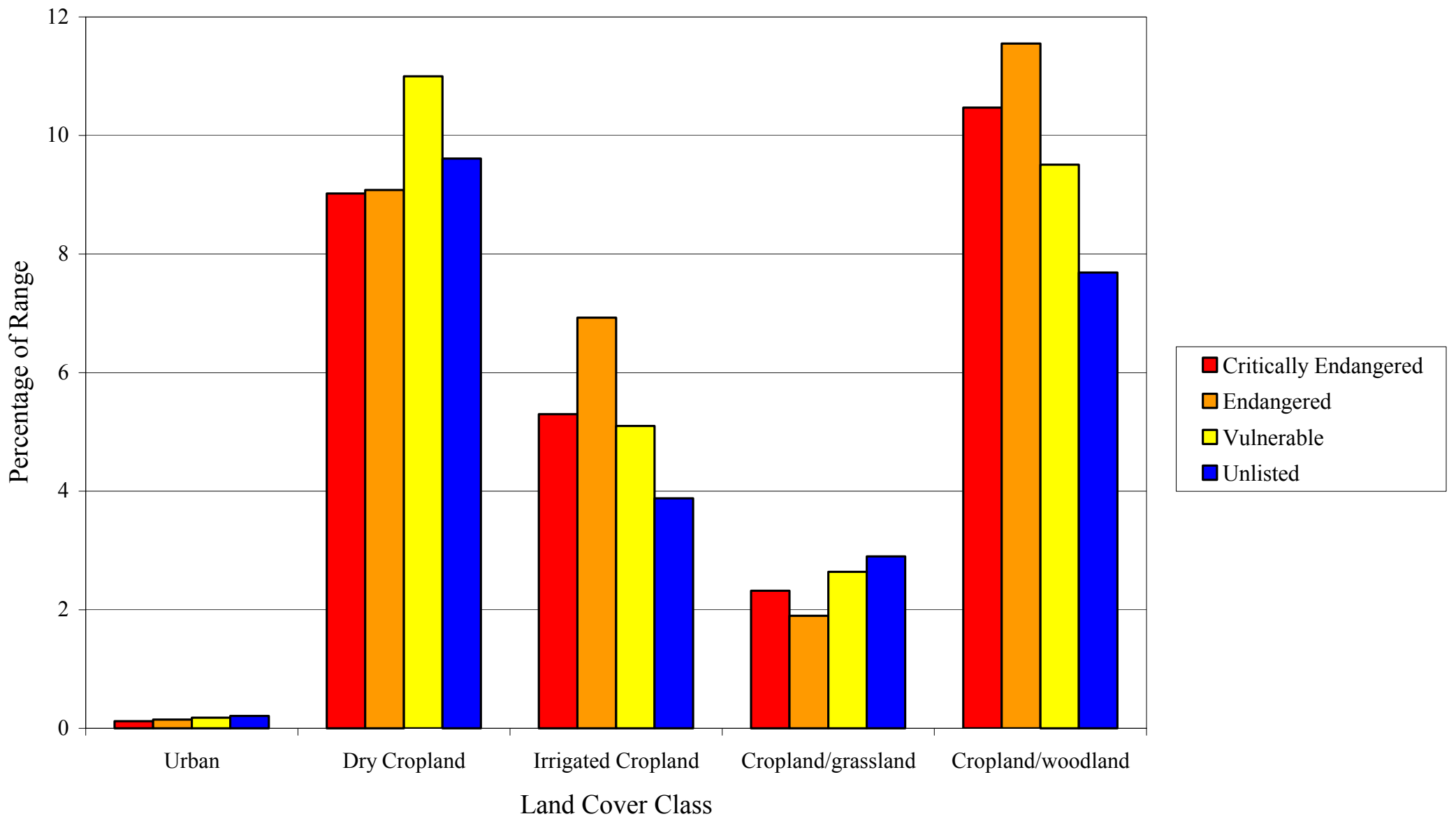

Figure 9: Percentage of range within land cover classes for threatened and unlisted species 


\section{Chapter 6}

\section{Preface}

This chapter was published in the Proceedings of the National Academy of Sciences in 2002. I performed the majority of the analytical work and wrote the initial draft of the manuscript. Tom Brooks and John Gittleman contributed significantly to the ideas and final writing, while the other authors contributed updated data on Primates and contributed to the writing of the final publication.

Sechrest, W., T. M. Brooks, G. A. B. da Fonseca, W. R. Konstant, R. A. Mittermeier, A. Purvis, A. B. Rylands, and J. L. Gittleman. 2002. Hotspots and the conservation of evolutionary history. Proceedings of the National Academy of Sciences of the United States of America 99:2067-2071. 


\title{
Chapter 6
}

\section{Hotspots and the conservation of evolutionary history}

\begin{abstract}
Species diversity is unevenly distributed across the globe, with terrestrial diversity concentrated in a few restricted biodiversity hotspots. These areas are associated with high losses of primary vegetation and increased human population density, resulting in growing numbers of threatened species. We show that conservation of these hotspots is critical because they harbor higher amounts of evolutionary history than expected by species numbers alone. Using supertrees for carnivores and primates, we estimate that nearly $70 \%$ of the total amount of evolutionary history represented in these groups is found in 25 biodiversity hotspots.
\end{abstract}

\section{Introduction}

Biodiversity is distributed unequally across the globe - only a few, small areas hold most species (Gaston, 2000). At least $44 \%$ of vascular plants and $35 \%$ of vertebrates are endemic to 25 biodiversity "hotspots" (Mittermeier et al., 1999). Disconcertingly, people and hence threats to biodiversity are similarly distributed (Cincotta et al., 2000). Thus, none of the hotspots retain above $30 \%$ of their natural habitat, and together they represent only 1.4\% of the planet's land (Myers et al., 2000). A hitherto unknown component of biodiversity hotspots is the evolutionary history of species residing within them - a more inclusive measure of biodiversity than species numbers (Purvis and Hector, 2000). If this is disproportionately large, we may face 
losses of phylogenetic diversity (Vane-Wright et al., 1991; Faith, 1994) and/or evolutionarily ancient lineages (May, 1990) even more devastating than reflected by species losses alone. For example, the 103 endemic mammal species of Madagascar include no less than five endemic families and 14 endemic genera of primates (Wilson and Reeder, 1993; Harcourt, 2000). Such areas may not only be important reservoirs for phylogenetic history, they may also be critical for preserving the future of evolutionary processes where biodiversity is created (Myers and Knoll, 2001). Here, using complete phylogenies of two mammalian orders, we show that significantly more primate and carnivore evolutionary history (343 million years) is endemic to the hotspots than expected under a random model. Maybe even more serious, considering only threatened endemic species (Hilton-Taylor, 2000), hotspots also hold 163 million years more evolutionary history than expected.

We use two measures of evolutionary history, or phylogenetic diversity (PD) that are derived by examining branch lengths in a phylogenetic tree (Faith, 1992). The first measure incorporates clade evolutionary history, which includes all the branches within an included clade in a phylogeny (see Figure 1), and hence takes higher-level diversity into account (Vane-Wright et al., 1991). For species corresponding to an area or set of areas, clade evolutionary history is equal to the amount of branch length uniquely represented by this set of species. It is the amount of phylogenetic diversity inevitably lost if those areas are lost. The other represents the species evolutionary history, measured as the branch length from the present to the time of last divergence (Altschul and Lipman, 1991; Erwin, 1991; Faith, 1994). In order to obtain these measures, we used complete phylogenies (Sanderson et al., 1998) (with dated branch lengths) for all extant 
primate (Purvis, 1995) and carnivore (Bininda-Emonds et al., 1999) species. For both orders, we measured the two PD parameters using lists of species endemic to the hotspots. We then compared these values with those for 1,000 simulations of the same number of species removed at random (Purvis et al., 2000a) from the entire species lists for each order (Wilson and Reeder, 1993). We repeated this analysis using lists of all primates and carnivores occurring within the hotspots.

\section{Methods}

Species range designations to hotspots

Allocation of species to hotspots was made in two ways. Carnivore and primate species were either listed as being strictly endemic to a hotspot or as occurring in a hotspot. Species that were endemic to multiple hotspots were classified as hotspot endemics. Most primate species are endemic to a hotspot (127 species from a total 233, with only 29 species occurring outside of hotspots). By contrast, fewer terrestrial carnivores are endemic to hotspots (only 51 out of 234 species); however, no less than 208 carnivore species occur in at least one hotspot. We give full primary references used to assess primate and carnivore distributions at the following website: http://www.gittleman.net.

\section{Tests of phylogenetic diversity}

Phylogenetic information was based on complete trees of the primates (Purvis, 1995) and carnivores (excluding pinnipeds) (Bininda-Emonds et al., 1999). Branch lengths are derived from a combination of absolute (fossil and point molecular estimates) and relative molecular dates. Date estimates were available for a majority of nodes in 
both trees. Nodes without times of divergence were dated by interpolation using a pure birth model, whereby a clade's age is proportional to the logarithm of the number of species it contains (Purvis, 1995). Based on the numbers of species and their associated branch lengths in hotspots, 1000 simulations were run on the same numbers of species removed at random (Purvis et al., 2000a); the phylogenies and computer programs used to conduct the simulations are available at http://www.bio.ic.ac.uk/evolve/.

\section{Results and Discussion}

Approximately $55 \%$ of the world's primates and $22 \%$ of carnivores are endemic to hotspots. For example, entire primate lineages (Figure 2a) are found in Madagascar (Cheirogaleidae, Megaladapidae, Lemuridae, Indriidae and Daubentoniidae), South-east Asia (Tarsiidae and Hylobatidae), and the Atlantic Forest of Brazil (Leontopithecus and Brachyteles). Comparatively few carnivores are endemic to hotspots (Figure 2b), although notable endemic clades include the Malagasy viverrids and the majority of New World procyonids.

With around $59 \%$ of species evolutionary history and $71 \%$ of clade evolutionary history, both measures of PD for hotspot endemic primates are significantly greater than expected under the random model (Table 1). Branch lengths with dates of divergence allow analysis of whether lineages within hotspots are on average younger or older than those outside of hotspots. There are no overall differences with respect to mean (logtransformed) ages of species endemic to hotspots compared to non-hotspot species, although there are some patterns within continents. Primates within the Indo-Burma hotspot are older than Asian non-hotspot species $(\mathrm{t}=2.007, \mathrm{p}<0.05, \mathrm{df}=18)$. 
Conversely, species endemic to the West African Guinea Forests and the Tanzanian Eastern Arc show a younger mean age than African non-hotspot species $(\mathrm{t}=2.144, \mathrm{p}<$ $0.05, \mathrm{df}=60)$. No consistent patterns were found in South American hotspot regions.

Carnivore species have unusually large distributions worldwide (Hunt, 1996; Mills et al., 2001), and few species have restricted ranges. Thus, the amount of evolutionary history endemic to hotspots is less than in primates. Nevertheless, using either measure of PD, hotspots do contain a greater amount of carnivore PD than under a random model (Table 1). The ages of hotspot endemic carnivores are not significantly different from non-hotspot endemic species. Taken together, the ages of primate and carnivore species are not consistently older or younger in hotspots; a similar pattern is observed in other taxa whereby there is no consistency in the ages of lineages living in particular eco-climatic zones (Fjeldså and Lovett, 1997; Chown and Gaston, 2000). Hotspots contain endemic primates and carnivores that, according to times of divergences in the phylogenies, represent over 343 million years more evolutionary history than expected from the random model. The reason for hotspots containing a great amount of PD is that, with exceptions such as rapid radiations in Old world monkeys (Purvis et al., 1995) and some canids (Bininda-Emonds et al., 1999), a clade's evolutionary history within a given geographic region is generally gradual with respect to ages of divergence.

A rank ordering of the top five hotspots according to endemic evolutionary history reveals taxonomic differences in the amount of unique evolutionary history (in millions of years) residing in them (see Figure 3). In primates, they are Madagascar (257), Sundaland (65), Wallacea (50), Brazil's Atlantic forest (44), and Indo-Burma (40). For carnivores, they are Sundaland (53), Madagascar (51), Mesoamerica (35), Western 
Ghats and Sri Lanka (26), and the Guinean Forests of West Africa (22). Madagascar and Sundaland are clearly outstanding for both groups.

The same analyses were performed using all species occurring in the hotspots. The ranges of over $89 \%$ of carnivore species overlapped with at least one hotspot; for primates, the percentage is $67 \%$. For both orders, the clade phylogenetic diversity occurring in hotspots was significantly greater than predicted by the random model (Table 2). The amount of species evolutionary history occurring in hotspots was also significantly greater for primates, but not for carnivores.

Taxonomic revision can certainly affect the results of interspecific studies. Species level systematics are far from fully resolved even for groups as well known as primates and carnivores. For example, recent advances in primate taxonomy suggest that 110 Neotropical species exist (Rylands et al., 2000), compared to the 84 traditionally listed (Wilson and Reeder, 1993). With the revised taxonomy, however, there would be only three additional species endemic to hotspots, and four more occurring in hotspots. Further, recent phylogenetic analyses (Yoder et al., 2000) identifying up to seven mouse lemur species (genus Microcebus) would make the value of PD even greater in Madagascar. Carnivore taxonomy is rather more stable (Flynn et al., 1988; Wozencraft, 1989; Bininda-Emonds et al., 1999), and so changes within this order will have even smaller effects. Future analyses should allow the incorporation of more finely resolved systematic levels, such as sub-species or phylogenetic species (Wheeler and Platnick, 2000), or even character diversity (Williams and Humphries, 1996). Nonetheless, we doubt that these will alter our fundamental conclusion that evolutionary history is disproportionately concentrated in small - and highly threatened - areas. Generalizing 
these results, it is important to recognize that our analysis is restricted to primates and carnivores, two orders that comprise only $11 \%$ of all mammalian biodiversity (Wilson and Reeder, 1993). Although these taxa do represent both comparatively narrow (primates) and broad (carnivores) distributions globally (Anderson and Jones, 1984), further mammalian and terrestrial vertebrate taxa should be examined across hotspots to evaluate differences in amounts of phylogenetic diversity living within them.

If hotspot lineages include many species listed on the IUCN Red List (HiltonTaylor, 2000) as having a high probability of extinction in the medium-term future, impending losses of evolutionary history could be even more severe than the above results suggest (Purvis et al., 2000a; Pimm et al., 1995). We used the Red List to examine the patterns in threatened species (species classified as LRcd and above; DD, EW and EX species excluded) (Hilton-Taylor, 2000). The majority of the species most likely to become extinct are endemic to the hotspots: $77 \%$ of threatened primates and $60 \%$ of threatened carnivores. For all primate species endemic to hotspots, $77 \%$ are threatened, whereas only $28 \%$ of species outside of hotspots are threatened; for carnivores, the numbers are $61 \%$ and $24 \%$, respectively. We repeated the previous PD analyses using only the threatened species. In terms of endemic clade evolutionary history, hotspots contain $63 \%$ of threatened primate PD and $37 \%$ of threatened carnivore PD, in both cases these figures are significantly higher than under the random model (see Table 1). When, considering only threatened endemic species, hotspots also hold 163 million years more evolutionary history than expected. When endemic species evolutionary history is analyzed, $82 \%$ of threatened primate $\mathrm{PD}$ and $45 \%$ of threatened carnivore PD is only found in the hotspots (Table 1). The results are qualitatively similar 
considering all primates and carnivores occurring within hotspots (Table 2). Not only are hotspots critical for a large portion of the diversity of primates and carnivores overall, but the evolutionary history of extinction-prone species is disproportionately clustered in these areas.

Studies of past and present extinction rates have repeatedly shown taxonomically non-random patterns of threat to species (McKinney, 1997; Russell et al., 1998; Purvis et al., 2000b; Euler, 2001). Further, the distributions of both biodiversity (Myers et al., 2000) and of people and hence threats to this biodiversity (Cincotta et al., 2000) are also non-random across geographic space (Pimm and Raven, 2000). We expand these findings to show co-occurrence between the phylogenetic and the geographic clumping of both biodiversity and threats. A third of the evolutionary history of all primates and carnivores is completely encompassed within the hotspots, and cannot be saved unless the hotspots are conserved. Conversely, however, if we can save the hotspots, we can represent over 2.6 billion years of primate and carnivore evolutionary history, almost $70 \%$ of their total. Hotspots are not only vital areas of species-level endemism, but are also highly significant reservoirs of unique and threatened evolutionary history.

\section{Acknowledgements}

We thank Georgina Mace, Paul-Michael Agapow, Janis Antonovics, Kaycie Billmark, Dan Faith, Kate Jones, Norman Myers, Charlie Nunn, John Pilgrim, Cindy Sechrest, Paul Williams, Michael Rosenzweig, and an anonymous reviewer for comments and suggestions on the analysis and manuscript. This work was partially supported by the Center for Applied Biodiversity Science (CABS), Conservational International, and the 
National Center for Ecological Analysis and Synthesis through NSF grant DEB-94-

21535 (J.L.G.). 


\section{References}

Altschul, S. F. and D. J. Lipman. 1991. Equal animals. Nature 348:493-494.

Anderson, S. and J. N. Jones, Jr. 1984. Orders and Families of Recent Mammals of the World. John Wiley and Son, New York.

Bininda-Emonds, O., J. Gittleman, and A. Purvis. 1999. Building large trees by combining phylogenetic information: a complete phylogeny of the extant Carnivora (Mammalia). Biological Reviews of the Cambridge Philosophical Society 74:143-175.

Chown, S. L. and K. J. Gaston. 2000. Areas, cradles and museums: the latitudinal gradient in species richness. Trends in Ecology and Evolution 15:311-315.

Cincotta, R. P., J. Wisnewski, and R. Engelman. 2000. Human population in the biodiversity hotspots. Nature 404:990-992.

Erwin, T. L. 1991. An evolutionary basis for conservation strategies. Science 253:750752.

Euler, F. von. 2001. Selective extinction and rapid loss of evolutionary history in the bird fauna. Proceedings of the Royal Society of London, Series B 268:127-130.

Faith, D. P. 1992. Conservation evaluation and phylogenetic diversity. Biological Conservation 61:1-10.

Faith, D. P. 1994. Phylogenetic diversity: a general framework for the prediction of feature diversity. In P. L. Forey, C. J. Humphries, and R. I. Vane-Wright (eds.), Systematics and Conservation Evaluation, pp. 251-268. Clarendon, Oxford.

Fjeldså, J., and J. Lovett. 1997. Geographical patterns of old and young species in 
African forest biota: the significance of specific montane areas as evolutionary centers. Biodiversity and Conservation 6:325-346.

Flynn, J. J., N. A. Neff, and R. H. Tedford. 1988. Phylogeny of the Carnivora. In M. J. Benton (ed.), The Phylogeny and Classification of the Tetrapods, pp. 73-115. Clarendon Press, Oxford.

Gaston, K. J. 2000. Global patterns in biodiversity. Nature 405:220-227.

Harcourt, A. H. 2000. Coincidence and mismatch of biodiversity hotspots: A global survey for the order, Primates. Biological Conservation 93:163-175.

Hilton-Taylor, C., compiler. 2000. 2000 IUCN Red List of Threatened Species. IUCN, Gland, Switzerland.

Hunt, R. M., Jr. 1996. Biogeography of the Order Carnivora. In J. L.Gittleman, S. Funk, D. W. Macdonald, and R. K. Wayne (eds.), Carnivore Conservation, pp. 485-541. Cambridge University Press, Cambridge.

May, R. M. 1990. Taxonomy as destiny. Nature 347:129-130.

McKinney, M. L. 1997. Extinction vulnerability and selectivity: Combining ecological and paleontological views. Annual Review of Ecology and Systematics 28:495516.

Mills, M. G. L., S. Freitag, and A. S. van Jaarsveld. 2001. Geographic priorities for carnivore conservation in Africa. In J. L.Gittleman, S. Funk, D. W. Macdonald, and R. K. Wayne (eds.), Carnivore Conservation, pp. 467-483. Cambridge University Press, Cambridge.

Mittermeier, R. A., N. Myers, P. Robles Gil, and C. G. Mittermeier. 1999. Hotspots: 
Earth's Biologically Richest and Most Endangered Terrestrial Ecoregions. Cemex, Mexico City, Mexico.

Myers, N. and A. H. Knoll. 2001. The biotic crisis and the future of evolution. Proceedings of the National Academy of Sciences 98:5389-5392.

Myers, N., R. A. Mittermeier, C. G. Mittermeier, G. A. B. da Fonseca, and J. Kent. 2000. Biodiversity hotspots for conservation priorities. Nature 403:853-858.

Pimm, S. L., and P. Raven. 2000. Extinction by numbers. Nature 403:843-845.

Pimm, S. L., G. J. Russell, J. L. Gittleman, and T. M. Brooks. 1995. The future of biodiversity. Science 269:347-350.

Purvis, A. 1995. A composite estimate of primate phylogeny. Philosophical Transactions of the Royal Sociey of London B 348:405-421.

Purvis, A., P.-M. Agapow, J. L. Gittleman, and G. M. Mace. 2000a. Nonrandom extinction and the loss of evolutionary history. Science 288:328-330.

Purvis, A., J. L. Gittleman, G. Cowlishaw, and G. M. Mace. 2000b. Predicting extinction risk in declining species. Proceedings of the Royal Society of London B 267:1947-1952.

Purvis, A., S. Nee, and P. H. Harvey. 1995. Macroevolutionary inferences from primate phylogeny. Proceedings of the Royal Society of London B 260:329-333.

Purvis, A., and A. Hector. 2000. Getting the measure of biodiversity. Nature 405:212219.

Russell, G. J., T. M. Brooks, M. L. McKinney, and C. G. Anderson. 1998. Present and future taxonomic selectivity in bird and mammal extinctions. Conservation Biology 12:1365-1376. 
Rylands, A. B., H. Schneider, A. Langguth, R. A. Mittermeier, C. P. Groves, and E. Rodriguez-Luna. 2000. An assessment of the diversity of New World primates. Neotropical Primates 8:61-93.

Sanderson, M. J., A. Purvis, and C. Henze. 1998. Trends in Ecology and Evolution 13:105-109.

Vane-Wright, R. I., C. J. Humphries, and P. H. Williams. 1991. What to protect? systematics and the agony of choice. Biological Conservation 55:235-254.

Wheeler, Q. D. and N. I. Platnick. 2000. Species concepts and phylogenetic theory. In Q. D. Wheeler and R. Meier (eds.), Species Concepts and Phylogenetic Theory, pp. 55-69. Columbia University Press, New York.

Williams, P. H. and C. J. Humphries. 1996. Comparing character diversity among biotas. In K. J. Gaston (ed.), Biodiversity: A Biology of Numbers and Difference, pp. 5476. Blackwell Science, Oxford.

Wilson, D. E., and D. A. Reeder. 1993. Mammal Species of the World, Second edition. Smithsonian Institution, Washington.

Wozencraft, W. C. 1989. Classification of the Recent Carnivora. In J. L. Gittleman (ed.), Carnivore Behavior, Ecology, and Evolution, pp. 569-593. Cornell University Press, Ithaca.

Yoder, A. D., R. M. Rasoloarison, S. M. Goodman, J. A. Irwin, S. Atsalis, M. J. Ravosa, and J. U. Ganzhorn. 2000. Remarkable species diversity in Malagasy mouse lemurs (primates, Microcebus). Proceedings of the National Academy of Sciences 97:11325-11330. 

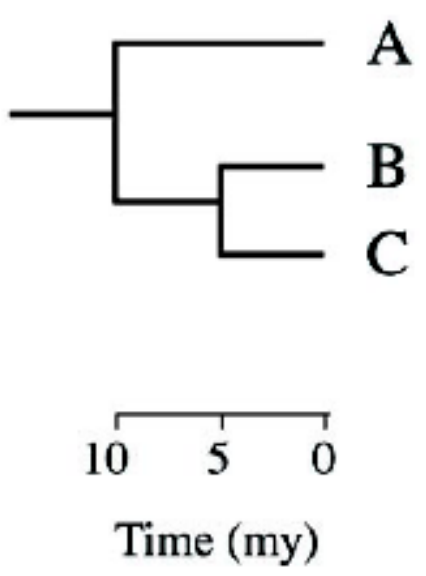

Fig. 1. A hypothetical phylogeny of three taxa. Measures of phylogenetic diversity are represented by branch lengths, with time (my, millions of years) measured across the horizontal axis. "Species evolutionary history" is calculated by the length of the branch to the most recent ancestral split. For example, for species $C$, this is equal to 5 my, whereas for species $A$ the value is 10 my. "Clade evolutionary history" includes all branches in a set of taxa. For the clade containing species $B$ and C this is equal to $15 \mathrm{my}$, because it includes all of the higher shared branches. 

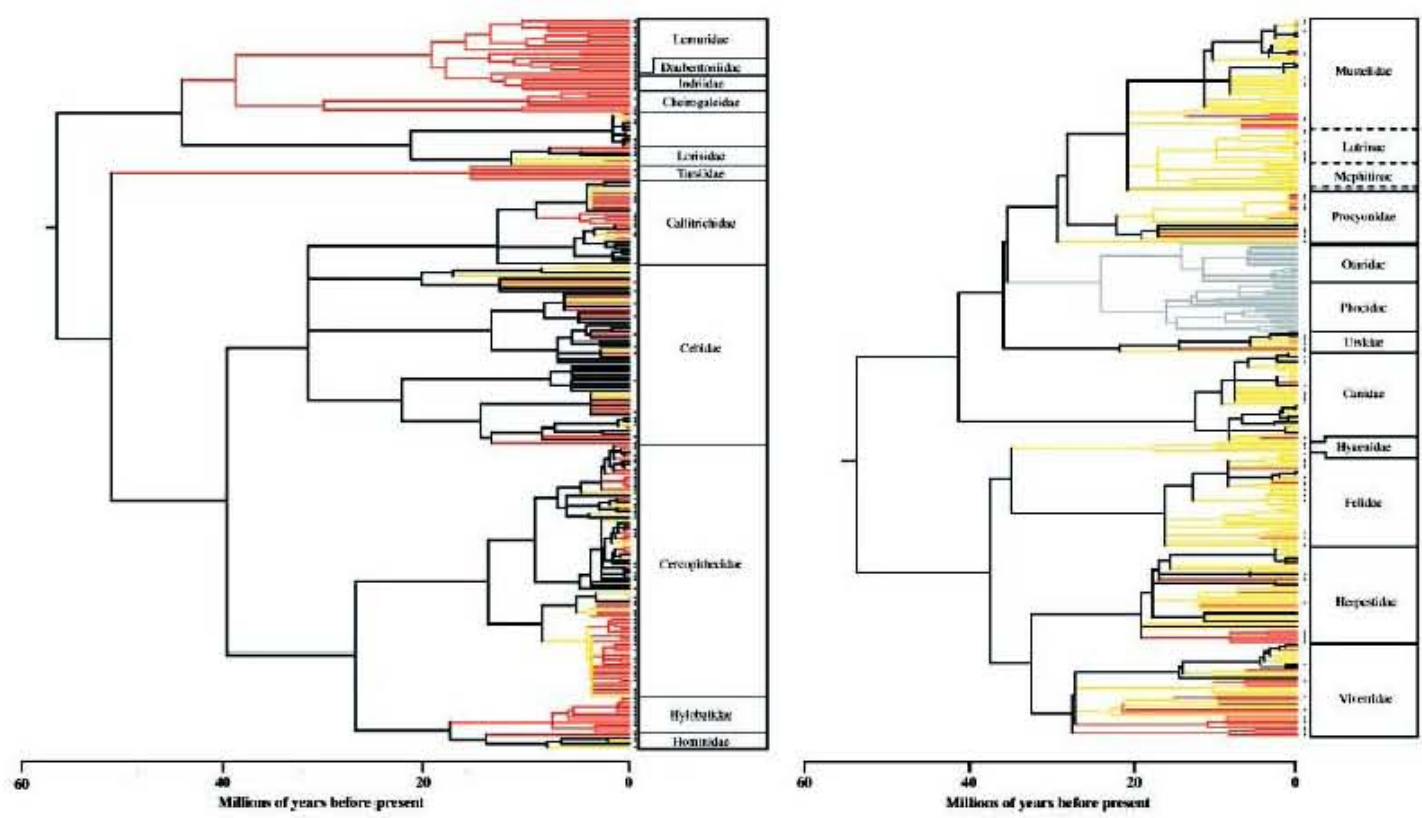

Fig. 2. Phylogenetic patterns of primates (Left) and carnivores (Right) residing in biodiversity hotspots. Species hotspot designation is used to color branches where extant PD exists. Red branches represent PD found only in hotspots (endemic), yellow branches represent PD occurring in hotspots, and black branches represent PD not occurring in hotspots. Threatened species are indicated with an asterisk. Ac ross carnivores, the pinnipeds are represented in gray to denote that they were excluded from analyses because of their aquatic geographic range distributions. 


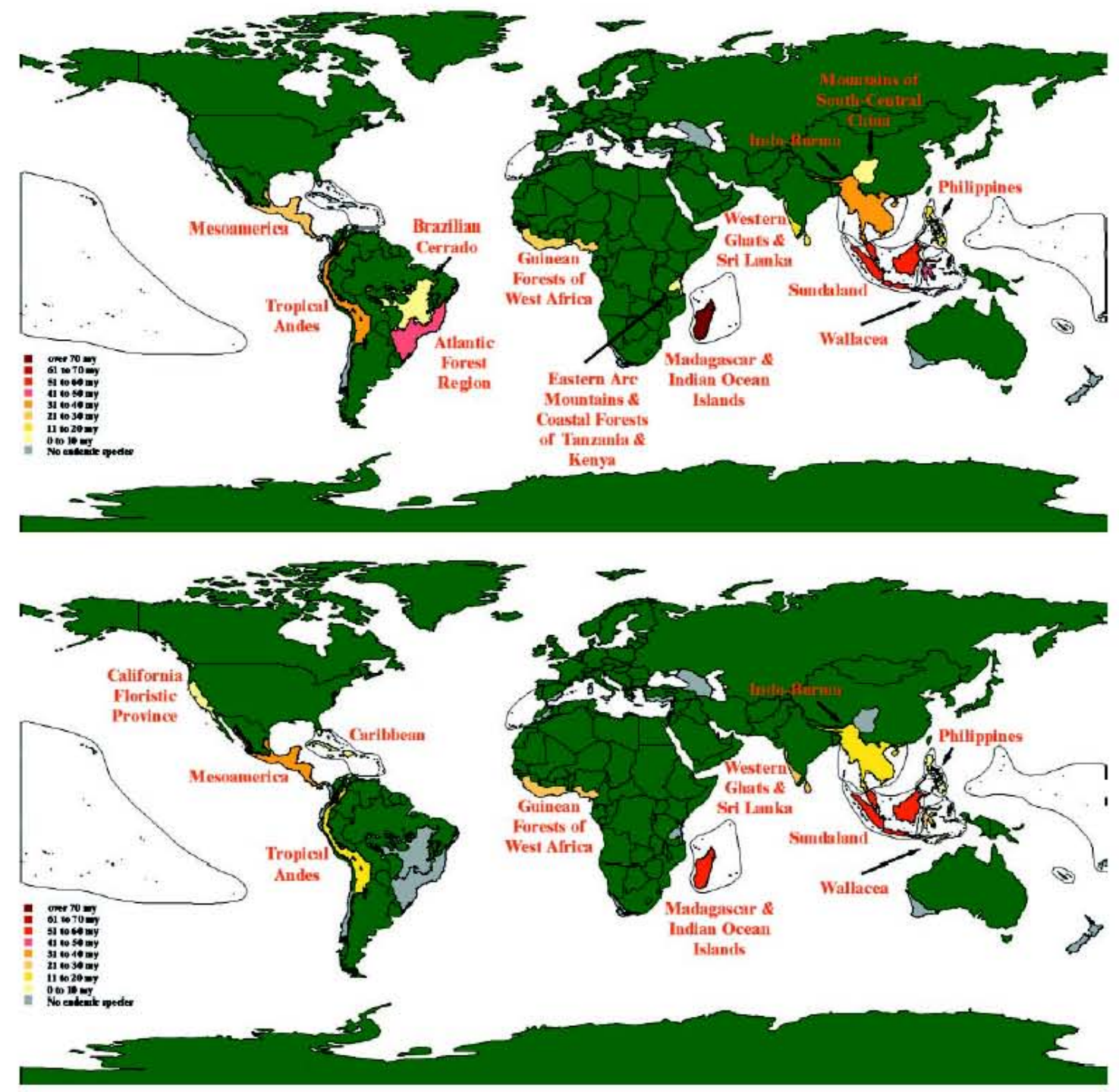

Fig. 3. Map of the top 25 biodiversity hotspots (from ref. 4) containing endemic primates (Upper) and carnivores (Lower). Hotspots with endemic species are labeled by name and colored corresponding to the scale with the amount of species evolutionary history in my. Species endemic to multiple hotspots were not used to calculate these amounts (for clarity), and hence the measure of endemic clade evolutionary history has not been included. 
Table 1. Numbers of endemic carnivore and primate species with associated amount of PD residing in hotspots

\begin{tabular}{lcccccc} 
& $\begin{array}{c}\text { No. of } \\
\text { Species }\end{array}$ & $\begin{array}{c}\text { No. of endemic } \\
\text { hotspot species }\end{array}$ & & \multicolumn{3}{c}{ Phylogenetic diversity, my } \\
\cline { 7 - 8 } & 233 & 127 & $838.9^{* *}$ & 613.0 & $617.6^{*}$ & 564.2 \\
\hline Primates & 128 & 98 & $549.6^{* *}$ & 460.6 & 468.0 & 434.0 \\
Threatened primates & 234 & 51 & $412.7^{* *}$ & 295.4 & $337.0^{*}$ & 283.8 \\
Carnivores & 75 & 31 & $249.3^{* *}$ & 175.3 & 211.7 & 171.6 \\
Threatened carnivores & 75 & &
\end{tabular}

PD is measured as clade evolutionary history (all branch lengths across clades) and species evolutionary history (branch length for each species from the most recentnode) relative to the mean expected amounts from 1,000 random simulations for each measure. Similar results were obtained when data deficient species were counted as threatened (see text). *, $P \leq 0.05 ; * *, P \leq 0.01$.

Table 2. Numbers of occurring carnivore and primate species with associated amount of PD residing in hotspots

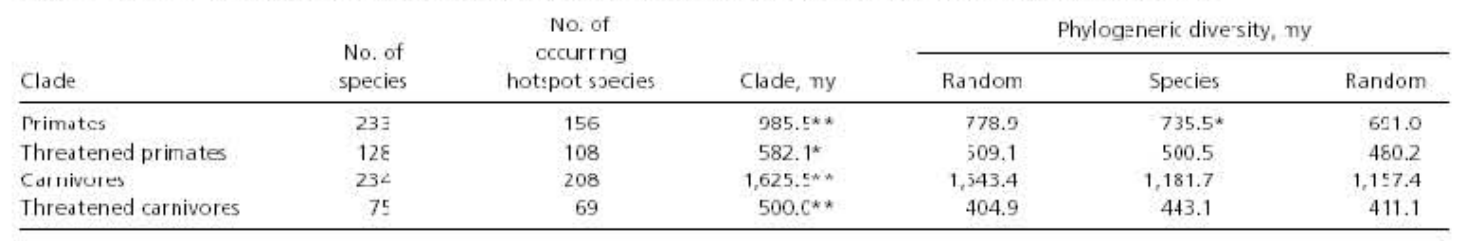

Measures of $P$ ) as in Tablı 1. *,P $P \leq 0.05 ; * *, P \leq 0.01$. 


\section{Conclusions}

This study has sought to advance our knowledge of patterns and processes behind global mammalian biodiversity. I have undertaken the first comprehensive description and analyses of the spatial patterns of mammal distributions. An understanding of the patterns of biodiversity can provide the framework for many avenues of research in ecology, evolution, and conservation science. The patterns of endemism in mammals, analogous to the patterns shown already in birds, are necessary components for determining the processes that generate endemism. Conservation science critically needs to solve where and why rare species exist, in the effort to apply research efforts towards protecting the world's biodiversity. Humans, as the driver of the sixth mass extinction, have caused and are causing massive losses of diversity in mammals. Population density and land-use provide broad indicators of the intensity of human threats, and can be used in conjunction with biodiversity patterns to provide sound scientific conservation strategies. The remaining biodiversity is concentrated in some relatively small areas, in the form of not only species but their evolutionary history. Thus, my research provides an increased understanding of geographic patterns of mammalian biodiversity, and how this relates to global conservation. 


\section{Acknowledgements}

I would like to thank everyone who has provided help in this effort. I greatly appreciate the support and ideas of John Gittleman and the rest of my dissertation committee; Tom Brooks, Hank Shugart, Janis Antonovics, and Steve Macko. Others who have provided insightful discussions on science and conservation include Kaycie Billmark, Luigi Boitani, Don Church, Gustavo Fonseca, John Lamoreux, Georgina Mace, John Pilgrim, Andy Purvis, Ana Rodrigues, Anthony Rylands, Jan Schipper, and Cindy Sechrest.

I would like to thank several organizations for financial support, including especially the Center for Applied Biodiversity Science at Conservation International, the National Science Foundation (Grant No. DEB/0129009), and the Department of Biology at the University of Virginia. 